\title{
HUMECTANTS TO AUGMENT CURRENT FROM METALLIZED ZINC CATHODIC PROTECTION SYSTEMS ON CONCRETE
}

Final Report

SPR 384 



\title{
HUMECTANTS TO AUGMENT CURRENT FROM METALLIZED ZINC CATHODIC PROTECTION SYSTEMS ON CONCRETE
}

\author{
Final Report
}

SPR 384

by

Gordon R. Holcomb, Bernard S. Covino, Jr., Stephen D. Cramer, James H. Russell, Sophie J. Bullard, and W. Keith Collins

Albany Research Center, U. S. Department of Energy, Albany OR 97321

Jack E. Bennett

J. E. Bennett Consulting, Inc., Chardon OH 44024

Steven M. Soltesz and H. Martin Laylor

Oregon Department of Transportation, Salem OR 97301

for

Oregon Department of Transportation, Research Group

200 Hawthorne SE, Suite B-240

Salem OR 97301-5192

and

Federal Highway Administration

Washington, D.C.

December 2002 

Technical Report Documentation Page

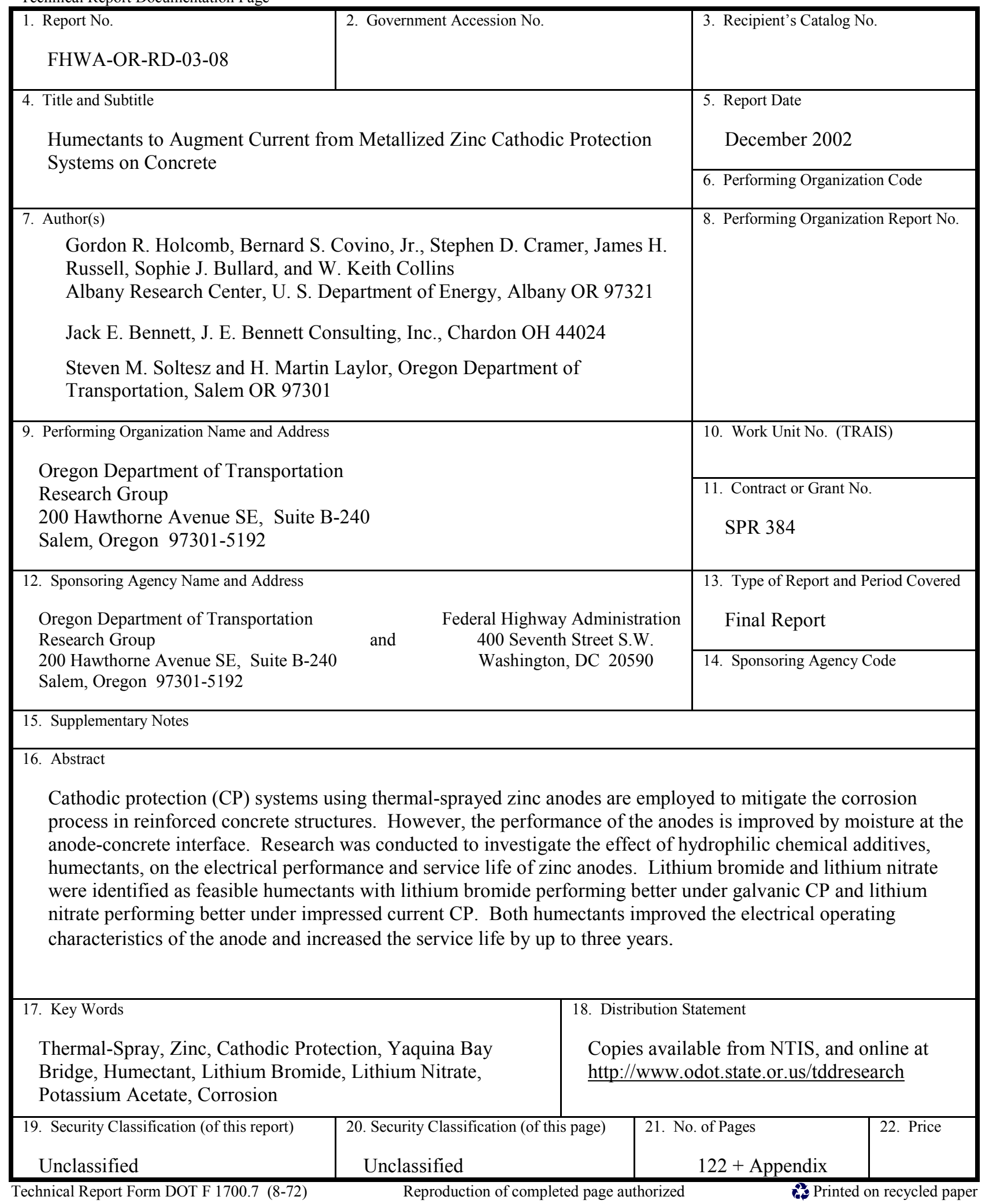




\begin{tabular}{|c|c|c|c|c|c|c|c|c|c|}
\hline \multicolumn{5}{|c|}{ IPPROXIMATE CONVERSIONS TO SI UNITS } & \multicolumn{5}{|c|}{ APPROXIMATE CONVERSIONS FROM SI UNITS } \\
\hline Symbol & When You Know & Multiply By & To Find & Symbol & Symbol & When You Know & Multiply By & To Find & Symbol \\
\hline \multicolumn{5}{|c|}{$\underline{\text { LENGTH }}$} & \multicolumn{5}{|c|}{$\underline{\text { LENGTH }}$} \\
\hline in & inches & 25.4 & millimeters & $\mathrm{Mm}$ & $\mathrm{mm}$ & millimeters & 0.039 & inches & in \\
\hline $\mathrm{ft}$ & feet & 0.305 & meters & M & $\mathrm{m}$ & meters & 3.28 & feet & $\mathrm{ft}$ \\
\hline yd & yards & 0.914 & meters & M & $\mathrm{m}$ & meters & 1.09 & yards & $\mathrm{yd}$ \\
\hline $\mathrm{mi}$ & miles & 1.61 & kilometers & $\mathrm{Km}$ & $\mathrm{km}$ & kilometers & 0.621 & miles & $\mathrm{mi}$ \\
\hline \multicolumn{5}{|c|}{$\underline{\text { AREA }}$} & \multicolumn{5}{|c|}{$\underline{\text { AREA }}$} \\
\hline $\mathrm{in}^{2}$ & square inches & 645.2 & millimeters squared & $\mathrm{mm}^{2}$ & $\mathrm{~mm}^{2}$ & millimeters squared & 0.0016 & square inches & in $^{2}$ \\
\hline $\mathrm{ft}^{2}$ & square feet & 0.093 & meters squared & $\mathrm{m}^{2}$ & $\mathrm{~m}^{2}$ & meters squared & 10.764 & square feet & $\mathrm{ft}^{2}$ \\
\hline $\mathrm{yd}^{2}$ & square yards & 0.836 & meters squared & $\mathrm{m}^{2}$ & ha & hectares & 2.47 & acres & $\mathrm{ac}$ \\
\hline ac & acres & 0.405 & hectares & $\mathrm{Ha}$ & $\mathrm{km}^{2}$ & kilometers squared & 0.386 & square miles & $\mathrm{mi}^{2}$ \\
\hline \multirow[t]{2}{*}{$\mathrm{mi}^{2}$} & square miles & 2.59 & kilometers squared & $\mathrm{km}^{2}$ & \multicolumn{5}{|c|}{ VOLUME } \\
\hline & & \multicolumn{3}{|l|}{ VOLUME } & $\mathrm{mL}$ & milliliters & 0.034 & fluid ounces & $\mathrm{fl} \mathrm{oz}$ \\
\hline $\mathrm{fl} \mathrm{oz}$ & fluid ounces & 29.57 & milliliters & ML & $\mathrm{L}$ & liters & 0.264 & gallons & gal \\
\hline gal & gallons & 3.785 & liters & $\mathrm{L}$ & $\mathrm{m}^{3}$ & meters cubed & 35.315 & cubic feet & $\mathrm{ft}^{3}$ \\
\hline $\mathrm{ft}^{3}$ & cubic feet & 0.028 & meters cubed & $\mathrm{m}^{3}$ & $\mathrm{~m}^{3}$ & meters cubed & 1.308 & cubic yards & $\mathrm{yd}^{3}$ \\
\hline $\mathrm{yd}^{3}$ & cubic yards & 0.765 & meters cubed & $\mathrm{m}^{3}$ & \multicolumn{5}{|c|}{ MASS } \\
\hline \multicolumn{5}{|c|}{ NOTE: Volumes greater than $1000 \mathrm{~L}$ shall be shown in $\mathrm{m}^{3}$. } & $\mathrm{g}$ & grams & 0.035 & ounces & $\mathrm{oz}$ \\
\hline \multicolumn{5}{|c|}{$\underline{\text { MASS }}$} & $\mathrm{kg}$ & kilograms & 2.205 & pounds & $1 b$ \\
\hline $\mathrm{oz}$ & ounces & 28.35 & grams & g & $\mathrm{Mg}$ & megagrams & 1.102 & short tons $(2000 \mathrm{lb})$ & $\mathrm{T}$ \\
\hline $\mathrm{lb}$ & pounds & 0.454 & kilograms & $\mathrm{kg}$ & \multicolumn{5}{|c|}{ CHARGE DENSITY } \\
\hline $\mathrm{T}$ & short tons $(2000 \mathrm{lb})$ & 0.907 & megagrams & $\mathrm{Mg}$ & $\mathrm{kC} / \mathrm{m}^{2}$ & kilocoulombs $/ \mathrm{m}^{2}$ & 0.02581 & amp-hours per $\mathrm{ft}^{2}$ & $\mathrm{~A}-\mathrm{hr} / \mathrm{ft}^{2}$ \\
\hline \multicolumn{5}{|c|}{ CHARGE DENSITY } & \multicolumn{5}{|c|}{ TEMPERATURE (exact) } \\
\hline \multirow[t]{2}{*}{$\mathrm{A}-\mathrm{hr} / \mathrm{ft}^{2}$} & Amp-hours per $\mathrm{ft}^{2}$ & 38.75 & kilocoulombs $/ \mathrm{m}^{2}$ & $\mathrm{kC} / \mathrm{m}^{2}$ & \multirow[t]{2}{*}{${ }^{\circ} \mathrm{C}$} & Celsius temperature & $1.8 \mathrm{C}+32$ & Fahrenheit & \multirow[t]{3}{*}{${ }^{\circ} \mathrm{F}$} \\
\hline & $\underline{\text { TEI }}$ & PERATURE (ex & & & & & $32 \quad{ }_{40} \quad{ }^{98.6} \quad{ }_{120}$ & $160 \quad 200^{212}$ & \\
\hline${ }^{\circ} \mathrm{F}$ & $\begin{array}{l}\text { Fahrenheit } \\
\text { temperature }\end{array}$ & $5(\mathrm{~F}-32) / 9$ & Celsius temperature & ${ }^{\circ} \mathrm{C}$ & & 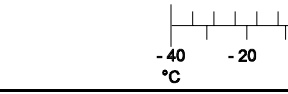 & 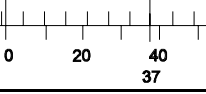 & 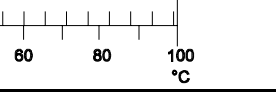 & \\
\hline \multicolumn{5}{|c|}{ * SI is the symbol for the International System of Measurement } & & & & & $(4-7-94 \mathrm{jbp})$ \\
\hline
\end{tabular}




\section{ACKNOWLEDGEMENTS}

The authors wish to thank John Westall of Oregon State University for several helpful discussions about humectant thermodynamics.

\section{DISCLAIMER}

This document is disseminated under the sponsorship of the Oregon Department of Transportation and the United States Department of Transportation in the interest of information exchange. The State of Oregon and the United States Government assume no liability of its contents or use thereof.

The contents of this report reflect the views of the authors, who are responsible for the facts and accuracy of the data presented herein. The contents do not necessarily reflect the official policies of the Oregon Department of Transportation or the United States Department of Transportation.

The State of Oregon and the United States Government do not endorse products of manufacturers. Trademarks or manufacturers' names appear herein only because they are considered essential to the object of this document.

This report does not constitute a standard, specification, or regulation. 


\section{HUMECTANTS TO AUGMENT CURRENT FROM METALLIZED ZINC CATHODIC PROTECTION SYSTEMS ON CONCRETE}

\section{TABLE OF CONTENTS}

1.0 INTRODUCTION .....................................................................................................................

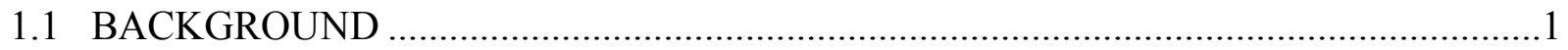

1.1.1 Bridge Rehabilitation with Cathodic Protection in Oregon ....................................1

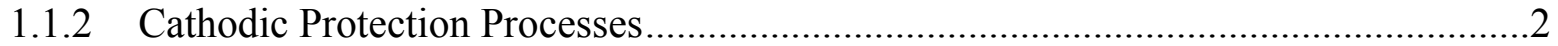

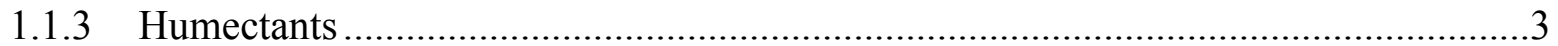

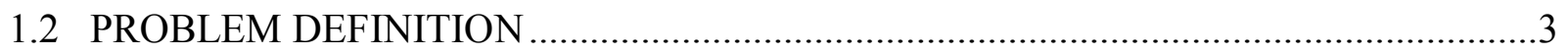

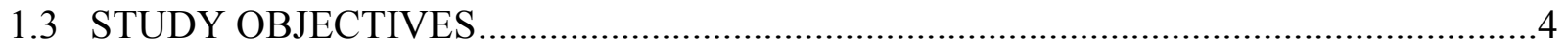

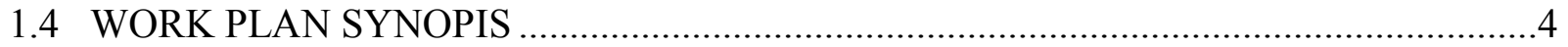

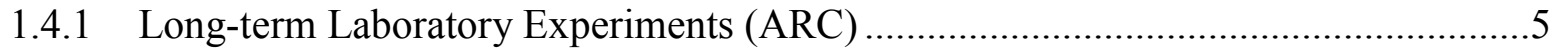

1.4.2 Short-Term Chamber Experiments (ARC) .......................................................

1.4.3 Long-Term Laboratory GCP Experiments (Ohio) ...............................................

1.4.4 Yaquina Bay Bridge Field Trial (Oregon)....................................................6

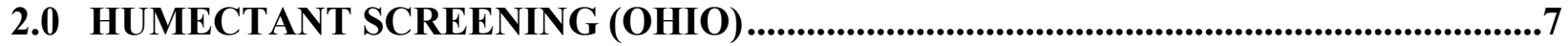

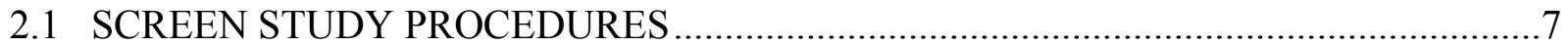

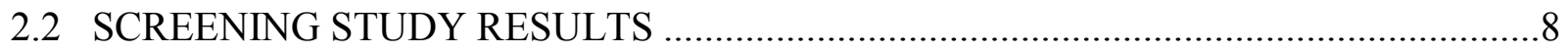

2.3 SELECTED HUMECTANTS ...........................................................................

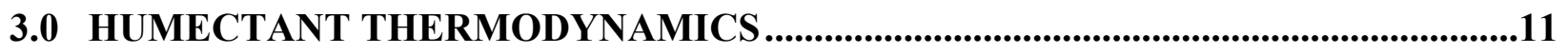

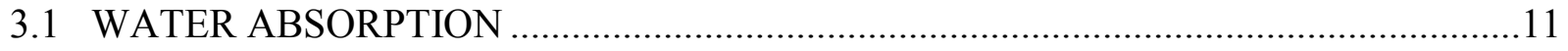

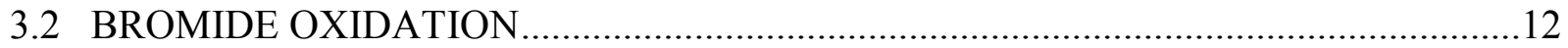

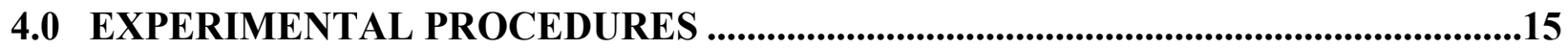

4.1 LONG-TERM LABORATORY EXPERIMENTS (ARC) ........................................15

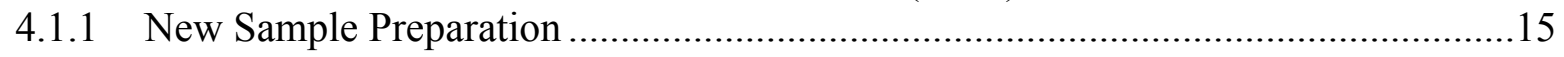

4.1.2 Aged Sample Preparation ................................................................................... 16

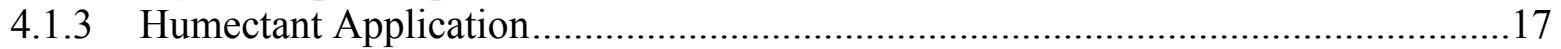

4.1.4 Environmental Conditions.............................................................................. 17

4.1.5 Accelerated Impressed Current Cathodic Protection ..............................................18

4.1.6 Cyclic Impressed Current Cathodic Protection .....................................................18

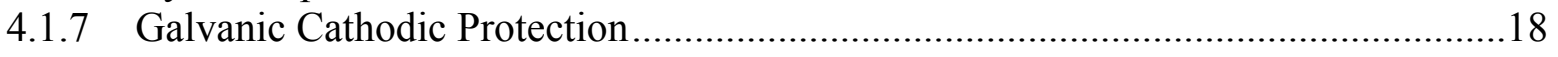

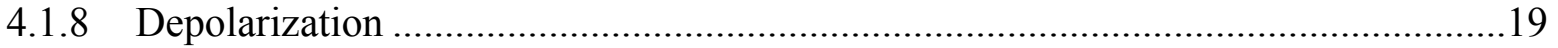

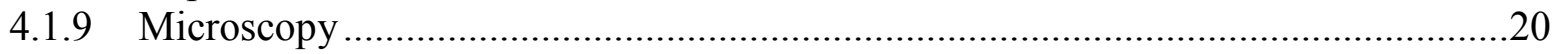

4.1.10 AC Resistance and Circuit Resistance .............................................................21

4.1.11 Adhesion Strength ...........................................................................................2

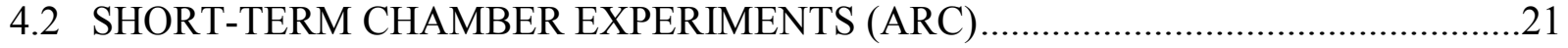

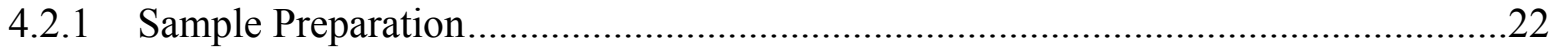

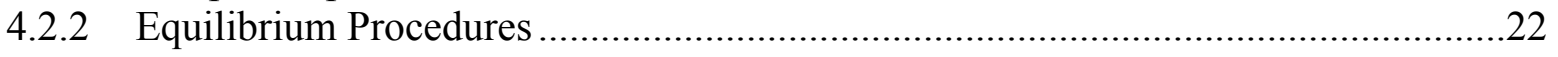

4.2.3 Mass Change Response to Temperature and Humidity ........................................23 
4.2.4 Circuit Resistance Response to Temperature and Humidity ....................................2.

4.3 LONG-TERM LABORATORY GCP EXPERIMENTS (OHIO) ...................................23

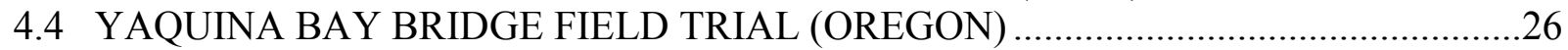

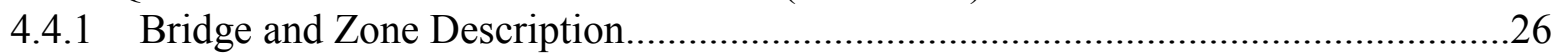

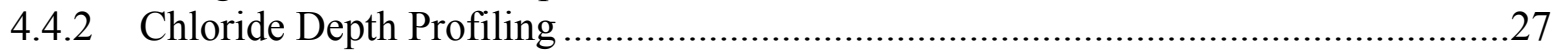

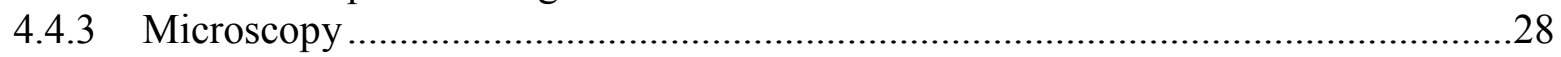

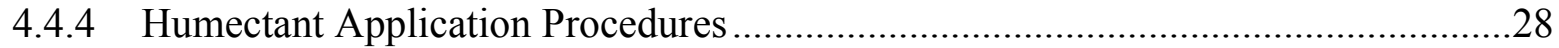

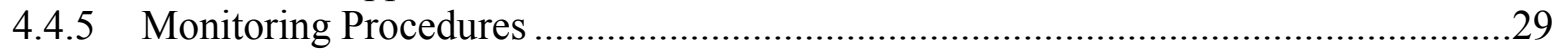

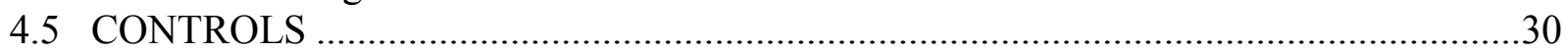

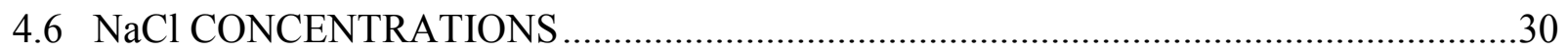

5.0 RESULTS AND ANALYSIS ...............................................................................................31

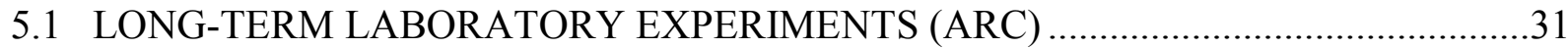

5.1.1 Accelerated Impressed Current Cathodic Protection ............................................... 31

5.1.2 Cyclic Impressed Current Cathodic Protection ........................................................

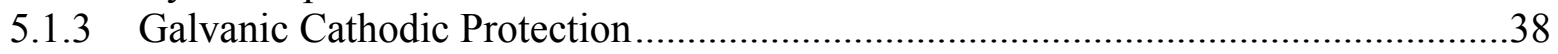

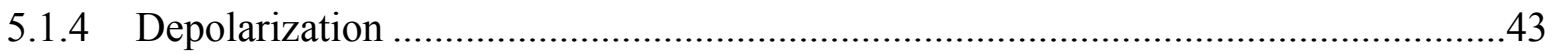

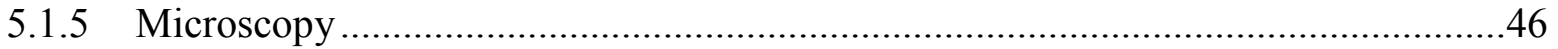

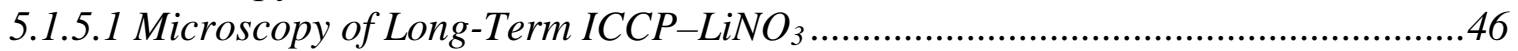

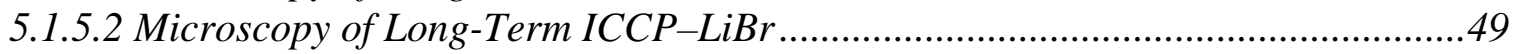

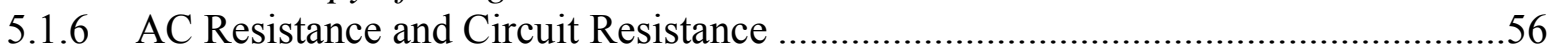

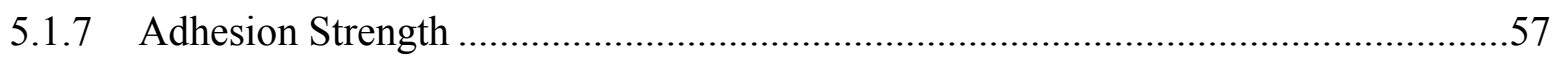

5.2 SHORT-TERM CHAMBER EXPERIMENTS (ARC)..................................................63

5.2.1 Mass Change Response to Temperature and Humidity …………………................63

5.2.2 Circuit Resistance Response to Temperature and Humidity .....................................68

5.3 LONG-TERM LABORATORY GCP EXPERIMENTS (OHIO) …………………..........70

5.3.1 Original Blocks with $3.0 \mathrm{~kg} / \mathrm{m}^{3}\left(5.1 \mathrm{lb} / \mathrm{yd}^{3}\right)$ of $\mathrm{NaCl}$............................................

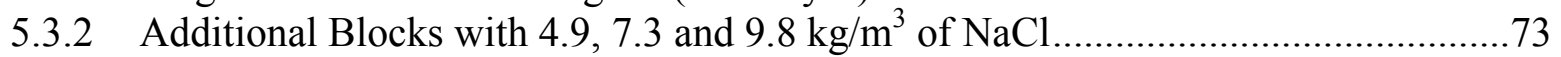

5.4 YAQUINA BAY BRIDGE FIELD EXPERIMENT ......................................................

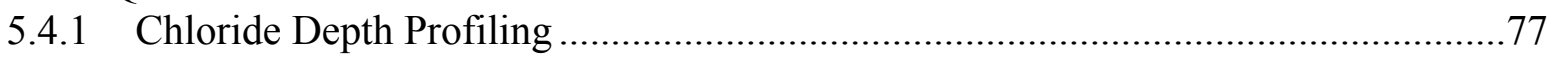

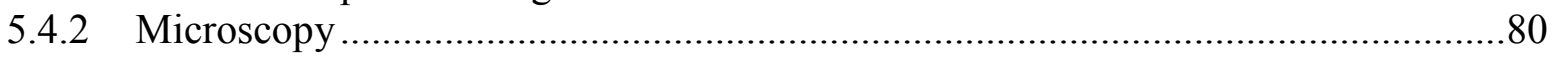

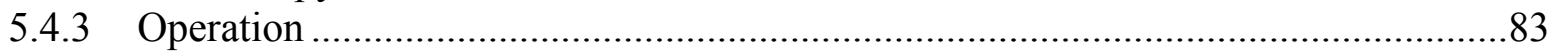

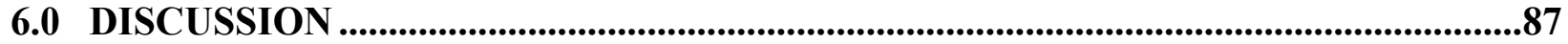

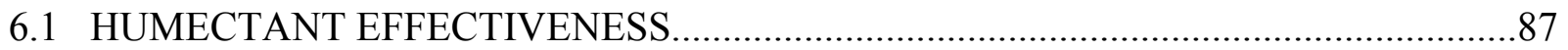

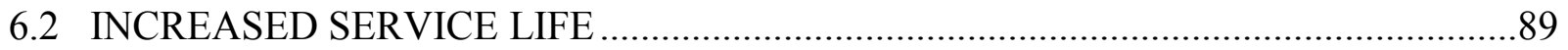

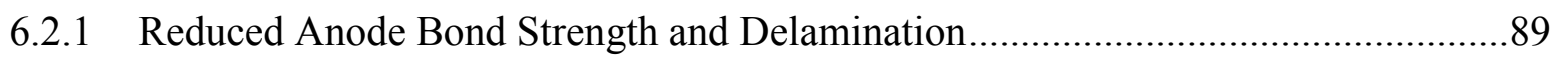

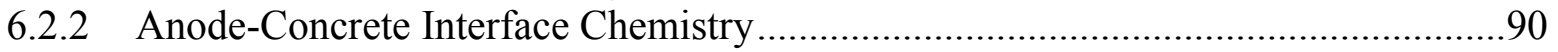

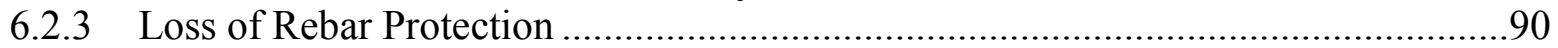

6.2.4 Excessive Required Voltage or Circuit Resistance ..................................................92

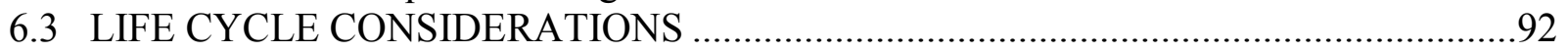

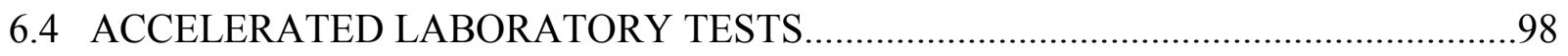

6.5 COLLECTING AND EXAMINING OPERATING DATA ………….............................98

7.0 CONCLUSIONS ...............................................................................................................99

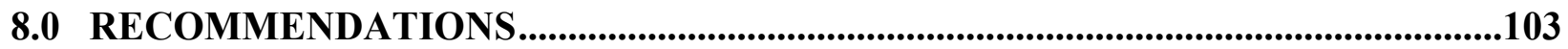




\section{APPENDIX: POTASSIUM ACETATE RESULTS}

\section{LIST OF TABLES}

Table 1.1: Oregon's thermal-sprayed zinc cathodic protection systems on coastal bridges ..................................

Table 2.1: Results of feasibility study of chemicals for use as humectants (Bennett 1998)..................................9

Table 3.1: Parameters used in Equation 3-1 to calculate the activity of water in binary mixtures of

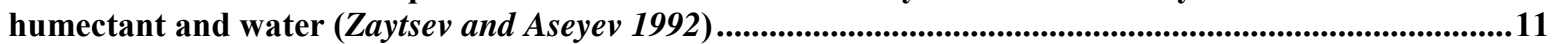

Table 3.2: Calculated humectant molality at $90^{\circ} \mathrm{F}\left(32.2^{\circ} \mathrm{C}\right)$ at values of $\mathrm{RH}$ in equilibrium experiments ........ 12

Table 3.3: Selected oxidation reactions in the $\mathrm{Br}-\mathrm{H}_{2} \mathrm{O}$ system at $25^{\circ} \mathrm{C}$ (Pourbaix 1974) ...................................14

Table 4.1: Number of slices for each condition ........................................................................................................22

Table 4.2: Humectant and Operating Environment for the Blocks ...............................................................24

Table 4.3: Second humectant treatments and operating environments..........................................................25

Table 4.4: Humectant treatments and operating environments for blocks of dfferent NaCl contents ...............26

Table 4.5: $\mathrm{NaCl}$ and $\mathrm{Cl}$ concentrations used in the laboratory experiments ....................................................30

Table 5.1: Long-term ICCP microanalyses ..............................................................................................49

Table 5.2: Equilibrated mass gain from a RH of 35\% .......................................................................................66

Table 5.3: Measured and calculated mass gain from 35\% RH for $\mathrm{LiNO}_{3}$ and $\mathrm{LiBr}$ humectant-treated

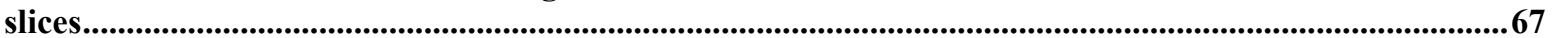

Table 5.4: Diffusion parameters for the ICCP field test zones on the Yaquina Bay Bridge ...............................79

Table 5.5: Summary of Yaquina Bay Bridge field trial......................................................................................85

Table 6.1: Summary of humectant rankings for each CP experiment.....................................................................88

Table 6.2: Summary of medium and long term galvanic current densities......................................................91

\section{LIST OF PHOTOS/FIGURES}

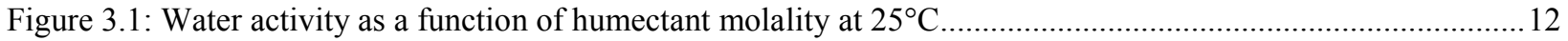

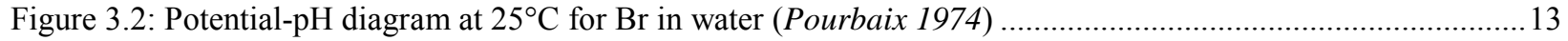

Figure 4.1: Thermal-spraying of zinc onto new slabs with robotic-controlled $x-y$ passes .....................................16

Figure 4.2: New and aged zinc slabs wired in series in the high RH enclosure..............................................17

Figure 4.3: Aged zinc slabs wired in series in the high RH enclosure. Note the reference electrode holders

(PVC pipe) mounted in areas without zinc left from prior adhesion strength pull tests.

Figure 4.4: The four field test zones on the Yaquina Bay Bridge. Each zone includes column and soffit areas.

Zone 14 is closest to Yaquina Bay. The closer a zone is to the ocean, the higher the expected $\mathrm{Cl}^{-}$level

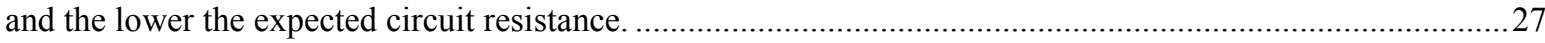

Figure 4.5: Application of humectants under the deck of the Yaquina Bay Bridge ...............................................28

Figure 4.6: Application of humectants to the base of a bent on the Yaquina Bay Bridge ....................................29

Figure 5.1: Circuit resistances of new ICCP slabs in high RH conditions...........................................................3

Figure 5.2: Circuit resistances of new ICCP slabs in low RH conditions.....................................................32

Figure 5.3: Circuit resistances of aged ICCP slabs in high RH conditions for $\mathrm{LiNO}_{3}$ (left) and $\mathrm{LiBr}(\mathrm{right})$.............33

Figure 5.4: Circuit resistances of aged ICCP slabs in low RH conditions for $\mathrm{LiNO}_{3}$ (left) and $\mathrm{LiBr}$ (right) .............33

Figure 5.5: Mean circuit resistances of new and aged slabs after an additional 3 years of aging in high (left) and

low (right) RH conditions. The "No Humectant" data are from an earlier study (Bullard et al. 1998;

Covino et al. 2002).

Figure 5.6: Cyclic ICCP voltages (left) and circuit resistances (right) for $\mathrm{LiNO}_{3}$ (top), $\mathrm{LiBr}$ (middle), and control (bottom) in high RH conditions. .................................................................................

Figure 5.7: Cyclic ICCP voltages (left) and circuit resistances (right) for $\mathrm{LiNO}_{3}$ (top), $\mathrm{LiBr}$
control (bottom) in low RH conditions. Gaps are from intermediate current levels. 
Figure 5.8: Galvanic currents for new and aged slabs with $\mathrm{LiNO}_{3}$ in high $\mathrm{RH}$ conditions .....................................39

Figure 5.9: Galvanic currents for new and aged slabs with $\mathrm{LiBr}$ in high $\mathrm{RH}$ conditions ......................................39

Figure 5.10: Galvanic currents for new and aged slabs with $\mathrm{LiNO}_{3}$ in low $\mathrm{RH}$ conditions ....................................40

Figure 5.11: Galvanic currents for new and aged slabs with $\mathrm{LiBr}$ in low $\mathrm{RH}$ conditions......................................40

Figure 5.12: Galvanic currents for the new control slab in high RH conditions..................................................41

Figure 5.13: Galvanic currents for the new control slab in low RH conditions................................................41

Figure 5.14: Long-term current densities for new and aged GCP slabs in high RH conditions ............................42

Figure 5.15: Long-term current densities for new and aged GCP slabs in low RH conditions ...............................42

Figure 5.16: 24-hour depolarization voltages for long-term laboratory ICCP samples in low RH (top) and high

RH (bottom) conditions.

Figure 5.17: 24-hour depolarization voltages for long-term laboratory GCP samples in low RH (top) and high RH (bottom) conditions.

Figure 5.18: BSE and elemental x-ray maps of a $\mathrm{LiNO}_{3}$-treated new slab exposed in the high-RH exposure after the equivalent of 5.3 years of ICCP. The zinc anode is at the top right and the unaltered concrete is at the bottom left of each cross section.

Figure 5.19: BSE and elemental x-ray maps of a $\mathrm{LiNO}_{3}$-treated new slab exposed in the low-RH exposure after the equivalent of 6.1 years of ICCP. The zinc anode is at the top and the unaltered concrete is at the bottom of each cross section.

Figure 5.20: BSE and elemental x-ray maps of a LiBr-treated new slab exposed in the high-RH exposure after the equivalent of 5.3 years of ICCP. The $\mathrm{Zn}$ anode is at the top and the unaltered concrete is at the bottom of each cross section.

Figure 5.21: BSE and elemental x-ray maps of a LiBr-treated new slab exposed in the low-RH exposure after the equivalent of 6.1 years of ICCP. The $\mathrm{Zn}$ anode is at the top and the unaltered concrete is at the bottom of each cross section.

Figure 5.22: BSE and elemental x-ray maps of a LiBr-treated aged slab exposed in the low-RH exposure after the equivalent of 0.8 additional years of ICCP. The initial electrochemical age was 19 years. The $\mathrm{Zn}$ anode is at the top and the unaltered concrete is at the bottom of each cross section.

Figure 5.23: X-ray line scans of a LiBr-treated new slab exposed in the high-RH exposure after the equivalent of 5.3 years of ICCP.

Figure 5.24: Elemental zinc x-ray maps for both humectants and both humidities after the equivalent of 5.3 years (high $\mathrm{RH}$ ) and 6.1 years (low RH) of ICCP.

Figure 5.25: Elemental $\mathrm{Cl}$ x-ray maps for both humectants and both humidities after the equivalent of 5.3 years (high RH) and 6.1 years (low RH) of ICCP

Figure 5.26: AC resistance compared with circuit resistance (defined as operating voltage divided by impressed current density)

Figure 5.27: Bond strength results for accelerated ICCP in low RH environments. The aged slabs had initial equivalent ages of $3,8,13.1$, and 19 years.

Figure 5.28: Bond strength results for accelerated ICCP in high RH environments. The aged slabs had initial equivalent ages of $3,8,13.1$, and 19 years.

Figure 5.29: Bond strength results for GCP in low RH environments. The aged slabs had initial equivalent ages of $1.6,5.1,12$, and 16.1 years.

Figure 5.30: Bond strength results for GCP in high RH environments. The aged slabs had initial equivalent ages of $1.6,5.1,12$, and 16.1 years.

Figure 5.31: Bond strength results for ICCP aged slabs. ICCP in high RH environments in comparison with their initial strength.

Figure 5.32: Bond strength results for ICCP aged slabs. ICCP in low RH environments in comparison with their initial strength.

Figure 5.33: Bond strengths for different $\mathrm{NaCl}$ concentrations with accelerated ICCP (equivalent electrochemical age of 17.9 years) in high $\mathrm{RH}$ environments. The $\mathrm{NaCl}$ concentrations correspond to 2.0, 5.0 , and $10.0 \mathrm{lb} / \mathrm{yd}^{3}$

Figure 5.34: Mass change with exposure time of $\mathrm{LiNO}_{3}$-treated and $\mathrm{LiBr}$-treated slices at $90^{\circ} \mathrm{F}\left(32.2^{\circ} \mathrm{C}\right)$. The $\mathrm{NaCl}$ concentrations were $2.0,5.0$, and $10.0 \mathrm{lb} / \mathrm{yd}^{3}\left(1.2,3.0\right.$, and $\left.5.9 \mathrm{~kg} / \mathrm{m}^{3}\right)$.

Figure 5.35: Mass change with exposure time of surfactant-treated and control slices at $90^{\circ} \mathrm{F}\left(32.2^{\circ} \mathrm{C}\right)$. The $\mathrm{NaCl}$ concentrations were $2.0,5.0$, and $10.0 \mathrm{lb} / \mathrm{yd}^{3}\left(1.2,3.0\right.$, and $\left.5.9 \mathrm{~kg} / \mathrm{m}^{3}\right)$.

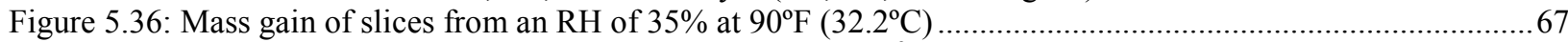

Figure 5.37: Circuit resistance as a function of time for $0.02 \mathrm{~mA} / \mathrm{ft}^{2}$ at $90^{\circ} \mathrm{F}\left(32.2^{\circ} \mathrm{C}\right)$ 
Figure 5.38: Circuit resistance after 24 hours of $0.02 \mathrm{~mA} / \mathrm{ft}^{2} \mathrm{ICCP}$ at $90^{\circ} \mathrm{F}\left(32.2^{\circ} \mathrm{C}\right)$

Figure 5.39: Galvanic current for $\mathrm{LiNO}_{3}$-treated blocks with $3.0 \mathrm{~kg} / \mathrm{m}^{3}(5.11 \mathrm{~b} / \mathrm{yd}$ ) $) \mathrm{NaCl}$. Retreatment of one block after about 200 days (shown in bold). The environments were a) $55 \% \mathrm{RH}$ (left) and b) $80 \% \mathrm{RH}$ (right).

Figure 5.40: Galvanic current for LiBr-treated blocks with $3.0 \mathrm{~kg} / \mathrm{m}^{3}\left(5.1 \mathrm{lb} / \mathrm{yd}^{3}\right) \mathrm{NaCl}$. Retreatment of one block after about 200 days (shown in bold). The environments were a) $55 \% \mathrm{RH}$ (left) and b) $80 \% \mathrm{RH}$ (right).

Figure 5.41: Galvanic current for humectant-treated blocks with $3.0 \mathrm{~kg} / \mathrm{m}^{3}\left(5.1 \mathrm{lb} / \mathrm{yd}^{3}\right) \mathrm{NaCl}$. The environments outdoors in the Cleveland Ohio area in a) Exposed (left) and b) Covered (right) conditions.

Figure 5.42: Galvanic currents for blocks with $4.9,7.3$, and $9.8 \mathrm{~kg} / \mathrm{m}^{3} \mathrm{NaCl}$ in $55 \% \mathrm{RH}$ conditions.......................75

Figure 5.43: Galvanic currents for blocks with $4.9,7.3$, and $9.8 \mathrm{~kg} / \mathrm{m}^{3} \mathrm{NaCl}$ in $80 \% \mathrm{RH}$ conditions......................75

Figure 5.44: Galvanic currents for blocks with $4.9,7.3$, and $9.8 \mathrm{~kg} / \mathrm{m}^{3} \mathrm{NaCl}$ in covered outdoor exposures ............76

Figure 5.45: Mean galvanic currents (over 150-240 days) as a function of concrete $\mathrm{NaCl}$ contents..........................77

Figure 5.46: Chloride profiles from the soffits of the four ICCP test zones on the Yaquina Bay Bridge south

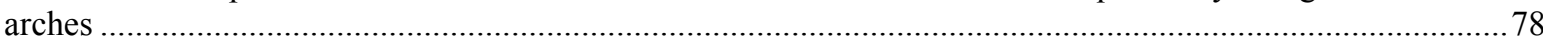

Figure 5.47: Chloride profiles from the west side of the base of bent $3 \mathrm{~N}$ on the north side of the Yaquina Bay Bridge.

5.48: X-ray line scans across a cross-section of control Zone 10 of the Yaquina Bay Bridge, immediately

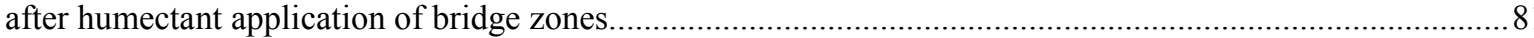

Figure 5.50: X-ray line scans across a cross-section of $\mathrm{LiNO}_{3}$-treated Zone 13 of the Yaquina Bay Bridge, immediately after humectant application.

Figure 5.49: X-ray line scans across a cross-section of LiBr-treated Zone 11 of the Yaquina Bay Bridge, immediately after humectant application.

Figure 5.51: X-ray line scans across a cross-section of control Zone 14 of the Yaquina Bay Bridge, immediately

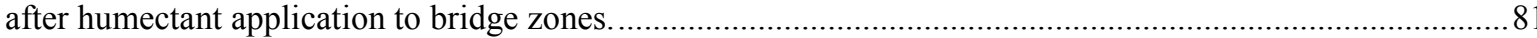

Figure 5.52: X-ray line scans across a cross-section of LiBr-treated Zone 11 of the Yaquina Bay Bridge, after 2 years of ICCP.

Figure 5.53: X-ray line scans across a cross-section of $\mathrm{LiNO}_{3}$-treated Zone 13 of the Yaquina Bay Bridge, after 2 years of ICCP.

Figure 5.54: Circuit resistance data from the Yaquina Bay Bridge field trial .....

Figure 5.55: Mean circuit resistance data from periods with nominal current of $2.2 \mathrm{~mA} / \mathrm{m}^{2}$. Period I was prior to humectant application.

Figure 6.1: Benefits of using humectants, as a \% of ICCP installation costs as functions of humectant application costs and cycle times $\left(\mathrm{y}_{\mathrm{H}}\right)$ for 27 years of anode life (without humectants), an interest Rate of $4 \%$, and an anode life extension of a) 9 years (top) and b) 6 years (bottom). Calculations cover 40 years. .....95

Figure 6.2: Benefits of using humectants, as a \% of ICCP installation costs as functions of humectant application costs and cycle times $\left(\mathrm{y}_{\mathrm{H}}\right)$ for 15 years of anode life (without humectants), an interest Rate of $4 \%$, and an anode life extension of a) 5 years (top) and b) 3 years (bottom). Calculations cover 40 years......96

Figure 6.3: Benefits of using humectants, as a \% of ICCP installation costs as a function of interest rate for 27 years of anode life (without humectants), a lifetime extension of 6 years, 3 years between humectant applications, and the cost of applying humectants equal to $1 \%$ of the ICCP installation costs. Calculations cover 40 years.

Figure A5.1: Circuit resistances of new ICCP slabs in high RH conditions........................................................

Figure A5.2: Circuit resistances of new ICCP slabs in low RH conditions .........................................................

Figure A5.3: Circuit resistances of aged ICCP slabs in high RH conditions .......................................................

Figure A5.4: Circuit resistances of aged ICCP slabs in low RH conditions ....................................................

Figure A5.6: Cyclic ICCP voltages (left) and circuit resistances (right) in high RH conditions ...............................A-3

Figure A5.7: Cyclic ICCP voltages (left) and circuit resistances (right) in low RH conditions ...............................A-4

Figure A5.8: Galvanic currents for new and aged slabs with $\mathrm{KC}_{2} \mathrm{H}_{3} \mathrm{O}_{2}$ in high $\mathrm{RH}$ conditions ...............................

Figure A5.10: Galvanic currents for new and aged slabs with $\mathrm{KC}_{2} \mathrm{H}_{3} \mathrm{O}_{2}$ in low $\mathrm{RH}$ conditions .............................

Figure A5.34: Mass change with exposure time of $\mathrm{KC}_{2} \mathrm{H}_{3} \mathrm{O}_{2}$-treated slices at $90^{\circ} \mathrm{F}\left(32.2^{\circ} \mathrm{C}\right)$. The $\mathrm{NaCl}$

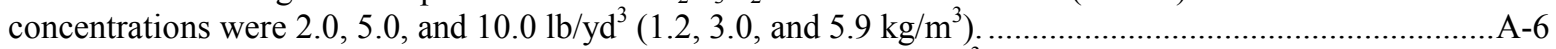

Figure A5.39: Galvanic current for $\mathrm{KC}_{2} \mathrm{H}_{3} \mathrm{O}_{2}$-treated blocks (with $3.0 \mathrm{~kg} / \mathrm{m}^{3} \mathrm{NaCl}$ ). Retreatment of one block after about 200 Days (shown in bold). The environments were a) 55\% RH (left) and b) $80 \%$ RH (right).....A-7 


\subsection{INTRODUCTION}

\subsection{BACKGROUND}

\subsubsection{Bridge Rehabilitation with Cathodic Protection in Oregon}

Reinforced concrete bridges exposed to chloride environments, such as on the Oregon coast, can undergo extensive corrosion damage. Chloride ions $\left(\mathrm{Cl}^{-}\right)$deposited onto the concrete migrate in towards the reinforcing steel, where the ions disrupt the passive films that normally protect steel in concrete from corrosion. Subsequent corrosion of the steel results in a volume expansion that causes cracking and delamination of the concrete, which aids in further $\mathrm{Cl}^{-}$transport to the steel. Section loss of the steel eventually results in loss of structural integrity of the structure.

Corrosion of bridges is a national problem. A report to the federal government reported that 15 percent of the nation's 583,000 bridges are structurally deficient, with corrosion of steel and steel reinforcement the primary cause (Koch, et al. 2002). The annual direct cost of corrosion for highway bridges was estimated at $\$ 8.3$ billion per year. Indirect costs from traffic delays and lost productivity were estimated at more than ten times this amount. Costs for bridge maintenance, rehabilitation, and replacement are a necessary use of Department of Transportation (DOT) funds.

Beginning in the early 1990s, Oregon DOT started rehabilitating reinforced coastal bridges and protecting them with cathodic protection $(\mathrm{CP})$ using thermal-sprayed (TS) zinc ( $\mathrm{Zn}$ ) anodes. These extensive rehabilitation and protection projects cost approximately 35 percent of that estimated for damaged section replacement (Holcomb and Cryer 1998). Table 1.1 shows the extent of Oregon's efforts in bridge rehabilitation and protection with TS Zn CP. Average costs, in 1997 dollars, for the first four projects, was $\$ 52 / \mathrm{ft}^{2}\left(\$ 556 / \mathrm{m}^{2}\right)$ based on total project costs, and $\$ 14 / \mathrm{ft}^{2}\left(\$ 151 / \mathrm{m}^{2}\right)$ based on the CP portion of the projects (Holcomb and Cryer 1998).

Table 1.1: Oregon's thermal-sprayed zinc cathodic protection systems on coastal bridges

\begin{tabular}{c|c|c|c|c}
\hline PROJECT & YEAR BUILT & YEAR OF CP & $\begin{array}{c}\text { CP SURFACE } \\
\text { AREA ft } \\
\left(\mathbf{m}^{2}\right)\end{array}$ & $\begin{array}{c}\text { TOTAL } \\
\text { COST }^{*}\end{array}$ \\
\hline Cape Creek & 1931 & 1991 & $102,500(9,520)$ & $\$ 2.5 \mathrm{M}$ \\
\hline Yaquina Bay Arches & 1934 & 1994 & $195,500(18,160)$ & $\$ 10.8 \mathrm{M}$ \\
\hline Depoe Bay & 1927 (widened in 1939) & 1995 & $67,000(6,220)$ & $\$ 4.4 \mathrm{M}$ \\
\hline Yaquina Bay South Approach & 1934 & 1997 & $65,000(6,040)$ & $\$ 2.4 \mathrm{M}$ \\
\hline Big Creek Bridge & 1931 & 1998 & $20,000(1,860)$ & $\$ 2.1 \mathrm{M}$ \\
\hline Rocky Creek Bridge & 1927 & 2001 & $40,000(3,720)$ & $\$ 3.9 \mathrm{M}$ \\
\hline Cummins Creek Bridge & 1931 & 2001 & $20,000(1,860)$ & $\$ 1.7 \mathrm{M}$ \\
\hline Rogue River Patterson Bridge & 1930 & 2003 & $350,000(32,520)$ & $\$ 18.4 \mathrm{M}$ \\
\hline
\end{tabular}

* Contract cost at the time of the CP project. 


\subsubsection{Cathodic Protection Processes}

Cathodic Protection (CP) systems work by preferentially oxidizing the $\mathrm{Zn}$ anode in place of the steel rebar. This can be accomplished with either galvanic CP (GCP) or impressed current CP (ICCP). In GCP (also known as sacrificial CP or SACP) the Zn anode is electrically connected to the steel rebar. This allows for the naturally higher chemical potential of $\mathrm{Zn}$, to drive the oxidation reactions to occur at the $\mathrm{Zn}$ anode as opposed to at the steel rebar. In comparison with ICCP, GCP has several advantages, ease of application and much less electrical hardware and system maintenance. Galvanic CP is extensively used in Florida for substructures in tidal and splash zones (Scannell, Sohanghpurwala and Powers 1995). In ICCP the Zn anode is connected to the steel rebar through a power supply. The power supply supplements the natural chemical potential between $\mathrm{Zn}$ and iron (Fe) with electrical potential. It offers the advantage of an assured amount of protection current. Most of the CP systems in Oregon are ICCP. Galvanic CP systems require high temperatures and humidity to maintain enough protection of the steel rebar.

In both GCP and ICCP systems, physical changes occur at the Zn-concrete interface with time (Covino, et al. 1996a; Covino, et al. 1996b; Covino, et al. 2002; Holcomb, et al. 1996). Zinc oxide $(\mathrm{ZnO})$ reaction products accumulate at the interface between the TS $\mathrm{Zn}$ anode and the concrete, as the anode is consumed. Zinc oxide occupies a larger volume than $\mathrm{Zn}$. As a consequence stresses can build up at the interface, leading to cracking and eventual delamination of the anode along the interface. Zinc oxide is also a relatively weak material. The accumulation of zinc oxide reaction products at the interface will eventually weaken the initial mechanical bond between the much stronger zinc anode and the concrete. To somewhat mitigate these effects, zinc ions $\left(\mathrm{Zn}^{2+}\right)$ have been shown to migrate into the cement paste and displace calcium (Ca) ions within the cement (Covino, et al. 2002). This migration and displacement results in secondary mineralization of the cement paste involving the zinc ions. To some extent, secondary mineralization of the $\mathrm{Zn}$ reaction products reduces the damaging effects of $\mathrm{Zn}$ oxide accumulation, by dissipating some of the oxidized $\mathrm{Zn}$ into the cement matrix.

The accumulation of $\mathrm{ZnO}$ at the $\mathrm{Zn}$-concrete interface increases the electrical resistivity at the interface. Increased electrical resistivity can result in GCP systems not generating enough current to protect the rebar. In ICCP systems, the required voltage to maintain a constant protection current can increase beyond the compliance voltage of the power supplies, resulting in a lowering of the protection current.

Hence, the accumulation of $\mathrm{ZnO}$ at the $\mathrm{Zn}$-concrete interface can result in three different failure modes of the CP system: 1) insertion of a weak intermediate layer between the anode and concrete to reduce bond strength, 2) delamination of the coating along the interface as the result of stresses produced in the reaction product layer, and 3) reduction of the protection current below needed levels by the growth of an insulating intermediate layer in the current path.

The presence of water at the $\mathrm{Zn}$-concrete interface improves the performance of the CP system and increases its service life (Bullard, et al. 1997a; Bullard, et al. 1998; Covino, et al. 2002). Water accomplishes this by: 
- Increasing the electrical conductivity of the $\mathrm{CP}$ system at the location where resistivities are highest. This increases the protection current in GCP systems and lowers the voltage needed to maintain a constant current in ICCP systems.

- Increasing the mobility of $\mathrm{Zn}^{2+}$ thereby delaying the buildup of the zinc oxide reaction layer. This delays the formation of the weak intermediate zinc oxide layer between the anode and concrete. It also allows for stress relief in the TS Zn coating because of increased secondary mineralization delaying delamination along the anode-concrete interface.

- Increasing the mobility of hydroxyl ions $\left(\mathrm{OH}^{-}\right)$, which allows the high $\mathrm{pH}$ pore water in the bulk cement to migrate to the anode-concrete interface, raises the $\mathrm{pH}$ from the low levels that are typically produced at the anode by $\mathrm{CP}(\mathrm{pH} 6-8)$. This helps maintain a stronger bond between the TS Zn and the concrete, since concrete is known to lose much of its strength below a pH of 7-8 (Mehta 1991).

Accelerated ICCP laboratory tests comparing the effects of a dry environment with that of an environment with wet and dry cycles have confirmed that water increases adhesion life and decreases the voltage needed to maintain a constant ICCP current.

\subsubsection{Humectants}

Humectants, as used in this report, are water-soluble chemical additives that attract water. When applied to the surface of the concrete, the idea is that they will increase the amount of moisture at the $\mathrm{Zn}$-concrete interface and thereby increase the lifetime of the $\mathrm{CP}$ system by the processes described above.

Three humectants, chosen on the basis of a screening experiment (Bennett 1998), were used in this study. They were lithium bromide $(\mathrm{LiBr})$, lithium nitrate $\left(\mathrm{LiNO}_{3}\right)$, and potassium acetate $\left(\mathrm{KC}_{2} \mathrm{H}_{3} \mathrm{O}_{2}\right)$. During this study, it was found that $\mathrm{KC}_{2} \mathrm{H}_{3} \mathrm{O}_{2}$ was not enhancing the performance of the $\mathrm{CP}$ system (and was at times detrimental). As a result it was dropped from further investigation. Adhesion strength results for $\mathrm{KC}_{2} \mathrm{H}_{3} \mathrm{O}_{2}$ are given in the main body of this report, including cases of early anode delamination. Other results relating to $\mathrm{KC}_{2} \mathrm{H}_{3} \mathrm{O}_{2}$ are found in the Appendix.

Related to this project, several publications have been written on laboratory and field study research in progress (Bennett, et al. 2000; Bullard, et al. 2000; Bullard, et al. 2001; Covino, et al. 1999a; Covino, et al. 1999b; Covino, et al. 1999c; Holcomb, et al. 2000a; Holcomb, et al. 2000b).

\subsection{PROBLEM DEFINITION}

Thermal-sprayed Zn anodes are being used increasingly in CP systems for steel-reinforced concrete structures. Recent research (SPR \#364) by Oregon DOT and the U.S. Department of Energy (DOE) has examined the effects of electrochemical aging on the long-term performance of TS Zn anodes, primarily for ICCP systems (Covino, et al. 2002). Both laboratory and field 
studies have shown that $\mathrm{Zn}$ anode reaction products accumulate at the $\mathrm{Zn}$-concrete interface with increasing electrochemical age. These reaction products eventually: decrease the bond strength of the anode to the concrete, increase the driving voltage needed to maintain a specified level of protection for the rebar, decrease the permeability of the Zn-concrete interface to gases and precipitation, and alter the chemistry of the interface. The level of moisture at the Zn-concrete interface was of particular importance in assuring a long service life for the anode. Based on bond strength, the anode service life was projected to be in excess of 25 years when the anode was repeatedly wetted, but it decreased to roughly five years when not wetted. Equally important, driving voltages were substantially lower when the anode was wetted.

Sheltered areas on structures receive less moisture than those fully exposed to the environment. Humectants are chemical solutions that, when applied to a TS Zn anode, can maintain a high moisture level at the $\mathrm{Zn}$-concrete interface regardless of weather conditions or the location on the structure. This elevated moisture level should help dissipate $\mathrm{Zn}$ reaction products, promote improved current flow, reduce operating voltages, maximize secondary mineralization of $\mathrm{Zn}$ anode dissolution products, and improve long-term anode bond strength.

\subsection{STUDY OBJECTIVES}

- Determine the effectiveness of humectants (chemical additives) for improving the performance and extending the service life of TS Zn anodes used in the CP of steelreinforced concrete.

- Examine the impact of the choice of humectant on the performance of $\mathrm{Zn}$ anodes, and the relationship between periodic wetting of the anode surface, ambient humidity level, electrochemical aging, and prior electrochemical aging on anode performance.

- Develop an understanding of how humectants affect the overall performance of ICCP and GCP systems.

- Determine an estimate of the increased service life to be gained by using humectants.

- Perform life cycle cost calculations for anode systems with and without humectants.

- Provide recommendations and guidelines for the implementation of humectant treatments on TS Zn anode CP systems.

\subsection{WORK PLAN SYNOPSIS}

Three humectants $\left(\mathrm{LiBr}, \mathrm{LiNO}_{3}\right.$, and $\left.\mathrm{KC}_{2} \mathrm{H}_{3} \mathrm{O}_{2}\right)$ were examined for their usefulness in a variety of laboratory and field experiments. Due to poor results with $\mathrm{KC}_{2} \mathrm{H}_{3} \mathrm{O}_{2}$, this humectant was dropped from consideration during testing. Limited results for $\mathrm{KC}_{2} \mathrm{H}_{3} \mathrm{O}_{2}$ are given in the main text of this report; additional results are presented in the Appendix. 


\subsubsection{Long-term Laboratory Experiments (ARC)}

Long-term laboratory experiments were conducted at the Albany Research Center (ARC). Humectants were applied to both new and previously-aged concrete slabs coated with TS Zn. New concrete slabs contain an expanded steel mesh and were thermal-sprayed with Zn. Slab surface preparations were according to Oregon DOT practices. Previously-aged slabs were selected from those used as part of SPR \# 364 (Covino, et al. 2002). Accelerated aging of both types of slabs was done galvanostatically at a nominal current density of $2.5 \mathrm{~mA} / \mathrm{ft}^{2}\left(27 \mathrm{~mA} / \mathrm{m}^{2}\right)$ (compared to $0.2 \mathrm{~mA} / \mathrm{ft}^{2}\left(2.2 \mathrm{~mA} / \mathrm{m}^{2}\right)$ used by Oregon DOT) for up to 12 months. A smaller group of the new slabs were cyclically aged at $2.5 \mathrm{~mA} / \mathrm{ft}^{2}\left(27 \mathrm{~mA} / \mathrm{m}^{2}\right)$ for 3 weeks, then 0.2 $\mathrm{mA} / \mathrm{ft}^{2}\left(2.2 \mathrm{~mA} / \mathrm{m}^{2}\right)$ for 1 week. The purpose of the cyclic tests was to age the slabs rapidly to a given electrochemical age as an ICCP anode, and then determine the operating voltages at the current density used by Oregon DOT to protect its coastal bridges. Galvanic aging of a group of both new and previously aged slabs was done by shorting the $\mathrm{Zn}$ anode coating to the steel mesh cathode.

Measurements were made to determine the effect of the humectants on operating characteristics such as ICCP voltage requirements, GCP current flow, and bond strength. Anode bond strength was measured at periodic intervals during electrochemical aging. Depolarization from 0.2 $\mathrm{mA} / \mathrm{ft}^{2}\left(2.2 \mathrm{~mA} / \mathrm{m}^{2}\right)$ on the cyclic slabs was measured. The chemistry of the $\mathrm{Zn}$-concrete interface was characterized during the electrochemical aging using an analytical scanning electron microscope (ASEM) and an electron microprobe.

\subsubsection{Short-Term Chamber Experiments (ARC)}

A small humidity chamber was used for two types of experiments. Circuit resistance responses to temperature and humidity were measured on slabs prepared similarly to the new slabs described above after at least one month of equilibration at a constant temperature and humidity. Very low current levels of $0.02 \mathrm{~mA} / \mathrm{ft}^{2}\left(0.22 \mathrm{~mA} / \mathrm{m}^{2}\right)$ were used, so as to eliminate any effects of electrochemical aging from test to test.

The other type of test measured mass changes as functions of temperature and humidity due to the humectants attracting water. Thin slices of concrete were cut from 3 -inch $(7.62 \mathrm{~cm})$ diameter cylinders that were made with 2,5 , and $10 \mathrm{lb} / \mathrm{yd}^{3}$ of $\mathrm{NaCl}\left(1.2,3.0\right.$, and $\left.5.9 \mathrm{~kg} / \mathrm{m}^{3}\right)$. Half were thermal-sprayed with zinc. Humectants were applied with pipettes to allow an exact amount to be added to each slice. The humectant treated slices, along with the controls, were equilibrated at constant temperature and humidity. The mass of each slice was measured periodically during the equilibration process.

\subsubsection{Long-Term Laboratory GCP Experiments (Ohio)}

The effectiveness of each humectant was tested on thermal-sprayed $\mathrm{Zn}$ anodes as a function of environment (low RH, high RH, outdoor exposed, and outdoor sheltered) in Chardon Ohio. Concrete blocks were constructed with $5.1 \mathrm{lb} / \mathrm{yd}^{3}\left(3.0 \mathrm{~kg} / \mathrm{m}^{3}\right)$ of NaCl . They were then aged, sandblasted, thermal-sprayed with $\mathrm{Zn}$, and humectant treated (except the controls). The galvanic current was monitored during the length of the test. Additional items were examined, including 
the effects of reapplying the humectant and the concentration of $\mathrm{Cl}^{-}$in the concrete, using additional blocks.

\subsubsection{Yaquina Bay Bridge Field Trial (Oregon)}

Four ICCP zones of the Yaquina Bay Bridge (located on the Pacific coast of Oregon) were selected for a field study. Two of the zones were untreated controls, one zone was treated with $\mathrm{LiBr}$, and one zone was treated with $\mathrm{LiNO}_{3}$. Operating current and voltage were monitored, and the interfacial chemistry was examined as part of the trial. 


\subsection{HUMECTANT SCREENING (OHIO)}

Experience has shown that metallized $\mathrm{Zn}$ delivers a relatively large protective galvanic current when first connected to the steel, but the current decreases significantly with time (Cramer, et al. $2002 \mathrm{~b}$ ). The amount of current that flows is dependent on several factors, including the following: the resistivity of the concrete (largely a function of concrete quality and composition, $\mathrm{Cl}^{-}$contamination, moisture content, and temperature), depth of cover over the reinforcement, charge history of the anode, and frequency of wetting. Studies have indicated that galvanic $\mathrm{Zn}$ anode performance is not likely to be adequate unless the anode is subjected to periodic direct wetting (Powers, Sagues and Murase 1992; Sagues, et al. 1994).

If a technique could be found to enhance the flow of GCP current, particularly in dryer environments, then the number of sites where simple GCP systems could be used to control corrosion could be greatly increased. The resulting reduction in installation, monitoring, and maintenance costs could encourage the acceptance of CP for reinforced concrete structures.

The choice of chemicals used in this report for use as humectants on $\mathrm{Zn}$ anodes for CP systems, on reinforced concrete, arose from a screening study by Bennett (1998). The results of this screening study are presented below.

\subsection{SCREENING STUDY PROCEDURES}

Thirty concrete blocks were constructed with dimensions of $12 \times 9 \times 2$ inch $(30.5 \times 22.9 \times 5.1$ $\mathrm{cm})$. The concrete contained a 3/16 diameter x 72-inch $(0.5$ diameter $\times 183 \mathrm{~cm})$ long mild steel rod that was bent back and forth to form a layer at a depth of 1.5-inch $(3.8 \mathrm{~cm})$ from the top surface of the concrete block. The surface area of the steel rod was $0.29 \mathrm{ft}^{2}\left(0.027 \mathrm{~m}^{2}\right)$. The mix proportions for the concrete were as follows:

$\begin{array}{ll}\text { Type 1A Portland Cement - } & 715 \mathrm{lb} / \mathrm{yd}^{3}\left(425 \mathrm{~kg} / \mathrm{m}^{3}\right) \\ \text { Lake Sand Fine Aggregate - } & 1010 \mathrm{lb} / \mathrm{yd}^{3}\left(600 \mathrm{~kg} / \mathrm{m}^{3}\right) \\ \text { No.8 Marblehead Limestone - } & 1830 \mathrm{lb} / \mathrm{yd}^{3}\left(1090 \mathrm{~kg} / \mathrm{m}^{3}\right) \\ \text { Water - } & 285 \mathrm{lb} / \mathrm{yd}^{3}\left(170 \mathrm{~kg} / \mathrm{m}^{3}\right) \\ \mathrm{NaCl}- & 0 \text { and } 8.2 \mathrm{lb} / \mathrm{yd}^{3}\left(4.9 \mathrm{~kg} / \mathrm{m}^{3}\right) \\ \text { Entrained Air - } & \text { about } 6 \%\end{array}$

Following a 24-hour mold curing period, the blocks were wrapped wet in plastic and allowed to cure for 28 days at room temperature. The top surfaces of the specimens were prepared by sandblasting to remove the cement paste layer, but care was taken not to expose too much coarse aggregate. The top surface of the concrete blocks was then coated with pure $\mathrm{Zn}$ by combustion spray using an oxy-acetylene flame. The blocks were not preheated. Zinc was hand-applied to a thickness of approximately $15 \mathrm{mil}(0.38 \mathrm{~mm})$. An electrical connection was made between the 
metallized $\mathrm{Zn}$ and the embedded steel across a $10 \Omega$ resistor to facilitate measurement of galvanic current. The blocks were then placed in a controlled room where the relative humidity (RH) was maintained between $55 \%$ and $60 \%$. Temperature was maintained at $20^{\circ} \mathrm{C} \pm 2{ }^{\circ} \mathrm{C}$.

Each block was then brush coated with a solution containing $300 \mathrm{~g} / 1$ of a performance-enhancing chemical. Since metallized coatings are inherently porous, the solution was transported to the anode-concrete interface by capillary action. Two coats were applied resulting in a total application rate of about $30 \mathrm{ml} /$ block. Control blocks were coated with distilled water with no chemical addition.

Current flowing between the $\mathrm{Zn}$ anode and the embedded steel was monitored and recorded for a period of 60 days. After 60 days the RH was raised to 80-85\%. Current was then monitored and recorded under this condition for an additional 30-day period.

\subsection{SCREENING STUDY RESULTS}

At the start of the experiment the $\mathrm{Zn}$ anode was wet with distilled water, which produced a large galvanic current. Since these specimens were maintained at low humidity $(55-60 \% \mathrm{RH})$, the current rapidly decayed with time. This current decay was much more pronounced for $\mathrm{Cl}^{-}$free specimens than for specimens contaminated with $8.2 \mathrm{lbs} \mathrm{NaCl} / \mathrm{yd}^{3}\left(4.9 \mathrm{~kg} / \mathrm{m}^{3}\right)$. After 11 days, distilled water was again applied to the $\mathrm{Zn}$ anode and galvanic current again surged to relatively high levels. Following wetting, the current again decayed and appeared to reach a stable value of approximately $1.4 \mathrm{~mA} / \mathrm{m}^{2}$ for the $\mathrm{Cl}^{-}$contaminated specimen, and less than $0.1 \mathrm{~mA} / \mathrm{m}^{2}$ for the $\mathrm{Cl}^{-}$free.

After 60 days the specimens were placed in an environment of about $80 \% \mathrm{RH}$ and galvanic current increased to approximately 2.7 and $10.0 \mathrm{~mA} / \mathrm{m}^{2}$ for the $\mathrm{Cl}^{-}$free and $\mathrm{Cl}^{-}$contaminated specimens respectively. In the absence of direct periodic wetting of the anode, it is likely that these specimens would require impressed current to insure protection against corrosion of embedded steel.

A total of 13 chemicals were selected and investigated for their ability to enhance galvanic current from metallized $\mathrm{Zn}$ anodes on concrete. Chemicals were chosen primarily for their efficiency as humectants (chemicals that are either deliquescent or hygroscopic). Potassium (K)and lithium (Li)-based chemicals were targeted since these are generally more deliquescent. In the case of Li-based chemicals, their ability to inhibit alkali-silica reaction (ASR) was also targeted. Results are summarized in Table 2.1. The most effective chemicals were bromides, acetates, chlorides, and nitrates. Several others, including certain organics, resulted in only slight improvement in galvanic current. 
Table 2.1: Results of feasibility study of chemicals for use as humectants (Bennett 1998)

\begin{tabular}{c|c}
\hline CHEMICAL & PERFORMANCE \\
\hline Lithium Bromide & Exceptional improvement $($ galvanic current $=10-20 \times$ control) \\
\hline Potassium Acetate & Good improvement $($ galvanic current $=5-10 \times$ control) \\
\hline Lithium Acetate & Good improvement $($ galvanic current $=5-10 \times$ control) \\
\hline Sodium Chloride & Good improvement $($ galvanic current $=5-10 \times$ control) \\
\hline Calcium Chloride & Good improvement $($ galvanic current $=5-10 \times$ control) \\
\hline Lithium Nitrate & Good improvement $($ galvanic current $=5-10 \times$ control) \\
\hline Glycerol & Slight improvement $($ galvanic current $=1-2 \times$ control) \\
\hline Ethylene Glycol & Slight improvement $($ galvanic current $=1-2 \times$ control) \\
\hline Potassium Phosphate & Slight improvement $($ galvanic current $=1-2 \times$ control) \\
\hline Potassium Carbonate* & Slight improvement $($ galvanic current $=1-2 \times$ control) \\
\hline Potassium Nitrate* & Slight improvement $($ galvanic current $=1-2 \times$ control) \\
\hline Lithium Hydroxide & Slight improvement $($ galvanic current $=1-2 \times$ control) \\
\hline Potassium Borate* & Slight improvement $($ galvanic current $=1-2 \times$ control)
\end{tabular}

* From a previous study conducted January, 1997

Lithium bromide ( $\mathrm{LiBr}$ ) was the best chemical tested from the standpoint of maximum galvanic current, about 15 times that of the control specimen at 55\% RH. Even after equilibrating at 80\% $\mathrm{RH}$, galvanic current for the specimen treated with $\mathrm{LiBr}$ was about 7 times that of the control specimen.

Treatment with potassium acetate $\left(\mathrm{KC}_{2} \mathrm{H}_{3} \mathrm{O}_{2}\right)$ and lithium acetate $\left(\mathrm{LiC}_{2} \mathrm{H}_{3} \mathrm{O}_{2}\right)$ both increased the flow of galvanic current by a factor of approximately $7-9$ at $55 \% \mathrm{RH}$, and by a factor of 2 at $80 \%$ $\mathrm{RH}$. These chemicals are both readily available, non-toxic, and environmentally acceptable.

Lithium nitrate $\left(\mathrm{LiNO}_{3}\right)$ had some potential, increasing galvanic current by a factor of 7 at $55 \%$ $\mathrm{RH}$. Sodium chloride $(\mathrm{NaCl})$ was also an effective chemical for enhancing galvanic current, increasing current up to an order of magnitude at $55 \% \mathrm{RH}$ and by a factor of about 2 at $80 \% \mathrm{RH}$. Calcium chloride $\left(\mathrm{CaCl}_{2}\right)$ was found to be about as effective as $\mathrm{NaCl}$.

\subsection{SELECTED HUMECTANTS}

Application of solutions of potassium or lithium bromide, acetate, chloride or nitrate was shown to greatly enhance the flow of galvanic current for CP systems using metallized Zn anodes. Such chemicals were capable of increasing current by a factor of between 2 and 15, depending on $\mathrm{RH}$ and $\mathrm{Cl}^{-}$contamination of the concrete.

The use of chlorides or bromides may be viewed with concern since both of these anions are capable of destroying the protective passive film that forms on steel in concrete. Again, it may be reasoned that electromigration will maintain these anions in the vicinity of the anode-concrete interface and away from the reinforcing steel, but this assumption is yet to be demonstrated. Acetates and nitrates are expected to raise no such concern.

It has been reported, and is generally accepted, that the presence of Li ions in the concrete will prevent or inhibit expansion due to ASR. It has been suggested that the lithium silicate reaction product does not have the capacity to expand, as do the sodium and potassium silicates. It has 
been demonstrated that $\mathrm{Li}$ compounds mixed into fresh concrete as an admixture will prevent damage that would otherwise occur later due to ASR. It has also been shown that lithium cations can be injected into concrete during electrochemical chloride extraction and will prevent or inhibit damage due to ASR (Bennett, et al. 1993).

Based on this feasibility study, three chemicals were chosen for use as humectants for the research part of this project: Lithium Bromide $(\mathrm{LiBr})$, Lithium Nitrate $\left(\mathrm{LiNO}_{3}\right)$, and Potassium Acetate $\left(\mathrm{KC}_{2} \mathrm{H}_{3} \mathrm{O}_{2}\right)$. 


\subsection{HUMECTANT THERMODYNAMICS}

\subsection{WATER ABSORPTION}

Humectants lower the activity of water (which for an ideal solution is the RH above the solution) by retaining it within the system. If the cement-humectant-water ternary system is simplified to a humectant-water binary system, then Equation 3-1 can be used with the data in Table 3.1 to calculate the water activity, $a_{w}$, as a function of humectant molality, $m_{i}$ (Zaytsev and Aseyev 1992). Molality is the number of moles dissolved in $1 \mathrm{~kg}$ of solvent.

$$
\ln a_{w}=\frac{t m_{i} M_{i}}{55510 R T}\left\{B_{1 i}+a_{i} t+b_{i} t^{2}+\frac{B_{2 i} m_{i} M_{i}}{1000+m_{i} M_{i}}\right\}
$$

In Equation 3-1, $t$ is the temperature in ${ }^{\circ} \mathrm{C}, M_{i}$ is the molecular weight of the humectant, $R$ is the gas constant $(8.31441 \mathrm{~J} / \mathrm{kmol}), T$ is the absolute temperature in $K$, and $B_{1 i}, a_{i}, b_{i}$, and $B_{2 i}$ are constants which are given in Table 3.1 .

Table 3.1: Parameters used in Equation 3-1 to calculate the activity of water in binary mixtures of humectant and water (Zaytsev and Aseyev 1992)

\begin{tabular}{c|c|c|c|c}
\hline \multirow{2}{*}{ PARAMETER } & \multicolumn{2}{|c|}{ LiBr } & \multicolumn{2}{c}{ LiNO $_{\mathbf{3}}$} \\
\cline { 2 - 5 } & $\mathbf{0 . 2 9 3 - 4 . 7 8} \boldsymbol{m}$ & $\mathbf{5 . 0 5 - 1 5 . 9} \boldsymbol{m}$ & $\mathbf{0 . 2 9 7 - 5 . 4 8} \boldsymbol{m}$ & $\mathbf{5 . 9 1 9 . 5 4} \boldsymbol{m}$ \\
\hline $\mathrm{M}_{\mathrm{i}}$ & 86.845 & 86.845 & 68.946 & 68.946 \\
\hline $\mathrm{B}_{1 \mathrm{i}}$ & -7295.73 & -8192.00 & -4096.00 & -6212.82 \\
\hline $\mathrm{a}_{\mathrm{i}}$ & 299.97 & 659.93 & -128.00 & -66.15 \\
\hline $\mathrm{b}_{\mathrm{i}}$ & -2.36 & -8.35 & 7.74 & 7.50 \\
\hline $\mathrm{B}_{2 \mathrm{i}}$ & -9213.91 & -21117.89 & -5573.42 & -3683.06 \\
\hline
\end{tabular}

Figure 3.1 shows the results of such calculations at $25^{\circ} \mathrm{C}$. The gaps between the molality ranges in Table 3.1 were smoothed and interpolated. Based on cold-water solubility limits (Weast 1979) of $1.45 \mathrm{~kg} / \mathrm{L}(16.7 \mathrm{~m})$ for $\mathrm{LiBr}$ and $0.898 \mathrm{~kg} / \mathrm{L}(13.0 \mathrm{~m})$ for $\mathrm{LiNO}_{3}$, the calculated $\mathrm{RH}$ above saturated solutions will be $8 \%$ and $45 \%$, respectively. This value for $\mathrm{LiNO}_{3}$ closely agrees with an experimentally determined water activity of 0.47 above saturated $\mathrm{LiNO}_{3} \cdot 3 \mathrm{H}_{2} \mathrm{O}$ at $25^{\circ} \mathrm{C}$ (Stokes and Robinson 1949; Robinson and Stokes 1959). Figure 3.1 is useful in understanding how humectants work. For example, a saturated solution of $\operatorname{LiBr}(16.7 \mathrm{~m})$ in an environment with a $\mathrm{RH}$ of $50 \%$ will absorb water until the concentration of $\mathrm{LiBr}$ is down to approximately 8 $\mathrm{m}$ (the concentration of $\mathrm{LiBr}$ in Figure 3.1 at a $\mathrm{RH}$ of $50 \%$ ). Figure 3.1 also suggests that $\mathrm{LiBr}$ should be a more powerful humectant than $\mathrm{LiNO}_{3}$, especially in dry environments, i.e., below a RH of $50 \%$. 


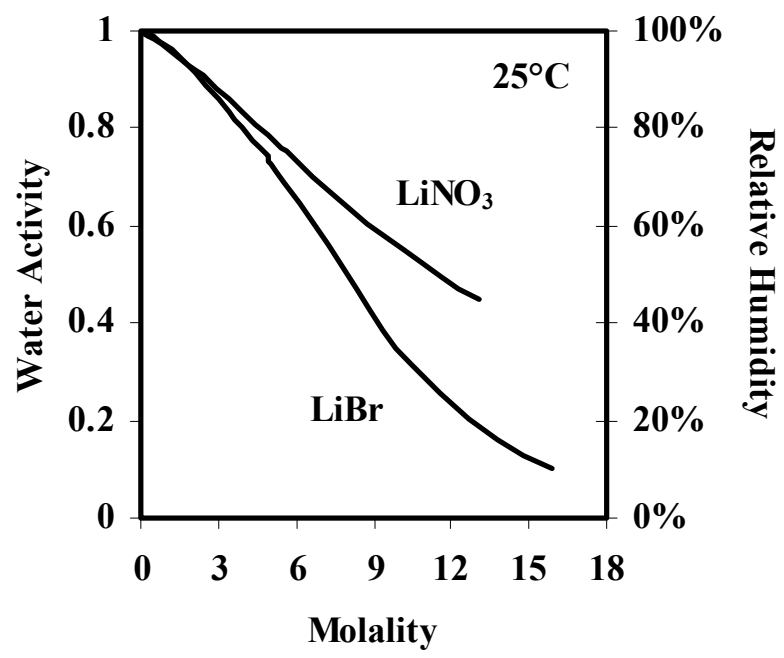

Figure 3.1: Water activity as a function of humectant molality at $25^{\circ} \mathrm{C}$

Equilibration experiments, described in Section 4.2, used a humidity chamber to expose humectant-treated and control samples at fixed values of temperature and RH. Table 3.2 shows the results of using Equation 3-1, and the parameters in Table 3.1, to calculate humectant molality under these conditions.

Table 3.2: Calculated humectant molality at $90^{\circ} \mathrm{F}\left(32.2^{\circ} \mathrm{C}\right)$ at values of $\mathrm{RH}$ in equilibrium experiments

\begin{tabular}{c|c|c}
\hline RH & CALCULTATED LiBr MOLALITY & CALCULATED LiNO $_{3}$ MOLALITY \\
\hline 35 & 9.9 & $13.0^{\mathrm{a}}$ \\
\hline 50 & 8.1 & $13.0^{\mathrm{a}}$ \\
\hline 70 & 5.8 & 10.7 \\
\hline 80 & 4.4 & 7.7 \\
\hline
\end{tabular}

${ }^{\mathrm{a}}$ Saturated solution of $\mathrm{LiNO}_{3}$ (using the solubility limit at $25^{\circ} \mathrm{C}$ ).

\subsection{BROMIDE OXIDATION}

Since the humectants are expected to reside in the $\mathrm{Zn}$-concrete reaction zone, and this is the region of the highest voltage drop (Orlova, et al. 1999), it is possible that bromide ions ( $\mathrm{Br}^{-}$) could be oxidized in LiBr-treated ICCP. Nitrate ions are already fully oxidized, so no such reactions are possible with $\mathrm{LiNO}_{3}$ treatments. The potential-pH diagram (Pourbaix 1974) for $\mathrm{Br}$ in water at $25^{\circ} \mathrm{C}$ is shown in Figure 3.2. The reactions of interest in Figure 3.2 are shown in Table 3.3. 


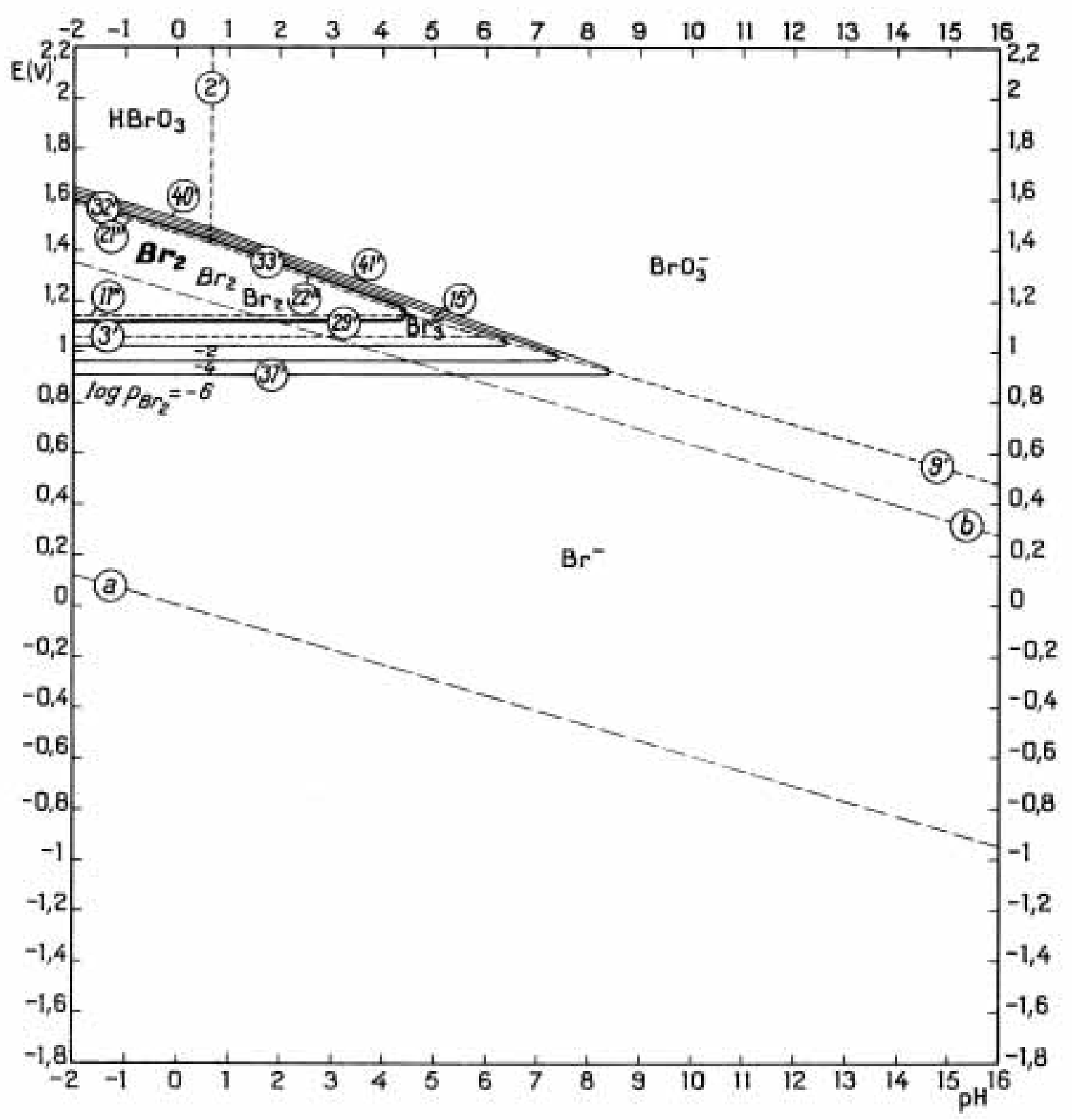

Figure 3.2: Potential-pH diagram at $25^{\circ} \mathrm{C}$ for $\mathrm{Br}$ in water (Pourbaix 1974) 
Table 3.3: Selected oxidation reactions in the $\mathrm{Br}-\mathrm{H}_{2} \mathrm{O}$ system at $25^{\circ} \mathrm{C}$ (Pourbaix 1974)

\begin{tabular}{l|lr|c|c}
\hline \multicolumn{1}{c|}{ OXIDATION REACTION } & \multicolumn{1}{c|}{$\mathbf{E}_{\mathbf{0}}, \mathbf{V}$} & $\begin{array}{c}\text { FIGURE 3.2 } \\
\text { LINE }\end{array}$ & EQUATION \\
\hline $2 \mathrm{H}_{2} \mathrm{O}=4 \mathrm{H}^{+}+\mathrm{O}_{2}+4 \mathrm{e}^{-}$ & $1.228-0.0591 \mathrm{pH}+0.0147 \log \mathrm{P}_{\mathrm{O}_{2}}$ & $\mathrm{~b}$ & $\mathbf{3 - 2}$ \\
\hline $2 \mathrm{Br}^{-}=\mathrm{Br}_{2}+2 \mathrm{e}^{-}$ & 1.082 & $+0.0295 \log \left(\mathrm{P}_{\mathrm{Br}_{2}} / \mathrm{C}_{\mathrm{Br}^{2}}{ }^{2}\right)$ & $37^{\prime}$ & $\mathbf{3 - 3}$ \\
\hline $\mathrm{Br}^{-}+3 \mathrm{H}_{2} \mathrm{O}=\mathrm{BrO}_{3}^{-}+6 \mathrm{H}^{+}+6 \mathrm{e}^{-}$ & $1.423-0.0591 \mathrm{pH}+0.0098 \log \left(\mathrm{C}_{\mathrm{BrO}_{3}}-/ \mathrm{C}_{\mathrm{Br}^{-}}\right)$ & $9^{\prime}$ & $\mathbf{3 - 4}$ \\
\hline $3 \mathrm{Br}^{-}=\mathrm{Br}_{3}^{-}+2 \mathrm{e}^{-}$ & 1.051 & $+0.0295 \log \left(\mathrm{C}_{\mathrm{Br}_{3}}-/ \mathrm{C}_{\mathrm{Br}^{-}}{ }^{3}\right)$ & $3^{\prime}$ & $\mathbf{3 - 5}$ \\
\hline
\end{tabular}

Loss of $\mathrm{Br}$ from the system could occur by $\mathrm{Br}^{-}$oxidizing to form $\mathrm{Br}_{2}$ (Equation 3-3), which could then be released into the atmosphere. Figure 3.2 shows this as the " $\mathrm{Br}_{2}$ nose" that extends up to a $\mathrm{pH}$ of 8 . The $\mathrm{pH}$ of zinc anode-concrete interfaces from bridge ICCP systems were measured after electrochemical aging of about 3 years, and were found to be between 7 and 8 (Covino, et al. 1997a; Covino, et al. 2002). In the absence of a humectant it was surmised that Equation 3-2 was occurring, which lowered the interfacial pH. In Figure 3.2, the transition from $\mathrm{O}_{2}$ evolution (line b, Equation 3-2) to $\mathrm{Br}_{2}$ evolution (line37', Equation 3-3) at a $\mathrm{P}_{\mathrm{Br}_{2}}$ of $10^{-6}$ occurs at a $\mathrm{pH}$ of about 5.5, which is lower than the observed $\mathrm{pH}$ values.

It is possible, however, that the potentials of these reactions could differ in the more complex concrete-zinc system such that the oxidation to $\mathrm{Br}_{2}$ occurs in preference to $\mathrm{O}_{2}$ evolution. This would result in $\mathrm{Br}_{2}$ production with $\mathrm{pH}$ values of up to 8 . Such a situation occurs with $\mathrm{Cl}^{-}$ oxidation to $\mathrm{Cl}_{2}$ in the presence of graphite. In this case, the overvoltage for oxygen evolution is much higher than that of $\mathrm{Cl}_{2}$ evolution, and when anodically polarized, a graphite anode generates $\mathrm{Cl}_{2}$ (Wagner 1992; Cramer, et al. 2002a).

Alternatively, if the $\mathrm{pH}$ at the $\mathrm{Zn}$ anode interface is greater than about 8 , it is possible that $\mathrm{Br}^{-}$ will be oxidized to other oxygen derivatives of bromine, such as hypobromite $\left(\mathrm{BrO}^{-}\right)$or bromate $\left(\mathrm{BrO}_{3}{ }^{-}\right)$. Electrochemical generation of the latter species is especially likely (line 9' in Figure 3.2), and is the basis for a commercial process for production of both potassium bromate and sodium bromate (Sugino 1964). In this case, loss of Br from the system would not occur, but conversion to oxygen derivatives of $\mathrm{Br}$ would compromise the effectiveness of the chemical as a humectant. 


\subsection{EXPERIMENTAL PROCEDURES}

The experiments conducted for this project can be divided into four main categories: long-term laboratory experiments performed at ARC, short-term experiments performed at ARC, long-term experiments performed in Ohio, and the field trial on the Yaquina Bay Bridge in Newport, Oregon.

\subsection{LONG-TERM LABORATORY EXPERIMENTS (ARC)}

The goal of the long-term laboratory experiments conducted at ARC was to test the effectiveness of each humectant on TS Zn anodes as a function of environment. Environmental conditions included low and high RH, electrochemical age (both new and a variety of initial electrochemical ages) and current density (both GCP and accelerated ICCP).

\subsubsection{New Sample Preparation}

Concrete slabs with an imbedded steel mesh were prepared to chemically, physically, and mechanically approximate a section of a reinforced concrete structure. The slab dimensions were $9 \times 13 \times 2$ in $(23 \times 33 \times 5 \mathrm{~cm})$. Reinforcing steel was simulated with a layer of No. 16 expanded steel mesh and was cast with 1.25 in $(3.2 \mathrm{~cm})$ concrete cover. Wires were welded to the mesh at two corners and protruded beyond the top surface of the slab to provide electrical contact leads. The concrete mix design approximated that used in Oregon's coastal bridges that were constructed in the 1930 s and had a water-cement ratio of 0.48 . Sodium chloride $(\mathrm{NaCl})$ was added to the concrete mix at $5.0 \mathrm{lb} / \mathrm{yd}^{3}\left(3.0 \mathrm{~kg} / \mathrm{m}^{3}\right)$ to approximate the present salt content of coastal bridges and to increase the electrical conductivity of the concrete. The slabs were cured for 28 days in a moist room, and then air-dried for one month. The top face of each slab was sandblasted to remove the weak laitance layer present on the surface and to produce a medium sandpaper surface with some aggregate exposed. The sandblasted surface was then air-blasted to remove dust. The areas around the two wire leads were masked with tape to a distance of 1 in $(2.4 \mathrm{~cm})$ to prevent shorting between the mesh and the $\mathrm{Zn}$ anode. The top surface of the slab was then thermally sprayed with $15 \pm 1 \mathrm{mil}(0.38 \pm 0.02 \mathrm{~mm})$ of zinc using multiple roboticallycontrolled $x-y$ passes over the surface to produce uniformly coated concrete slabs, Figure 4.1. A twin wire arc-spray process with $1 / 8$-inch $(3.2 \mathrm{~mm})$ diameter $\mathrm{Zn}$ wire was used to coat the slabs. These slabs are referred to as "new" slabs. 


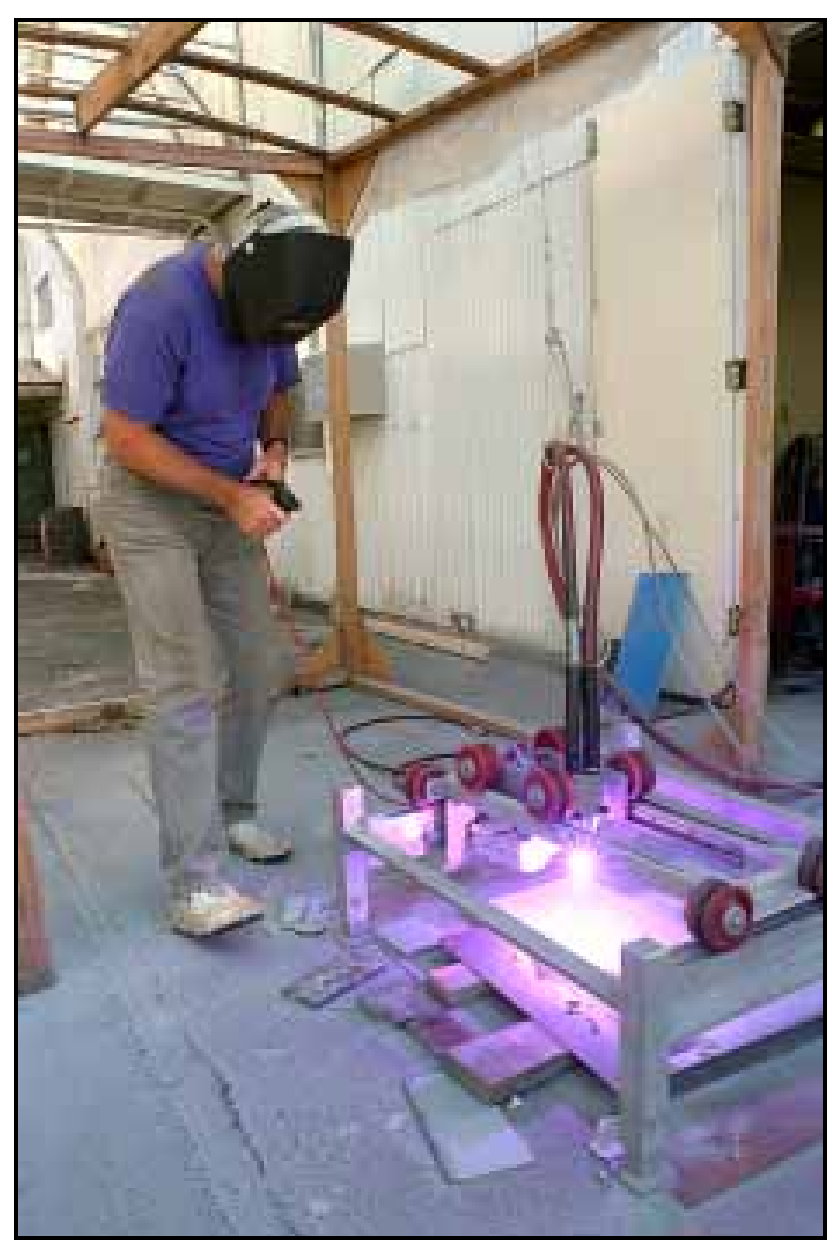

Figure 4.1: Thermal-spraying of zinc onto new slabs with robotic-controlled $x-y$ passes

A few additional "new" slabs were cast with 2.0 and $10.0 \mathrm{lb} / \mathrm{yd}^{3}\left(1.2\right.$ and $\left.5.9 \mathrm{~kg} / \mathrm{m}^{3}\right)$ of $\mathrm{NaCl}$ in the concrete mix. Since $\mathrm{NaCl}$ is a humectant, these were made to show the effects from $\mathrm{NaCl}$.

\subsubsection{Aged Sample Preparation}

Zinc-coated concrete slabs from earlier studies (Covino, et al. 1996a; Covino, et al. 1996b; Covino, et al. 2002; Holcomb, et al. 1996), representing a broad range of electrochemical ages, were used to study humectant effects on aged anodes. They had $5.0 \mathrm{lb} / \mathrm{yd}^{3}\left(3.0 \mathrm{~kg} / \mathrm{m}^{3}\right)$ of NaCl . Pairs of slabs with initial electrochemical ages, based on the Oregon DOT ICCP current density of $0.2 \mathrm{~mA} / \mathrm{ft}^{2}\left(2.2 \mathrm{~mA} / \mathrm{m}^{2}\right)$, of $1.6,3,5.1,8,12,13.1,16.1$, and 19 years were selected. Slabs aged 3, 8, 13.1, and 19 years were used in the ICCP experiment and slabs aged 1.6, 5.1, 12, and 16.1 years were used in the GCP experiment. Each slab was cut into three pieces with each piece having approximately the same surface area. Electrical lead wires were welded to the exposed steel mesh to make an electrical contact and bare concrete areas were masked with epoxy paint. The surface area of zinc on each piece was then measured and recorded. These slabs are referred to as "aged" slabs and represent existing CP systems. 


\subsubsection{Humectant Application}

Solutions containing $300 \mathrm{~g} / \mathrm{L}$ of humectant $\left(\mathrm{LiBr}\right.$ at $3.45 \mathrm{M}, \mathrm{LiNO}_{3}$ at $4.35 \mathrm{M}$, and $\mathrm{KC}_{2} \mathrm{H}_{3} \mathrm{O}_{2}$ at $3.06 \mathrm{M}$ ) plus $10 \mathrm{ml} / \mathrm{L}$ of a commercially available surfactant were brush applied to both new and aged slabs in two applications on two different days. This resulted in approximately $86 \mathrm{~g} / \mathrm{m}^{2}(8$ $\mathrm{g} / \mathrm{ft}^{2}$ ) of humectant on the anode surface. A control solution, containing only the surfactant, was applied to some of the new slabs as controls.

\subsubsection{Environmental Conditions}

Two enclosures were used to provide either a high or a low RH environment. Humidifiers and dehumidifiers controlled the RH. Heaters and air coolers controlled the temperature. Fans also provided air circulation. Mean values in the high $\mathrm{RH}$ enclosure were $81 \pm 5 \% \mathrm{RH}$ and $26 \pm 2^{\circ} \mathrm{C}$ $\left(79 \pm 4^{\circ} \mathrm{F}\right)$. Mean values in the low $\mathrm{RH}$ enclosure were $45 \pm 4 \% \mathrm{RH}$ and $29 \pm 2^{\circ} \mathrm{C}\left(84 \pm 4^{\circ} \mathrm{F}\right)$. Figure 4.2 shows the samples in the high RH enclosure.

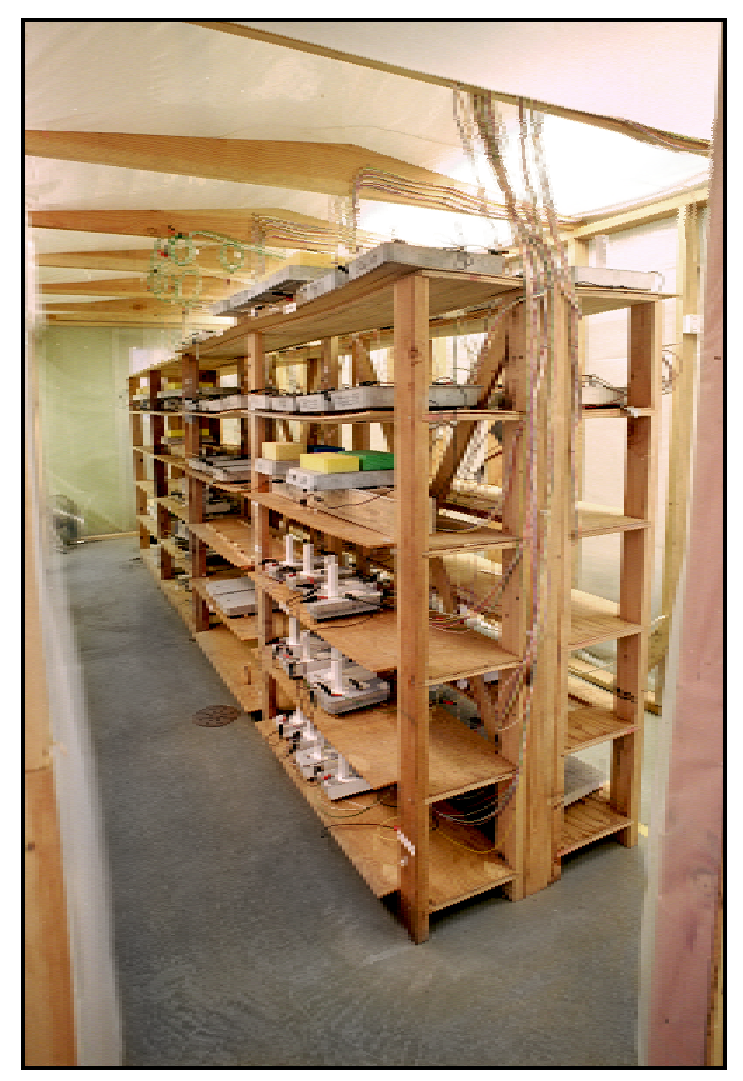

Figure 4.2: New and aged zinc slabs wired in series in the high RH enclosure

High-purity water was sprayed every day in the enclosures to simulate rainfall and to aid in maintaining the slab resistances low enough for each series of slabs to stay under the compliance voltages of their current sources. 


\subsubsection{Accelerated Impressed Current Cathodic Protection}

Current was provided for the ICCP experiment using stable, constant, current sources with compliance voltages of either 100 or $300 \mathrm{~V}$. Slabs were connected in series for each current source. Initially, all of the ICCP slabs had a nominal current density of $2.5 \mathrm{~mA} / \mathrm{ft}^{2}\left(27 \mathrm{~mA} / \mathrm{m}^{2}\right)$. Soon after the experiment started, the compliance voltages of the current sources supplying the aged slabs, within the low RH enclosure, were limiting the current. Due to the limiting current of the supply sources, the current densities of the aged slabs were reduced to a nominal value of $0.9 \mathrm{~mA} / \mathrm{ft}^{2}\left(10 \mathrm{~mA} / \mathrm{m}^{2}\right)$.

In the ICCP experiments, potentials and currents were monitored hourly using a data acquisition system. Potentials of the $\mathrm{Zn}$ anode were measured with respect to the steel cathode.

Differences in the current densities used in the experiments, and periods when the compliance voltage of the current sources were exceeded, combined together creating difficulties in comparing results in terms of voltage. Thus, circuit resistance was used (operating voltage/impressed current density) to better compare results at differing current densities (and with field installations). In this case, the current density was based on anode area and not cathode area. A lower circuit resistance means there is less polarization of the anode.

Later in this report, when mean circuit resistances are reported, the initial $204 \mathrm{kC} / \mathrm{m}^{2}$ (3 years at Oregon DOT ICCP current densities) are not included in the mean so as to remove the initial low values of circuit resistance.

\subsubsection{Cyclic Impressed Current Cathodic Protection}

One of the concerns about accelerated electrochemical aging is the effect of higher current densities on the measured parameter slab polarization and the derived parameter circuit resistance. Higher current densities tend to produce greater values of polarization and circuit resistance. Accelerated aging is necessary, however, because it is not possible to conduct 20-30 year aging experiments in real time. To accomplish the accelerated aging while still minimizing its effects on parameters, a modified procedure was used on one set of slabs. Over a repeated 4week cycle, one set of slabs was aged for three weeks at an accelerated rate of $2.5 \mathrm{~mA} / \mathrm{ft}^{2}(2.8$ $\mathrm{mA} / \mathrm{m}^{2}$ ) identical to that of the rest of the slabs. At the start of the fourth week, the current density was decreased to $0.2 \mathrm{~mA} / \mathrm{ft}^{2}\left(2.2 \mathrm{~mA} / \mathrm{m}^{2}\right)$, a value similar to that typically used by Oregon DOT on their coastal bridges. This was termed a cyclic ICCP procedure. The goal of cycling the slabs for one week to the lower current density was to allow the aged $\mathrm{Zn}$-concrete interface to approach a steady-state value that was similar to that which would exist on a coastal bridge under ICCP. At the end of the fourth week, depolarization values were measured.

\subsubsection{Galvanic Cathodic Protection}

In the GCP experiments, the galvanic current was measured and recorded every hour. Resistors used to measure the current in the GCP experiment ranged from 3 to $4000 \Omega$. The values of the resistors were chosen and maintained such that the potentials across them remained between 1.5 and $8 \mathrm{mV}$. This maximized the signal while keeping the voltage drop across the resistor small. 
The usefulness of the anode is characterized by the current density, in $\mathrm{mA} / \mathrm{m}^{2}$, where the area is based on cathode area.

The new slabs have anode to cathode area ratios that are very close to one, so the distinction between anode and cathode areas is not necessary. Aged slabs, on the other hand, have anode to cathode area ratios that have a mean value of 0.8 and the distinction is necessary.

In cases where an average galvanic current is presented, it is called the long-term current density. The long-term current density is defined as the average current density for the experiment after removing the first year of current density values. This has the advantage of establishing the long-term protection current, which can be compared with the minimum current needed to protect the structure. It also ignores short periods of high galvanic current sometimes observed, especially in the initial days and months of GCP (Cramer, et al. 2002b).

The minimum current needed for protection is an empirically derived value and may well be different for different climates and chloride levels. For example, Oregon DOT has found that 0.2 $\mathrm{mA} / \mathrm{ft}^{2}\left(2.2 \mathrm{~mA} / \mathrm{m}^{2}\right)$ is sufficient for their coastal thermal-sprayed zinc ICCP systems (Bullard, et al. 1998; Covino, et al. 1997a; Covino, et al. 2002), while Fontana and Greene (1978, p. 207) give $0.1-0.5 \mathrm{~mA} / \mathrm{ft}^{2}\left(1.1-5.4 \mathrm{~mA} / \mathrm{m}^{2}\right)$ as sufficient for protecting reinforcing bars in concrete.

\subsubsection{Depolarization}

Depolarization was measured on the cyclic ICCP slabs at various times throughout the experiment. Prior to depolarization, the impressed current was reduced to $0.2 \mathrm{~mA} / \mathrm{ft}^{2}(2.2$ $\mathrm{mA} / \mathrm{m}^{2}$ ) to reduce the polarization caused by the accelerated aging experiment. $\mathrm{A} \mathrm{Cu} / \mathrm{CuSO}$ reference electrode was used with a wet sponge between the reference electrode and an area of bare concrete (without $\mathrm{Zn}$ ) on the sample. For the new slabs the reference electrode was contacted to the underside of the sample. On the aged slabs the reference electrode made contact in an area without $\mathrm{Zn}$ left from prior adhesion strength pull tests, Figure 4.3.

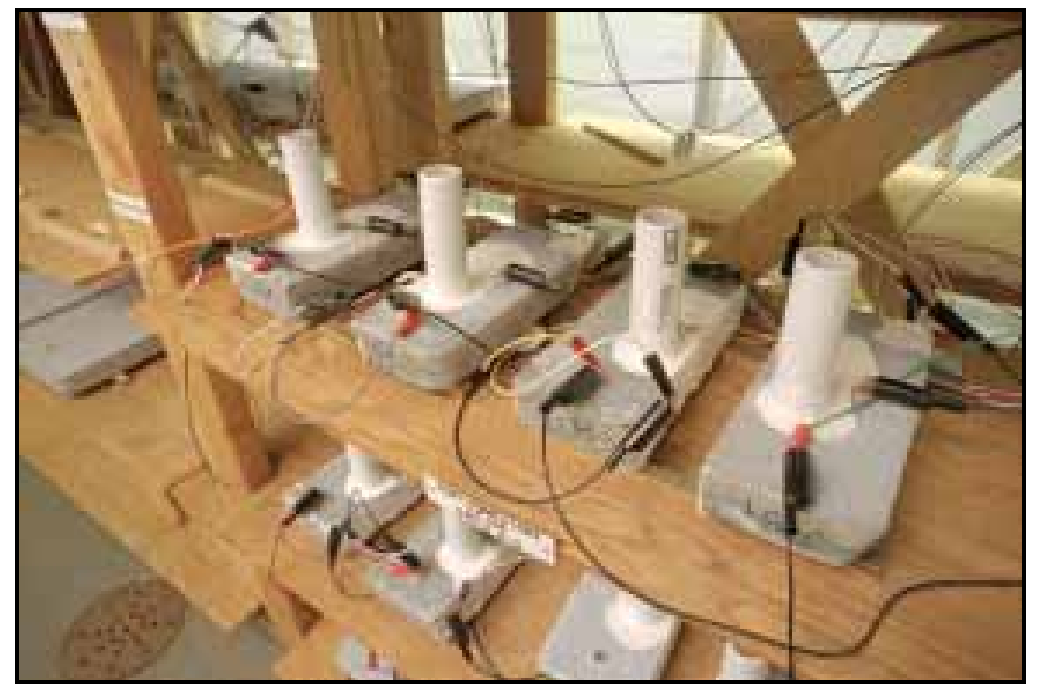

Figure 4.3: Aged zinc slabs wired in series in the high RH enclosure. Note the reference electrode holders (PVC pipe) mounted in areas without zinc left from prior adhesion strength pull tests. 
Measurements of the potential between the steel mesh and the reference electrode were made every minute for 30 minutes. The impressed current was then removed and the potential was recorded every minute for 2 hours. After that, the potential was recorded every hour for an additional 22 hours. The reported value of depolarization was the difference between the "instant off" potential (measured immediately after the impressed current was removed) and the potential measured at a later time during depolarization, typically 24 hours.

\subsubsection{Microscopy}

The TS Zn surface of selected ICCP slabs was stabilized by a coating of clear epoxy so that cutting, grinding and polishing could be performed without separating the anode from the concrete. The slabs were cross-sectioned to expose the anode-concrete interface. The crosssections were mounted in epoxy, ground and polished to a $1 \mu \mathrm{m}$ diamond finish. To prevent charging, the polished cross-sections were lightly coated with Palladium in a vacuum coating unit. The moisture in the concrete samples required substantial pumping to achieve the vacuum necessary for coating and for examination in the scanning electron microscope (SEM). SEM images were obtained with back-scattered electrons (BSE). Back-scattered electron images exhibit contrast based on average atomic number, so that cross-section composition can be qualitatively observed (low atomic number elements are darker). Analytical SEM (ASEM) was used to determine the composition of the $\mathrm{Zn}$-concrete interface. The following elements were included in all analyses: $\mathrm{Zn}, \mathrm{Ca}, \mathrm{Mg}, \mathrm{Na}, \mathrm{K}, \mathrm{S}, \mathrm{Cl}, \mathrm{O}, \mathrm{Fe}$, and $\mathrm{Al}$. Line scans were done using Xray fluorescence microanalyses and a wavelength dispersive spectrometer (WDS) with four crystals. Line scans across the anode-concrete interface typically contained 100 to 150 individual point analyses along the line. Data acquisition times for each element at each point on the line scan were typically $20 \mathrm{~s}$. Element x-ray maps were all obtained using an energy dispersive spectrometer (EDS) to qualitatively show the distribution of individual elements in the cross-section.

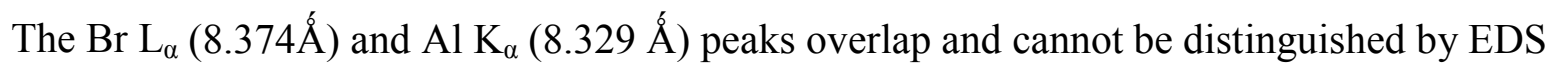
when both elements are present. EDS could determine $\mathrm{Br}$ only in the $\mathrm{Zn}$ anode and in anode mineral products not containing cement paste. The $\mathrm{Br}_{\beta}$ peak, which is separate and identifiable from other peaks by WDS, was used to quantify Br concentrations for the line scans.

Lithium is a light element that cannot be detected by either EDS or WDS. While Ti $\mathrm{K}_{\alpha}$ and $\mathrm{N} \mathrm{K}_{\alpha}$ peaks overlap, there was insufficient $\mathrm{Ti}$ in the cement paste (as rutile or other $\mathrm{Ti}$ oxide) to prevent analysis for N. However, the polished slab cross-sections were not analyzed for N.

A line scan across an electrochemically aged $\mathrm{Zn}$ anode can be simplified into zones representing: the unreacted anode, a growing mineral reaction layer characterized largely as $\mathrm{ZnO}$ or $\mathrm{Zn}(\mathrm{OH})_{2}$, altered cement paste containing varying levels of $\mathrm{Zn}$ from anode dissolution, and unaltered cement paste. Anions migrate to the anode under the influence of the ICCP potential gradient (Covino, et al. 2002). The total mass of $\mathrm{Cl}$ and $\mathrm{Br}$ in the different zones was found by integrating the ASEM line scan across the cross-section. There was about a $20 \%$ error in these calculations, a tolerable error given that the line scans represent a single traverse across an anode-concrete interface fractions of a millimeter wide (the analysis volume was roughly $5 \mu \mathrm{m}$ in diameter). 


\subsubsection{AC Resistance and Circuit Resistance}

Circuit resistance, as measured by the operating voltage divided by impressed current density, includes both ohmic resistances across the anode-cement-cathode electrochemical cell, and the effects of polarization of the steel cathode and zinc anode (Covino, et al. 2002). An attempt was made to separate the ohmic and polarization components. This was attempted by making alternating current (AC) resistance measurements between the zinc anode and the steel cathode; and then comparing them with the circuit resistance measurements.

The procedure was to obtain a mean value for the circuit resistance over the last 24 hours of impressed current. A subsequent $60 \mathrm{~Hz} \mathrm{AC}$ resistance measurement was made between the steel mesh and the zinc coating. On some slabs the AC measurements were made as early as one day after the impressed current ended, and on other slabs as much as 320 days elapsed. In all cases the slabs were stored in the same humidity enclosure where the impressed current tests were performed. Measurements were taken on both new and aged slabs, from high and low RH enclosures, and from control and humectant-treated slabs. The humectant-treated slabs included $\mathrm{KC}_{2} \mathrm{H}_{3} \mathrm{O}_{2}$-treated slabs removed from the main study.

\subsubsection{Adhesion Strength}

Slabs were removed from the electrochemical aging experiment at regular time intervals. The slabs were equilibrated with dry air for one day, and prepared for bond strength measurements by attaching aluminum dollies to the $\mathrm{Zn}$ coating using epoxy. For the new slabs the dollies were attached at six predetermined locations, and dollies were $50 \mathrm{~mm}$ (1.9 in) in diameter. For the aged slabs, which had much less $\mathrm{Zn}$ surface remaining from prior adhesion tests, smaller dollies were used that were $19 \mathrm{~mm}(0.75 \mathrm{in})$ in diameter. A high viscosity, high strength, short cure time (300 s) epoxy was used to eliminate failures at the epoxy-dolly interface and to prevent epoxy penetration through the coating to the concrete. $\mathrm{Zn}$ bond strength measurements were made using a universal testing machine (Bullard, et al. 1997a; Covino, et al. 1995; Covino, et al. 1997b; Covino, et al. 2002).

\subsection{SHORT-TERM CHAMBER EXPERIMENTS (ARC)}

The short-term chamber experiments used a small humidity and temperature-controlled chamber to equilibrate sixty 2 -inch diameter concrete slices and four TS concrete slabs at specific conditions. Equilibration lasted a minimum of 50 days. Half of the slices were TS with $\mathrm{Zn}$ and half were not. Three $\mathrm{NaCl}$ levels were used in the slices, each containing 2.0, 5.0, and 10.0 $\mathrm{lb} / \mathrm{yd}^{3}\left(1.2,3.0,5.9 \mathrm{~kg} / \mathrm{m}^{3}\right)$ of $\mathrm{NaCl}$. Humectants in surfactant solutions were applied to some of the slices, surfactants without humectants were applied to some slices, and some slices were left untreated as controls. All of the slabs were TS with $\mathrm{Zn}$. Three of the slabs were humectant treated and one was untreated for a control.

Mass changes of the slices were periodically recorded throughout the experiment. The TS concrete slabs underwent ICCP at very low current densities for 24 hours and the applied voltage was recorded and converted into circuit resistance. Very low current densities were used to 
minimize any effects from electrochemical aging of the anode. After the ICCP the RH of the chamber was changed and a new equilibration was begun.

\subsubsection{Sample Preparation}

The sample preparations for the slabs were the same as for the long-term laboratory experiments (indoor) and are described in Section 4.1.2.

Nominally 0.25 -inch $(0.635 \mathrm{~cm})$ thick slices were cut from 3 -inch $(7.62 \mathrm{~cm})$ diameter cylinders. The cylinders were cast with a sand to cement ratio of 3 to 1 (by weight). The sand was partially absorbed with water (1.1\%). After allowing for the sand to be fully absorbed with water (4.5\%), the water to cement ratio was calculated to be 0.43 . Added to the mix was $\mathrm{NaCl}$ at 2.0, 5.0, and $10.0 \mathrm{lb} / \mathrm{yd}^{3}\left(1.2,3.0\right.$, and $\left.5.9 \mathrm{~kg} / \mathrm{m}^{3}\right)$. The cylinders were cured in a high humidity chamber for four weeks prior to slicing.

Half of the slices were TS with $15 \mathrm{mil}(0.38 \mathrm{~mm})$ of $\mathrm{Zn}$ using the twin-wire arc-spray process used for the slabs (Section 4.1.2).

The slices without zinc were divided into 5 groups: those humectant-treated with $\mathrm{LiNO}_{3}, \mathrm{LiBr}$, and $\mathrm{KC}_{2} \mathrm{H}_{3} \mathrm{O}_{2}$, those treated with just the surfactant, and those left untreated (as controls). The slices with zinc had the same arrangement except without $\mathrm{KC}_{2} \mathrm{H}_{3} \mathrm{O}_{2}$. The humectants were brush applied to each side of the slice with each side receiving two applications. The solutions were made from $300 \mathrm{~g} / \mathrm{L}$ of humectant with $1 \%$ surfactant. Solution was measured out with a pipette for $0.65 \mathrm{ml}$ per side per application. This resulted in a total of $0.7854 \mathrm{~g}$ of humectant on each slice. Table 4.1 lists the number of slices for each condition.

Table 4.1: Number of slices for each condition

\begin{tabular}{l|c|c|c|c|c|c}
\hline \multirow{2}{*}{ HUMECTANT } & \multicolumn{3}{|c|}{ No Zn } & \multicolumn{3}{c}{ TS Zn } \\
\cline { 2 - 7 } & $\begin{array}{c}2.01 \mathrm{~b} / \mathrm{yd}^{3} \\
\left(1.2 \mathrm{~kg} / \mathrm{m}^{3}\right) \\
\mathrm{NaCl}\end{array}$ & $\begin{array}{c}5.01 \mathrm{~b} / \mathrm{yd}^{3} \\
\left(3.0 \mathrm{~kg} / \mathrm{m}^{3}\right) \\
\mathrm{NaCl}\end{array}$ & $\begin{array}{c}10.01 \mathrm{~b} / \mathrm{yd}^{3} \\
\left(5.9 \mathrm{~kg} / \mathrm{m}^{3}\right) \\
\mathrm{NaCl}\end{array}$ & $\begin{array}{c}2.01 \mathrm{~b} / \mathrm{yd}^{3} \\
\left(1.2 \mathrm{~kg} / \mathrm{m}^{3}\right) \\
\mathrm{NaCl}\end{array}$ & $\begin{array}{c}5.01 \mathrm{~b} / \mathrm{yd}^{3} \\
\left(3.0 \mathrm{~kg} / \mathrm{m}^{3}\right) \\
\mathrm{NaCl}\end{array}$ & $\begin{array}{c}10.01 \mathrm{~b} / \mathrm{yd}^{3} \\
\left(5.9 \mathrm{~kg} / \mathrm{m}^{3}\right) \\
\mathrm{NaCl}\end{array}$ \\
\hline $\mathrm{LiNO}$ & 2 & 2 & 3 & 3 & 3 \\
\hline $\mathrm{LiBr}$ & 2 & 2 & 2 & 3 & 3 & 3 \\
\hline Surfactant & 2 & 2 & 2 & 2 & 2 & 2 \\
\hline Control & 2 & 2 & 2 & 2 & 2 & 2 \\
\hline $\mathrm{KC}_{2} \mathrm{H}_{3} \mathrm{O}_{2}$ & 2 & 2 & 2 & & & \\
\hline
\end{tabular}

\subsubsection{Equilibrium Procedures}

Prior to the experiments, the humidity chamber was calibrated with saturated solutions of $\mathrm{NaCl}$ $\left(75.3 \% \mathrm{RH}\right.$ at $\left.25^{\circ} \mathrm{C}\right)$ and lithium chloride $(\mathrm{LiCl})\left(11.3 \% \mathrm{RH}\right.$ at $\left.25^{\circ} \mathrm{C}\right)$. After removing the calibration solutions, the slices and slabs were placed on racks so that both faces were free of obstruction. All of the samples were kept in the humidity chamber at $90^{\circ} \mathrm{F}\left(32.2^{\circ} \mathrm{C}\right)$ and at a fixed RH. The initial RH was $70 \%$ and was held for 89 days. Subsequent conditions were 50\% $\mathrm{RH}$ for 51 days, $35 \% \mathrm{RH}$ for 52 days, $80 \% \mathrm{RH}$ for 72 days, and then $70 \% \mathrm{RH}$ for 94 days. 
Slice masses were periodically monitored and used to decide when the samples had equilibrated. The voltage and circuit resistance response to ICCP was measured at the end of each RH period.

\subsubsection{Mass Change Response to Temperature and Humidity}

The procedures used to measure the mass changes in the slices were as follows:

1) Remove the rack containing the slices from the chamber.

2) Weigh each slice to the nearest $0.1 \mathrm{mg}$. The slices were weighed in the same order each time; with the first two slices weighed again after all 60 slices were weighed. The rack and samples were then placed back into the humidity chamber.

3) Since the slices were outside the humidity chamber during weighing, the masses in the first two slices (that were also weighed again after all 60 slices were weighed) tended to dry a bit and decrease in mass by $10-20 \mathrm{mg}$. This change was used to correct (increase) the masses of the slices with a linear correction factor, proportional to the sequence number of that slice.

The mass change response was measured for the first four RH conditions $(70 \%, 50 \%, 35 \%$ and $80 \% \mathrm{RH})$.

\subsubsection{Circuit Resistance Response to Temperature and Humidity}

The slabs were connected in series to a constant current power supply, with the anode (TS Zn) of one slab connected to the cathode (steel mesh) of the next. After the mass changes of the slices had been deemed good enough for equilibration, the chamber was allowed to be at the set temperature and RH for one more day. Then a constant current of $0.015 \mathrm{~mA}\left(0.020 \mathrm{~mA} / \mathrm{ft}^{2}, 0.22\right.$ $\mathrm{mA} / \mathrm{m}^{2}$ ) was applied for 24 hours. The voltage drop across each slab was monitored. The voltage was recorded every minute for the first 10-15 minutes (when the voltage was changing rapidly). It was then recorded every few hours (with a longer gap overnight). A final reading was taken after 24 hours. The voltages were then converted into circuit resistance $\left(\mathrm{k} \Omega-\mathrm{m}^{2}\right)$ using the surface area of the TS zinc anode and the applied current density.

\subsection{LONG-TERM LABORATORY GCP EXPERIMENTS (OHIO)}

The goal of these long-term laboratory experiments was to test the effectiveness of each humectant on thermal-sprayed zinc anodes as a function of environment (low RH, high RH, outdoor sheltered and outdoor exposed), concrete chloride levels, and reapplication. The experiments were conducted in Chardon, Ohio (near Cleveland).

Thirty-six concrete blocks were constructed with dimensions of $12 \times 9 \times 2$ inch $(30.5 \times 22.9 \times$ $5.1 \mathrm{~cm})$. The concrete contained a $1 / 16$-inch thick mild steel mesh $(1.25$-inch LWD x 0.5 -inch SWD) at a depth of 1.5 -inch $(3.8 \mathrm{~cm})$ from the top surface of the concrete block. The steel mesh provided a surface area of about $1 \mathrm{ft}^{2}$ steel $/ \mathrm{ft}^{2}$ of concrete. The mix proportions for the concrete were as follows: 
Type 1A Portland Cement -

Lake Sand Fine Aggregate -

No.8 Marblehead Limestone-

Water -

$\mathrm{NaCl}$ -

Entrained Air -
$715 \mathrm{lb} / \mathrm{yd}^{3}\left(425 \mathrm{~kg} / \mathrm{m}^{3}\right)$

$1010 \mathrm{lb} / \mathrm{yd}^{3}\left(600 \mathrm{~kg} / \mathrm{m}^{3}\right)$

$1830 \mathrm{lb} / \mathrm{yd}^{3}\left(1090 \mathrm{~kg} / \mathrm{m}^{3}\right)$

$285 \mathrm{lb} / \mathrm{yd}^{3}\left(170 \mathrm{~kg} / \mathrm{m}^{3}\right)$

$5.1 \mathrm{lb} / \mathrm{yd}^{3}\left(3.0 \mathrm{~kg} / \mathrm{m}^{3}\right)$

about $6 \%$

Following a 24-hour mold curing period, the blocks were wrapped wet in plastic and allowed to cure for 28-days at room temperature.

The top surfaces of the specimens were prepared by sandblasting to remove the cement paste layer, but care was taken not to expose too much coarse aggregate. The blocks were then coated on their top surface with a pure zinc anode by the twin-wire arc-spray process to a thickness of about $15 \mathrm{mil}(0.38 \mathrm{~mm})$. Zinc was applied using a robot to insure consistency between applications. The blocks were not preheated. Electrical connection was made between the metallized $\mathrm{Zn}$ and the embedded steel across a $10 \Omega$ resistor to facilitate measurement of galvanic current.

Each block was then brush coated with a solution containing $300 \mathrm{~g} / \mathrm{L}$ of humectant plus $10 \mathrm{ml} / \mathrm{L}$ of a commercially available surfactant. Since metallized coatings are inherently porous, the solution was transported to the anode-concrete interface by capillary action. Three coats were applied resulting in a total application rate of about $30 \mathrm{ml} / \mathrm{block}$. Control blocks were coated with distilled water with no chemical addition. Exact amounts of chemical applied to groups of blocks are shown in Table 4.2.

Table 4.2: Humectant and Operating Environment for the Blocks

\begin{tabular}{|c|c|c|}
\hline BLOCK & OPERATING ENVIRONMENT & $\begin{array}{c}\text { CHEMICAL APPLIED } \\
\mathrm{g} / \mathrm{m}^{2}\left(\mathrm{~g} / \mathrm{ft}^{2}\right)\end{array}$ \\
\hline $1,2,3$ & $80 \%$ RH, No Wetting & Distilled Water (Control) \\
\hline $4,5,6$ & $80 \%$ RH, No Wetting & $78.5(7.29) \mathrm{KC}_{2} \mathrm{H}_{3} \mathrm{O}_{2}$ \\
\hline $7,8,9$ & $80 \%$ RH, No Wetting & $82.9(7.70) \mathrm{LiNO}_{3}$ \\
\hline $10,11,12$ & $80 \%$ RH, No Wetting & $81.5(7.57) \mathrm{LiBr}$ \\
\hline $15,16,17$ & $55 \%$ RH, No Wetting & Distilled Water (Control) \\
\hline $18,19,20$ & $55 \%$ RH, No Wetting & $87.3(8.11) \mathrm{KC}_{2} \mathrm{H}_{3} \mathrm{O}_{2}$ \\
\hline $21,22,23$ & $55 \%$ RH, No Wetting & $99.2(9.22) \mathrm{LiNO}_{3}$ \\
\hline $24,25,26$ & $55 \%$ RH, No Wetting & $99.1(9.21) \mathrm{LiBr}$ \\
\hline 29,30 & Outdoors (Exposed, Covered) & Distilled Water (Control) \\
\hline 31,32 & Outdoors (Exposed, Covered) & $72.0(6.69) \mathrm{KC}_{2} \mathrm{H}_{3} \mathrm{O}_{2}$ \\
\hline 33,34 & Outdoors (Exposed, Covered) & 76.7 (7.13) $\mathrm{LiNO}_{3}$ \\
\hline 35,36 & Outdoors (Exposed, Covered) & 77.8 (7.23) LiBr \\
\hline
\end{tabular}

As shown on the table above, blocks were placed in one of three operating environments: $80 \%$ $\mathrm{RH}, 55 \% \mathrm{RH}$, and outdoors. Blocks placed indoors in $80 \%$ and $55 \% \mathrm{RH}$ were never wetted, and therefore became relatively dry. Indoor blocks were maintained at a temperature of $20^{\circ} \mathrm{C} \pm 2^{\circ} \mathrm{C}$. The outdoor blocks were maintained outdoors in northeast Ohio in one of two conditions: 
exposed (placed at a $45^{\circ}$ angle and exposed to all natural precipitation), and covered (receiving no direct precipitation, but experiencing natural excursions of temperature and humidity).

Blocks placed in $80 \%$ and $55 \%$ RH were energized on January 23, 1998. Blocks placed outdoors were energized on April 1, 1998.

In addition to the treatment above, the blocks listed in Table 4.3 were subjected to a second chemical treatment after 230 days of operation. Blocks receiving a second treatment were placed back into the same operating environment from which they were taken.

Table 4.3: Second humectant treatments and operating environments

\begin{tabular}{|c|c|c|}
\hline BLOCK & OPERATING ENVIRONMENT & CHEMICAL APPLIED, $\mathrm{g} / \mathrm{m}^{2}\left(\mathrm{~g} / \mathrm{ft}^{2}\right)$ \\
\hline 2 & $80 \%$ RH, No Wetting & Distilled Water (Control) \\
\hline 5 & $80 \%$ RH, No Wetting & $105.3(9.78) \mathrm{KC}_{2} \mathrm{H}_{3} \mathrm{O}_{2}$ \\
\hline 8 & $80 \%$ RH, No Wetting & $116.2(10.80) \mathrm{LiNO}_{3}$ \\
\hline 11 & $80 \%$ RH, No Wetting & $87.5(8.13) \mathrm{LiBr}$ \\
\hline 16 & $55 \%$ RH, No Wetting & Distilled Water (Control) \\
\hline 19 & $55 \%$ RH, No Wetting & $92.4(8.58) \mathrm{KC}_{2} \mathrm{H}_{3} \mathrm{O}_{2}$ \\
\hline 22 & $55 \%$ RH, No Wetting & $122.1(11.34) \mathrm{LiNO}_{3}$ \\
\hline 25 & $55 \%$ RH, No Wetting & $96.3(8.95) \mathrm{LiBr}$ \\
\hline
\end{tabular}

The blocks described in Tables 4.2 and 4.3 were constructed with an admixed salt content of 3.0 $\mathrm{kg} / \mathrm{m}^{3}\left(5.1 \mathrm{lb} / \mathrm{yd}^{3}\right) \mathrm{NaCl}$. In early 1999 it was decided to examine the effect of chloride ion content on performance. Twenty-seven blocks were therefore constructed containing 4.9, 7.3, and $9.8 \mathrm{~kg} / \mathrm{m}^{3}\left(8.2,12.4\right.$, and $\left.16.5 \mathrm{lb} / \mathrm{yd}^{3}\right)$ of $\mathrm{NaCl}$. Otherwise, construction of the blocks was the same as that described above for the original blocks. These blocks received chemical treatment as shown in Table 4.4. 
Table 4.4: Humectant treatments and operating environments for blocks of different NaCl contents

\begin{tabular}{|c|c|c|c|}
\hline BLOCK & $\begin{array}{c}\text { NaCl CONTENT } \\
\mathrm{kg} / \mathrm{m}^{3}\left(\mathrm{lb} / \mathrm{yd}^{3}\right)\end{array}$ & OPERATING ENVIRONMENT & $\begin{array}{c}\text { CHEMICAL APPLIED } \\
\mathrm{g} / \mathrm{m}^{2}\left(\mathrm{~g} / \mathrm{ft}^{2}\right)\end{array}$ \\
\hline-1 & $4.9(8.2)$ & $55 \%$ RH, No Wetting & Distilled Water (Control) \\
\hline-2 & $4.9(8.2)$ & $55 \%$ RH, No Wetting & $150.3(13.96) \mathrm{LiNO}_{3}$ \\
\hline-3 & $4.9(8.2)$ & $55 \%$ RH, No Wetting & $154.7(14.37) \mathrm{LiBr}$ \\
\hline-4 & $7.3(12.4)$ & $55 \%$ RH, No Wetting & Distilled Water (Control) \\
\hline-5 & $7.3(12.4)$ & $55 \%$ RH, No Wetting & $144.1(13.39) \mathrm{LiNO}_{3}$ \\
\hline-6 & $7.3(12.4)$ & $55 \%$ RH, No Wetting & $147.7(13.72) \mathrm{LiBr}$ \\
\hline-7 & $9.8(16.5)$ & $55 \%$ RH, No Wetting & Distilled Water (Control) \\
\hline-8 & $9.8(16.5)$ & $55 \%$ RH, No Wetting & $141.4(13.14) \mathrm{LiNO}_{3}$ \\
\hline-9 & $9.8(16.5)$ & $55 \%$ RH, No Wetting & $166.0(15.42) \mathrm{LiBr}$ \\
\hline-10 & $4.9(8.2)$ & $80 \%$ RH, No Wetting & Distilled Water (Control) \\
\hline-11 & $4.9(8.2)$ & $80 \%$ RH, No Wetting & $151.3(14.06) \mathrm{LiNO}_{3}$ \\
\hline-12 & $4.9(8.2)$ & $80 \%$ RH, No Wetting & $166.0(15.42) \mathrm{LiBr}$ \\
\hline-13 & $7.3(12.4)$ & $80 \%$ RH, No Wetting & Distilled Water (Control) \\
\hline-14 & $7.3(12.4)$ & $80 \%$ RH, No Wetting & $145.6(13.53) \mathrm{LiNO}_{3}$ \\
\hline-15 & $7.3(12.4)$ & $80 \%$ RH, No Wetting & $143.5(13.33) \mathrm{LiBr}$ \\
\hline-16 & $9.8(16.5)$ & $80 \%$ RH, No Wetting & Distilled Water (Control) \\
\hline-17 & $9.8(16.5)$ & $80 \%$ RH, No Wetting & $152.8(14.20) \mathrm{LiNO}_{3}$ \\
\hline-18 & $9.8(16.5)$ & $80 \%$ RH, No Wetting & $157.6(14.64) \mathrm{LiBr}$ \\
\hline-19 & $4.9(8.2)$ & Outdoors Covered & Distilled Water (Control) \\
\hline-20 & $4.9(8.2)$ & Outdoors Covered & $156.5(14.54) \mathrm{LiNO}_{3}$ \\
\hline-21 & $4.9(8.2)$ & Outdoors Covered & $170.2(15.81) \mathrm{LiBr}$ \\
\hline-22 & $7.3(12.4)$ & Outdoors Covered & Distilled Water (Control) \\
\hline-23 & $7.3(12.4)$ & Outdoors Covered & $156.0(14.49) \mathrm{LiNO}_{3}$ \\
\hline-24 & $7.3(12.4)$ & Outdoors Covered & $143.5(13.33) \mathrm{LiBr}$ \\
\hline-25 & $9.8(16.5)$ & Outdoors Covered & Distilled Water (Control) \\
\hline-26 & $9.8(16.5)$ & Outdoors Covered & $144.0(13.38) \mathrm{LiNO}_{3}$ \\
\hline-27 & $9.8(16.5)$ & Outdoors Covered & $149.1(13.85) \mathrm{LiBr}$ \\
\hline
\end{tabular}

\subsection{YAQUINA BAY BRIDGE FIELD TRIAL (OREGON)}

Field installation of humectants under the south approach of the Yaquina Bay Bridge in Newport, Oregon took place in October 1999. Four large under-deck, thermal-sprayed, zinc ICCP Zones, with areas of approximately $5000 \mathrm{ft}^{2}\left(465 \mathrm{~m}^{2}\right)$, were chosen for this two-year field trial. The two center zones had humectants applied to them, one with $\mathrm{LiBr}$ and one with $\mathrm{LiNO}_{3}$. The two zones on each side of the treated zones were controls and had nothing applied to them. Concrete core samples and $\mathrm{Cl}^{-}$depth profiles were taken and analyzed at the start of the trial.

\subsubsection{Bridge and Zone Description}

The south approach of the Yaquina Bay Bridge was chosen to be the site of an ICCP field trial of the humectants. Four zones (ICCP Zones 10, 11, 13, and 14) were selected to be part of the trial, Figure 4.4. 


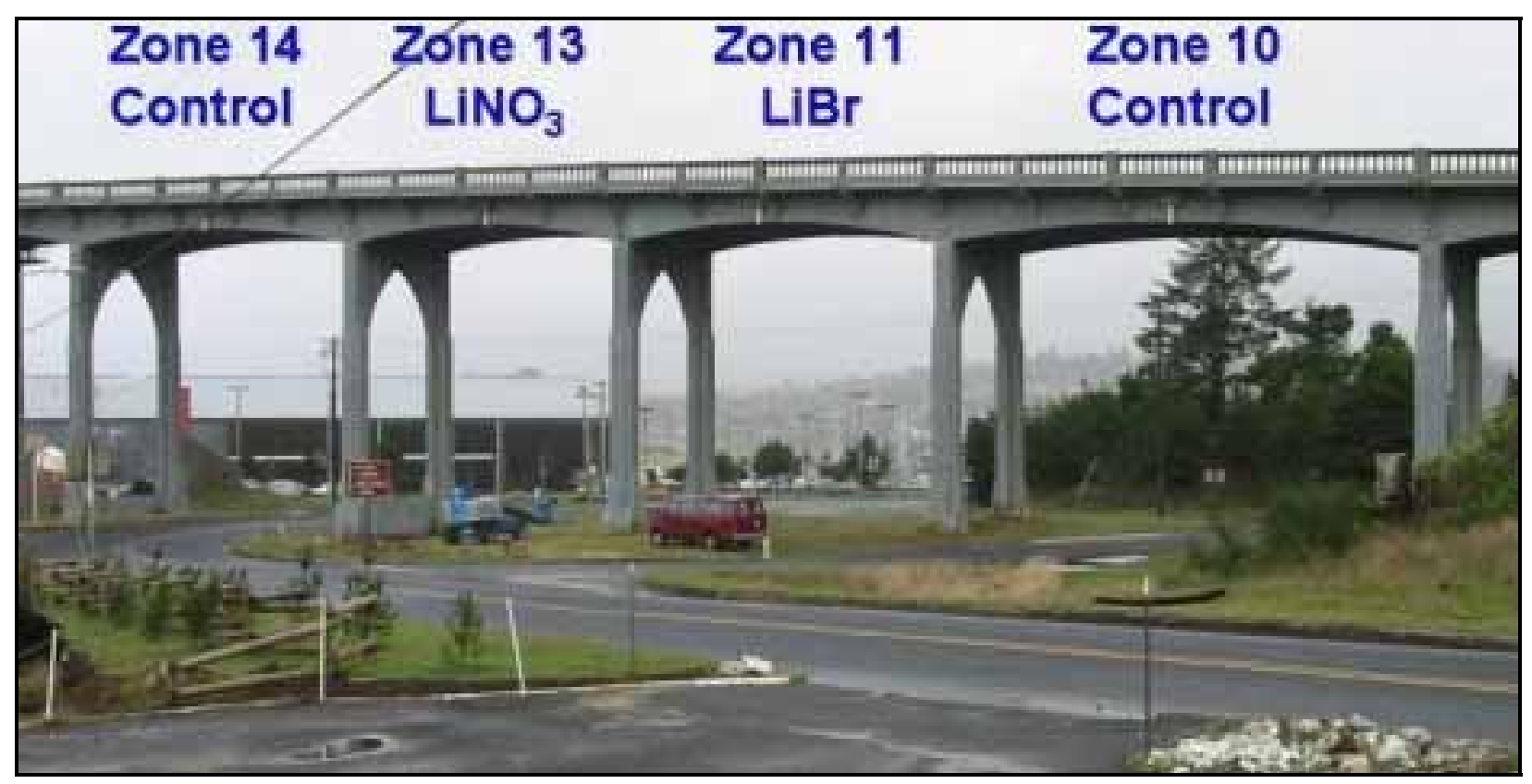

Figure 4.4: The four field test zones on the Yaquina Bay Bridge. Each zone includes column and soffit areas. Zone 14 is closest to Yaquina Bay. The closer a zone is to the ocean, the higher the expected $\mathrm{Cl}^{-}$level and the lower the expected circuit resistance.

All four zones are part of the approach and are not over water. The ICCP Zones are numbered beginning at the south end of the bridge, so the higher the zone number, the closer it is to Yaquina Bay. Zone 10 was $131 \mathrm{~m}(429 \mathrm{ft})$ from the bay, Zone 11 was $113 \mathrm{~m} \mathrm{(370} \mathrm{ft)} \mathrm{from} \mathrm{the}$ bay, Zone 13 was $94 \mathrm{~m}$ (308 ft) from the bay, and Zone 14 was $73 \mathrm{~m}(239 \mathrm{ft})$ from the bay. The $\mathrm{LiBr}$ humectant was applied to Zone $11, \mathrm{LiNO}_{3}$ to Zone 13, and Zones 10 and 14 were used as controls. The surface areas of Zones 10,11, 13, and 14 were $556.7 \mathrm{~m}^{2}\left(5992 \mathrm{ft}^{2}\right), 443.3 \mathrm{~m}^{2}$ $\left(4771 \mathrm{ft}^{2}\right), 451.7 \mathrm{~m}^{2}\left(4862 \mathrm{ft}^{2}\right)$, and $556.7 \mathrm{~m}^{2}\left(5992 \mathrm{ft}^{2}\right)$, respectively.

\subsubsection{Chloride Depth Profiling}

The concentration of chloride ion $\left(\mathrm{Cl}^{-}\right)$, as a function of depth, was measured on the four Yaquina Bay Bridge test zones prior to the application of humectants. The $\mathrm{Cl}^{-}$profiles were taken from beams in the soffits supporting the roadbed. Thus, they were taken from areas sheltered from direct precipitation, but fully exposed to wind, fog, and dew formation. As a comparison, $\mathrm{Cl}^{-}$profiles from the west side of the base of Bent $3 \mathrm{~N}$, on the north side of the bridge were also measured; one from the north face and one from the south face. The north side of Bent $3 \mathrm{~N}$ is much more sheltered from wind and rain than the south side.

Chloride samples, taken as powdered concrete, were taken at 0.5 inches $(1.27 \mathrm{~cm})$ depth increments into the concrete. Precautions were taken to avoid sample cross-contamination. The procedures for sampling are described in detail in the report on Project SPR 364 (Covino 2002, Appendix C). Chloride analysis was performed following AASHTO T260-94 (AASHTO 1995) for both total and water-soluble $\mathrm{Cl}^{-}$. More detailed procedures for $\mathrm{Cl}^{-}$analyses are described in the report on Project SPR 364 (Covino 2002, Appendix D). 


\subsubsection{Microscopy}

Concrete core samples $5 \mathrm{~cm}$ ( 2 inches) in diameter were taken from the two humectant-treated zones and from the two control zones immediately after the humectant treatment (10-22-99) and again after about 2 years of service (12-5-01). The cores were prepared, cross-sectioned, ground and polished as was done for the concrete slabs, Section 4.1.9. SEM examination of the cores was the same as for the concrete slabs. In performing the line scans, the core from Zone 13 receiving the $\mathrm{LiNO}_{3}$ treatment was analyzed for nitrogen using the $\mathrm{N} \mathrm{K}_{\alpha}$ line. The core from the control Zone 10 was analyzed for $\mathrm{Br}$ and $\mathrm{N}$, as well as the usual elements, to determine their background levels. Data acquisition times for $\mathrm{N}$ and $\mathrm{Br}$ during the line scans were increased from $20 \mathrm{~s}$ to $60 \mathrm{~s}$ to improve signal-to-noise ratios.

\subsubsection{Humectant Application Procedures}

Humectants were applied to the Yaquina Bay Bridge in a scaled up version of the procedures described in Section 4.1.3 for the laboratory studies. Solutions were prepared with $300 \mathrm{~g} / \mathrm{L}$ of humectant with $10 \mathrm{ml} / \mathrm{L}$ of surfactant. The surfaces were hand sprayed as shown in Figures 4.5 and 4.6. There was no surface preparation prior to spraying. Unlike the controls in the laboratory studies (that received water with surfactant), the controls here received no treatment at all.

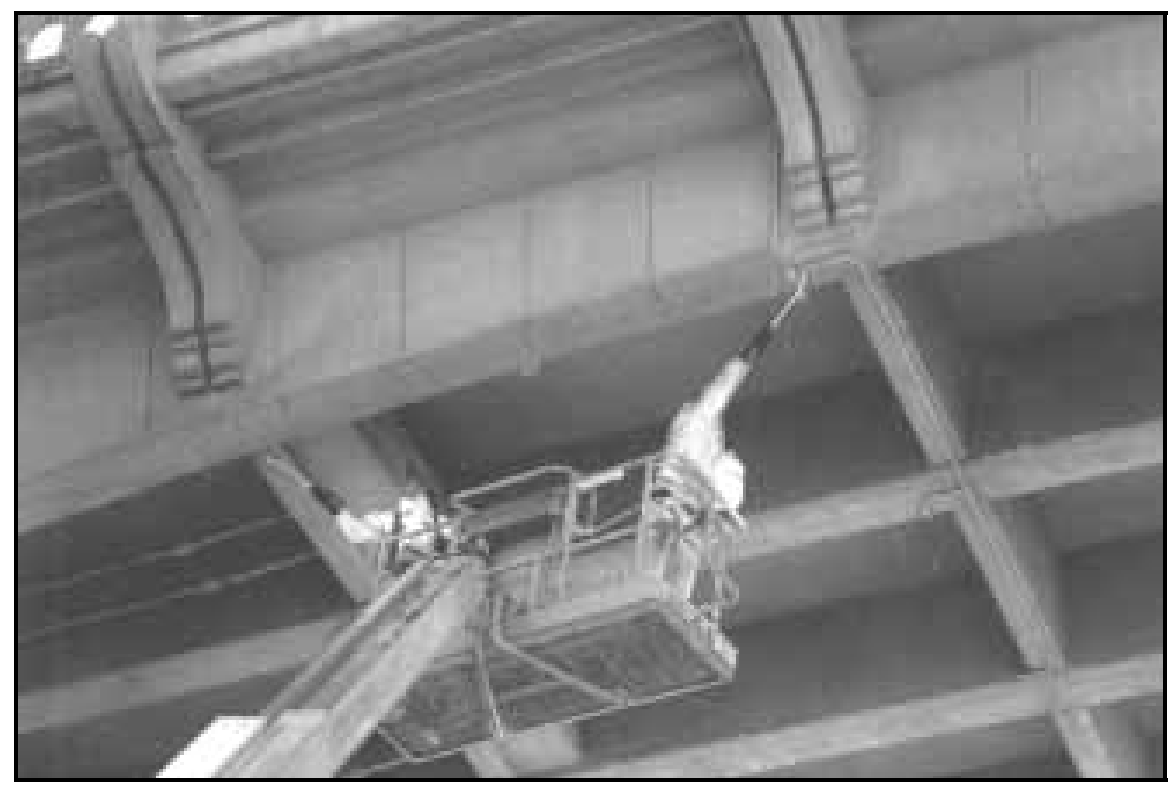

Figure 4.5: Application of humectants under the deck of the Yaquina Bay Bridge 


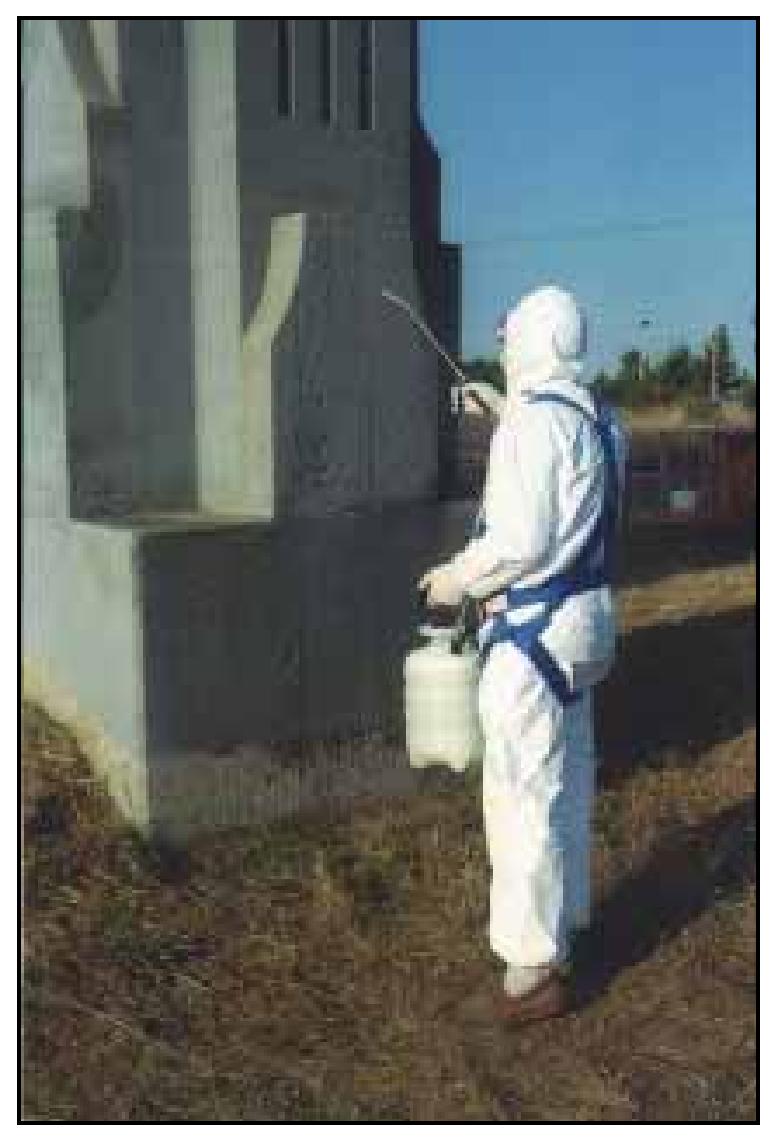

Figure 4.6: Application of humectants to the base of a bent on the Yaquina Bay Bridge

\subsubsection{Monitoring Procedures}

The humectant test covered four ICCP Zones: 10, 11, 13, and 14. The rectifiers operate in the constant-voltage, current-limited mode. The Yaquina Bay Bridge data acquisition system (DAS) was a CORD-4 System by Corexco. The system monitored the output voltage and current on an hourly basis. Depolarization measurements were made versus a graphite electrode. The integrity of the graphite electrodes was monitored with comparisons to silver/silver chloride electrodes.

The data was retrieved from the DAS by two methods. The first was by downloading the stored hourly data from the DAS, the "ON" reports. The "ON" reports were retrieved at the bridge several times each year. The second method was to manually download instantaneous data from the station reports that were available to be viewed from a remote location, the "SRP" reports. The "SRP" reports were retrieved daily. The "ON" reports have greater precision than the "SRP" reports, so the "ON" reports were used in preference to the "SRP" reports. However, between $2 / 26 / 98$ to $11 / 06 / 98,11 / 26 / 98$ to $2 / 25 / 99,4 / 18 / 00$ to $7 / 21 / 00$, and $7 / 25 / 01$ to $11 / 26 / 01$, the data recorder malfunctioned. Some, but not all of the "ON" data was recovered by the manufacturer by downloading the information and decoding it. Data from the "SRP" reports 
were used to fill gaps in the data. This resulted in differences in the observed noise in the data since the "SRP" and "ON" data had different formats and precisions.

On 5/3/01 the voltage and currents in the four zones increased sharply by up to seven times the intended set points. This was discovered on $11 / 21 / 01$ by an inspection of the rectifier cabinets. This rise was traced to failures of the potentiometers in the rectifiers, which caused the voltages/currents to drift upward. The voltages and currents were 2 to 7 times higher than the intended set points. This problem was corrected on 12/30/01 and the voltages/currents were reduced to the correct set values.

\subsection{CONTROLS}

There are minor differences in terms of what is meant by control samples or control zones between the four main categories of experiments. In the long-term experiments at ARC and Ohio, the surfactant was applied to the control samples. In the short-term experiments at ARC and in the Yaquina Bay Bridge field trial, the controls had nothing applied to them. The shortterm experiments at ARC also had some samples with just a surfactant treatment; thus it essentially had two types of controls (differentiated as "controls" and "surfactant-treated").

\subsection{NaCI CONCENTRATIONS}

A variety of $\mathrm{NaCl}$ concentrations were used in the laboratory experiments. For ease of comparison, Table 4.5 presents these various concentrations in terms of both $\mathrm{NaCl}$ and $\mathrm{Cl}$ concentrations in commonly used units.

Table 4.5: $\mathrm{NaCl}$ and $\mathrm{Cl}$ concentrations used in the laboratory experiments

\begin{tabular}{|c|c|c|c|c|}
\hline \multirow{2}{*}{ EXPERIMENT } & \multicolumn{2}{|c|}{$\mathrm{NaCl}$} & \multicolumn{2}{|c|}{ Cl } \\
\hline & $\mathrm{lb} / \mathrm{yd} \mathrm{d}^{3}$ & $\mathrm{~kg} / \mathrm{m}^{3}$ & $\mathrm{lb} / \mathbf{y d}^{3}$ & $\mathrm{~kg} / \mathrm{m}^{3}$ \\
\hline ARC Long Term (Primary) & 5.0 & 3.0 & 3.0 & 1.8 \\
\hline ARC Long Term (Secondary) & 2.0 & 1.2 & 1.2 & 0.7 \\
\hline ARC Long Term (Secondary) & 10.0 & 5.9 & 6.1 & 3.6 \\
\hline ARC Short Term & 2.0 & 1.2 & 1.2 & 0.7 \\
\hline ARC Short Term & 5.0 & 5.9 & 3.0 & 1.8 \\
\hline ARC Short Term & 10.0 & 3.0 & 6.1 & 3.6 \\
\hline Ohio Long Term (Primary) & 5.1 & 3.0 & 3.1 & 1.8 \\
\hline Ohio Long Term (Secondary) & 8.2 & 4.9 & 5.0 & 3.0 \\
\hline Ohio Long Term (Secondary) & 12.4 & 7.3 & 7.5 & 4.4 \\
\hline Ohio Long Term (Secondary) & 16.5 & 9.8 & 10.0 & 5.9 \\
\hline Screening Experiments & 8.2 & 4.9 & 5.0 & 3.0 \\
\hline
\end{tabular}




\subsection{RESULTS AND ANALYSIS}

\subsection{LONG-TERM LABORATORY EXPERIMENTS (ARC)}

\subsubsection{Accelerated Impressed Current Cathodic Protection}

The circuit resistances of the new ICCP slabs are shown in Figure 5.1 for high RH conditions and in Figure 5.2 for low RH conditions. In high $\mathrm{RH}$ conditions the $\mathrm{LiNO}_{3}$-treated slabs had consistently lower values of circuit resistance than either the LiBr-treated slabs or the controls. This indicates an improvement with $\mathrm{LiNO}_{3}$. The $\mathrm{LiBr}$-treated slabs showed much the same response as the control slabs. In low RH conditions, Figure 5.2, the circuit resistances of the $\mathrm{LiNO}_{3}$-treated slabs were again the lowest. However, in this case the $\mathrm{LiBr}$-treated slabs had circuit resistances lower than the control slabs, which were removed from the experiment at an early date due to their large voltages.

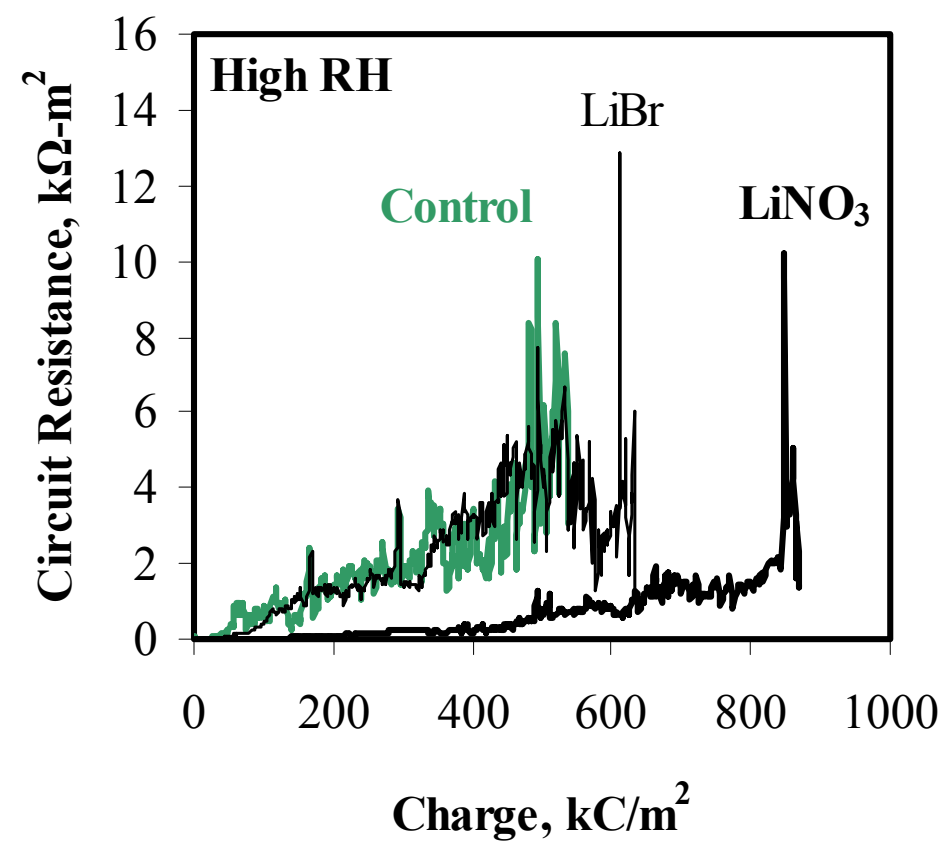

Figure 5.1: Circuit resistances of new ICCP slabs in high RH conditions 


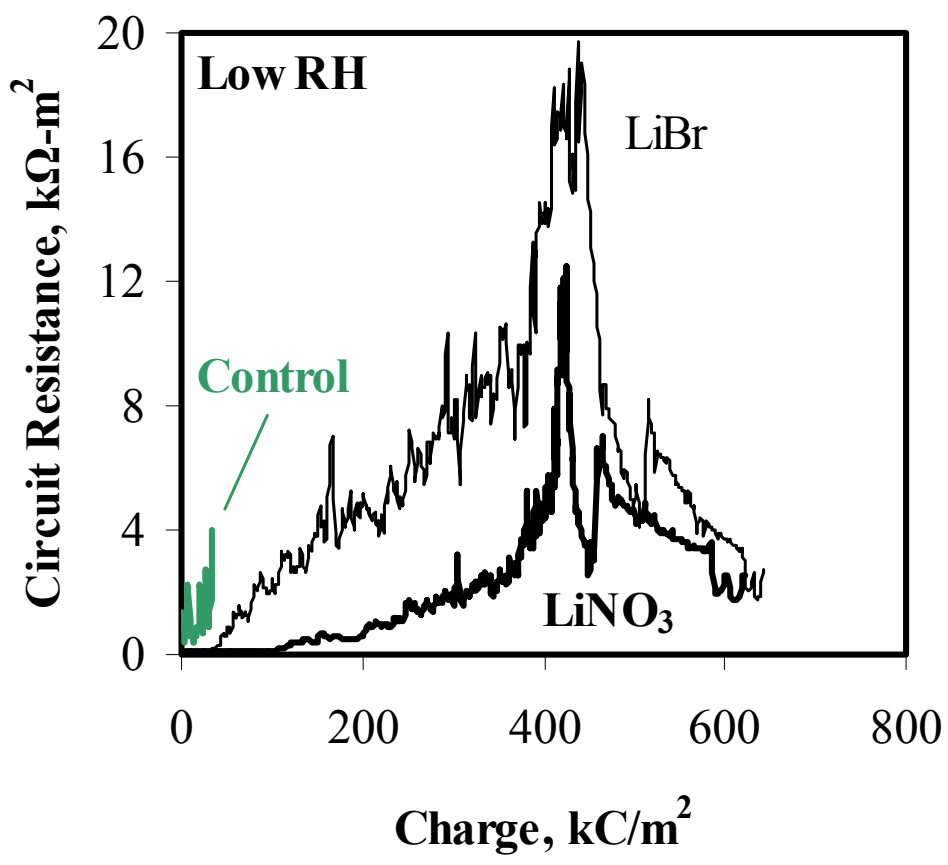

Figure 5.2: Circuit resistances of new ICCP slabs in low RH conditions

The sharp decreases in the circuit resistances in Figure 5.2 at around $400 \mathrm{kC} / \mathrm{m}^{2}$ and the sharp increases following shortly thereafter, are artifacts from the curves representing an average of three slabs, then two slabs, and then just one slab. When the slabs with very high circuit resistance were removed (for both $\mathrm{LiBr}$ and $\mathrm{LiNO}_{3}$ ) the plotted circuit resistance fell. Then when the next slabs were removed (with the lowest circuit resistances), the plotted circuit resistances rose.

The circuit resistances of the aged ICCP slabs are shown in Figure 5.3 for high RH conditions and in Figure 5.4 for low RH conditions. In general, the higher the initial electrochemical age, the higher the circuit resistance. In high RH conditions (Figure 5.3) up to an additional charge of approximately $700 \mathrm{kC} / \mathrm{m}^{2}$ the $\mathrm{LiNO}_{3}$-treated slabs had lower circuit resistances than the $\mathrm{LiBr}$ treated slabs. In low RH conditions, Figure 5.4, the differences were similar: $\mathrm{LiNO}_{3}$-treated slabs had lower circuit resistances for the first $300 \mathrm{kC} / \mathrm{m}^{2}$ of additional charge. Overall the circuit resistances were higher in low RH conditions than in high RH conditions. 

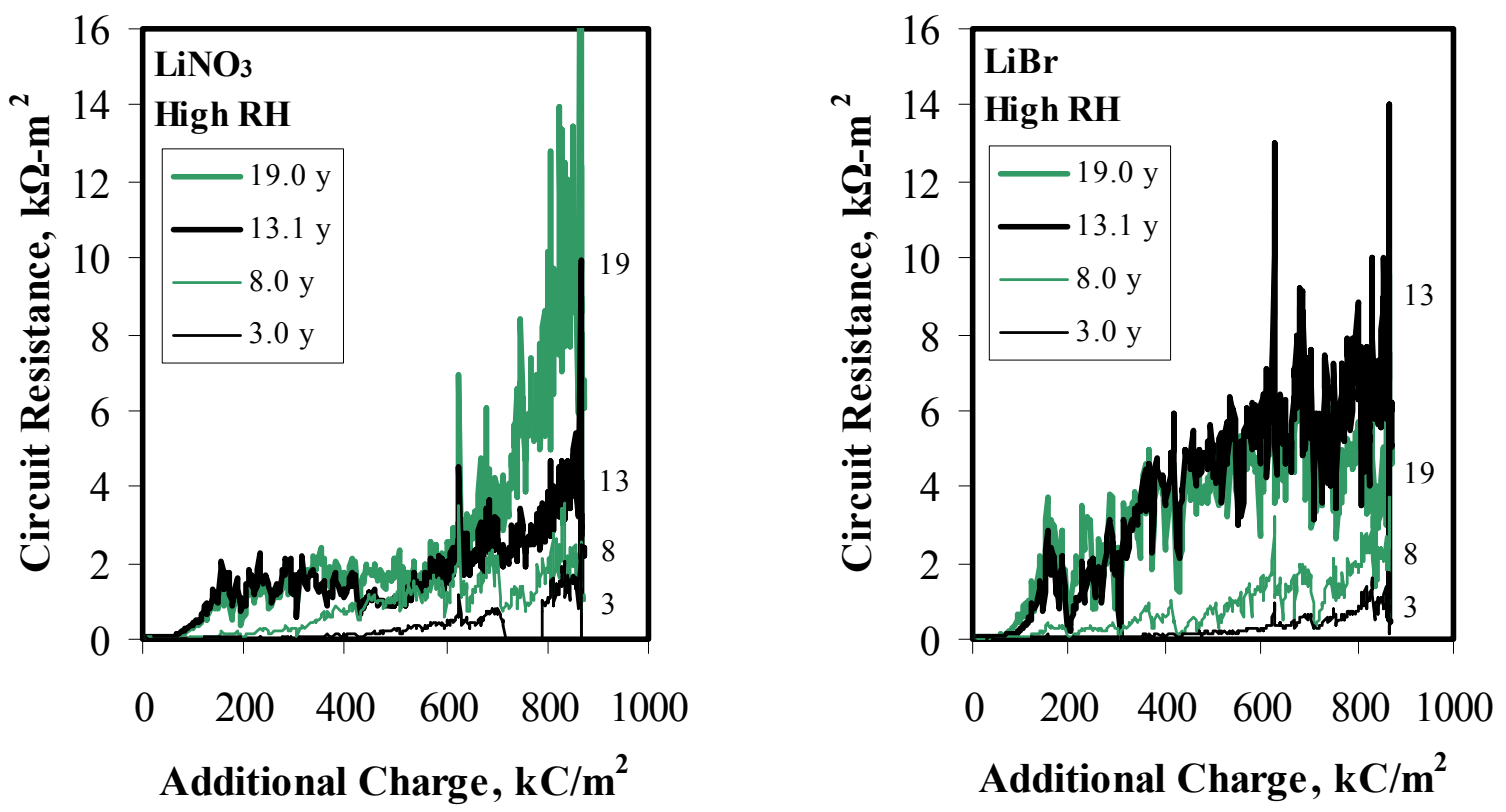

Figure 5.3: Circuit resistances of aged ICCP slabs in high RH conditions for $\mathrm{LiNO}_{3}$ (left) and $\mathrm{LiBr}$ (right)
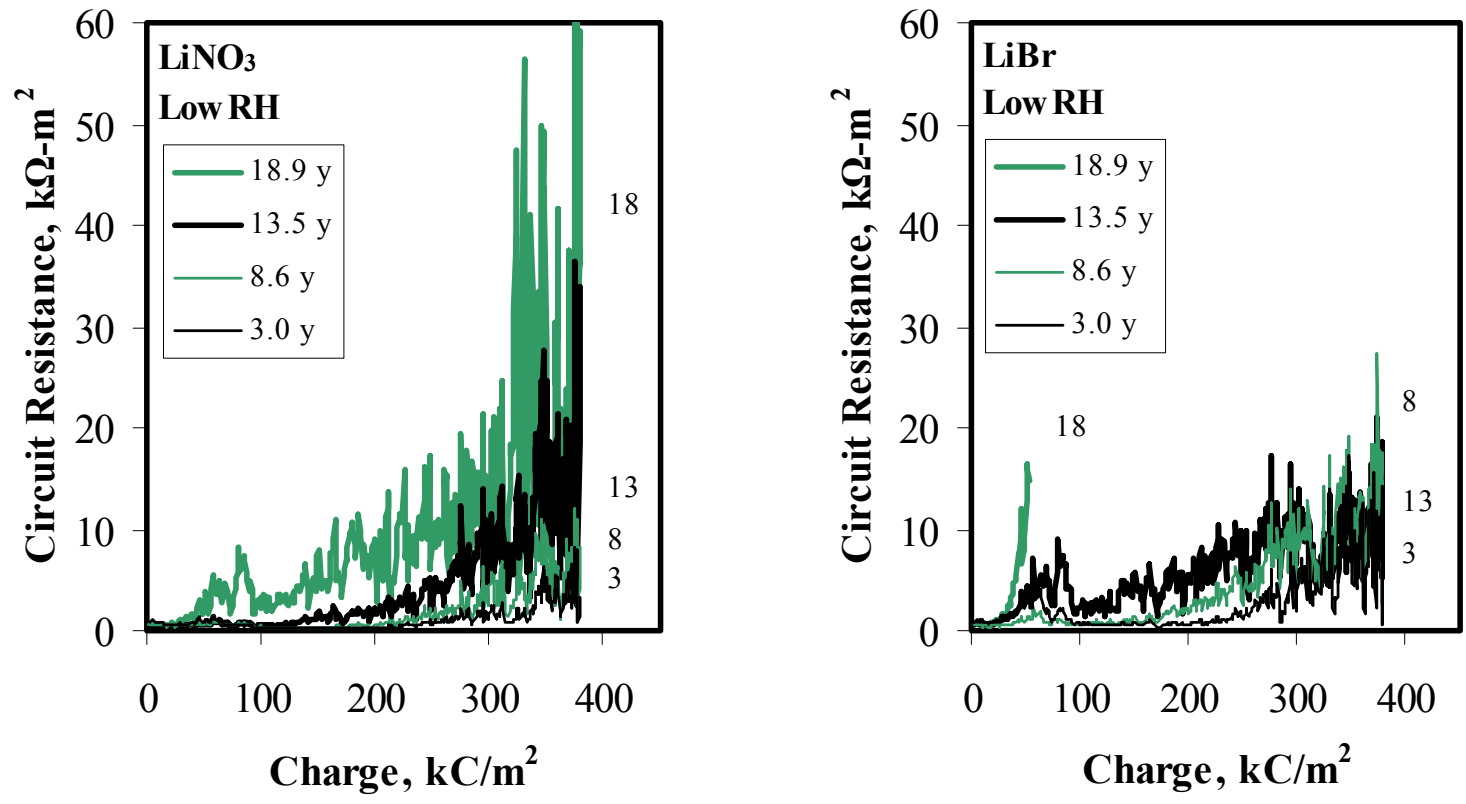

Figure 5.4: Circuit resistances of aged ICCP slabs in low RH conditions for $\mathrm{LiNO}_{3}$ (left) and $\mathrm{LiBr}$ (right) 
Mean values of circuit resistance of humectant-treated slabs are shown in Figure 5.5 for high RH conditions (left) and low RH conditions (right). To discount the low initial circuit resistances obtained during aging (Figures 5.1-5.4), the mean circuit resistance was calculated ignoring the first $204 \mathrm{kC} / \mathrm{m}^{2}$ of charge, equivalent to 3 years of aging at $0.2 \mathrm{~mA} / \mathrm{ft}^{2}\left(2.2 \mathrm{~mA} / \mathrm{m}^{2}\right)$. Thus, the mean values represent the mean circuit resistances from 3 to 11.7 years of aging in high $\mathrm{RH}$ conditions and from 3 to 5.1 years in low RH conditions. Results from an earlier study without humectants in a high RH environment were converted ${ }^{1}$ to the same data format and shown in Figure 5.5 as "No Humectant" (Bullard, et al. 1998; Covino, et al. 2002). Humectant-treated slabs in high RH conditions had much lower circuit resistances than the untreated slabs. In both $\mathrm{RH}$ conditions the $\mathrm{LiNO}_{3}$-treated slabs tended to have lower circuit resistances than the $\mathrm{LiBr}$ treated slabs.
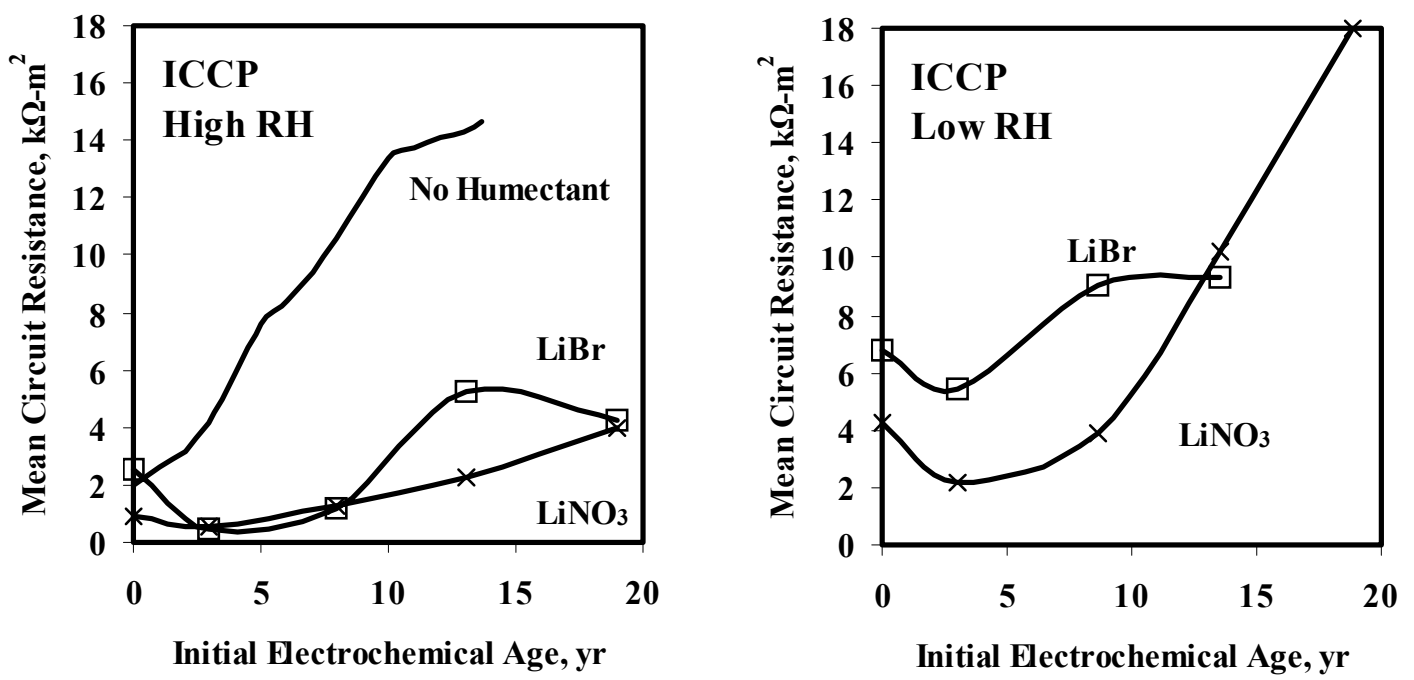

Figure 5.5: Mean circuit resistances of new and aged slabs after an additional 3 years of aging in high (left) and low (right) RH conditions. The "No Humectant" data are from an earlier study (Bullard et al. 1998; Covino et al. 2002).

\subsubsection{Cyclic Impressed Current Cathodic Protection}

The results for the experiments where the impressed current alternated between accelerated aging (high currents) and normal aging (low currents) are shown in Figure 5.6 for high RH conditions and in Figure 5.7 for low RH conditions. For these figures, low currents are defined as being from 0.10 to $0.16 \mathrm{~mA}\left(1.4\right.$ to $\left.2.3 \mathrm{~mA} / \mathrm{m}^{2}\right)$; and high currents are defined as being above $0.50 \mathrm{~mA}$ $\left(7.2 \mathrm{~mA} / \mathrm{m}^{2}\right)$. The gaps in Figure 5.7 result from currents having intermediate values. In terms of voltage (the left side in Figures 5.6-5.7) the higher currents resulted in higher voltage values. These differences disappeared when examined in terms of circuit resistance (the right side in Figures 5.6-5.7). Both humectants resulted in much lower voltages and circuit resistances than

\footnotetext{
${ }^{1}$ For a given electrochemical age (referred to as the initial electrochemical age in Figure 5.5), the mean circuit resistance was calculated from circuit resistance values between 3 and 10 years of additional electrochemical charge.
} 
the slabs without humectants (control results). In general the $\mathrm{LiNO}_{3}$-treated slabs had lower circuit resistances than the LiBr-treated slabs, which is consistent with the non-cyclic results. The circuit resistance values for the cyclic and non-cyclic tests were similar, as shown in Figures 5.1 and 5.6 for high RH conditions and in Figures 5.2 and 5.7 for low RH conditions.

The sharp decreases in voltages and circuit resistances in Figure 5.7 at around 450 and 500 $\mathrm{kC} / \mathrm{m}^{2}$ are artifacts from the curves representing an average of three slabs, then two slabs, and then just 1 slab. When the slabs with very high circuit resistance were removed (for both $\mathrm{LiBr}$ and $\mathrm{LiNO}_{3}$ ) the plotted voltages and circuit resistances fell. Then when the next slabs were removed (again with the highest circuit resistances), the plotted circuit resistances decreased. 

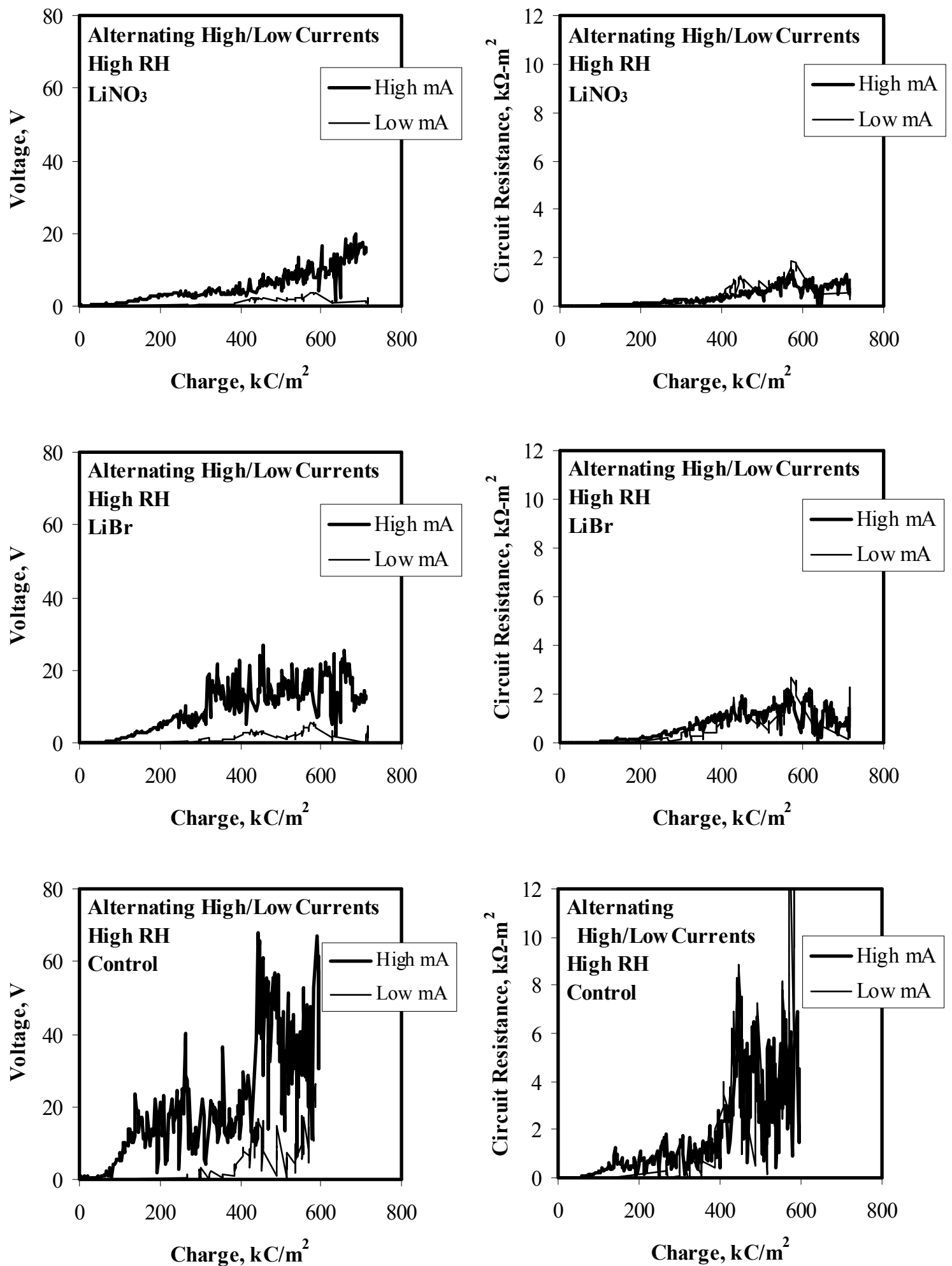

Figure 5.6: Cyclic ICCP voltages (left) and circuit resistances (right) for $\mathrm{LiNO}_{3}$ (top), $\mathrm{LiBr}$ (middle), and control (bottom) in high RH conditions. 

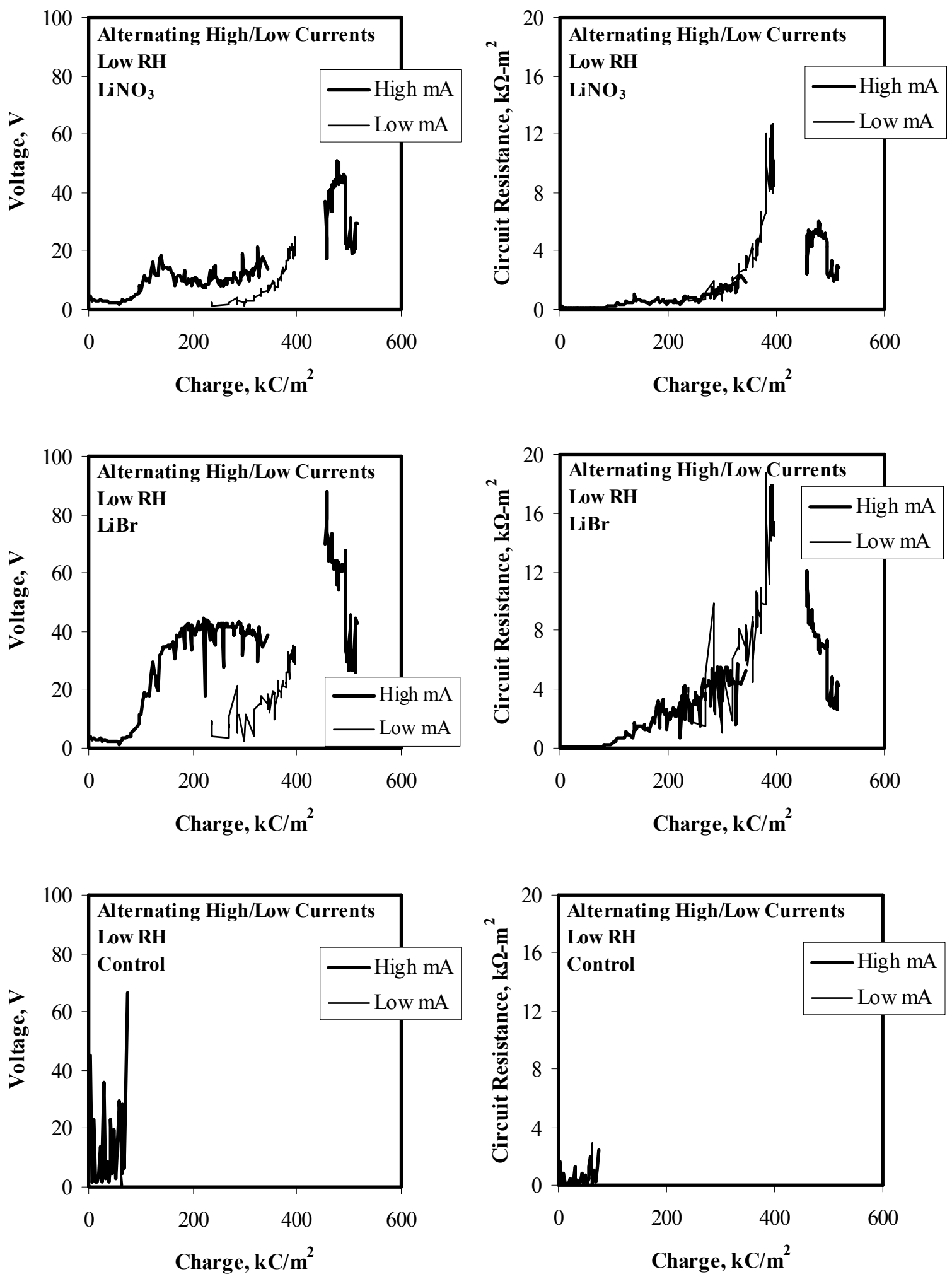

Figure 5.7: Cyclic ICCP voltages (left) and circuit resistances (right) for $\mathrm{LiNO}_{3}$ (top), $\mathrm{LiBr}$ (middle), and control (bottom) in low RH conditions. Gaps are from intermediate current levels. 


\subsubsection{Galvanic Cathodic Protection}

In interpreting GCP results, the desired galvanic current needs to be above the minimum needed for protection. The minimum current needed for protection is an empirically derived value and may well be different for different climates and chloride levels. For example, Oregon DOT has found that $0.2 \mathrm{~mA} / \mathrm{ft}^{2}\left(2.2 \mathrm{~mA} / \mathrm{m}^{2}\right)$ is sufficient for their coastal thermal-sprayed zinc ICCP systems (Bullard, et al. 1998; Covino, et al. 1997a; Covino, et al. 2002); while Fontana and Greene $(1978, p .207)$ give $0.1-0.5 \mathrm{~mA} / \mathrm{ft}^{2}\left(1.1-5.4 \mathrm{~mA} / \mathrm{m}^{2}\right)$ as sufficient for protect reinforcing bars in concrete.

Galvanic currents in excess of the required current are not beneficial. Excess current results in loss of zinc and accelerated electrochemical aging that provide no additional $\mathrm{CP}$ benefits and may lead to earlier anode replacement.

The results for the GCP experiments are shown in Figures 5.8-5.13 in terms of galvanic current density based on the cathode surface area (SA). Figure 5.8 is for new and aged $\mathrm{LiNO}_{3}$-treated slabs in high RH conditions; Figure 5.9 is for new and aged LiBr-treated slabs in high RH conditions; Figure 5.10 is for new and aged $\mathrm{LiNO}_{3}$-treated slabs in low $\mathrm{RH}$ conditions; Figure 5.11 is for new and aged LiBr-treated slabs in low RH conditions; Figure 5.12 is for the control in high RH conditions; and Figure 5.13 is for the control in low RH conditions.

In high RH conditions (Figures 5.8, 5.9, and 5.12), the galvanic currents were initially very high and sufficient to protect the steel. In all cases the currents decreased in value with time and in some cases dropped below the minimum current needed for protection. In general the $\mathrm{LiBr}-$ treated slabs had higher galvanic currents than the $\mathrm{LiNO}_{3}$-treated slabs, which in turn were higher than the control slab.

In low RH conditions (Figures 5.10, 5.11, and 5.13), the galvanic currents started near the minimum required current density. Compared with the high RH conditions, galvanic currents did not drop nearly as much (even in terms of relative values). Again the LiBr-treated slabs had higher galvanic currents than the $\mathrm{LiNO}_{3}$-treated slabs, which in turn were higher than the control slab (except for the new $\mathrm{LiNO}_{3}$-treated slab in comparison with the control).

The galvanic currents in the controls, Figures 5.12-5.13, show a faster decline in current compared to the humectant-treated slabs. 


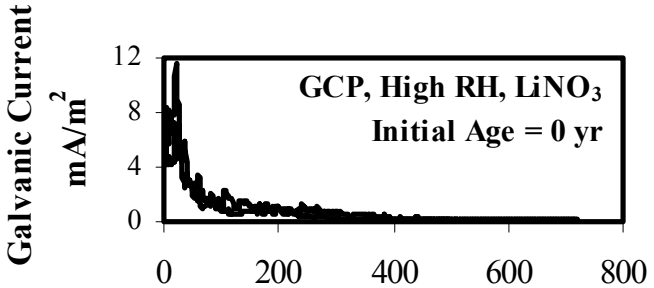

Elaps ed Time, days

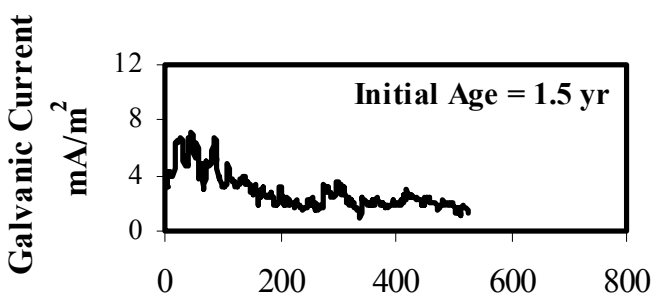

Elaps ed Time, days
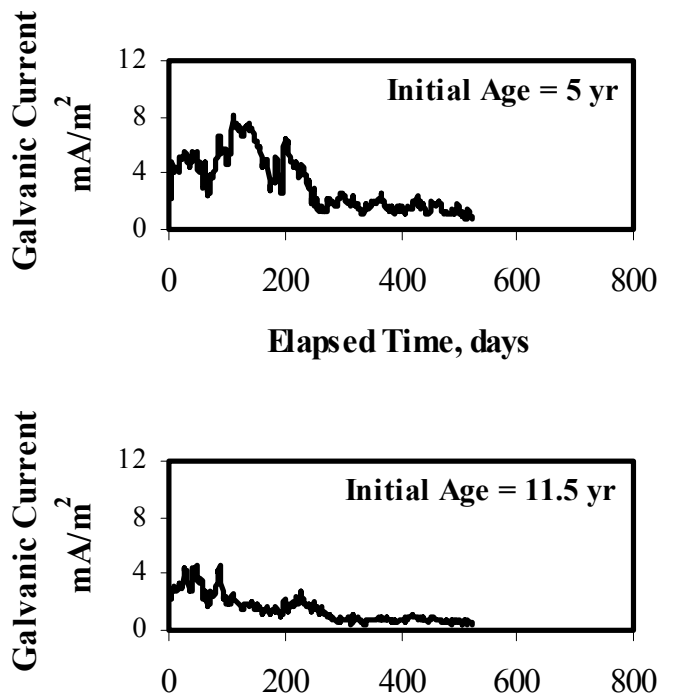

Elaps ed Time, days

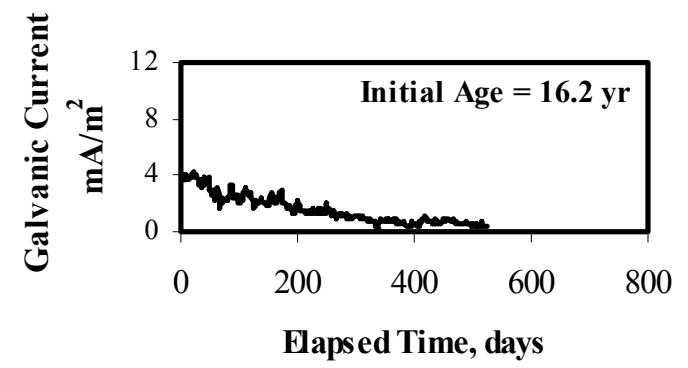

Figure 5.8: Galvanic currents for new and aged slabs with $\mathrm{LiNO}_{3}$ in high $\mathrm{RH}$ conditions

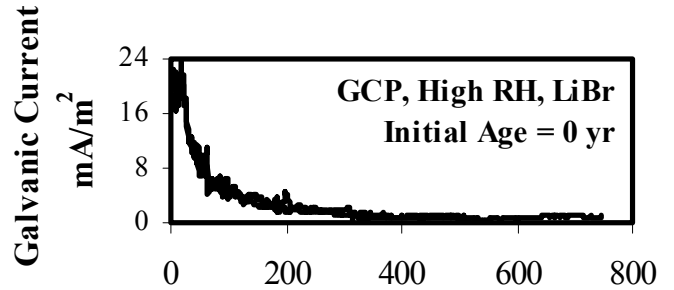

Elaps ed Time, days

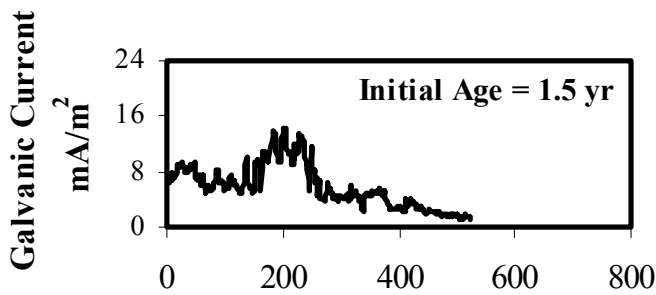

Elaps ed Time, days
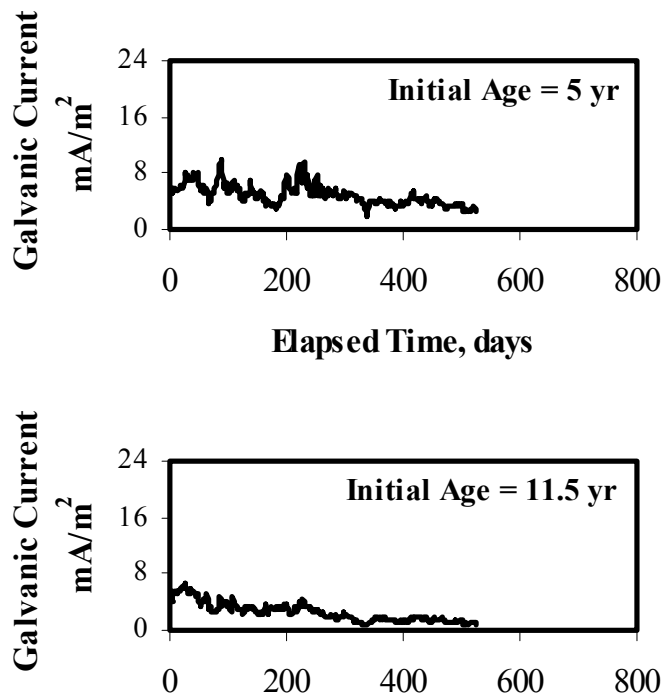

Elaps ed Time, days

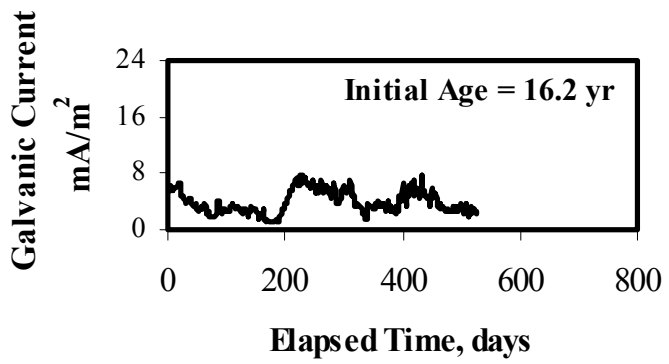

Figure 5.9: Galvanic currents for new and aged slabs with $\mathrm{LiBr}$ in high $\mathrm{RH}$ conditions 


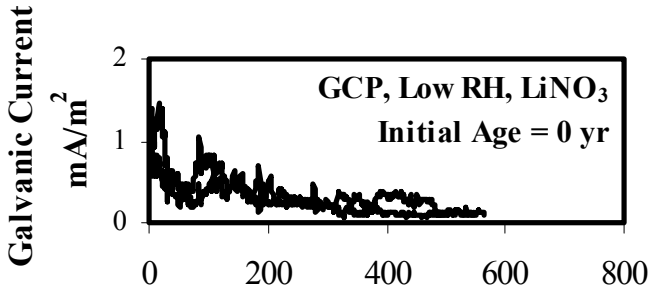

Elaps ed Time, days
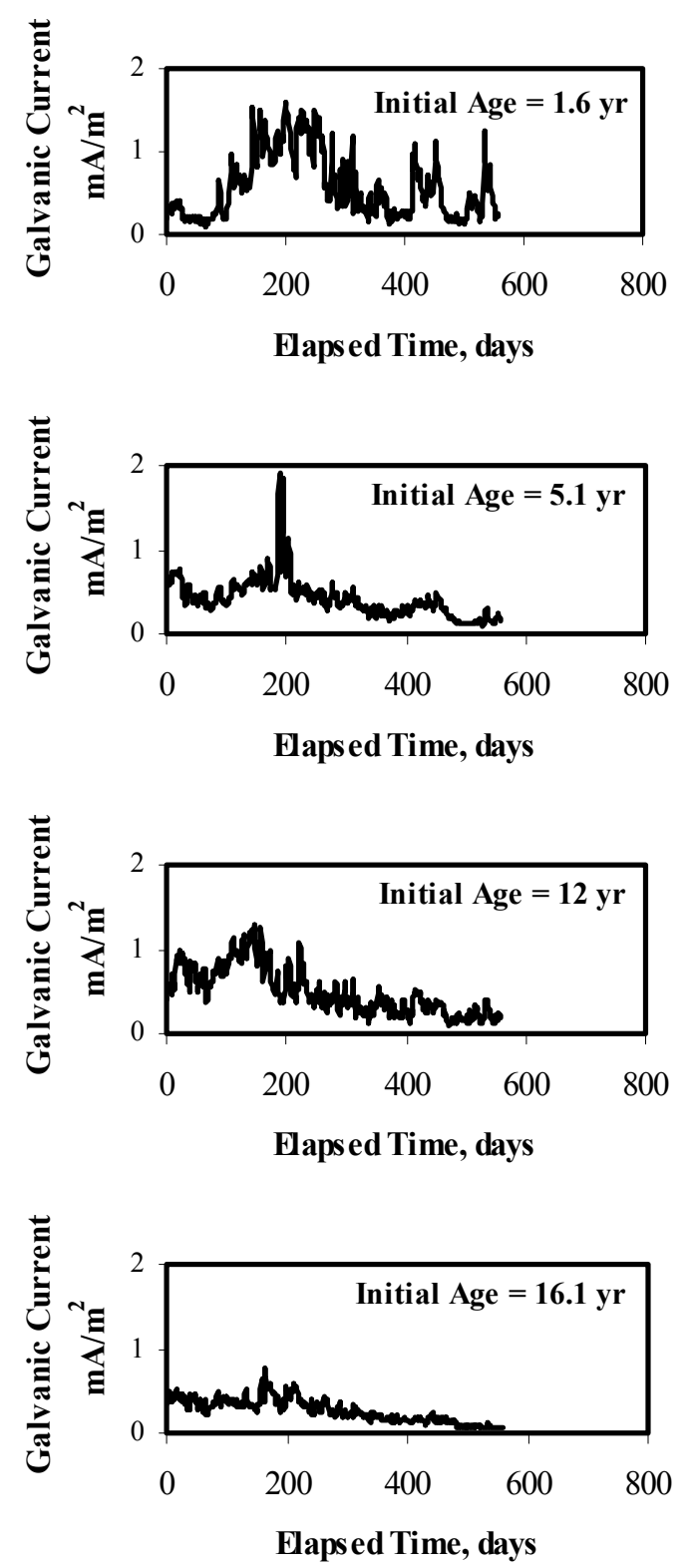

Figure 5.10: Galvanic currents for new and aged slabs with $\mathrm{LiNO}_{3}$ in low $\mathrm{RH}$ conditions

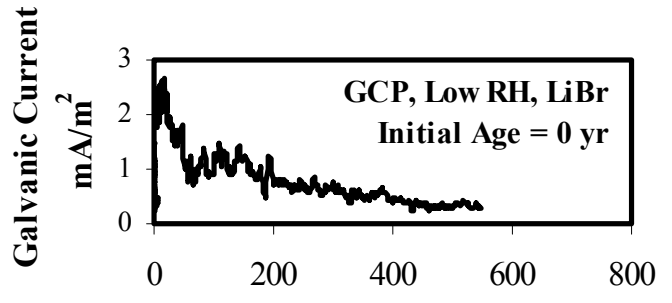

Elapsed Time, days

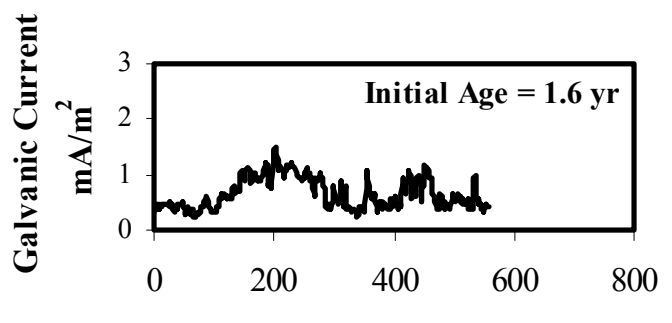

Elapsed Time, days
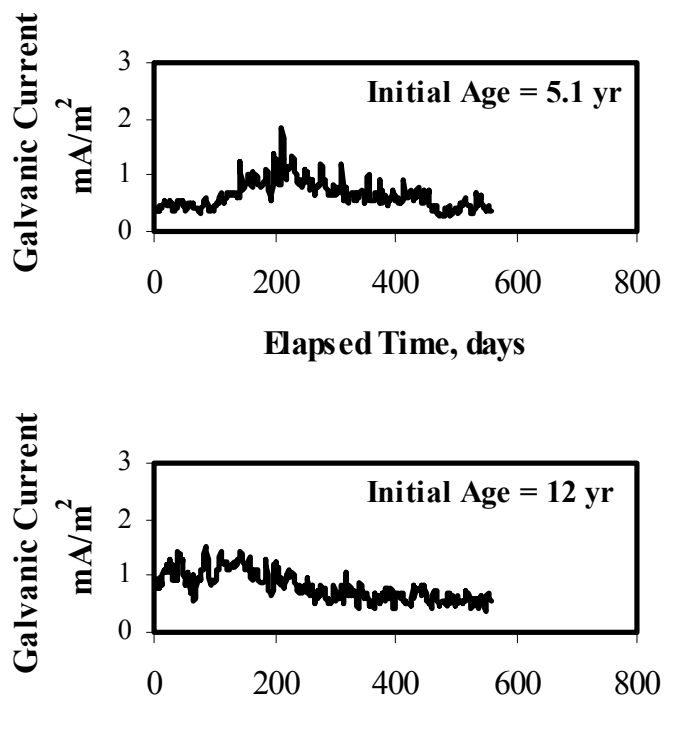

Elaps ed Time, days

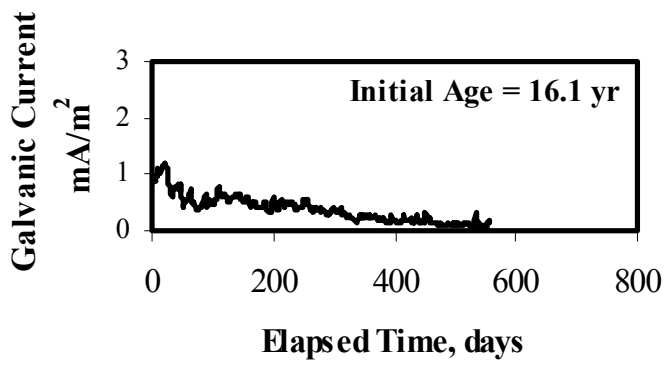

Figure 5.11: Galvanic currents for new and aged slabs with $\mathrm{LiBr}$ in low $\mathrm{RH}$ conditions 


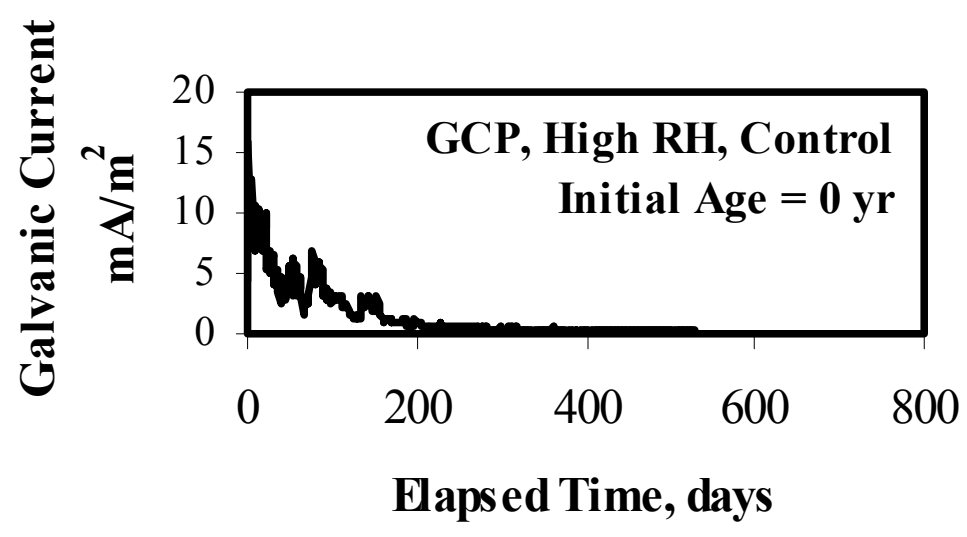

Figure 5.12: Galvanic currents for the new control slab in high RH conditions

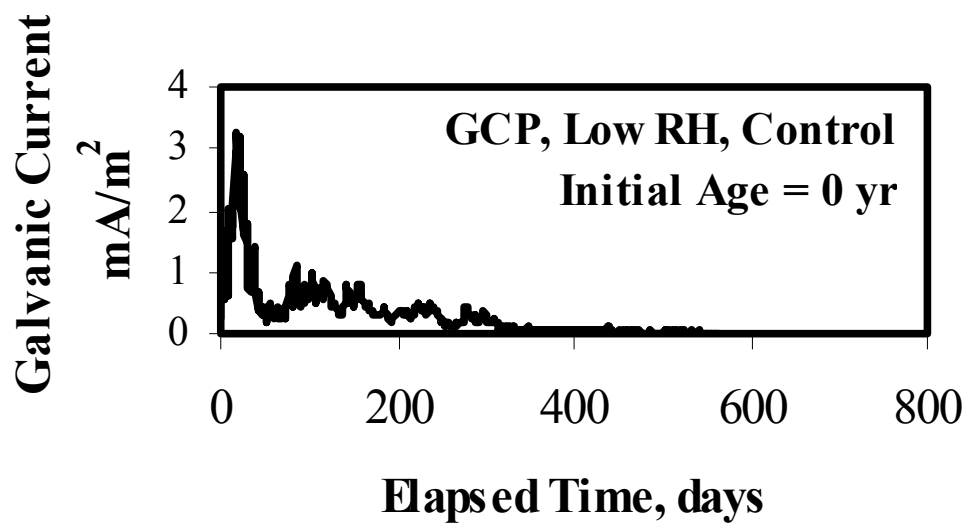

Figure 5.13: Galvanic currents for the new control slab in low RH conditions

Long-term galvanic current densities (the average current density after 1 year) in Figure 5.14 for high $\mathrm{RH}$ conditions show $\mathrm{LiBr}$ to provide more protection current than $\mathrm{LiNO}_{3}$ for both new and aged slabs. Even the $\mathrm{LiNO}_{3}$-treated slabs have sufficient current to protect the steel. However, the downward trends in current densities shown in Figures 5.8-5.13 suggest that LiBr-treatment may retain galvanic current densities above the minimum longer than $\mathrm{LiNO}_{3}$-treatment. 


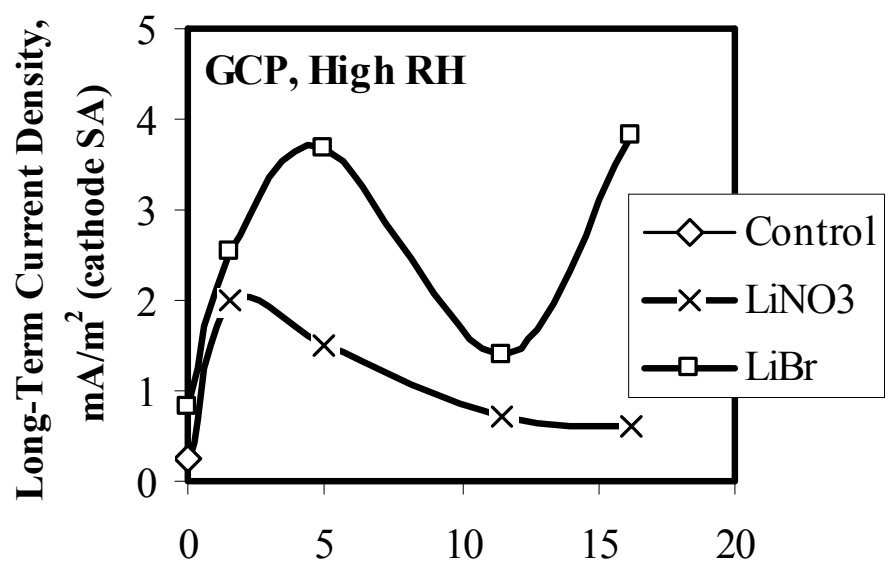

Initial Electrochemical Age, yr

Figure 5.14: Long-term current densities for new and aged GCP slabs in high RH conditions

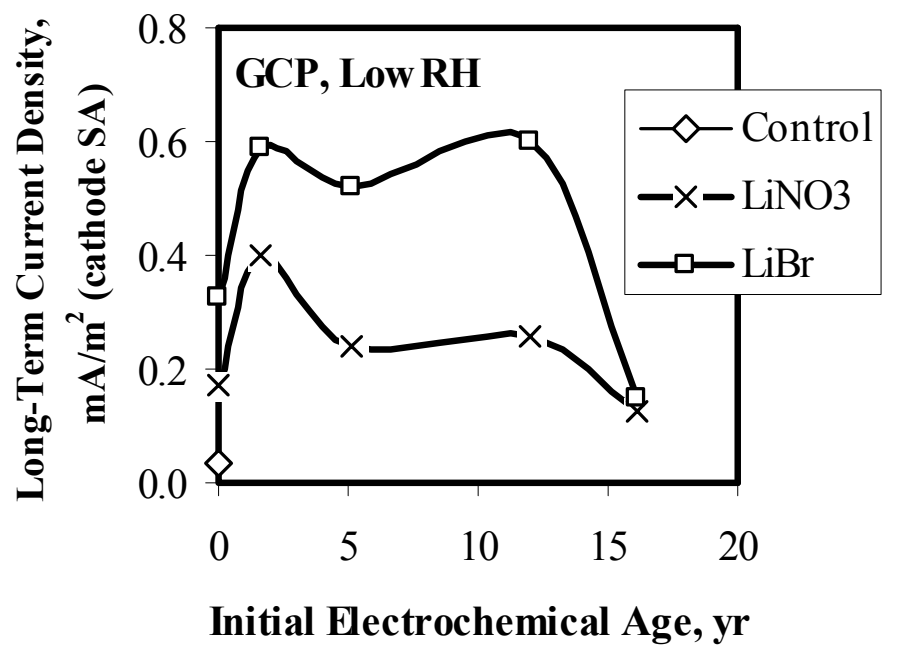

Figure 5.15: Long-term current densities for new and aged GCP slabs in low RH conditions

The long-term galvanic current densities in Figure 5.15 for low RH conditions show low values of current density. As in high $\mathrm{RH}$ conditions, $\mathrm{LiBr}$ resulted in higher currents than $\mathrm{LiNO}_{3}$. Both were superior to untreated controls, yet were still below protective current density thresholds 1.1 to $5.4 \mathrm{~mA} / \mathrm{m}^{2}$ (Fontana and Greene 1978) or $2.2 \mathrm{~mA} / \mathrm{m}^{2}$ used for Oregon DOT ICCP systems (Covino, et al. 2002). 


\subsubsection{Depolarization}

A common criterion for effective CP is depolarization of at least $100 \mathrm{mV}$. More than $100 \mathrm{mV}$ indicates that the steel is completely protected, while less than $100 \mathrm{mV}$ indicates that the steel protection may be incomplete. Note that the tests on slabs with ICCP were depolarized after a week at $0.2 \mathrm{~mA} / \mathrm{ft}^{2}\left(2.2 \mathrm{~mA} / \mathrm{m}^{2}\right)$; the value used by Oregon DOT on coastal bridges, and not the larger accelerated current density used in most of the laboratory study.

The amount of depolarization that occurred after 24 hours is shown in Figure 5.16 for the ICCP slabs in both low RH conditions (top) and high RH conditions (bottom). The equivalent age is the combined age from both the initial electrochemical age (if any) and the electrochemical age from this study just prior to depolarization. Most of the depolarization values were above 100 $\mathrm{mV}$. The exceptions were some of the LiBr-treated slabs in low RH conditions and some of the $\mathrm{LiNO}_{3}$-treated slabs in high RH conditions. The linear regression lines show a slight downward trend with equivalent age. $\mathrm{LiNO}_{3}$-treated slabs had, on average, higher depolarization values than LiBr-treated slabs.

Depolarization for GCP slabs is shown in Figure 5.17 in both low RH conditions (top) and high RH conditions (bottom). In contrast, with the ICCP results (Figure 5.16) there was a very distinct downward trend with equivalent age. Many depolarization values were below $100 \mathrm{mV}$, indicating insufficient protection. LiBr-treated slabs, on average had higher depolarization values under high RH conditions; the reverse was found under low RH conditions. The low depolarization values beyond an electrochemical age of 3-5 years correspond to the decreased current output from GCP anodes older than 5 years, Figure 5.14. 

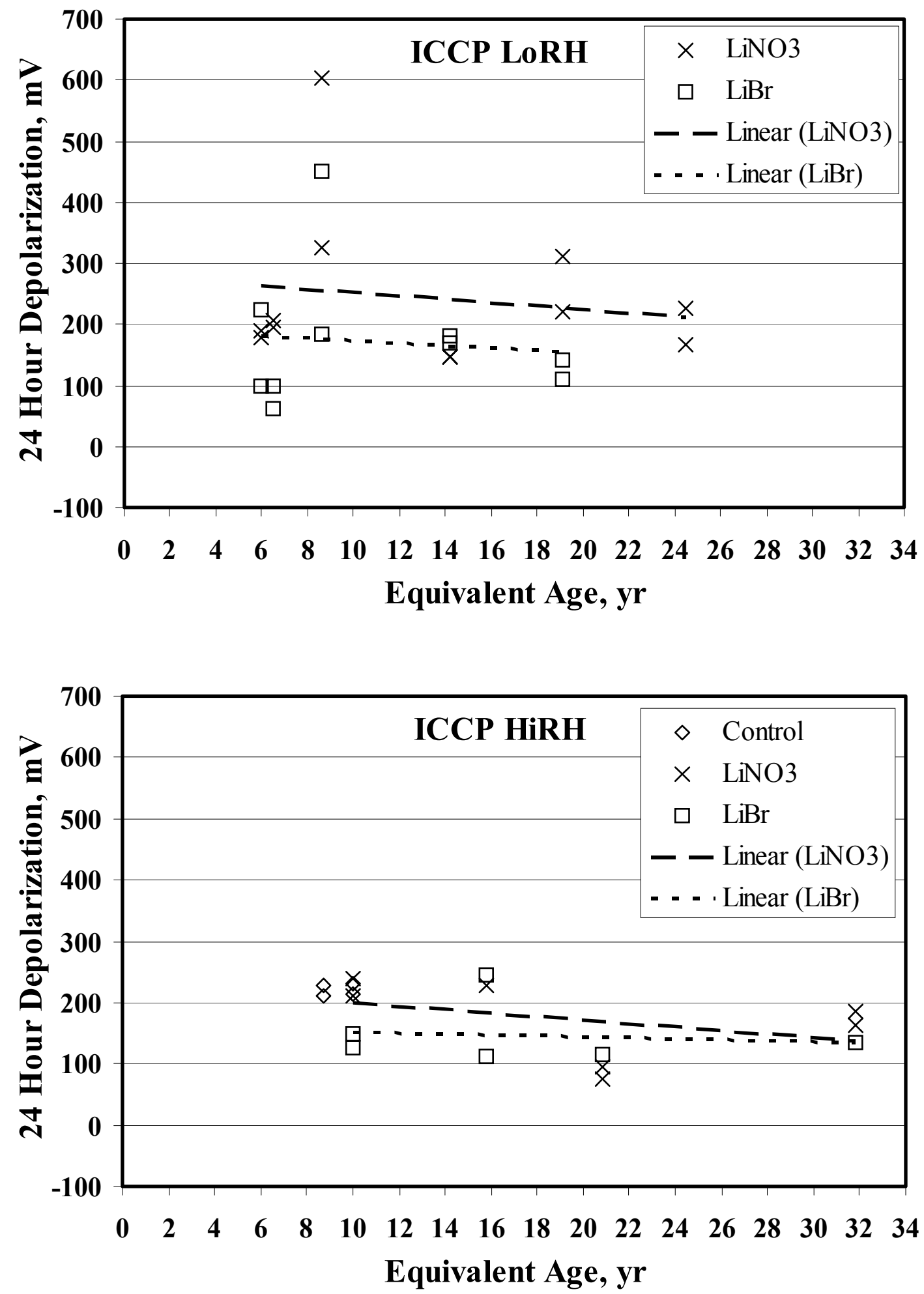

Figure 5.16: 24-hour depolarization voltages for long-term laboratory ICCP samples in low RH (top) and high RH (bottom) conditions 

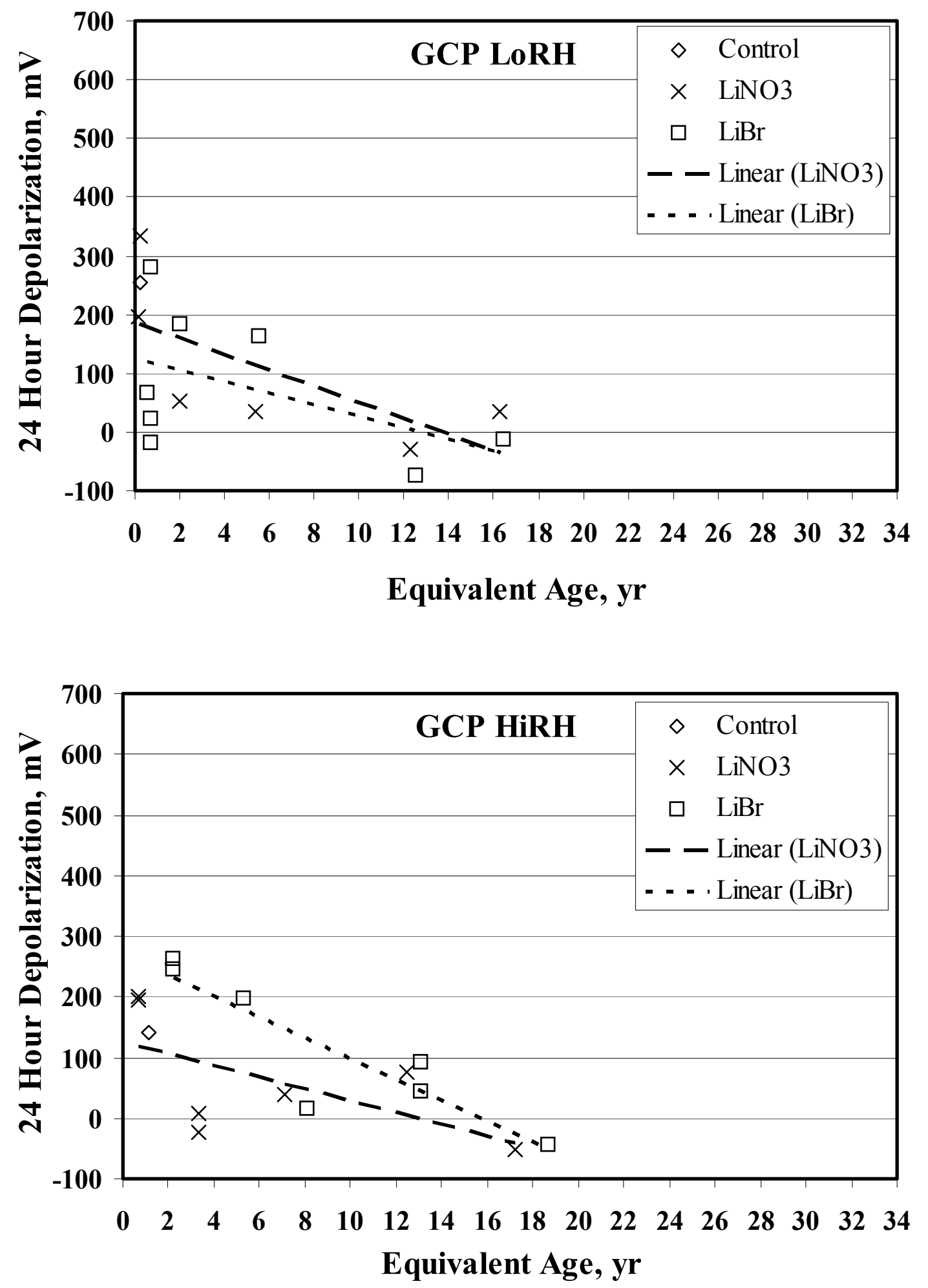

Figure 5.17: 24-hour depolarization voltages for long-term laboratory GCP samples in low RH (top) and high RH (bottom) conditions 


\subsubsection{Microscopy}

\subsubsection{Microscopy of Long-Term ICCP-LiNO}

The structure of the $\mathrm{LiNO}_{3}$-treated concrete-anode interface is shown in the BSE image and elemental x-ray maps; Figure 5.18 for high RH exposure, and Figure 5.19 for low RH exposure. The structure consists of three distinct layers or zones, which are typical of thermal-sprayed zinc CP systems (Bullard, et al. 1998; Covino, et al. 1996a; Covino, et al. 1996b; Covino, et al 1997a; Covino, et al. 2002). From top to bottom: the zinc anode, an anode-concrete reaction zone, and the undisturbed cement paste. The reaction zone can be further divided into three subzones or regions: 1) a layer of $\mathrm{ZnO}$ formed from and adjacent to the $\mathrm{Zn}$ anode; 2) a calcium-depleted, $\mathrm{Zn}$-rich layer formed within the cement paste; and 3) cement paste containing low levels of $\mathrm{Zn}$. The reaction zone resulted from the $\mathrm{Zn}$ anode oxidizing during ICCP. Zinc dissolution products migrated into the cement paste, interacted with moisture in the concrete, and replaced calcium within the cement paste (a secondary mineralization process). The rejected Ca migrated deeper into the reaction zone, where it deposited into and filled pores. The $\mathrm{ZnO}$ and the Ca-depleted, $\mathrm{Zn}$-rich sublayers of the reaction zone were enriched in chloride, which migrated to the anode, under the influence of the $\mathrm{CP}$ potential gradient. 


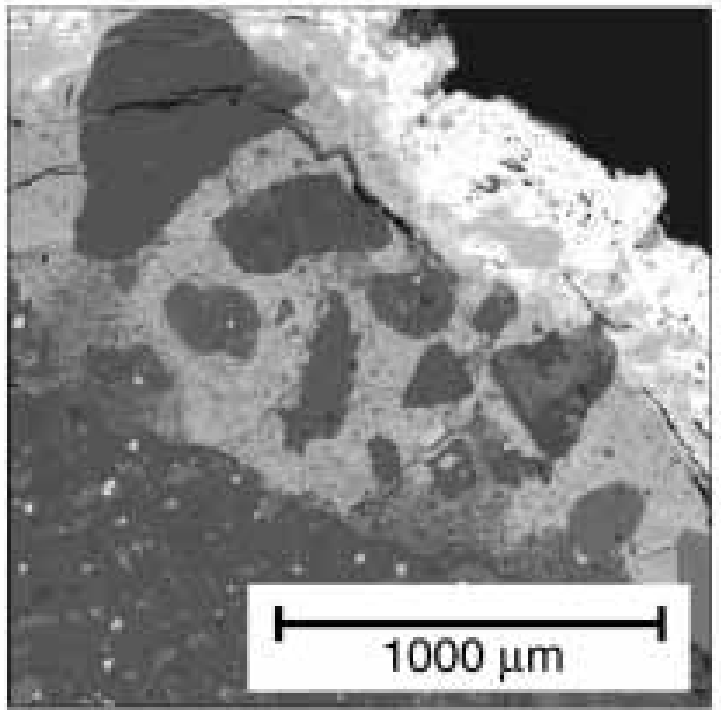

BSE

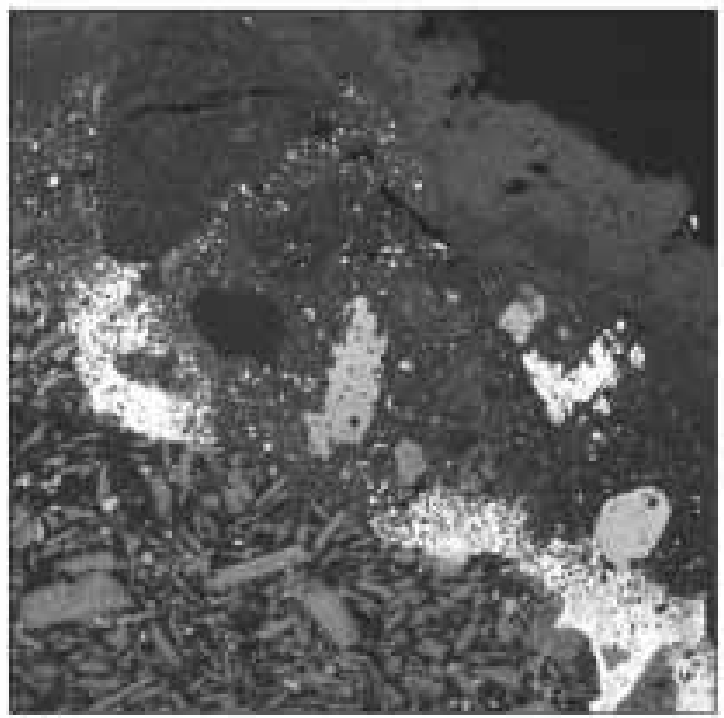

$\mathrm{Ca}$

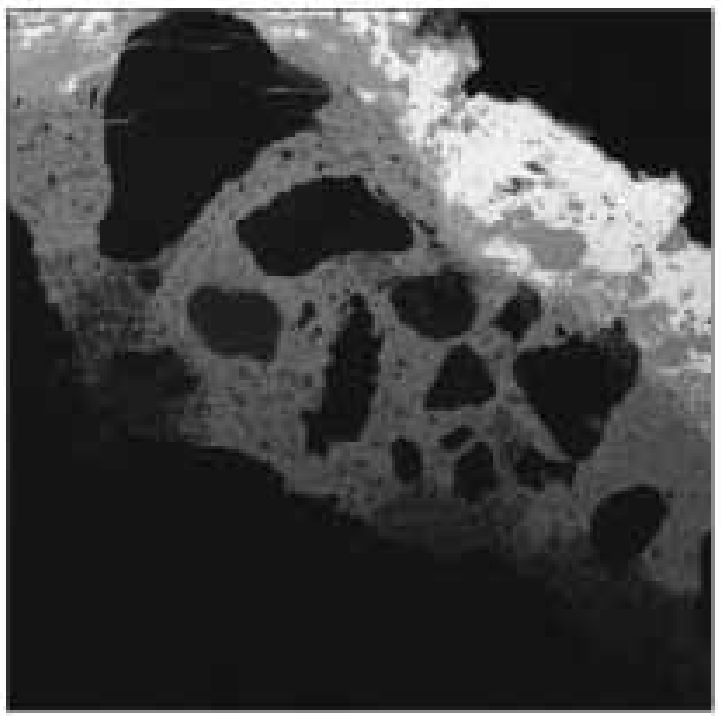

$\mathrm{Zn}$

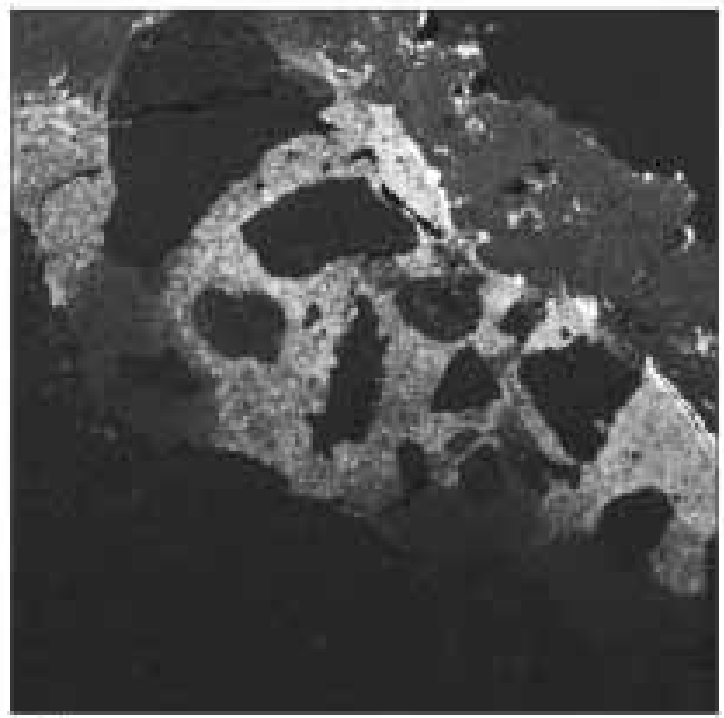

\section{$\mathrm{Cl}$}

Figure 5.18: BSE and elemental x-ray maps of a $\mathrm{LiNO}_{3}$-treated new slab exposed in the high-RH exposure after the equivalent of 5.3 years of ICCP. The zinc anode is at the top right and the unaltered concrete is at the bottom left of each cross section. 


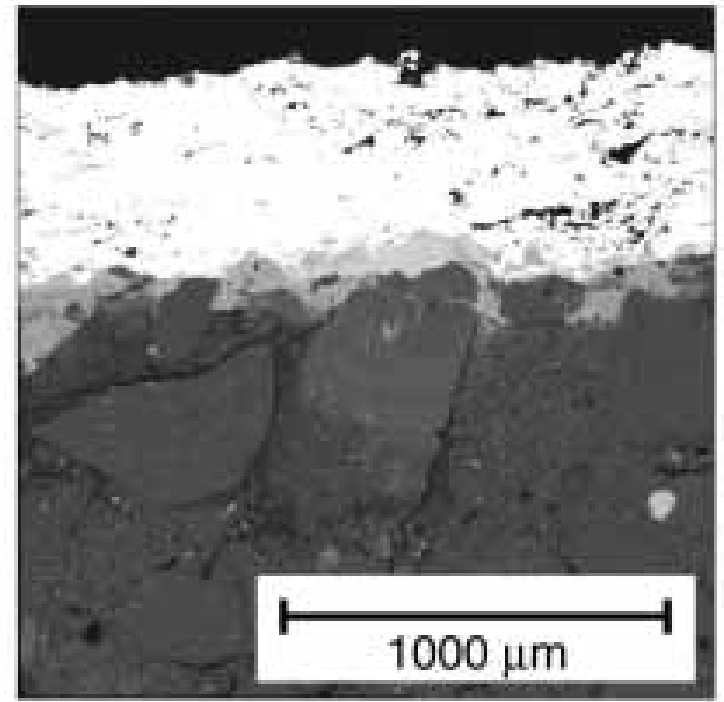

\section{BSE}

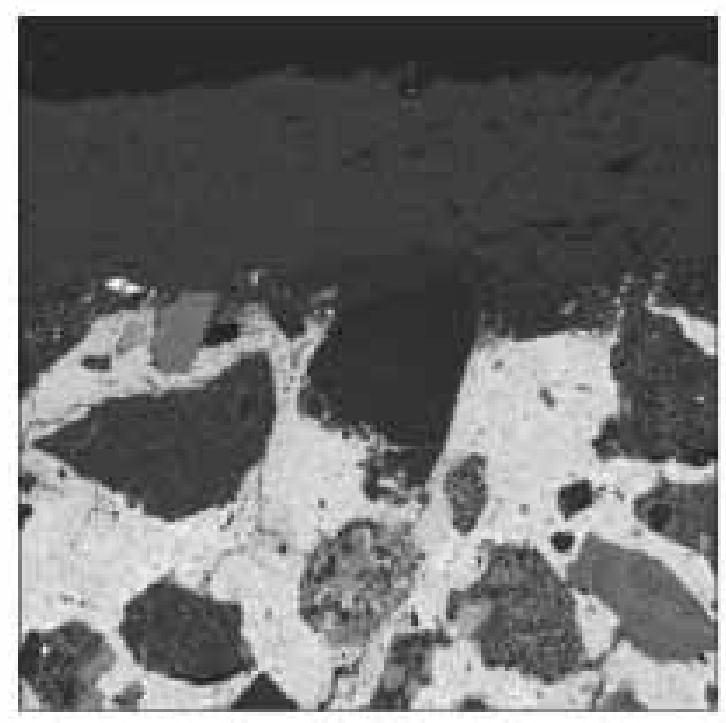

\section{$\mathrm{Ca}$}

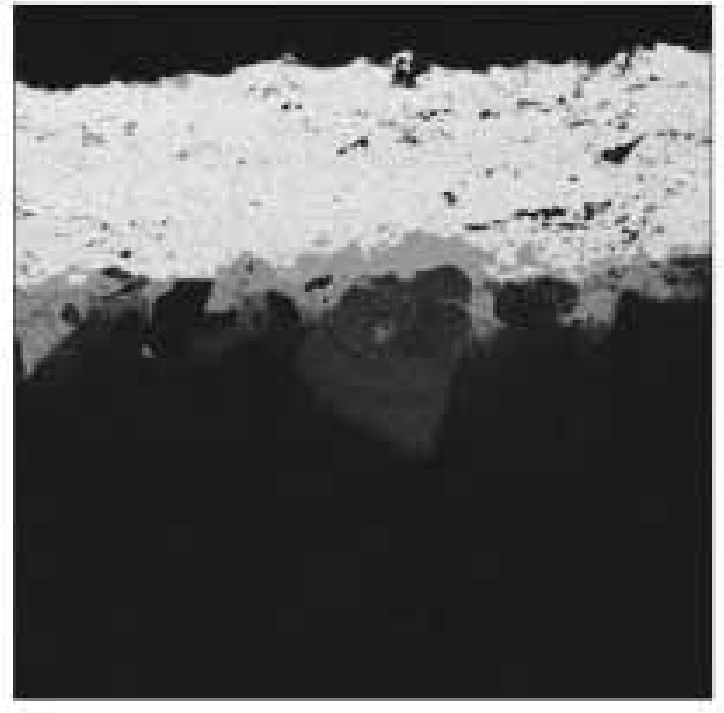

$\mathrm{Zn}$

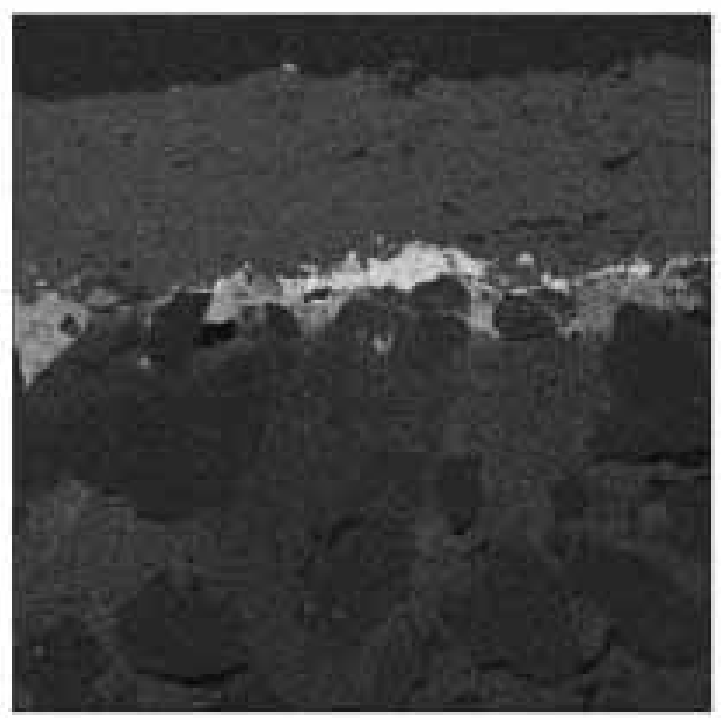

Cl

Figure 5.19: $\mathrm{BSE}$ and elemental x-ray maps of a $\mathrm{LiNO}_{3}$-treated new slab exposed in the low-RH exposure after the equivalent of 6.1 years of ICCP. The zinc anode is at the top and the unaltered concrete is at the bottom of each cross section. 
Element line scans obtained by ASEM were integrated and used to quantify the amount of selected elements in the various zones. Chloride results are presented in Table 5.1.

The biggest distinctions between the high and low $\mathrm{RH}$ exposures were the larger reaction zone and the greater amount of $\mathrm{Cl}^{-}$in the reaction zone for high $\mathrm{RH}$ conditions, indicating higher ion mobility under high RH conditions. The reaction zone was much larger in the high RH exposure $(0.90 \mathrm{~mm})$ than in the low RH exposure $(0.21 \mathrm{~mm})$, Table 5.1. The larger reaction zone in the high RH exposure shows the distinct reaction layer subzones (Figure 5.18) much clearer than in the low RH exposure (Figure 5.19). Table 5.1 also shows that there was much more $\mathrm{Cl}^{-}$in the reaction zone for the high $\mathrm{RH}$ exposure.

Table 5.1: Long-term ICCP microanalyses

\begin{tabular}{|c|c|c|c|c|c|}
\hline & \multicolumn{2}{|c|}{$\mathrm{LiNO}_{3}$} & \multicolumn{3}{|c|}{ LiBr } \\
\hline & High RH & Low RH & High RH & Low RH & Low RH \\
\hline Initial electrochemical age $^{\mathrm{A}}, \mathrm{yr}$ & 0 & 0 & 0 & 0 & 19.0 \\
\hline Final electrochemical age ${ }^{\mathrm{A}}, \mathrm{yr}$ & 5.3 & 6.1 & 5.3 & 6.1 & 19.8 \\
\hline Mean circuit resistance, $\mathrm{k} \Omega-\mathrm{m}^{2}$ & 0.13 & 0.95 & 0.28 & 2.45 & 3.68 \\
\hline Reaction zone thickness, mm & 0.90 & 0.21 & 0.79 & 0.54 & 0.80 \\
\hline
\end{tabular}

Retained $\mathrm{Cl}^{-}, \mathrm{g} \mathrm{Cl} / \mathrm{m}^{2}$ (\% of total)

\begin{tabular}{c|c|c|c|c|c}
\hline \multirow{2}{*}{ On surface } & 10.4 & 6.9 & 4.7 & 3.7 & 2.3 \\
\cline { 2 - 5 } & $(10.5)$ & $(24.9)$ & $(23.2)$ & $(9.8)$ & $(18.3)$ \\
\hline \multirow{2}{*}{ In anode } & 1.3 & 2.2 & 5.7 & 4.7 & 0.6 \\
\cline { 2 - 5 } & $(1.3)$ & $(8.1)$ & $(28.0)$ & $(12.5)$ & $(4.7)$ \\
\hline \multirow{2}{*}{ In reaction zone } & 82.9 & 15.7 & 9.3 & 21.7 & 9.5 \\
\hline \multirow{2}{*}{$\begin{array}{c}\text { In cement paste beyond the } \\
\text { reaction zone }\end{array}$} & $(83.9)$ & $(56.3)$ & $(45.8)$ & $(57.5)$ & $(75.6)$ \\
\cline { 2 - 6 } & $(4.4)$ & 3.0 & 0.6 & 7.6 & 0.2 \\
\hline Total & 98.9 & 27.8 & $20.8)$ & $(20.2)$ & $(1.4)$ \\
\hline
\end{tabular}

Retained $\mathrm{Br}, \mathrm{g} \mathrm{Br} / \mathrm{m}^{2}$ (\% of total)

\begin{tabular}{c|c|c|c|c|c}
\hline \multirow{2}{*}{ In anode } & & & 2.1 & 12.0 & 0.2 \\
\cline { 2 - 5 } & & & $(4.6)$ & $(9.1)$ & $(15.0)$ \\
\hline \multirow{2}{*}{\begin{tabular}{c} 
In reaction zone \\
\cline { 2 - 5 } $\begin{array}{c}\text { In cement paste beyond the } \\
\text { reaction zone }\end{array}$
\end{tabular}} & & 38.3 & 68.9 & 0.5 \\
\cline { 2 - 5 } & & & $(83.3)$ & $(52.4)$ & $(35.0)$ \\
\hline Total $^{\mathrm{B}}$ & & 5.5 & 50.7 & 0.7 \\
\hline
\end{tabular}

${ }^{\mathrm{A}}$ Years of service at the $0.2 \mathrm{~mA} / \mathrm{ft}^{2}\left(2.2 \mathrm{~mA} / \mathrm{m}^{2}\right)$ that Oregon DOT typically uses in coastal bridge ICCP systems.

${ }^{\mathrm{B}} \mathrm{The} \mathrm{LiBr}$ application rate was $86 \mathrm{~g} \mathrm{LiBr} / \mathrm{m}^{2}$, which corresponds to $79 \mathrm{~g} \mathrm{Br} / \mathrm{m}^{2}$.

\subsubsection{Microscopy of Long-Term ICCP-LiBr}

The structure of the LiBr-treated concrete-anode interface is shown in the BSE image and elemental x-ray maps in Figure 5.20 for a new slab in the high RH enclosure, in Figure 5.21 for a new slab in the low RH enclosure, and in Figure 5.22 for an aged slab in the 
low $\mathrm{RH}$ enclosure. The overall structure is similar to the $\mathrm{LiNO}_{3}$-treated slabs as described above. The elemental x-ray line scans shown in Figure 5.23 for the new slab in the high RH enclosure illustrates the type of line scans that are obtained by ASEM. It also shows the different zones in terms of the atomic concentration of each element. The zones are most discernable from changes in the $\mathrm{Zn}$ and $\mathrm{Ca}$ concentrations.

The interface in Figure 5.22 delaminated during sample preparation, creating a gap within the reaction zone, between the $\mathrm{ZnO}$ layer and the Ca-depleted, $\mathrm{Zn}$-rich layer formed within the cement paste.

The $\mathrm{Br}$ component of the humectant is detectable by $\mathrm{x}$-rays. Figures 5.20-5.21 show the highest concentration of bromide to be in the $\mathrm{ZnO}$ portion of the reaction zone. However, $\mathrm{Br}$ was also found in the anode and in the rest of the reaction zone. Table 5.1 shows that in the high RH exposure, 83.3 percent of the $\mathrm{Br}$ was found in the reaction zone. In the low $\mathrm{RH}$ exposure, 52.4 percent of the $\mathrm{Br}$ was found in the reaction zone. In both cases much or all of the applied $\mathrm{Br}\left(79 \mathrm{~g} \mathrm{Br} / \mathrm{m}^{2}\right)$ was retained at the anode. Only 1.4 $\mathrm{g} / \mathrm{m}^{2}$ of Br was found in the aged slab (Table 5.1), much less than the applied amount.

The sulfur (S) x-ray maps in Figures 5.20 and 5.22 show that S from the concrete can also concentrate at the anode-concrete interface. Sulfate ions migrate to the anode under the influence of the $\mathrm{CP}$ potential gradient similar to chloride ions.

Unlike the $\mathrm{LiNO}_{3}$-treated slabs, the reaction zone thickness in the LiBr-treated slabs did not differ much between the low and high RH exposures. As Table 5.1 shows, the high $\mathrm{RH}$ exposed reaction zone thickness was $0.79 \mathrm{~mm}$ compared to $0.54 \mathrm{~mm}$ for the low $\mathrm{RH}$ exposed reaction zone. The $\mathrm{Zn} \mathrm{x}$-ray maps for both humectants at both humidities, Figure 5.24 , show the relative sizes of the reaction zones quite clearly. Figure 5.24 also shows that the reaction zone thickness was approximately the same, regardless of the humectant at high $\mathrm{RH}$, but not at low RH.

A major difference between the $\mathrm{LiBr}$ - and $\mathrm{LiNO}_{3}$-treated slabs was how the $\mathrm{Cl}^{-}$was distributed. The $\mathrm{Cl}$ x-ray map for both humectants, at both humidities, (Figure 5.25) shows that in the $\mathrm{LiBr}$-treated slabs most of the $\mathrm{Cl}^{-}$was in the reaction zone nearest the $\mathrm{Zn}$ anode. This compares with the $\mathrm{LiNO}_{3}$-treated slabs where there was a much broader $\mathrm{Cl}^{-}$distribution within the reaction zone. 


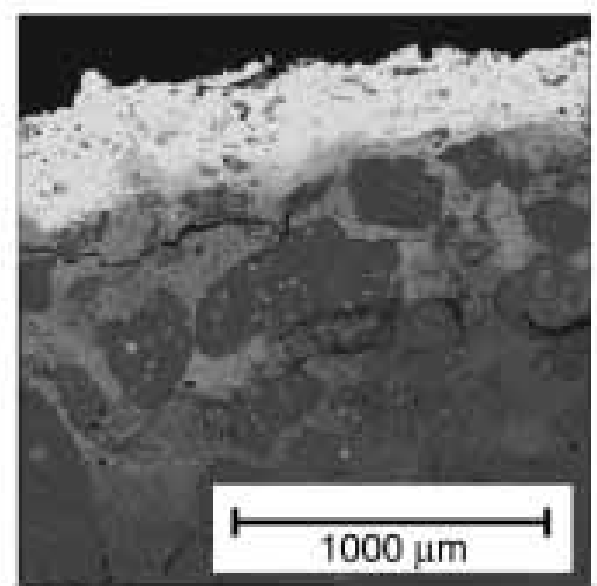

BSE

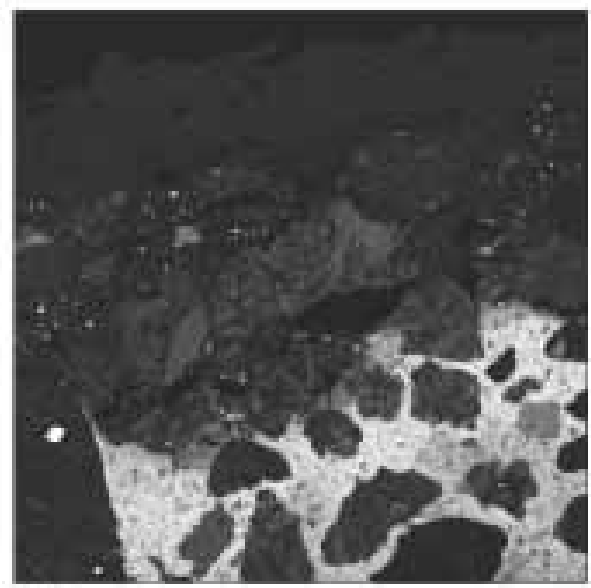

\section{$\mathrm{Ca}$}

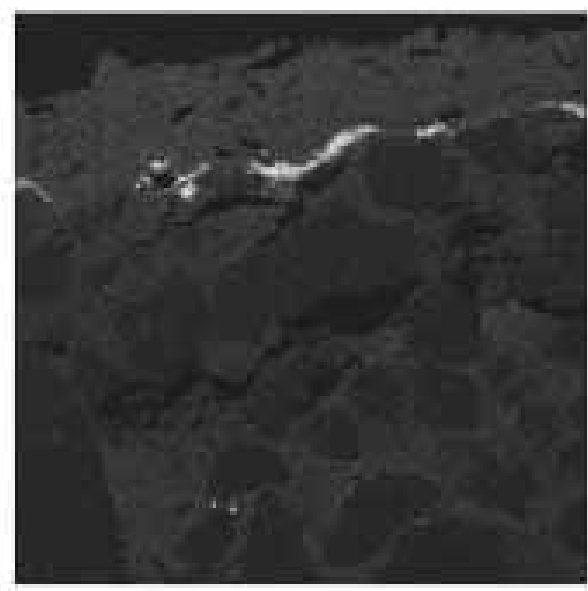

S

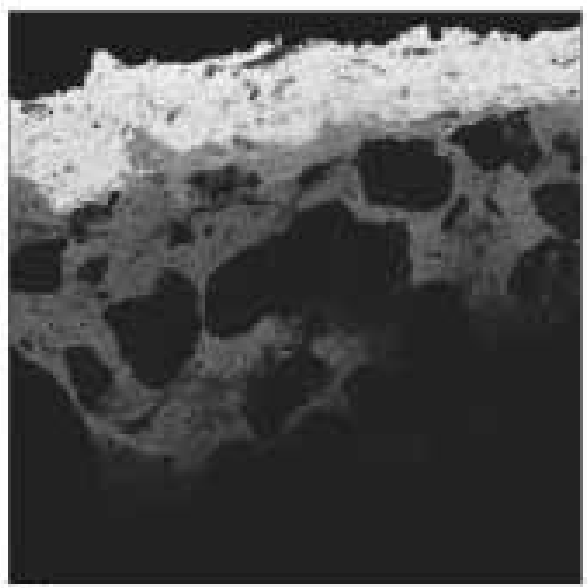

$\mathrm{Zn}$

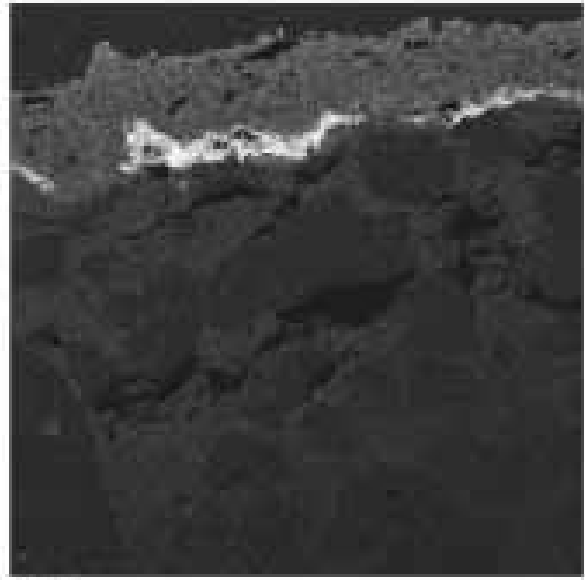

CI

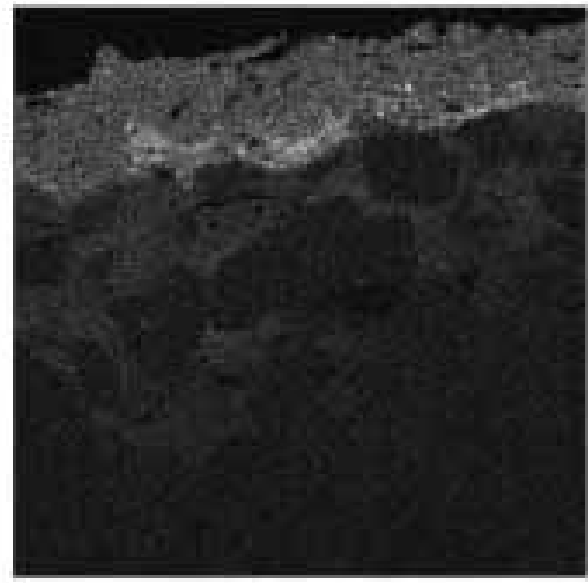

$\mathrm{Br}$

Figure 5.20: BSE and elemental x-ray maps of a LiBr-treated new slab exposed in the high-RH exposure after the equivalent of 5.3 years of ICCP. The $\mathrm{Zn}$ anode is at the top and the unaltered concrete is at the bottom of each cross section. 


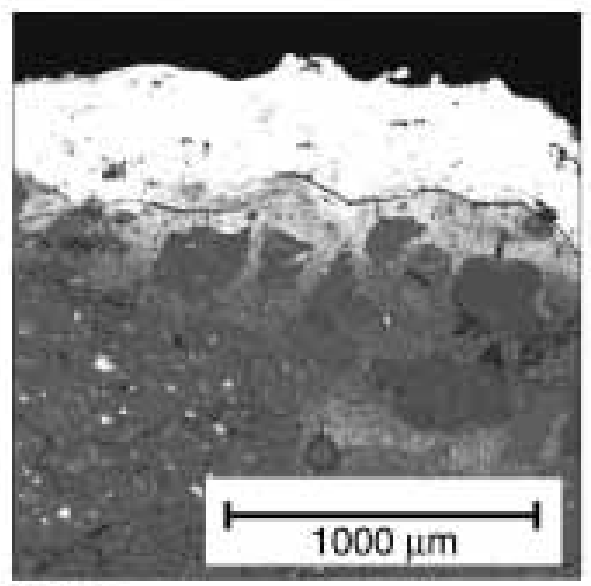

\section{BSE}

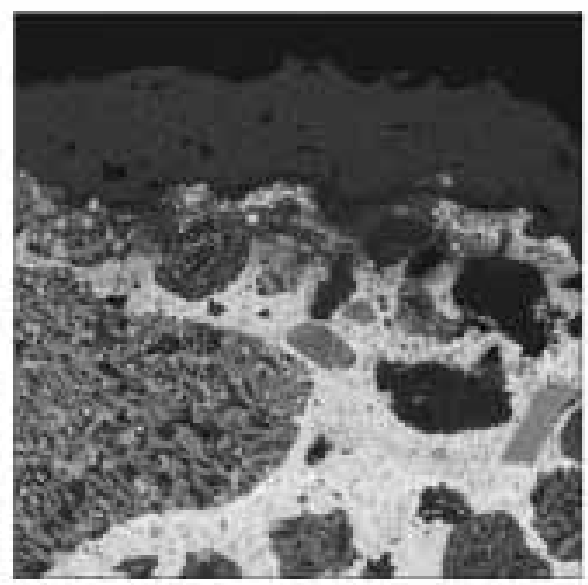

$\mathrm{Ca}$

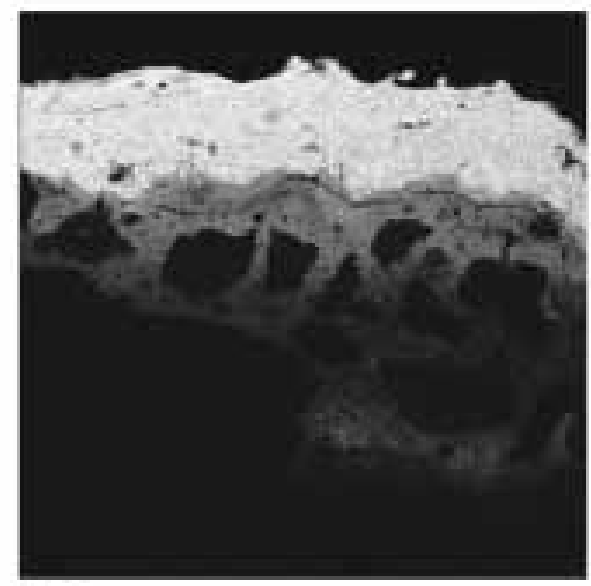

$\mathrm{Zn}$

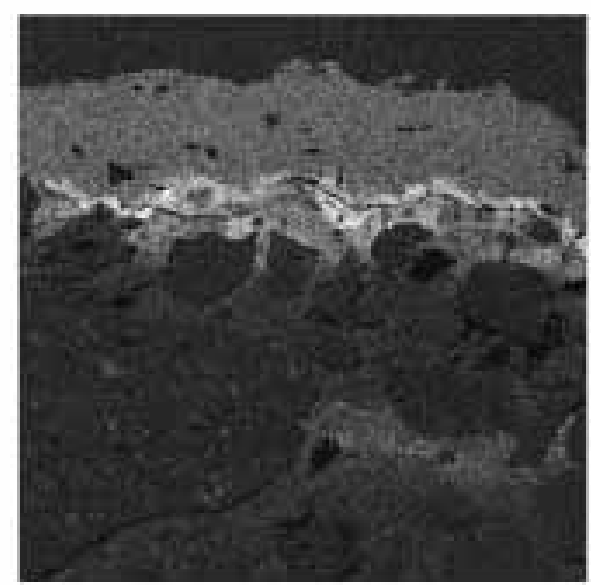

$\mathrm{Cl}$

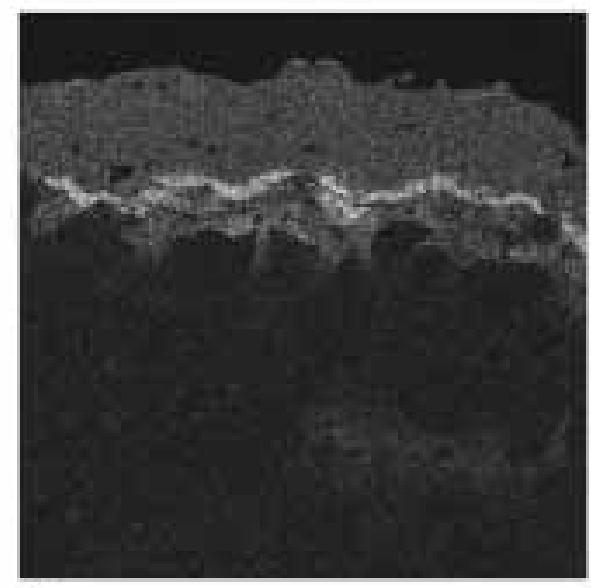

$\mathrm{Br}$

Figure 5.21: BSE and elemental x-ray maps of a LiBr-treated new slab exposed in the low-RH exposure after the equivalent of 6.1 years of ICCP. The $\mathrm{Zn}$ anode is at the top and the unaltered concrete is at the bottom of each cross section. 


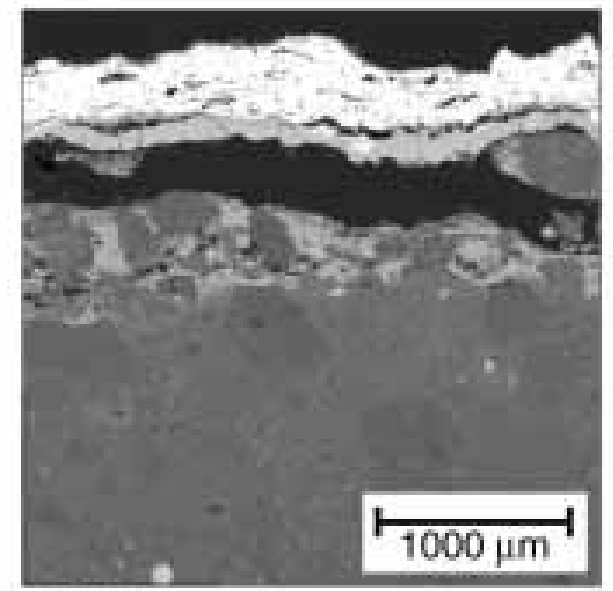

BSE

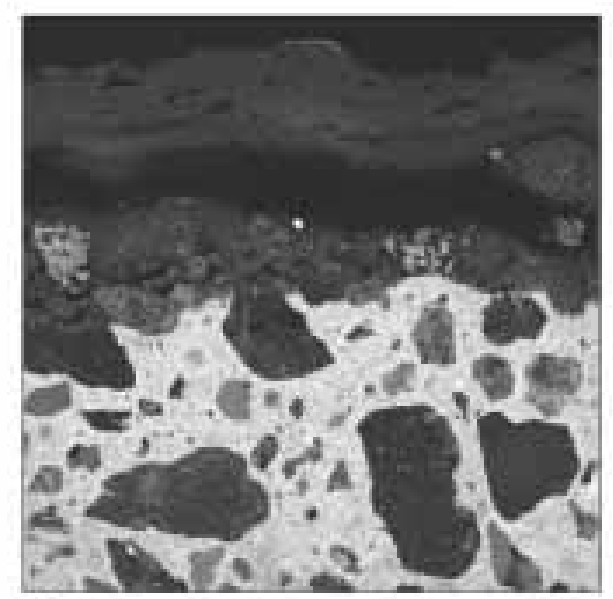

$\mathrm{Ca}$

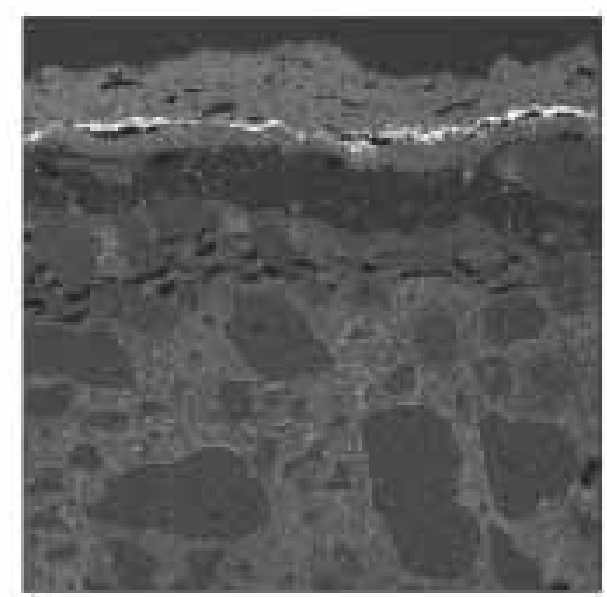

S

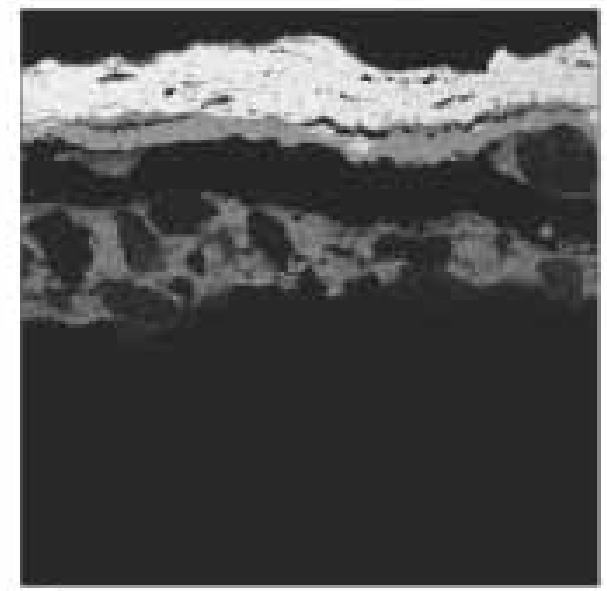

\section{$\mathrm{Zn}$}

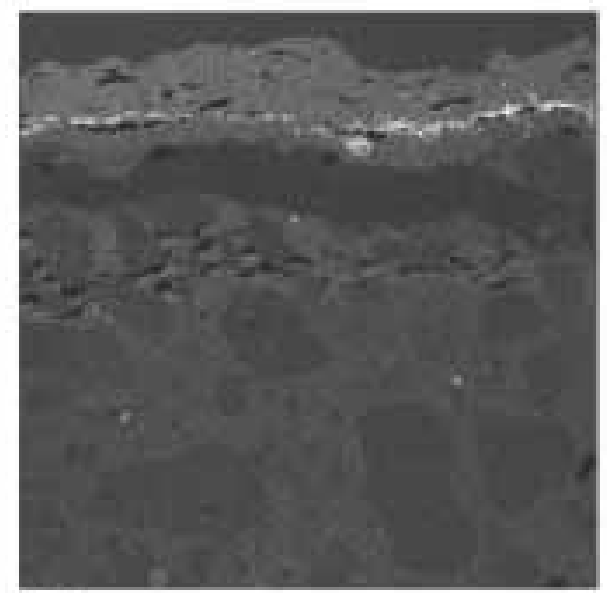

Cl

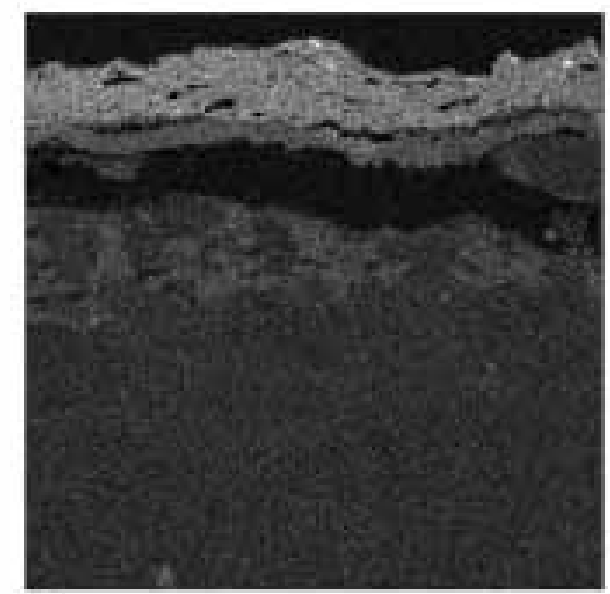

$\mathrm{Br}$

Figure 5.22: BSE and elemental x-ray maps of a LiBr-treated aged slab exposed in the low-RH exposure after the equivalent of 0.8 additional years of ICCP. The initial electrochemical age was 19 years. The $\mathrm{Zn}$ anode is at the top and the unaltered concrete is at the bottom of each cross section. 

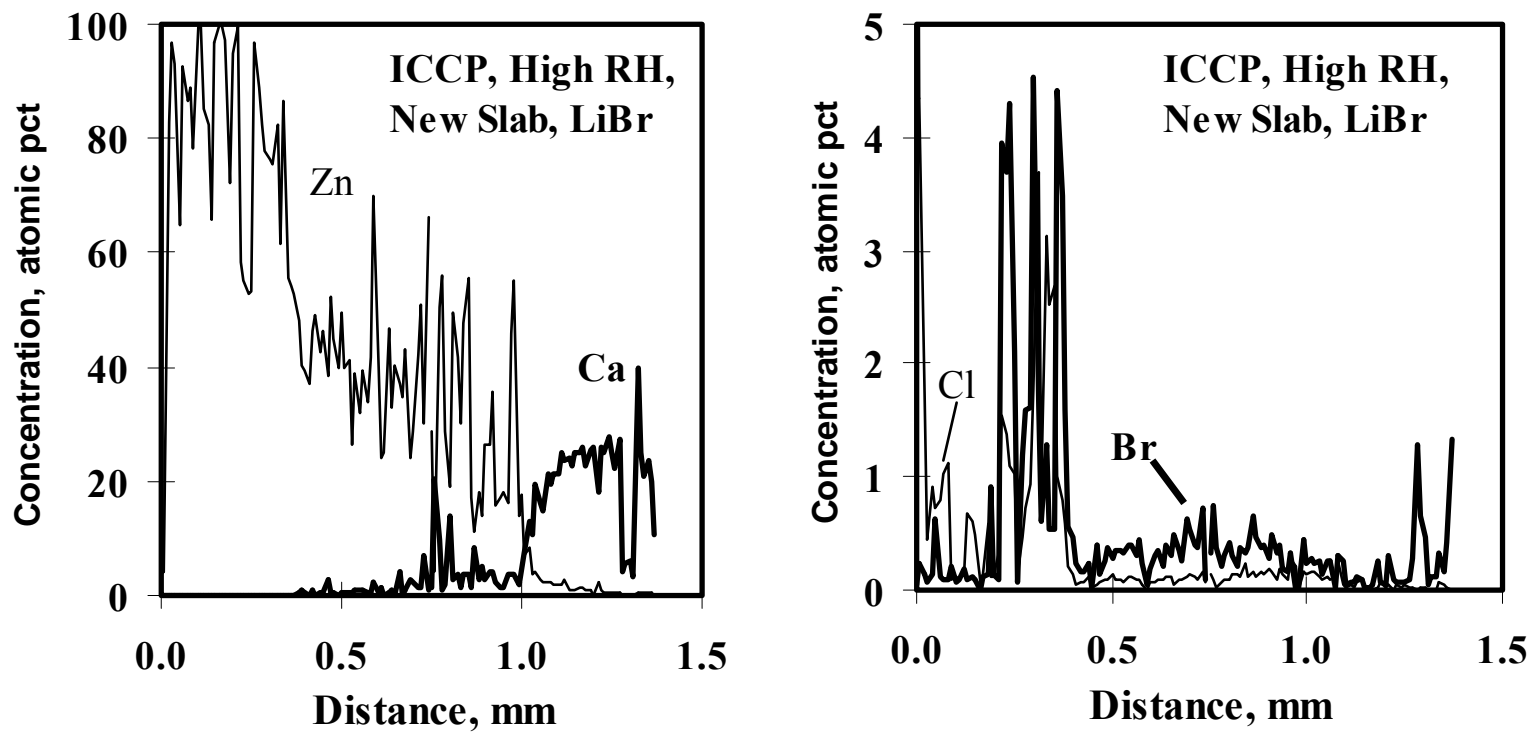

Figure 5.23: X-ray line scans of a LiBr-treated new slab exposed in the high-RH exposure after the equivalent of 5.3 years of ICCP 


\section{$\mathrm{LiBr}$}

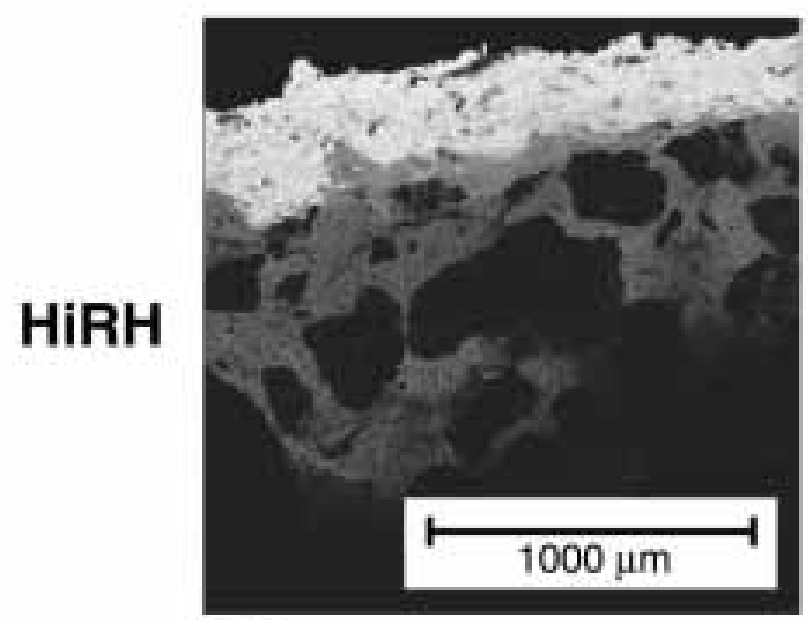

\section{$\mathrm{Zn}$}

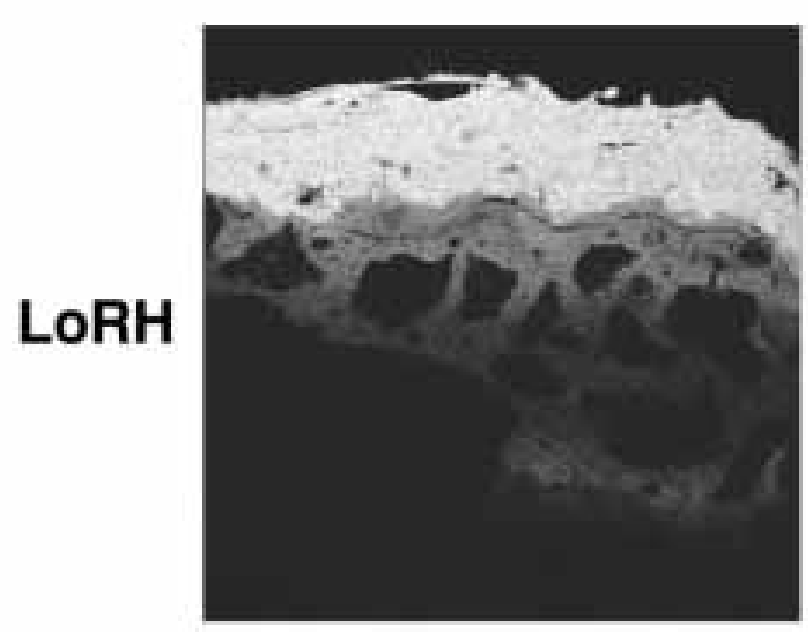

$\mathrm{Zn}$
$\mathrm{Li} \mathrm{NO}$

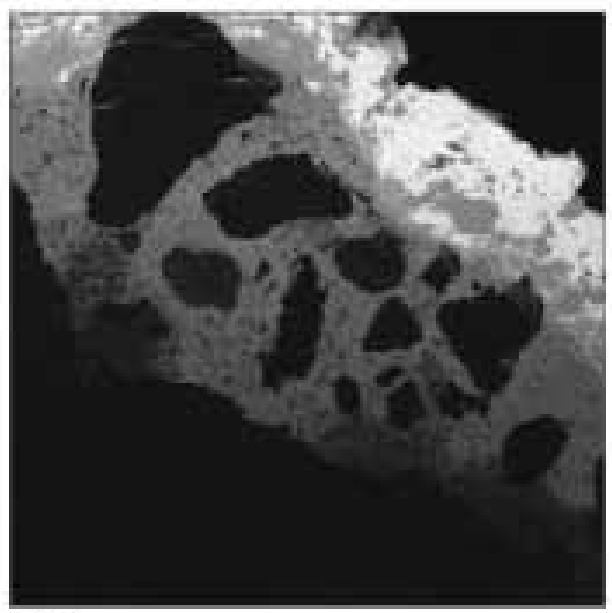

$\mathrm{Zn}$

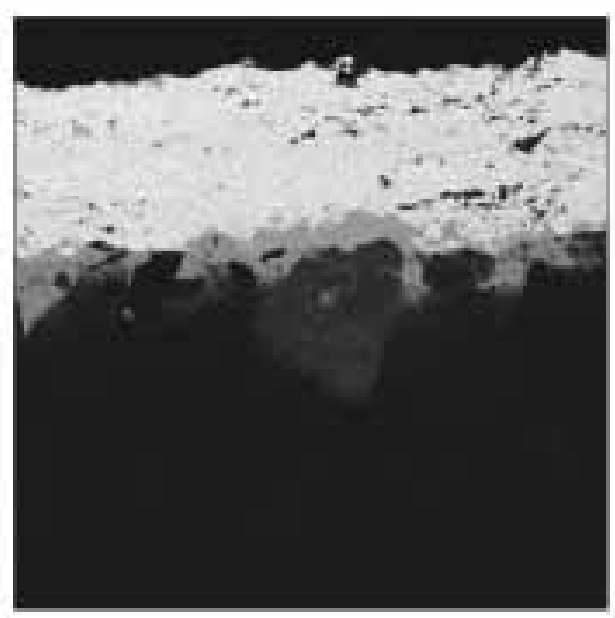

Zn

Figure 5.24: Elemental zinc x-ray maps for both humectants and both humidities after the equivalent of 5.3 years (high RH) and 6.1 years (low RH) of ICCP 


\section{$\mathrm{LiBr}$}

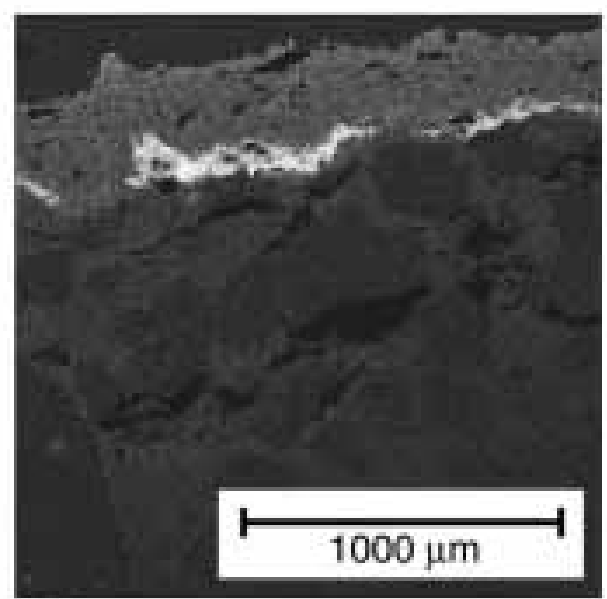

\section{$\mathrm{Cl}$}

\section{Lo RH}

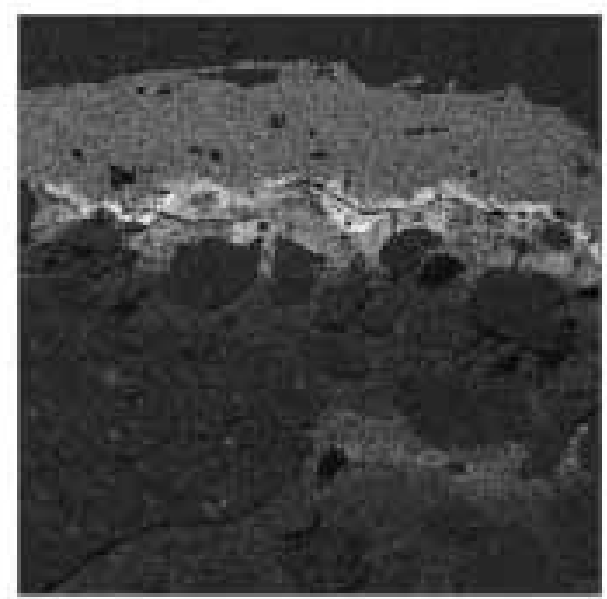

$\mathrm{Cl}$

\section{$\mathrm{Li} \mathrm{NO}_{3}$}

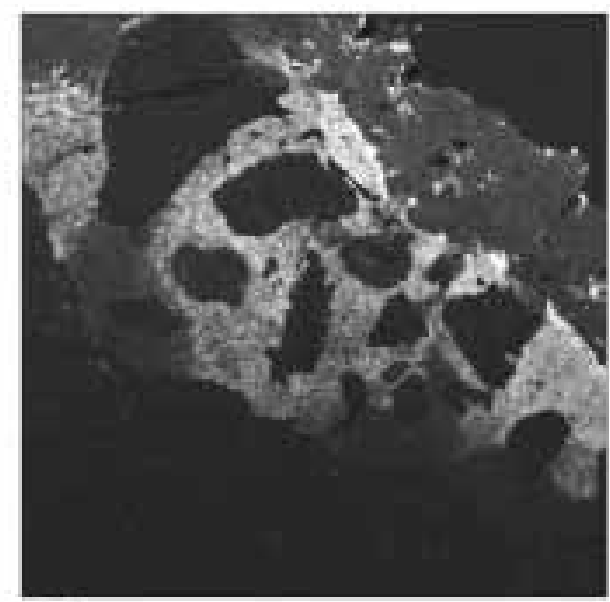

\section{Cl}

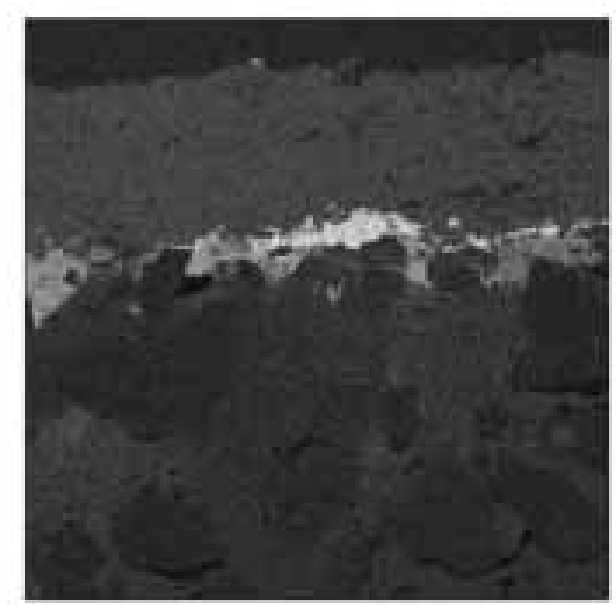

Cl

Figure 5.25: Elemental Cl x-ray maps for both humectants and both humidities after the equivalent of 5.3 years (high $\mathrm{RH}$ ) and 6.1 years (low RH) of ICCP

\subsubsection{AC Resistance and Circuit Resistance}

AC Resistance measurements between anode and cathode are compared with circuit resistances in Figure 5.26. Linear regression resulted in a slope of 0.25 with a $\mathrm{R}^{2}$ of 0.65 . Even with the wide range of sample types, elapsed time between measurements, and differing current densities (the aged low RH slabs were at a lower impressed current density), a general trend emerges that circuit resistance tracks AC resistance. This means that circuit resistance, which can be obtained directly from ICCP operation parameters, should give useful information about the state of the $\mathrm{Zn}$-concrete interface, where the buildup of corrosion products increases the ohmic resistance. 
This is consistent with the successful use of circuit resistance calculations to track performance for CP zones of widely varying size and total current in both laboratory and field installations (Bullard, et al. 1998; Covino, et al. 2000; Covino, et al. 2002).

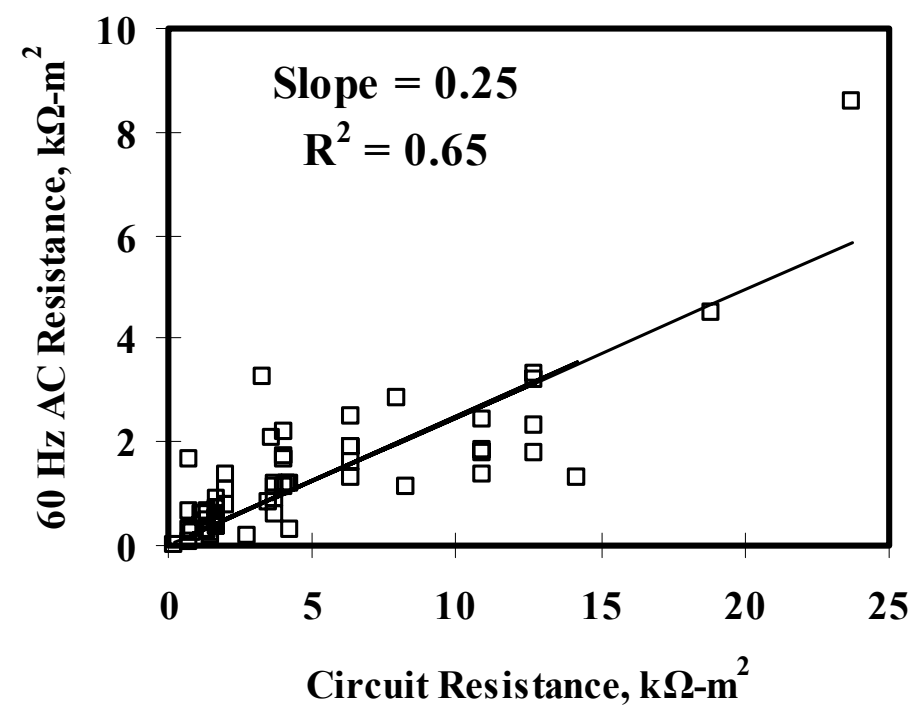

Figure 5.26: AC resistance compared with circuit resistance (defined as operating voltage divided by impressed current density)

\subsubsection{Adhesion Strength}

The adhesion strengths were measured at the conclusion of the CP test for each long-term ARC laboratory slab. In Figures 5.27-5.30, where bond strength is shown as a function of electrochemical age, the electrochemical age is the equivalent age based on the nominal current level of $2.2 \mathrm{~mA} / \mathrm{m}^{2}\left(0.2 \mathrm{~mA} / \mathrm{ft}^{2}\right)$ used by Oregon DOT on Oregon coast ICCP systems. The conversion is that $100 \mathrm{kC} / \mathrm{m}^{2}$ corresponds to 1.473 years of Oregon DOT coastal bridge service.

The fitted curved lines in Figures 5.27-5.30 are from the results of earlier adhesion strength experiments. The line reaching zero bond strength at 27 years is for environments with repeated wetting of the anode (Covino, et al. 1996a; Covino, et al. 1996b; Covino, et al. 2002; Holcomb, et al. 1996). This was essentially the same environment as used for the high RH conditions in this study. The curved line reaching zero bond strength at 5 years is for a much dryer environment with minimal wetting of the anode (Bullard, et al. 1997a; Bullard, et al. 1998; Covino, et al. 2002). This was a harsher environment than the low RH conditions used in this study because the anode was only infrequently wetted for the dryer environment measurements. However, the measurements from that work are illustrative of anode bond strengths from a dry environment. 
The results for accelerated ICCP at low RH are shown in Figures 5.27. While there is significant scatter in the data, the general trend is much like the high $\mathrm{RH}$ wetted environment that had a lifetime of 27 years. In most cases the $\mathrm{LiBr}$-treatments resulted in higher bond strengths than the $\mathrm{LiNO}_{3}$ or $\mathrm{KC}_{2} \mathrm{H}_{3} \mathrm{O}_{2}$ treatments. The new control and $\mathrm{KC}_{2} \mathrm{H}_{3} \mathrm{O}_{2}$ slabs were pulled early from the experiment (Figures 5.2 and A5.2) because bond strengths were low. Consequently, their electrochemical ages are much lower than for the new $\mathrm{LiBr}$ or $\mathrm{LiNO}_{3}$ slabs.

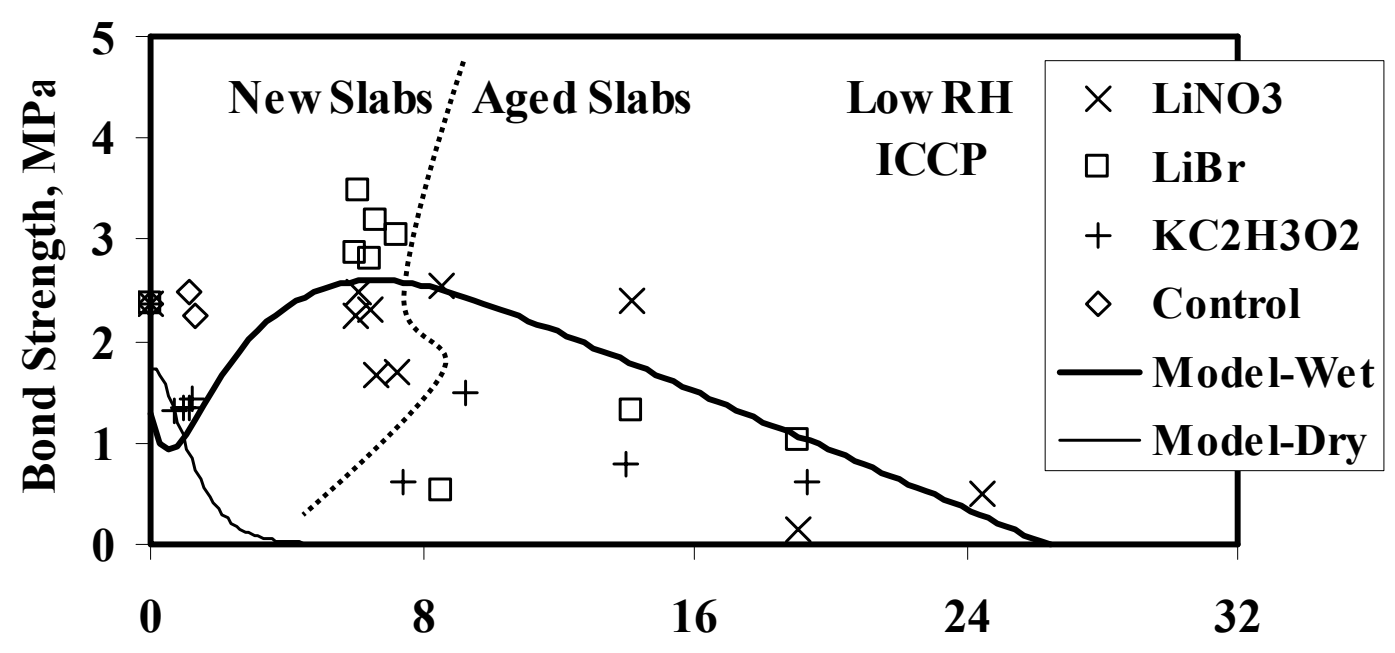

Equivalent Electrochemical Age, yr

Figure 5.27: Bond strength results for accelerated ICCP in low RH environments. The aged slabs had initial equivalent ages of $3,8,13.1$, and 19 years.

The aged slabs in Figures 5.27 have a mixed history. In the prior experiment they underwent accelerated ICCP at $27 \mathrm{~mA} / \mathrm{m}^{2}\left(2.5 \mathrm{~mA} / \mathrm{ft}^{2}\right)$ in high RH conditions to equivalent ages of 3,8 , 13.1, and 19 years. After treatment with humectants they underwent accelerated ICCP at 10 $\mathrm{mA} / \mathrm{m}^{2}\left(0.9 \mathrm{~mA} / \mathrm{ft}^{2}\right)$ in low RH conditions for approximately 5-6 more equivalent years. In Figures 5.27 these aged slabs showed poorer bond strengths as compared with the 27-year wet curve, but that could be expected from the low RH conditions.

The ranking of humectant treatments, in terms of bond strengths for new and aged ICCP slabs at low $\mathrm{RH}$, was $\mathrm{LiBr}>\mathrm{LiNO}_{3}>\mathrm{KC}_{2} \mathrm{H}_{3} \mathrm{O}_{2}$.

The results for accelerated ICCP at high RH are shown in Figure 5.28. The bond strengths for the new slabs were very low, with some showing complete disbondment at the higher ages. The new $\mathrm{KC}_{2} \mathrm{H}_{3} \mathrm{O}_{2}$ slabs had quite poor bond strengths even after as low as 3-5 equivalent years. The overall results for the new slabs were so poor that one could suspect that humectants were the cause. However, the control slab also had a very low bond strength that was consistent with the humectant-treated slabs. The cause for these low bond strengths has not been determined. 


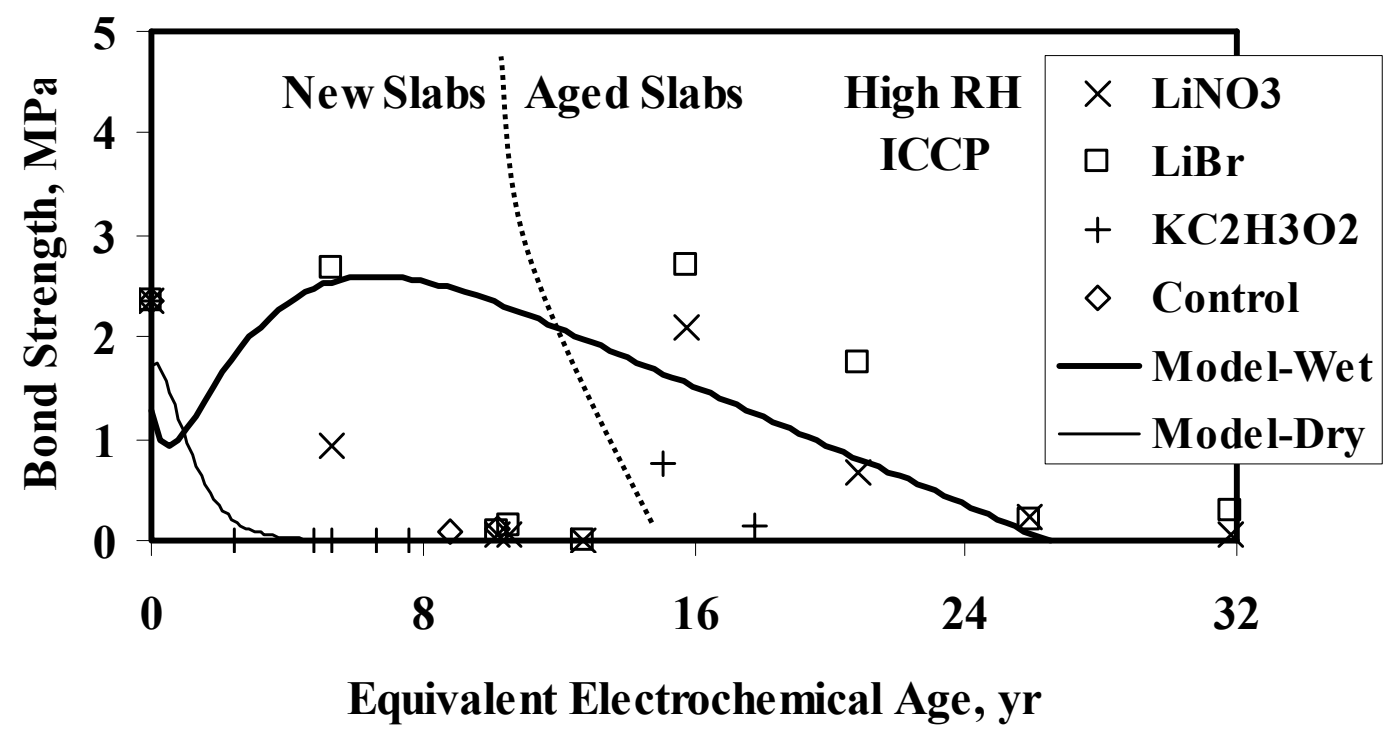

Figure 5.28: Bond strength results for accelerated ICCP in high RH environments. The aged slabs had initial equivalent ages of $3,8,13.1$, and 19 years.

The aged slabs in Figure 5.28 started with electrochemical ages of 3, 8, 13.1, and 19 years. After treatment with humectants they underwent approximately 12-13 additional equivalent years of electrochemical aging. Since the environments of the prior and present experiments were very similar, these samples should show the effects of humectants more clearly than in Figure 5.27.

The ranking of humectant treatments, in terms of bond strengths for new and aged ICCP slabs at high $\mathrm{RH}$, was $\mathrm{LiBr}>\mathrm{LiNO}_{3}>\mathrm{KC}_{2} \mathrm{H}_{3} \mathrm{O}_{2}$.

The results for GCP at low RH are shown in Figure 5.29. On this time scale the new slabs did not show much electrochemical age. They did show higher bond strengths than the ICCP lines from the prior experiments. 


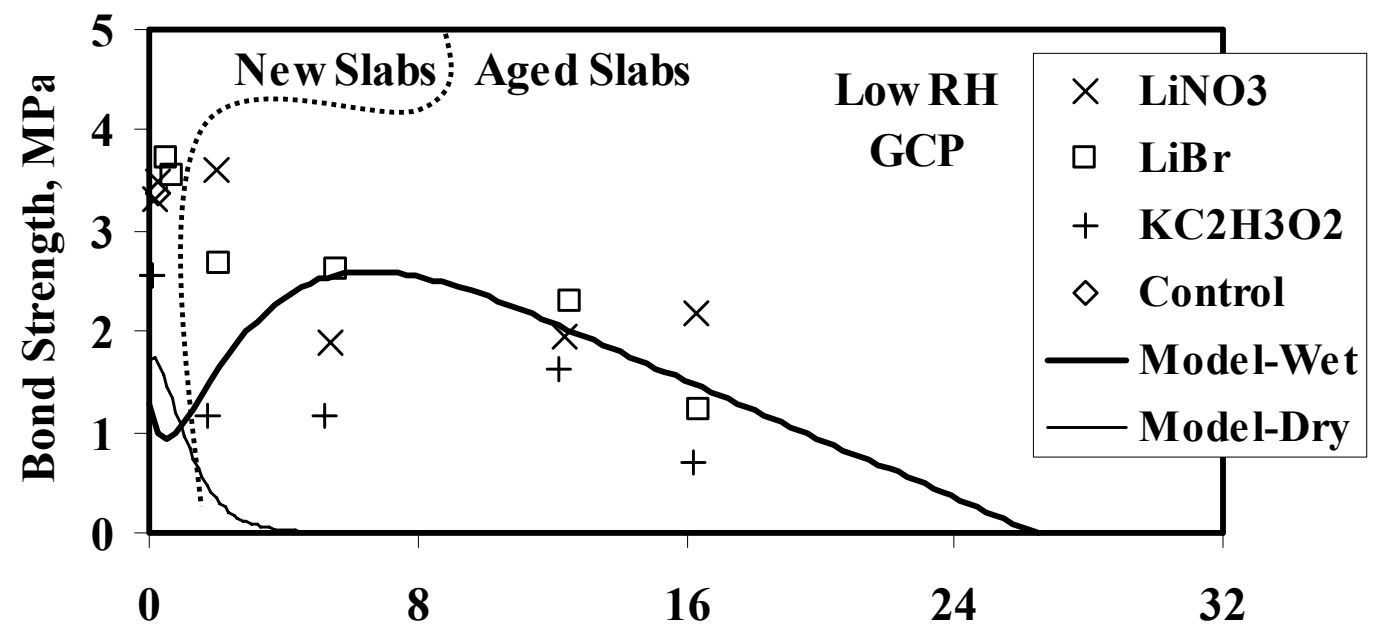

Equivalent Electrochemical Age, yr

Figure 5.29: Bond strength results for GCP in low RH environments. The aged slabs had initial equivalent ages of $1.6,5.1,12$, and 16.1 years.

The aged slabs in Figure 5.29 started with electrochemical ages of 1.6, 5.1, 12, and 16 years from accelerated ICCP. After treatment with humectants they underwent approximately 1 additional equivalent year of electrochemical aging. The bond strengths generally followed the 27 year wetted curve that the slabs had prior to the humectant treatments.

The ranking of humectant treatments, in terms of bond strengths for new and aged GCP slabs at low $\mathrm{RH}$, was $\mathrm{LiBr}=\mathrm{LiNO}_{3}>\mathrm{KC}_{2} \mathrm{H}_{3} \mathrm{O}_{2}$.

The results for GCP at high RH are shown in Figure 5.30. The new slabs underwent electrochemical aging based on their current densities, which for $\mathrm{LiBr}$ were much larger than for the other treatments (Figure 5.14). The bond strengths were high for the $\mathrm{LiNO}_{3}$ and control slabs. The bond strengths of the $\mathrm{KC}_{2} \mathrm{H}_{3} \mathrm{O}_{2}$-treated slabs were very low. 


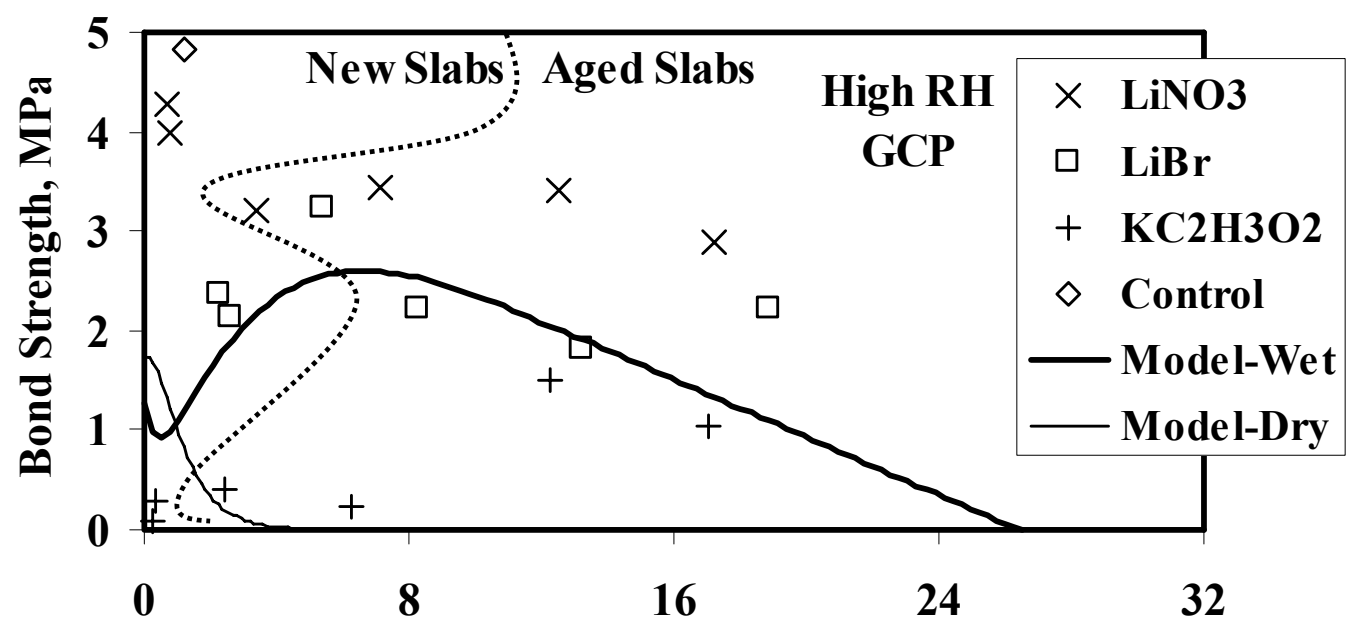

Equivalent Electrochemical Age, yr

Figure 5.30: Bond strength results for GCP in high RH environments. The aged slabs had initial equivalent ages of $1.6,5.1,12$, and 16.1 years.

The aged slabs in Figure 5.30 started with electrochemical ages of 1.6, 5.1, 12, and 16 years from accelerated ICCP. After the treatment with humectants the slabs underwent approximately 1-3 additional equivalent years of electrochemical aging. The $\mathrm{LiNO}_{3}$ bond strengths were higher than the 27-year wetted curve. The $\mathrm{LiBr}$ bond strengths straddled the 27-year wetted curve. The results for the $\mathrm{KC}_{2} \mathrm{H}_{3} \mathrm{O}_{2}$ slabs were mixed: two had very low bond strengths and two had bond strengths near the 27-year wetted curve.

The ranking of humectant treatments, in terms of bond strengths for new and aged GCP slabs at high $\mathrm{RH}$, was $\mathrm{LiNO}_{3}>\mathrm{LiBr}>>\mathrm{KC}_{2} \mathrm{H}_{3} \mathrm{O}_{2}$.

The results in Figures 5.27-5.30 are compared with the model curves generated from the earlier study for wetted and dry conditions (Covino, et al. 2002). One more way to compare the results is by comparing the bond strengths for the aged slabs compared to the bond strengths measured from the same slab in the prior investigation, rather than to the fitted model curve. These comparisons are shown in Figures 5.31-5.32 for the ICCP tests in high and low RH environments. These results show that the additional aging follows the same trends as the model curve showed, with just the one LiBr-treated point in Figure 5.32 (low RH) showing a significant deviation. 


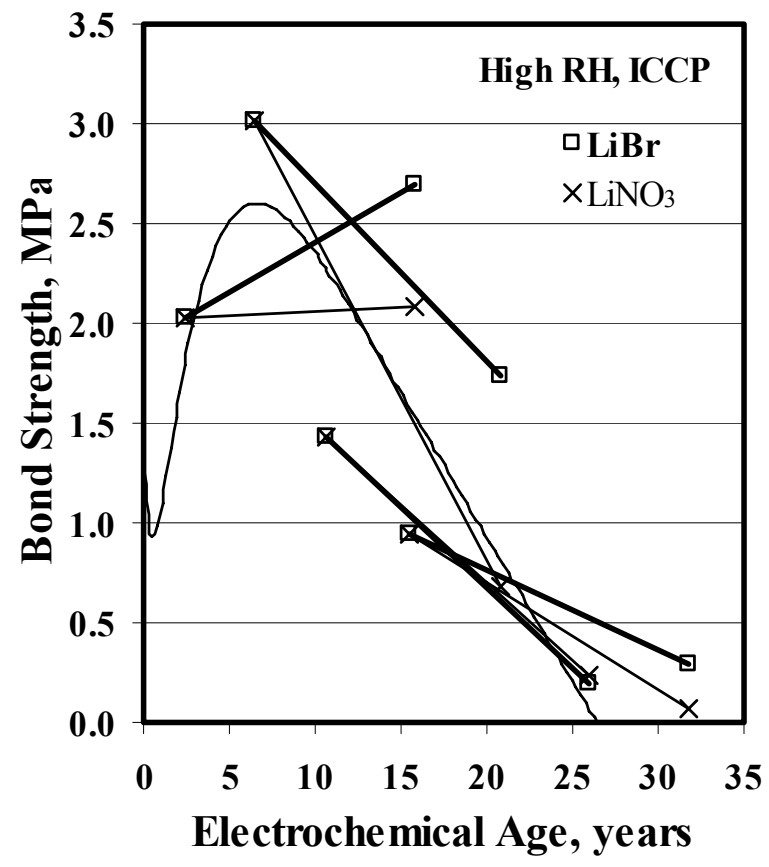

Figure 5.31: Bond strength results for ICCP aged slabs in high RH environments in comparison with their initial strength results

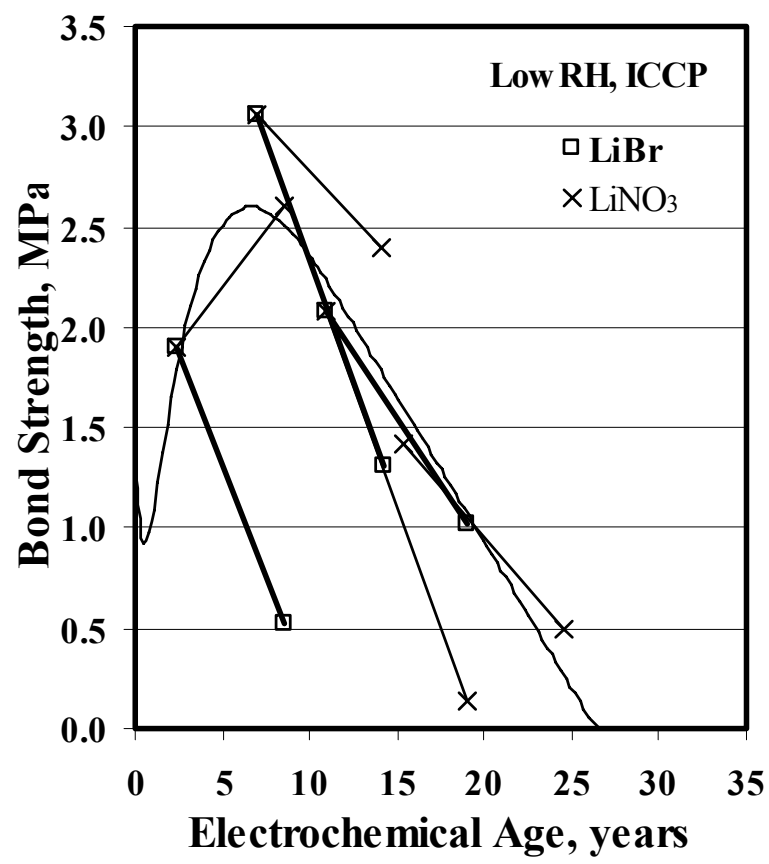

Figure 5.32: Bond strength results for ICCP aged slabs in low RH environments in comparison with their initial strength results 
The results for different $\mathrm{NaCl}$ concentrations are shown in Figure 5.33 after accelerated electrochemical aging (to an equivalent electrochemical age of 17.9 years) in a high $\mathrm{RH}$ environment. Very little differences in bond strengths are seen for different $\mathrm{NaCl}$ concentrations. Note the closeness between the results at $1.2 \mathrm{~kg} / \mathrm{m}^{3}\left(2.01 \mathrm{~b} / \mathrm{yd}^{3}\right)$ for the control, and the blank. The blank received no treatment and the control received the same diluted surfactant solution that the humectants were dissolved into.

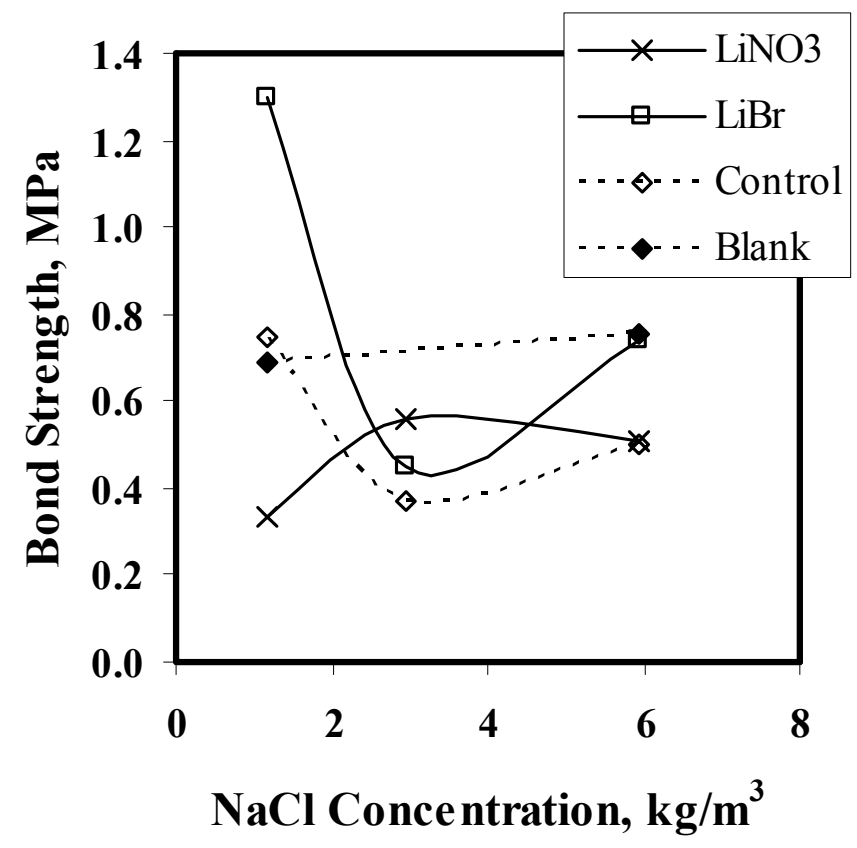

Figure 5.33: Bond strengths for different $\mathrm{NaCl}$ concentrations with accelerated ICCP (equivalent electrochemical age of 17.9 years) in high $\mathrm{RH}$ environments. The $\mathrm{NaCl}$ concentrations correspond to $2.0,5.0$, and $10.0 \mathrm{lb} / \mathrm{yd}^{3}$.

\subsection{SHORT-TERM CHAMBER EXPERIMENTS (ARC)}

\subsubsection{Mass Change Response to Temperature and Humidity}

Results for mass change, as the slices equilibrated to the specific $\mathrm{RH}$ of the $90^{\circ} \mathrm{F}\left(32.2^{\circ} \mathrm{C}\right)$ humidity chamber are shown in Figure 5.34 for the $\mathrm{LiNO}_{3}$ - and $\mathrm{LiBr}$ - treated slices. Figure 5.35. shows the results for the slices with just the surfactant treatment and for the control. Results for $\mathrm{KC}_{2} \mathrm{H}_{3} \mathrm{O}_{2}$-treated slices are in Appendix A. All of the plots are averages of 2 or 3 slices: 3 for $\mathrm{LiNO}_{3}$ - and LiBr-treated slices that have TS $\mathrm{Zn}$, and 2 for all the remaining slices. All of the curves show the same general trends as the RH changes from $70 \%, 50 \%, 35 \%$, and $80 \% \mathrm{RH}$. 

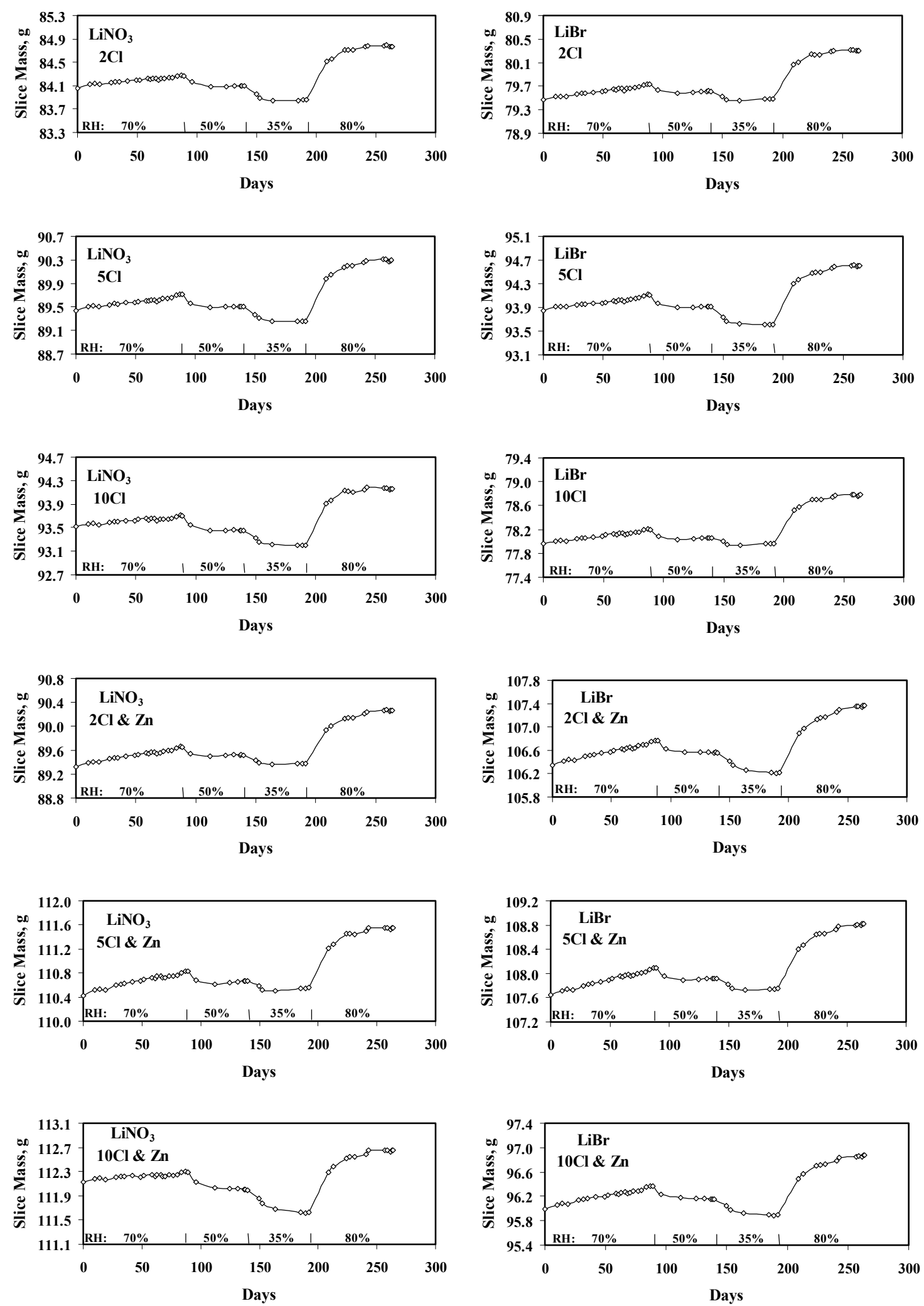

Figure 5.34: Mass change with exposure time of $\mathrm{LiNO}_{3}$-treated and $\mathrm{LiBr}$-treated slices at $90^{\circ} \mathrm{F}\left(32.2^{\circ} \mathrm{C}\right)$. The $\mathrm{NaCl}$ concentrations were $2.0,5.0$, and $10.0 \mathrm{lb} / \mathrm{yd}^{3}\left(1.2,3.0\right.$, and $\left.5.9 \mathrm{~kg} / \mathrm{m}^{3}\right)$. 

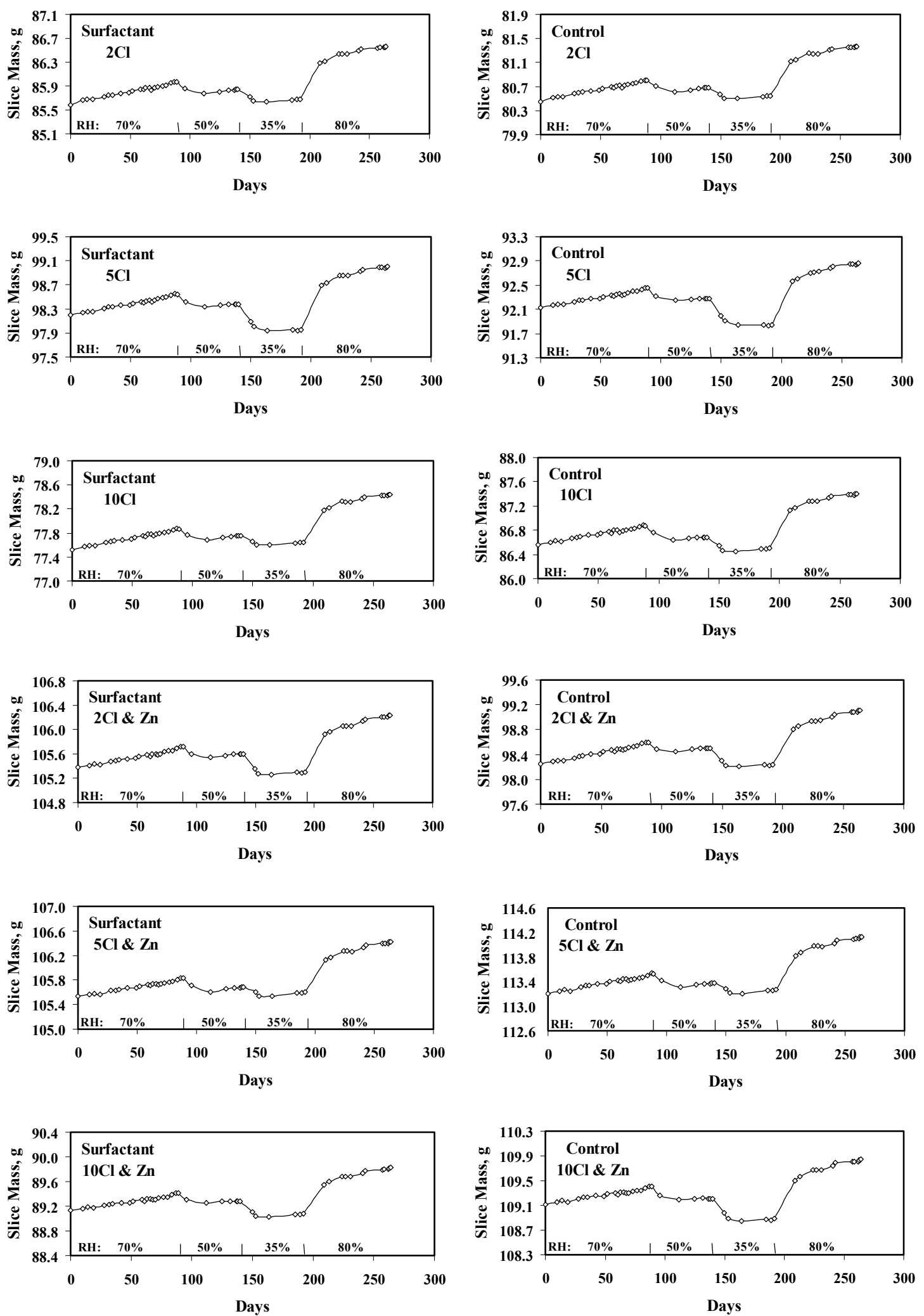

Figure 5.35: Mass change with exposure time of surfactant-treated and control slices at $90^{\circ} \mathrm{F}\left(32.2^{\circ} \mathrm{C}\right)$. The $\mathrm{NaCl}$ concentrations were $2.0,5.0$, and $10.0 \mathrm{lb} / \mathrm{yd}^{3}\left(1.2,3.0\right.$, and $\left.5.9 \mathrm{~kg} / \mathrm{m}^{3}\right)$. 
The data in Figures 5.34 and 5.35 were examined by calculating the mass gain at $50 \%, 70 \%$, and $80 \% \mathrm{RH}$ with respect to the mass at 35\% RH. The mass at each RH was the mean of the final 3 measurements at each RH. Table 5.2 shows the results of these calculations with the slices grouped together by humectant, $\mathrm{NaCl}$ level, and $\mathrm{Zn}$.

Table 5.2: Equilibrated mass gain from a RH of $35 \%$

\begin{tabular}{|c|c|c|c|c|}
\hline CONDITION & $50 \%$ RH, g & $70 \% \mathrm{RH}, \mathrm{g}$ & $80 \%$ RH, g & $\begin{array}{c}\text { NUMBER OF } \\
\text { SLICES }\end{array}$ \\
\hline \multicolumn{5}{|c|}{ Humectant } \\
\hline $\mathrm{LiNO}_{3}(0.7854 \mathrm{~g} /$ slice + surfactant $)$ & 0.232 & 0.433 & 0.968 & 15 \\
\hline $\operatorname{LiBr}(0.7854 \mathrm{~g} /$ slice + surfactant $)$ & 0.220 & 0.390 & 0.966 & 15 \\
\hline Surfactant $(1 \%$ of solution) & 0.216 & 0.344 & 0.866 & 12 \\
\hline Control (no treatment) & 0.247 & 0.398 & 0.901 & 12 \\
\hline \multicolumn{5}{|c|}{$\mathrm{NaCl}$} \\
\hline $2.0 \mathrm{lb} / \mathrm{yd}^{3}\left(1.2 \mathrm{~kg} / \mathrm{m}^{3}\right)$ & 0.216 & 0.349 & 0.903 & 18 \\
\hline $5.0 \mathrm{lb} / \mathrm{yd}^{3}\left(3.0 \mathrm{~kg} / \mathrm{m}^{3}\right)$ & 0.240 & 0.408 & 0.978 & 18 \\
\hline $10.0 \mathrm{lb} / \mathrm{yd}^{3}\left(5.9 \mathrm{~kg} / \mathrm{m}^{3}\right)$ & 0.231 & 0.417 & 0.894 & 18 \\
\hline \multicolumn{5}{|c|}{ Thermal-Spray (TS) } \\
\hline No TS Zn & 0.229 & 0.391 & 0.912 & 24 \\
\hline TS Zn & 0.228 & 0.392 & 0.938 & 30 \\
\hline
\end{tabular}

As Table 5.2 shows, there is little difference between samples with or with out TS Zn. There are also no consistent trends with different levels of $\mathrm{Cl}^{-}$in the concrete mix. However, there are trends within the humectant group that seem significant. First, at each RH the slices with just the surfactant treatment all had smaller mass gains than either the controls or the humectant-treated slices. These differences in equilibrated mass gains between the surfactant treated slices and humectant treated slices increased as the RH increased. Secondly, the humectant-treated slices gained less mass than the control slices at a RH of $50 \%$, gained more mass at a $\mathrm{RH}$ of $80 \%$, and gained about the same at a $\mathrm{RH}$ of $70 \%$ (the $\mathrm{LiNO}_{3}$-treated slices gained more than the control and the LiBr-treated slices gained just less than the control). It is as if the humectants need a certain amount of RH to overcome the effects of the surfactant. These results for the humectant group are summarized in Figure 5.36 


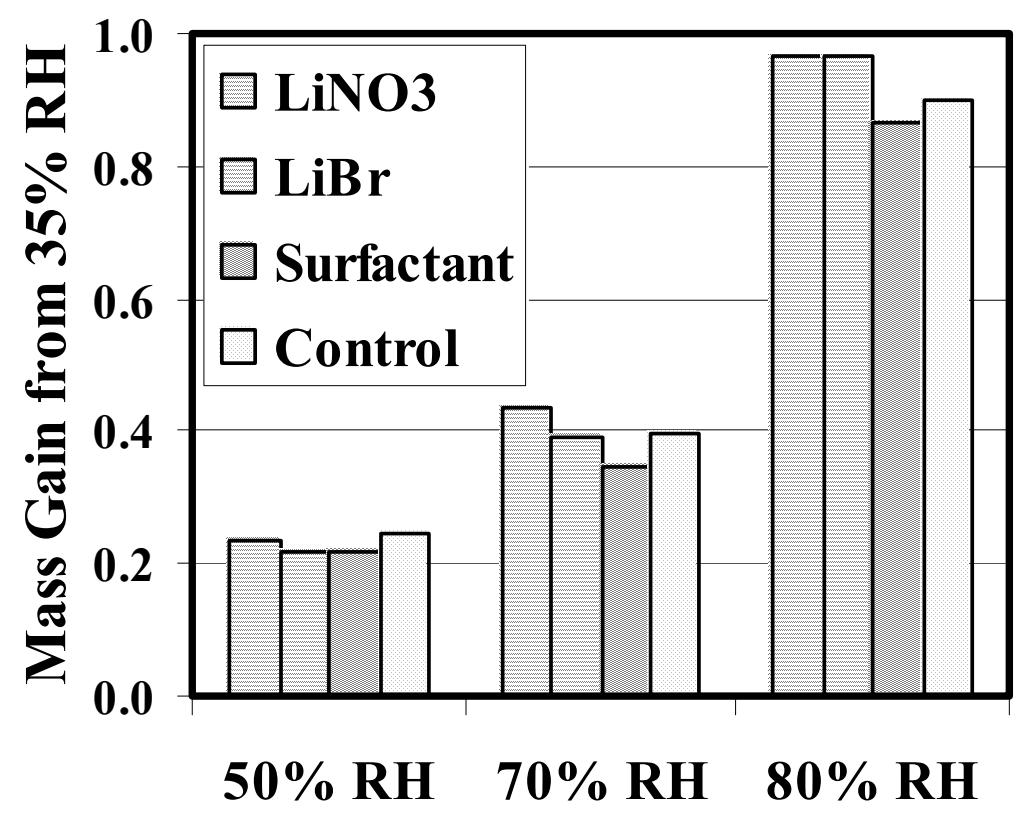

Figure 5.36: Mass gain of slices from an $\mathrm{RH}$ of $35 \%$ at $90^{\circ} \mathrm{F}\left(32.2^{\circ} \mathrm{C}\right)$

A comparison was made between the measured mass gain and the mass gain calculated from the thermodynamics of binary mixtures of humectant and water (Table 3.2). The measured mass gain is found from the mass gain difference in Table 5.2 between humectant-treated slices and surfactant-treated slices. The calculated mass change is found from Equation 5-1:

$$
\text { Calculated MassGain }(g)=\frac{1000 \times 0.7854}{M_{i}}\left(\frac{1}{m_{i}(R H=50,70,80)}-\frac{1}{m_{i}(R H=35)}\right)
$$

Where 0.7854 is the mass (grams) of humectant applied to each slice, $M_{i}$ is the atomic weight of the humectant, and $m_{i}$ is the molality of the humectant at a specific RH (Table 3.2). The results are shown in Table 5.3.

Table 5.3: Measured and calculated mass gain from 35\% RH for $\mathrm{LiNO}_{3}$ and $\mathrm{LiBr}$ humectant-treated slices

\begin{tabular}{c|c|c|c}
\hline CONDITION & $\begin{array}{c}\mathbf{5 0 \%} \mathbf{R H}, \\
\mathbf{g}\end{array}$ & $\begin{array}{c}\mathbf{7 0 \%} \mathbf{R H}, \\
\mathbf{g}\end{array}$ & $\begin{array}{c}\mathbf{8 0 \%} \mathbf{R H}, \\
\mathbf{g}\end{array}$ \\
\hline \multicolumn{5}{|c|}{ Measured Mass Change } \\
\hline $\mathrm{LiNO}_{3}$ & 0.017 & 0.089 & 0.102 \\
\hline $\mathrm{LiBr}$ & 0.005 & 0.046 & 0.100 \\
\hline \multicolumn{5}{|c|}{ Calculated Mass Change } \\
\hline $\mathrm{LiNO}_{3}$ & 0 & 0.188 & 0.603 \\
\hline $\mathrm{LiBr}$ & 0.203 & 0.646 & 1.142 \\
\hline
\end{tabular}


It is clear that the measured and calculated values in Table 5.3 do not agree. This disagreement is from the assumption of a binary humectant-water system used in the calculated mass change. The cement system is much more complicated, with many cement water interactions that already lower the activity of water. Thus, the introduction of the humectant does not lower the activity of water by as much in a binary humectant-water system.

\subsubsection{Circuit Resistance Response to Temperature and Humidity}

The results of applying low current $\left(0.020 \mathrm{~mA} / \mathrm{ft}^{2}\right) \mathrm{ICCP}$ are shown in Figure 5.37 at the end of the five $\mathrm{RH}$ exposure periods. The plots are shown in order starting at the top with the first one tested. The time axis is shown on a log scale to expand the readings at the early portions of the experiment. For all five ICCP periods, the control had a much higher circuit resistance than either of the humectant-treated slabs. The circuit resistances of the humectant-treated slabs had values very close to one another, with the $\mathrm{LiNO}_{3}$-treated slab having slightly lower values. For the $70 \%$ and $80 \% \mathrm{RH}$ periods, and the first hour of the $50 \% \mathrm{RH}$ period, the circuit resistances of the humectant-treated slabs were negative. This suggests that the current level was below what would have been the GCP current level, if the slabs were connected without the power supply. 

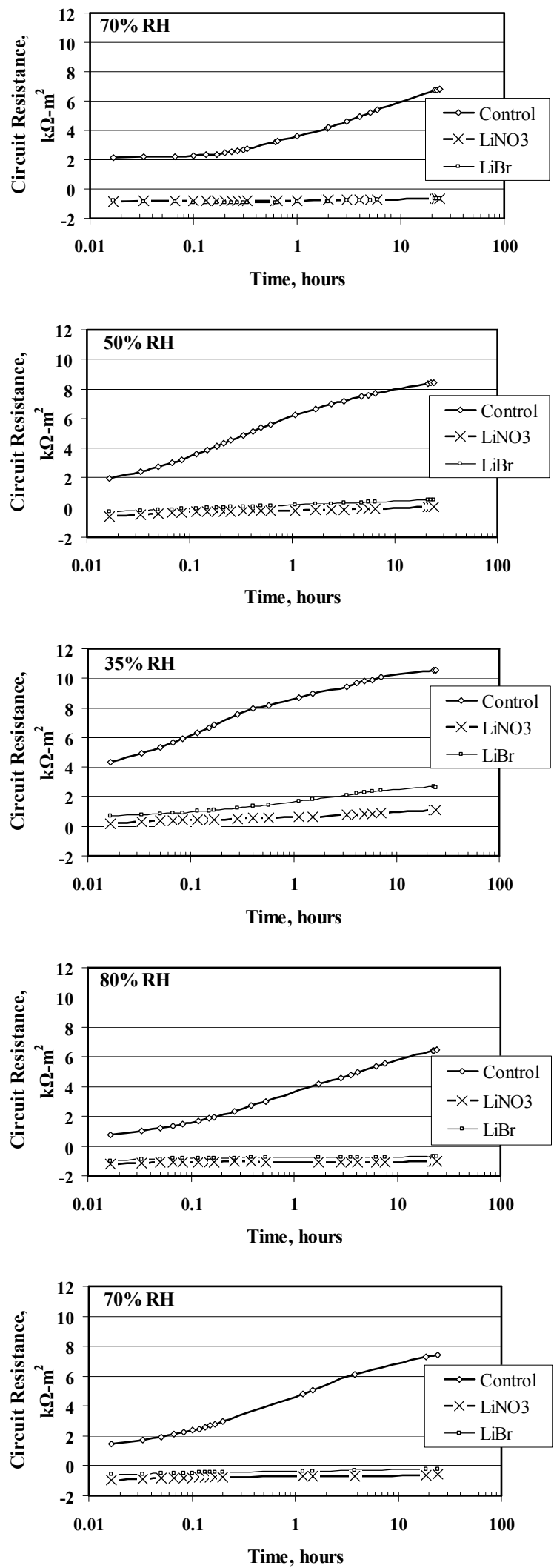

Figure 5.37: Circuit resistance as a function of time for $0.02 \mathrm{~mA} / \mathrm{ft}^{2}$ at $90^{\circ} \mathrm{F}\left(32.2^{\circ} \mathrm{C}\right)$ 
The circuit resistances at the end of each 24-hour ICCP period are shown in Figure 5.38 as a function of RH. Circuit resistance decreases with increasing RH. The control and both humectant-treated slabs show the same general trends, but with the humectant-treated slabs having much lower circuit resistances.

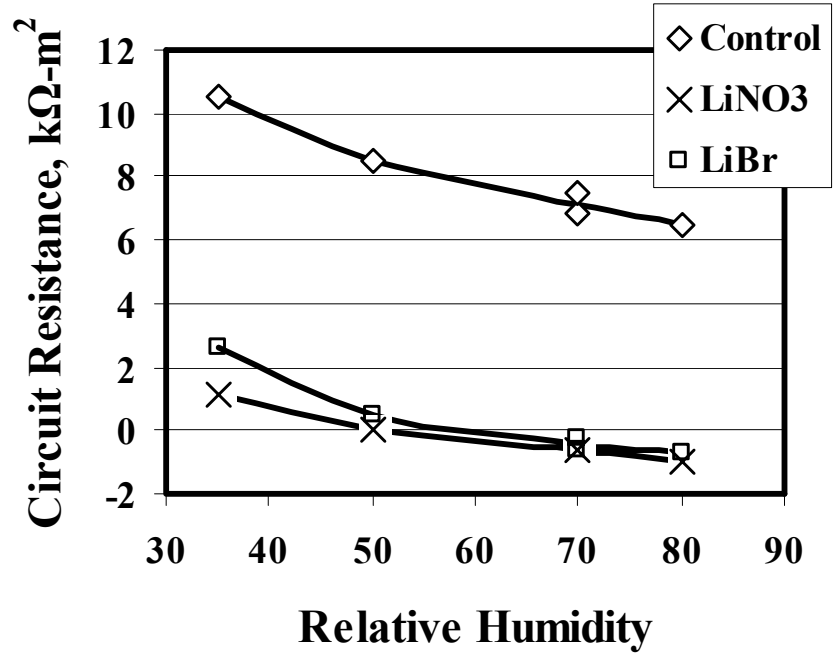

Figure 5.38: Circuit resistance after 24 hours of $0.02 \mathrm{~mA} / \mathrm{ft}^{2} \mathrm{ICCP}$ at $90^{\circ} \mathrm{F}\left(32.2^{\circ} \mathrm{C}\right)$

\subsection{LONG-TERM LABORATORY GCP EXPERIMENTS (OHIO)}

\subsubsection{Original Blocks with $3.0 \mathrm{~kg} / \mathrm{m}^{3}\left(5.11 \mathrm{~b} / \mathrm{yd}^{3}\right)$ of $\mathrm{NaCl}$}

Galvanic current delivered by the untreated control blocks at 55\% RH dropped to almost zero current within 3 weeks, Figures 5.39a and 5.40a. These blocks delivered virtually no protective current to the embedded steel. Galvanic current delivered by the blocks treated with potassium acetate dropped to nearly zero in less than 100 days, Figure 5.39a. Block 19, which was retreated with potassium acetate after 230 days, experienced only a brief increase in current. Galvanic current delivered by the lithium nitrate treated blocks, Figure 5.39a, remained relatively high initially (about $1 \mathrm{~mA} / \mathrm{m}^{2}$ after 6 months), dropping to 0.2 to $0.5 \mathrm{~mA} / \mathrm{m}^{2}$ after 720 days on line. Current delivered by the retreated block remained the highest throughout the test period. Galvanic current delivered by the lithium bromide treated blocks, Figure 5.40a, was also relatively high initially, but dropped to near zero after one year on line. This holds true except for current delivered by the retreated block, which was still at $0.5 \mathrm{~mA} / \mathrm{m}^{2}$ after 720 days. Performance in the $55 \%$ RH environment was as follows: $\mathrm{LiNO}_{3}>\mathrm{LiBr}>>\mathrm{KC}_{2} \mathrm{H}_{3} \mathrm{O}_{2}>$ Control. 

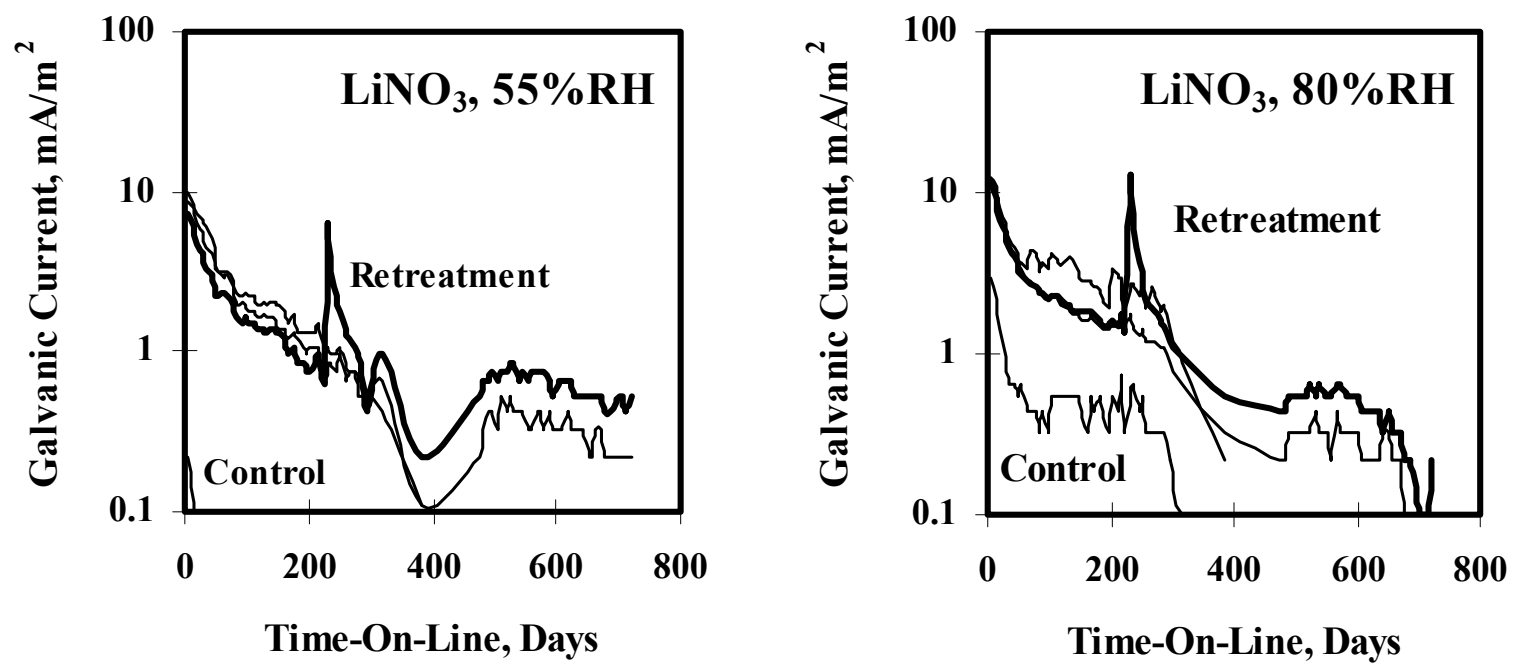

Figure 5.39: Galvanic current for $\mathrm{LiNO}_{3}$-treated blocks with $3.0 \mathrm{~kg} / \mathrm{m}^{3}\left(5.1 \mathrm{lb} / \mathrm{yd} \mathrm{d}^{3}\right) \mathrm{NaCl}$. Retreatment of one block after about 200 days (shown in bold). The environments were a) $55 \% \mathrm{RH}$ (left) and b) $80 \% \mathrm{RH}$ (right).

In the $80 \%$ RH environment, the untreated control blocks (Figures $5.39 \mathrm{~b}$ and $5.40 \mathrm{~b}$ ) were able to maintain a higher galvanic current at first (about $0.4 \mathrm{~mA} / \mathrm{m}^{2}$ up to 300 days), but after one year current had dropped to essentially zero. Current delivered by the potassium acetate treated blocks was higher than the control blocks at first, but approached that of the control blocks after approximately 250 days on line, Figure A5.39b. After nearly 300 days on line, the metallized $\mathrm{Zn}$ treated with $\mathrm{KC}_{2} \mathrm{H}_{3} \mathrm{O}_{2}$ began to delaminate and operation of those blocks was discontinued. Galvanic current delivered by the $\mathrm{LiNO}_{3}$-treated blocks (Figure 5.39b), was much higher than the control blocks (about $1.5 \mathrm{~mA} / \mathrm{m}^{2}$ after 250 days), and remained significant throughout most of the test period. Only after 700 days did the current decrease to near zero. The LiBr-treated blocks (Figure 5.40b), were the best performers in the $80 \%$ RH environment (about $2 \mathrm{~mA} / \mathrm{m}^{2}$ after 250 days), and were still delivering 0.4 to $0.8 \mathrm{~mA} / \mathrm{m}^{2}$ at the conclusion of the 720 -day test. Performance in the $80 \%$ RH environment was as follows: $\mathrm{LiBr}>\mathrm{LiNO}_{3}>\mathrm{KC}_{2} \mathrm{H}_{3} \mathrm{O}_{2}>>$ Control. 

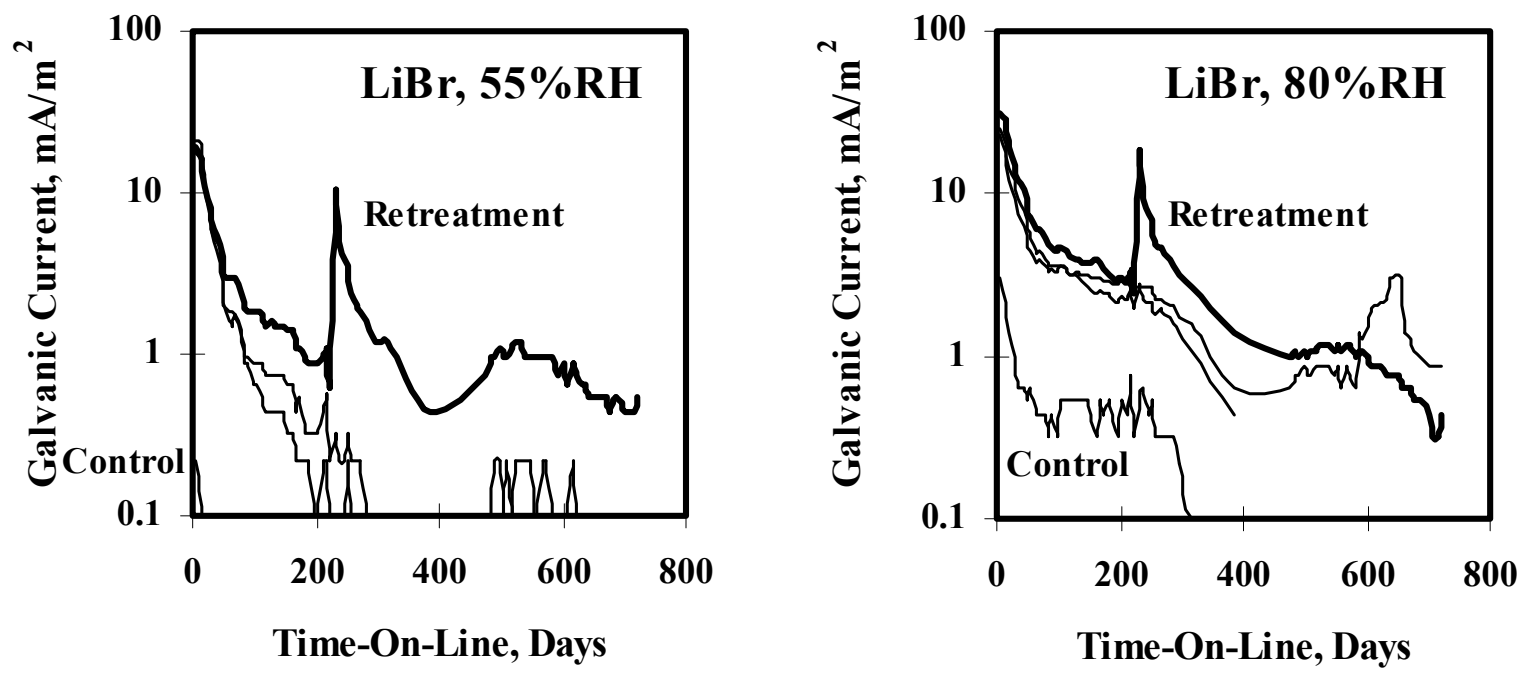

Figure 5.40: Galvanic current for LiBr-treated blocks with $3.0 \mathrm{~kg} / \mathrm{m}^{3}\left(5.1 \mathrm{lb} / \mathrm{yd}^{3}\right) \mathrm{NaCl}$. Retreatment of one block after about 200 days (shown in bold). The environments were a) 55\% RH (left) and b) $80 \%$ RH (right).

Performance in the outdoor environment (Figure 5.41) was very irregular due to excursions in temperature, humidity, and moisture content. Current irregularities were most pronounced for the untreated control blocks. The LiBr-treated blocks delivered the highest galvanic current while outdoors, both for the covered blocks and for those with direct exposure. Current delivered by the outdoor LiBr-treated blocks remained well above $1 \mathrm{~mA} / \mathrm{m}^{2}$ throughout the 500day test period. Current delivered by the $\mathrm{LiNO}_{3}$-treated blocks also remained well above the level delivered by the control blocks, with exception for those with direct exposure for which current dropped to near zero at the end of the test. Performance in the outdoor environment was: $\mathrm{LiBr}>\mathrm{LiNO}_{3}>$ Control (except after 350 days, for which $\mathrm{LiBr}>$ Control $>\mathrm{LiNO}_{3}$ ). 

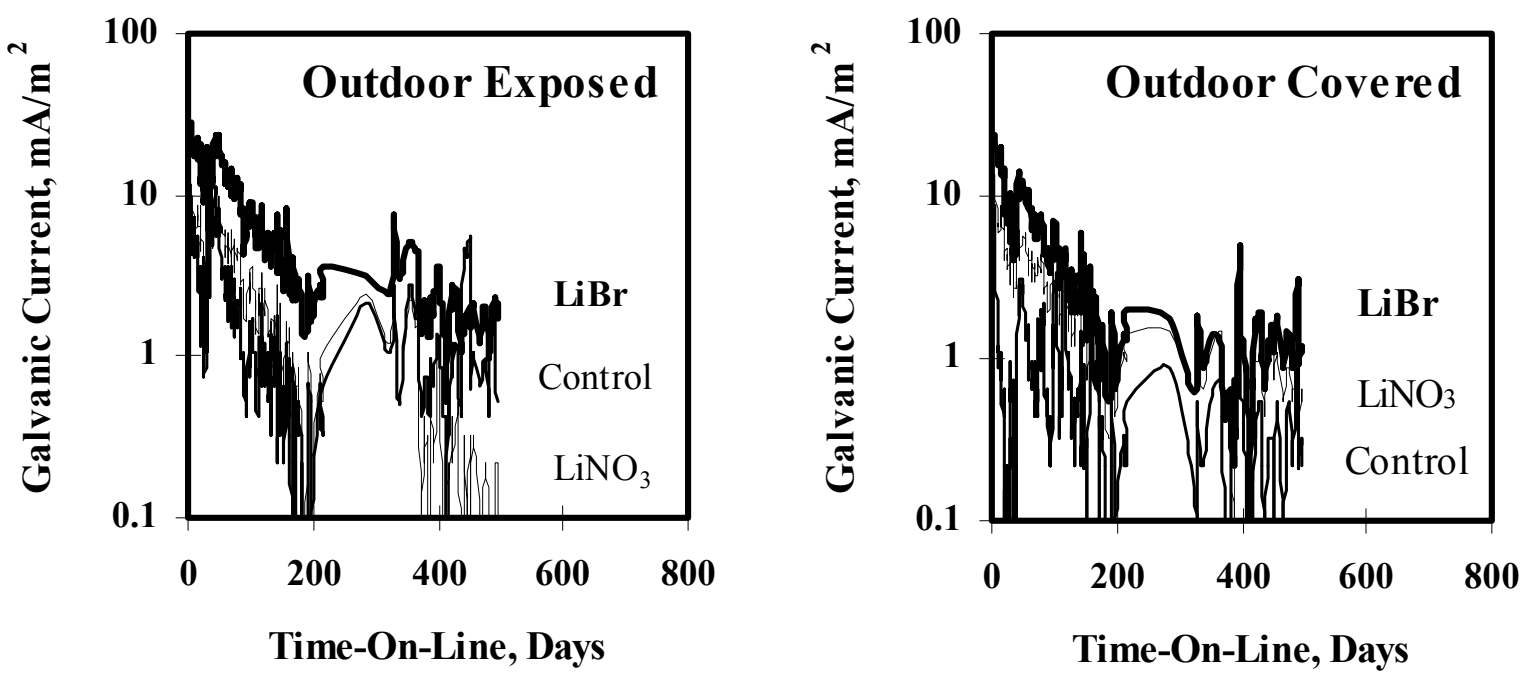

Figure 5.41: Galvanic current for humectant-treated blocks with $3.0 \mathrm{~kg} / \mathrm{m}^{3}\left(5.1 \mathrm{lb} / \mathrm{yd}^{3}\right) \mathrm{NaCl}$. The environments outdoors in the Cleveland Ohio area in a) Exposed (left) and b) Covered (right) conditions.

\subsubsection{Additional Blocks with 4.9, 7.3 and $9.8 \mathrm{~kg} / \mathrm{m}^{3}$ of $\mathrm{NaCl}$}

In the 55\% RH environment (Figure 5.42), galvanic current for the untreated control blocks constructed with $4.9,7.3$, and $9.8 \mathrm{~kg} / \mathrm{m}^{3}\left(8.2,12.4\right.$, and $\left.16.5 \mathrm{lb} / \mathrm{yd}^{3}\right)$ of $\mathrm{NaCl}$ still decreased to nearly zero in less than 50 days while on-line at $55 \% \mathrm{RH}$. Blocks constructed with 4.9 and 7.3 $\mathrm{kg} / \mathrm{m}^{3}$ of $\mathrm{NaCl}$ and treated with $\mathrm{LiNO}_{3}$ or $\mathrm{LiBr}$ solutions behaved similarly to those in the original study with $3.0 \mathrm{~kg} / \mathrm{m}^{3}$ of NaCl . Current was approximately 0.8 to $1 \mathrm{~mA} / \mathrm{m}^{2}$ at the end of the 250-day test period. Treated blocks constructed with $9.8 \mathrm{~kg} / \mathrm{m}^{3}$ of $\mathrm{NaCl}$ delivered approximately $20 \%$ higher current in the 55\% RH environment. Performance for the high $\mathrm{Cl}^{-}$ blocks in the $55 \% \mathrm{RH}$ environment was: $\mathrm{LiBr}=\mathrm{LiNO}_{3}>>$ Control.

In the $80 \%$ RH environment (Figure 5.43), galvanic current for the untreated control blocks constructed with higher chloride content was much greater, increasing significantly with $\mathrm{Cl}^{-}$ content. In fact, the untreated control block with $9.8 \mathrm{~kg} / \mathrm{m}^{3}$ of NaCl was still producing 0.6 $\mathrm{mA} / \mathrm{m}^{2}$ of current after 250 days. In this case, the $\mathrm{Cl}^{-}$admixture itself is acting as a humectant to increase protective current. Nevertheless, the $\mathrm{LiNO}_{3}$ - and $\mathrm{LiBr}$-treated blocks still delivered much higher current than the untreated controls, particularly early in the test period.

Performance for the high $\mathrm{Cl}^{-}$blocks in the $80 \% \mathrm{RH}$ environment was: $\mathrm{LiBr}=\mathrm{LiNO}_{3}>>$ Control.

In the outdoor environment (Figure 5.44), both $\mathrm{LiBr}$ - and $\mathrm{LiNO}_{3}$-treated blocks delivered significantly higher current than the untreated control blocks. Galvanic current delivered by the treated blocks was much more consistent, whereas current for the untreated control blocks cycled wildly with changes in moisture content. As noted for the $80 \% \mathrm{RH}$ environment, the untreated control block with $9.8 \mathrm{~kg} / \mathrm{m}^{3}$ of $\mathrm{NaCl}$ delivered significantly higher current than control blocks 
with lower $\mathrm{Cl}^{-}$content. Performance for the high $\mathrm{Cl}^{-}$blocks in the outdoor environment was: $\mathrm{LiBr}=\mathrm{LiNO}_{3}>>$ Control.

Comparisons of the $55 \%$ and $80 \% \mathrm{RH}$ environments as a function of the $\mathrm{NaCl}$ content are found in Figure 5.45. For this comparison, average galvanic currents are used from 150 to 250 days of time on-line. Data for the same time period range, with $\mathrm{NaCl}$ contents of $3.0 \mathrm{~kg} / \mathrm{m}^{3}\left(5.1 \mathrm{lb} / \mathrm{yd}^{3}\right)$, as shown in Figures 5.39 and 5.40, are also included. This comparison shows that the presence of humectants, and the $\mathrm{RH}$ of the environment influence the mean galvanic current much more than the $\mathrm{Cl}^{-}$level in the concrete. 

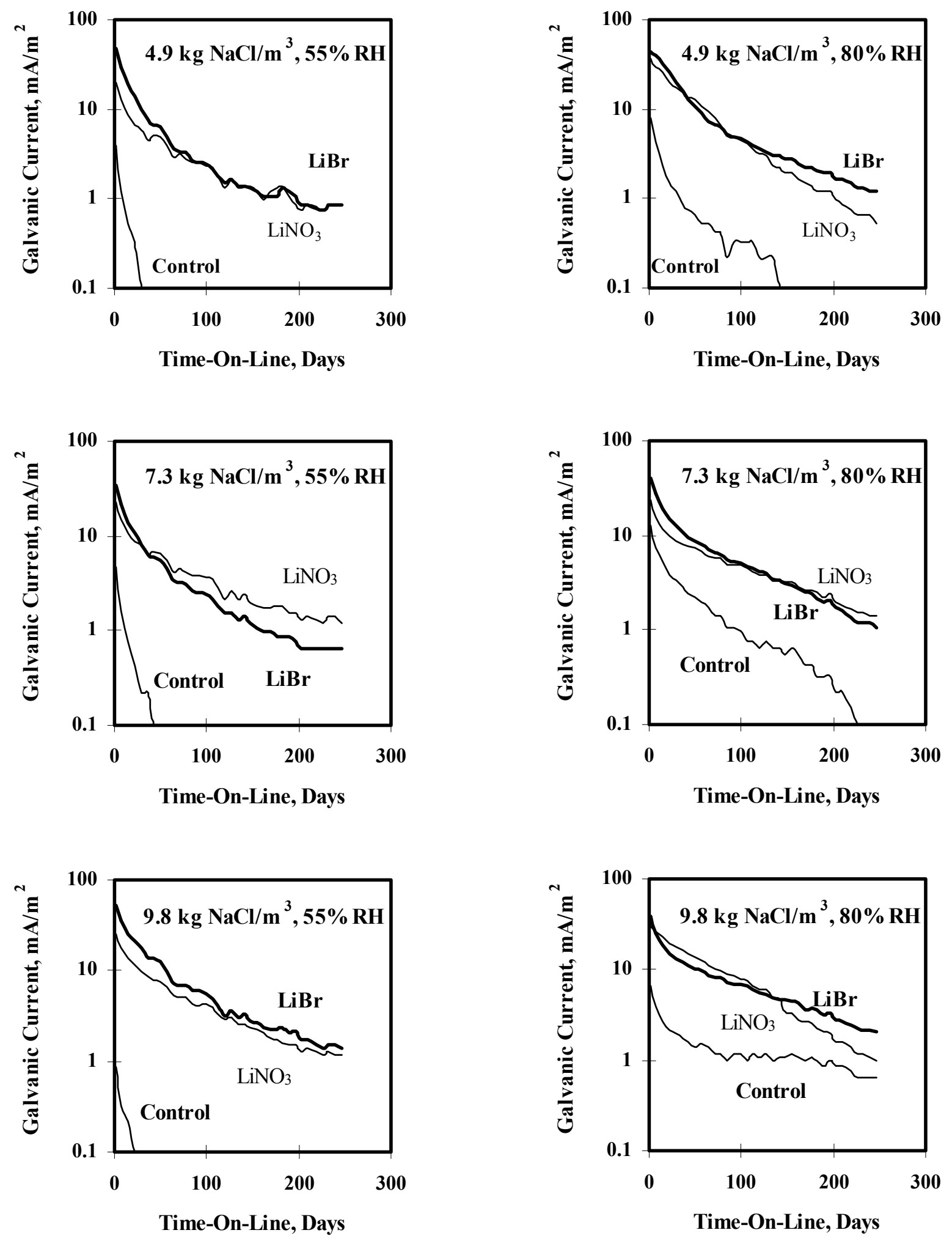

Figure 5.42: Galvanic currents for blocks with 4.9, 7.3 , and $9.8 \mathrm{~kg} / \mathrm{m}^{3} \mathrm{NaCl}$ in $55 \% \mathrm{RH}$ conditions

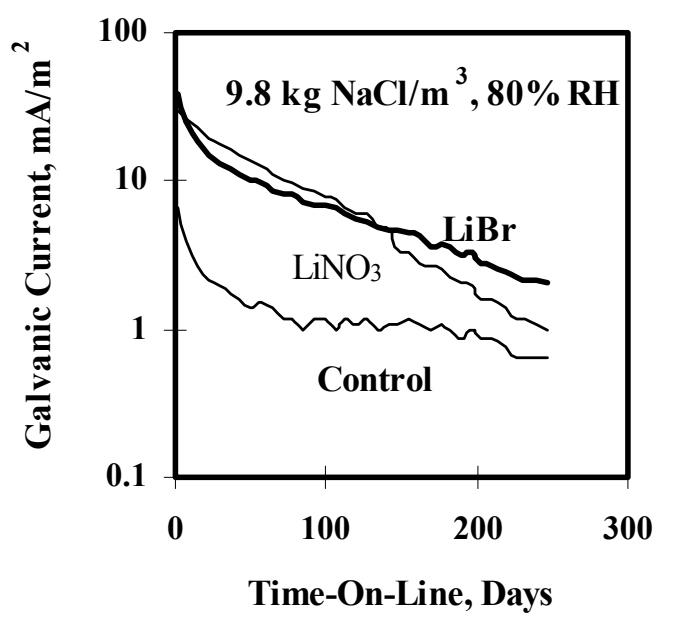

Figure 5.43: Galvanic currents for blocks with 4.9, 7.3 , and $9.8 \mathrm{~kg} / \mathrm{m}^{3} \mathrm{NaCl}$ in $80 \% \mathrm{RH}$ conditions 

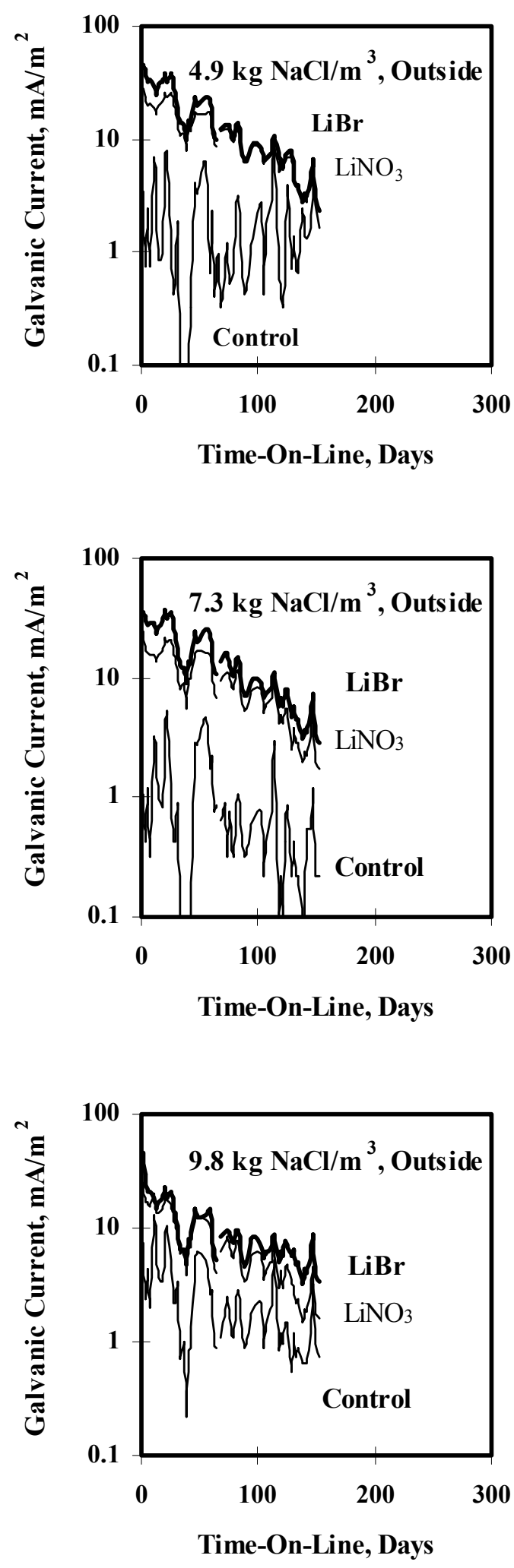

Figure 5.44: Galvanic currents for blocks with 4.9, 7.3, and $9.8 \mathrm{~kg} / \mathrm{m}^{3} \mathrm{NaCl}$ in covered outdoor exposures 


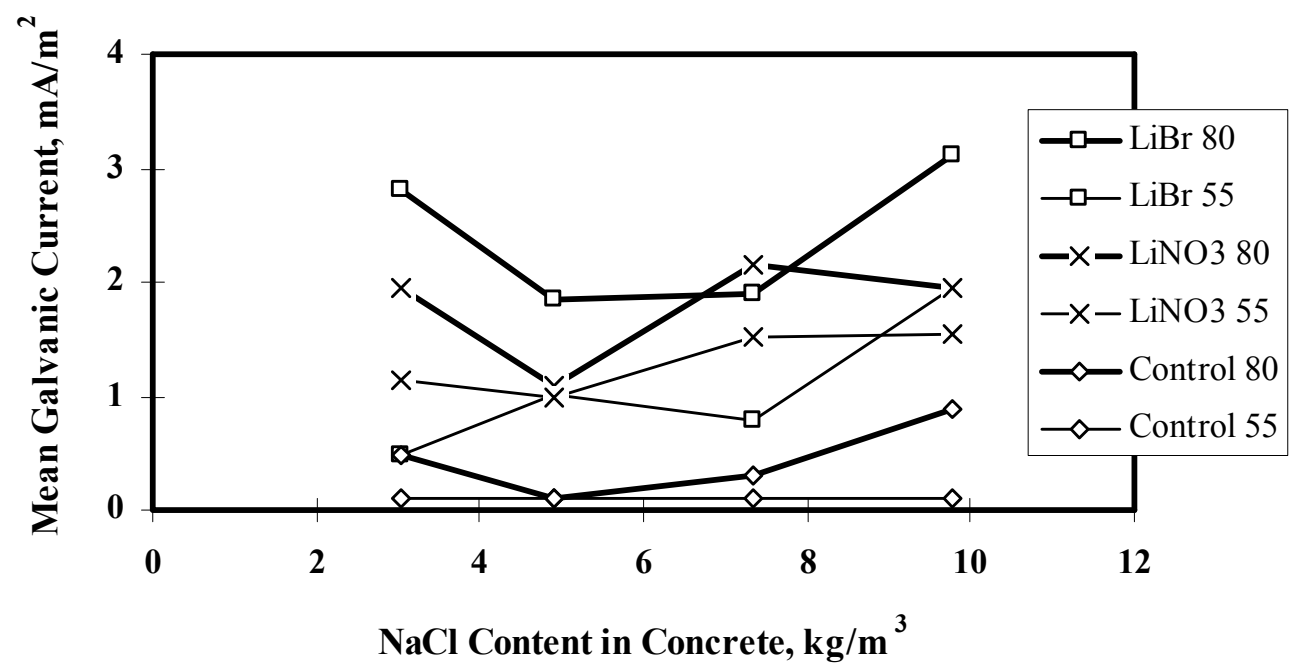

Figure 5.45: Mean galvanic currents (over 150-240 days) as a function of concrete $\mathrm{NaCl}$ contents

\subsection{YAQUINA BAY BRIDGE FIELD EXPERIMENT}

\subsubsection{Chloride Depth Profiling}

The results from chloride profiling, prior to humectant application, for the soffits of the four ICCP test zones are shown in Figure 5.46. All of the profiles show the diffusion of $\mathrm{Cl}^{-}$in from the concrete surface. Zones 11, 13, and 14 show the effects of washing at the surface, a decrease in $\mathrm{Cl}^{-}$concentration right at the surface. Figure 5.46 also shows an increase in $\mathrm{Cl}^{-}$levels, the closer the zone is to the ocean. All four zones have $\mathrm{Cl}^{-}$concentrations above the corrosion threshold to a depth of at least $4 \mathrm{~cm}$ (1.6 inches). 


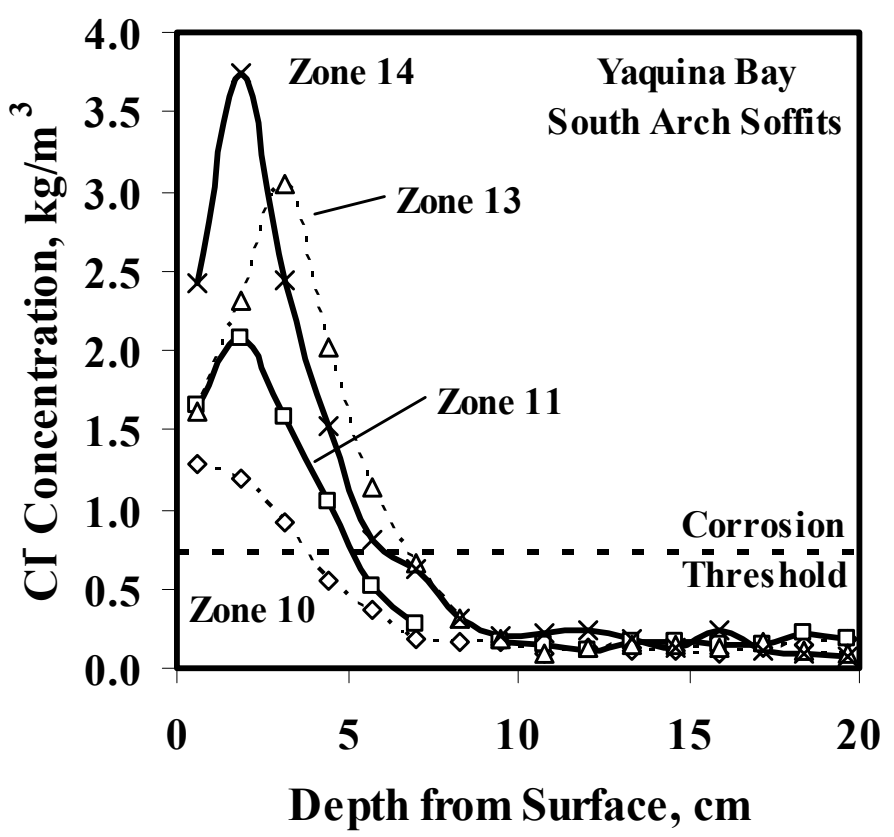

Figure 5.46: Chloride profiles from the soffits of the four ICCP test zones on the Yaquina Bay Bridge south arches

The results from chloride profiling on the west side base, of Bent $3 \mathrm{~N}$, on the north part of the Yaquina Bay Bridge are shown in Figure 5.47. The contrast between the north and south faces in Figure 5.47, illustrates the strong effect precipitation washing has on reducing chloride levels in the concrete. There is greater washing from the prevailing late fall and winter rains, on the more exposed south face, than on the more sheltered north face. The chloride levels are substantially lower on the south face compared to the north face. 


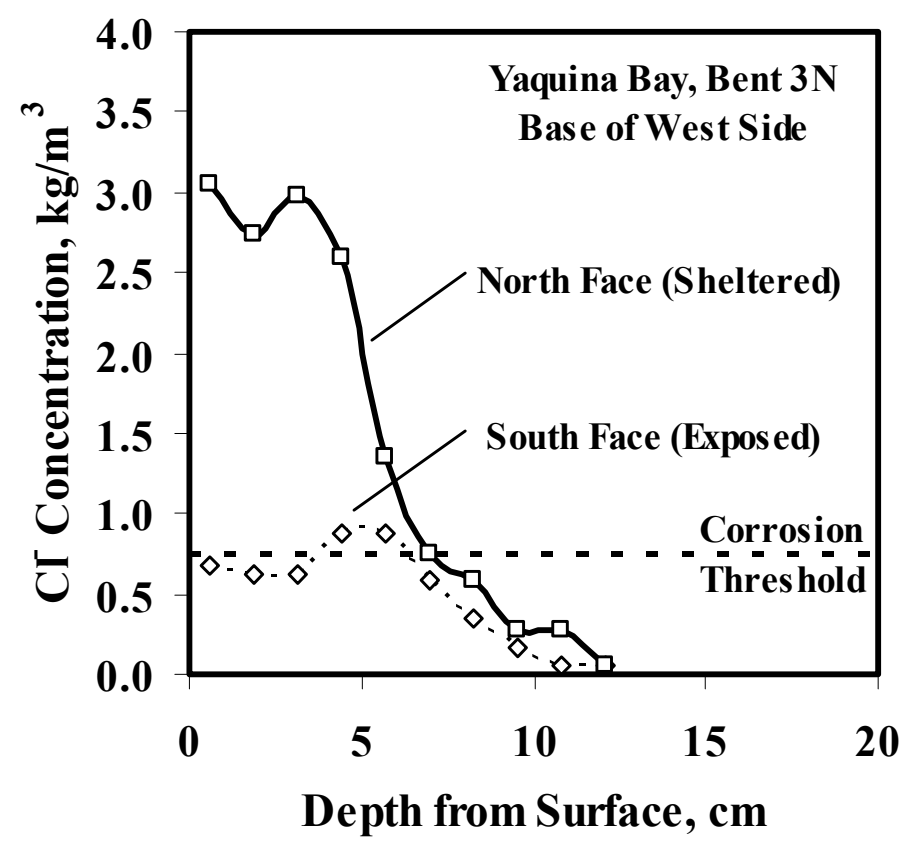

Figure 5.47: Chloride profiles from the west side of the base of bent $3 \mathrm{~N}$ on the north side of the Yaquina Bay Bridge

Figures 5.46 and 5.47 show the differences in chloride levels and washing effects that can occur on the same structure. This is consistent with results from other bridges on the Oregon coast (Cramer, et al. 2002b). Presumably, washing effects would also be found in humectant-treated zones where a multitude of microclimates exist. Washing effects would then affect the frequency of humectant reapplications.

The profiles in Figure 5.46 were examined with Fick's First Law, for the 63-year-old concrete to obtain effective diffusion coefficients, $D$, and surface $\mathrm{Cl}^{-}$concentrations (without the washing decrease), $C_{o}$. The results are in Table 5.4. These values are generally lower than those found on either the Rocky Point Viaduct or the Brush Creek Bridge (Cramer, et al. 2002b). The differences arise because the concrete at the bridges have different properties (different $D$ values) and the deposition of salt on the concrete surface is different in each microclimate (different $C_{o}$ values).

Table 5.4: Diffusion parameters for the ICCP field test zones on the Yaquina Bay Bridge

\begin{tabular}{c|c|c|c|c}
\hline ICCP Zone & Distance to Bay, $\mathbf{m}$ & $\mathbf{C}_{\mathbf{0}}, \mathbf{~} \mathbf{~ g ~ C l} / \mathbf{m}^{\mathbf{3}}$ & $\mathbf{C}_{\mathbf{0}} \mathbf{a}, \mathbf{~ k g ~ N a C l} / \mathbf{m}^{\mathbf{3}}$ & $\mathbf{D}, \mathbf{~ m}^{2} / \mathbf{s}$ \\
\hline 10 & 131 & 1.67 & 2.75 & $7.03 \times 10^{-9}$ \\
\hline 11 & 113 & 3.34 & 5.51 & $4.86 \times 10^{-9}$ \\
\hline 13 & 94 & 6.63 & 10.93 & $4.50 \times 10^{-9}$ \\
\hline 14 & 73 & 5.41 & 8.92 & $4.49 \times 10^{-9}$ \\
\hline
\end{tabular}

${ }^{\mathrm{a}}$ Assuming all of the $\mathrm{Cl}^{-}$was from $\mathrm{NaCl}$. 


\subsubsection{Microscopy}

SEM photomicrographs and x-ray maps of the anode-concrete cross-sections, exposed in core samples taken from CP Zones, 10,11,13, and 14, showed many of the same features as seen in earlier work (Covino, et al. 2002) and in the long-term laboratory experiments (Section 5.1, Figures 5.18-5.25). These include mineral zones representing the unreacted anode, a reaction zone containing anode dissolution products, and the unaltered cement paste. The reaction zone can be further divided into three subzones or regions: 1) a growing mineral layer characterized largely as $\mathrm{ZnO}$ or $\mathrm{Zn}(\mathrm{OH})_{2}$ adjacent to the $\mathrm{Zn}$ anode, 2) a calcium-depleted, Zn-rich layer formed within the cement paste, and 3) cement paste containing low levels of $\mathrm{Zn}$. These features are a consequence of the anode reaction and the consequent acidification of the anode-concrete interface, as well as the complex mineral interaction between the anode dissolution products, moisture, and the cement paste.

ASEM line scans for anode-concrete interfaces from Zones 10,11,13, and 14, are shown in Figures 5.48-5.51. The results are for cores taken from the zones immediately after humectant treatment (10-22-99). In terms of general features, the line scan for Zone 10, representing the driest environment, shows a sharply defined interface with little secondary mineralization, as would be indicated by a more complex mineral structure at the interface. Moving towards Zone 14 , the $\mathrm{Zn}$ mineral structure at the interface broadens and becomes more varied, with evidence of a $\mathrm{ZnO}$ layer and $\mathrm{Zn}$ diffused into the cement paste. The reaction zone width increases substantially, moving from Zone 10 to Zone 14 . The trend in reaction zone widths is similar to that for the chloride profiles (Figure 5.46), and $\mathrm{C}_{\mathrm{o}}$ values (Table 5.4): the closer to the bay, the greater the impact that moisture and salt deposition have on zone properties, which can affect the service life of the structure and the $\mathrm{CP}$ zone. 


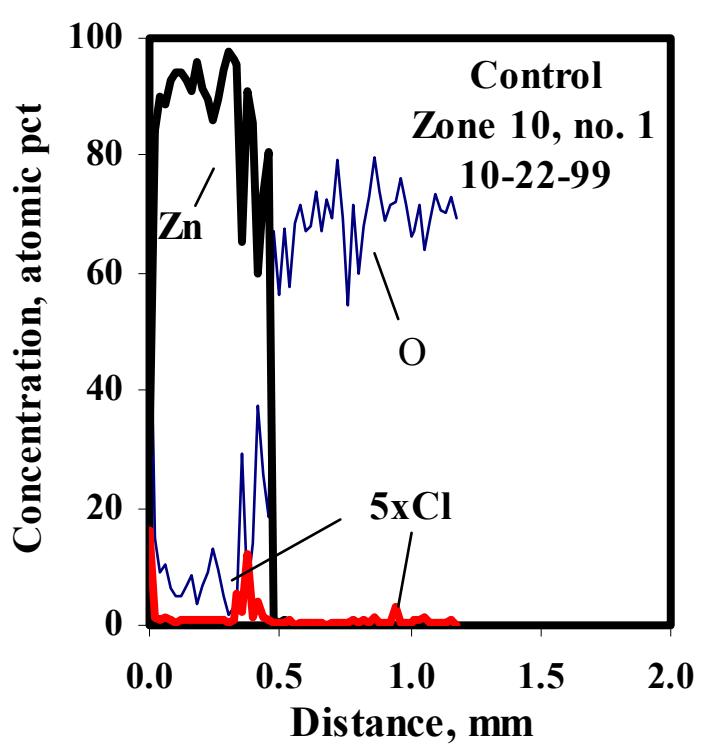

Figure 5.48: X-ray line scans across a cross-section of control Zone 10 of the Yaquina Bay Bridge, immediately after humectant application of bridge zones.

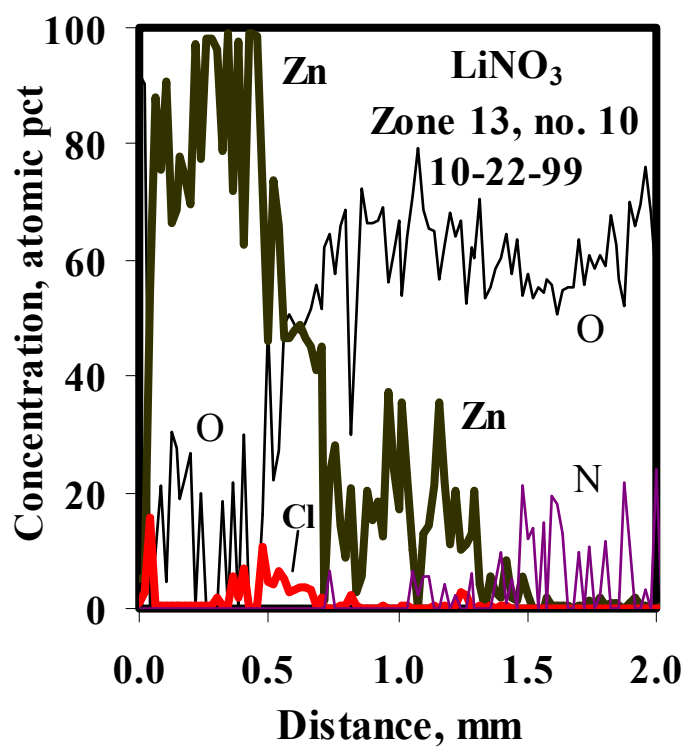

Figure 5.50: X-ray line scans across a cross-section of $\mathrm{LiNO}_{3}$-treated Zone 13 of the Yaquina Bay Bridge, immediately after humectant application.

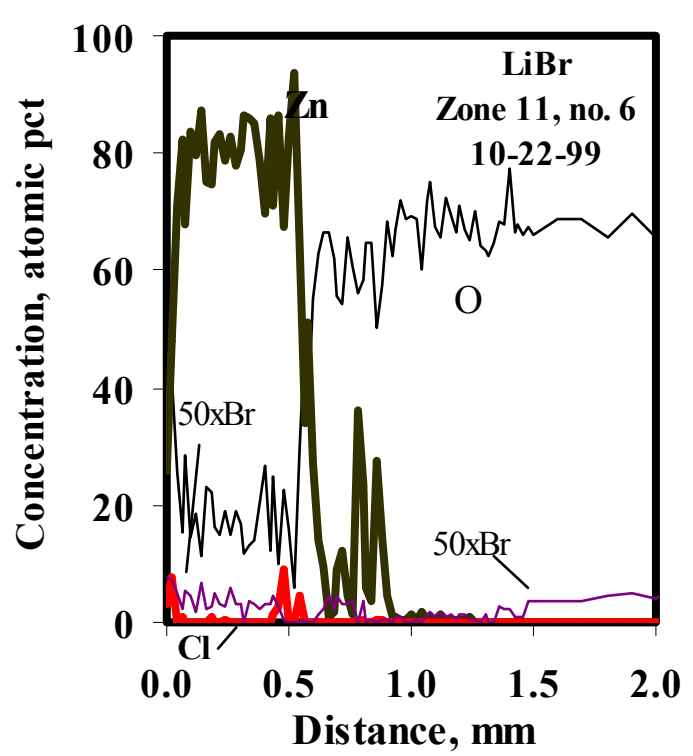

Figure 5.49: X-ray line scans across a cross-section of LiBr-treated Zone 11 of the Yaquina Bay Bridge, immediately after humectant application.

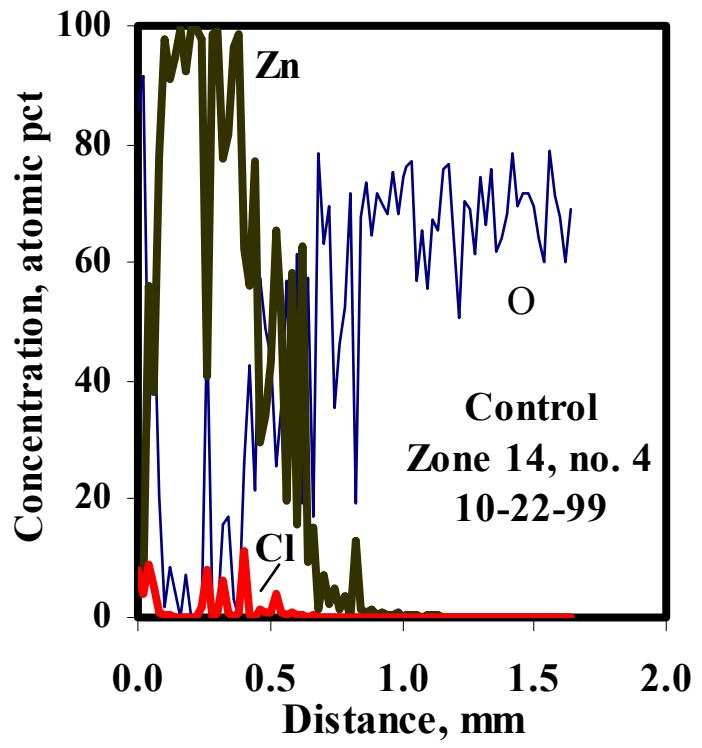

Figure 5.51: X-ray line scans across a cross-section of control Zone 14 of the Yaquina Bay Bridge, immediately after humectant application to bridge zones. 
Figures 5.48-5.51 all provide evidence that $\mathrm{Cl}^{-}$accumulate at the anode-concrete interface, most likely as a zinc hydroxylchloride (Covino, et al. 2002). The lowest $\mathrm{Cl}^{-}$levels at the anodeconcrete interface were in zone 10, where there was less moisture to aid penetration of $\mathrm{Cl}^{-}$into and transport them through the concrete.

Figure 5.49 for Zone 11 contains a curve for the $\mathrm{Br}_{\beta}$ line. Analysis of the spectra for the $\mathrm{KBr}$ standard and for the Zone 11 cross-section indicates that the values shown represent background. The levels of $\mathrm{Br}$ in the core sample from Zone 11 are not detectable by the sample preparation and analytical methods used. Consequently, the Br curve in Figure 5.52 also represents background. There were no significant changes between the line scans for the as-treated sample (Figure 5.49), and the aged sample (Figure 5.52). This suggests little modification of the anodeconcrete interfacial chemistry by the presence of the LiBr humectant for Zone 11. Chloride accumulation at the interface was greater for the aged sample. The zone representing zinc oxide was also broadened, which could be interpreted as evidence of increased ion mobility. However, sampling statistics (there was only one as-treated and one aged sample examined) suggest caution in generalizing this result.

Figure 5.50, for Zone 13, contains a curve for the $\mathrm{N} \mathrm{K}_{\alpha}$ line. Analysis of the spectra for the BN standard and for the Zone 13 cross-section indicates that the values shown are real. They also indicate the presence of $\mathrm{LiNO}_{3}$ in the cement paste. The line scan for the aged sample (Figure 5.53) also indicates the presence of $\mathrm{LiNO}_{3}$, but at a substantially reduced level. This would suggest that $\mathrm{LiNO}_{3}$ was leached from the sample over the course of the roughly 2-year aging experiment. In other respects, the line scans for the as-treated and aged samples were similar.

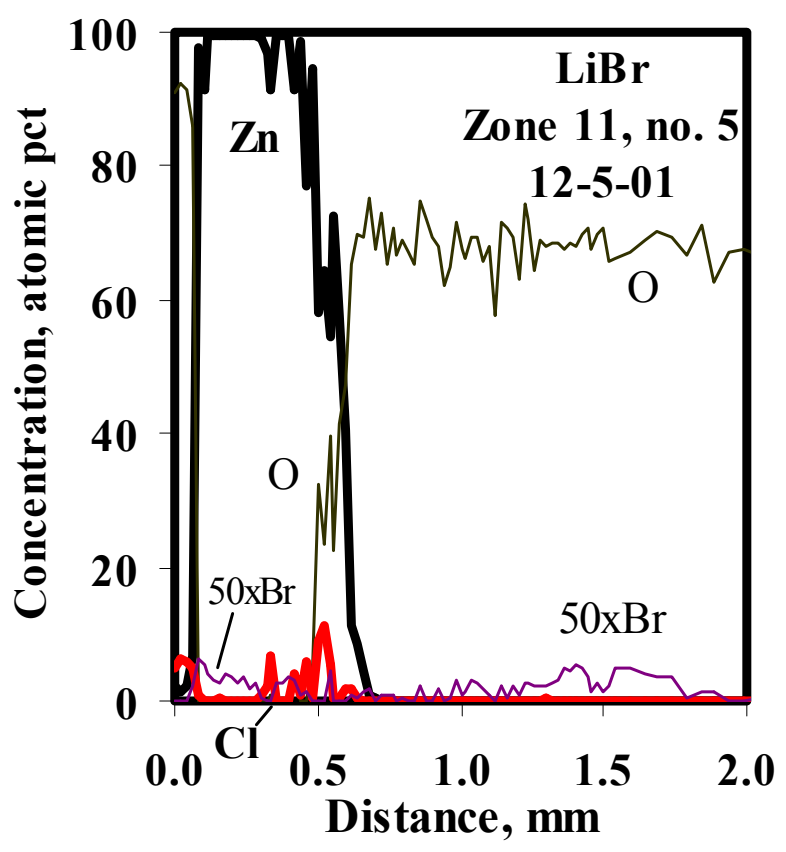

Figure 5.52: X-ray line scans across a cross-section of LiBr-treated Zone 11 of the Yaquina Bay Bridge, after 2 years of ICCP. 


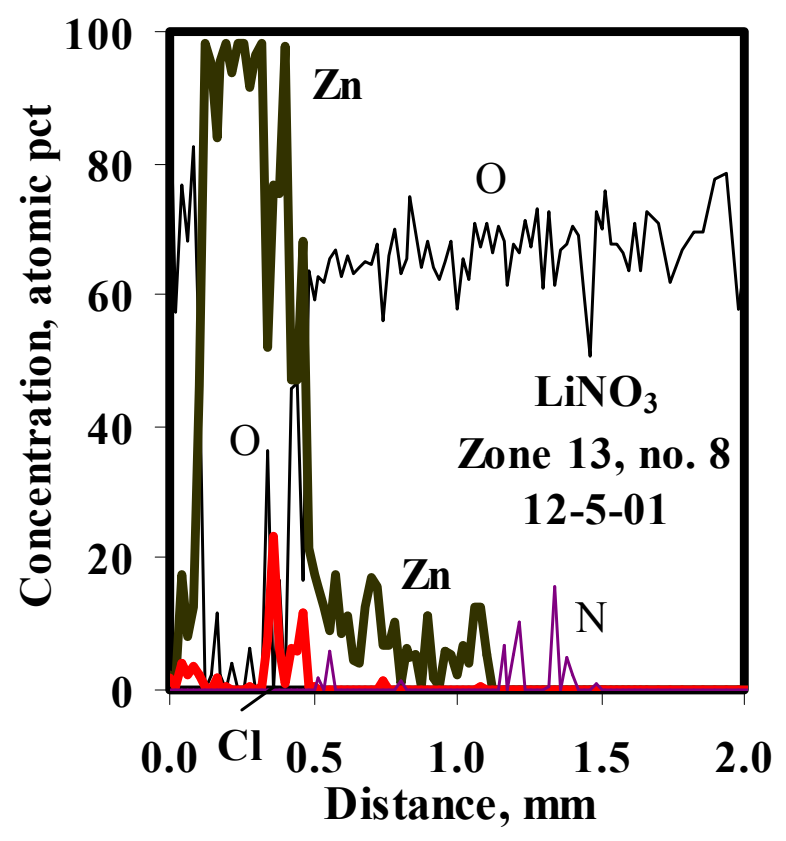

Figure 5.53: X-ray line scans across a cross-section of $\mathrm{LiNO}_{3}$-treated Zone 13 of the Yaquina Bay Bridge, after 2 years of ICCP.

\subsubsection{Operation}

The operating data, in terms of circuit resistance, for the Yaquina Bay Bridge field trial are shown in Figure 5.54. During the field trial there were gaps in the collection of data and significant changes in the current level. As a result, Figure 5.54 is broken down into six time periods (I-VI). 


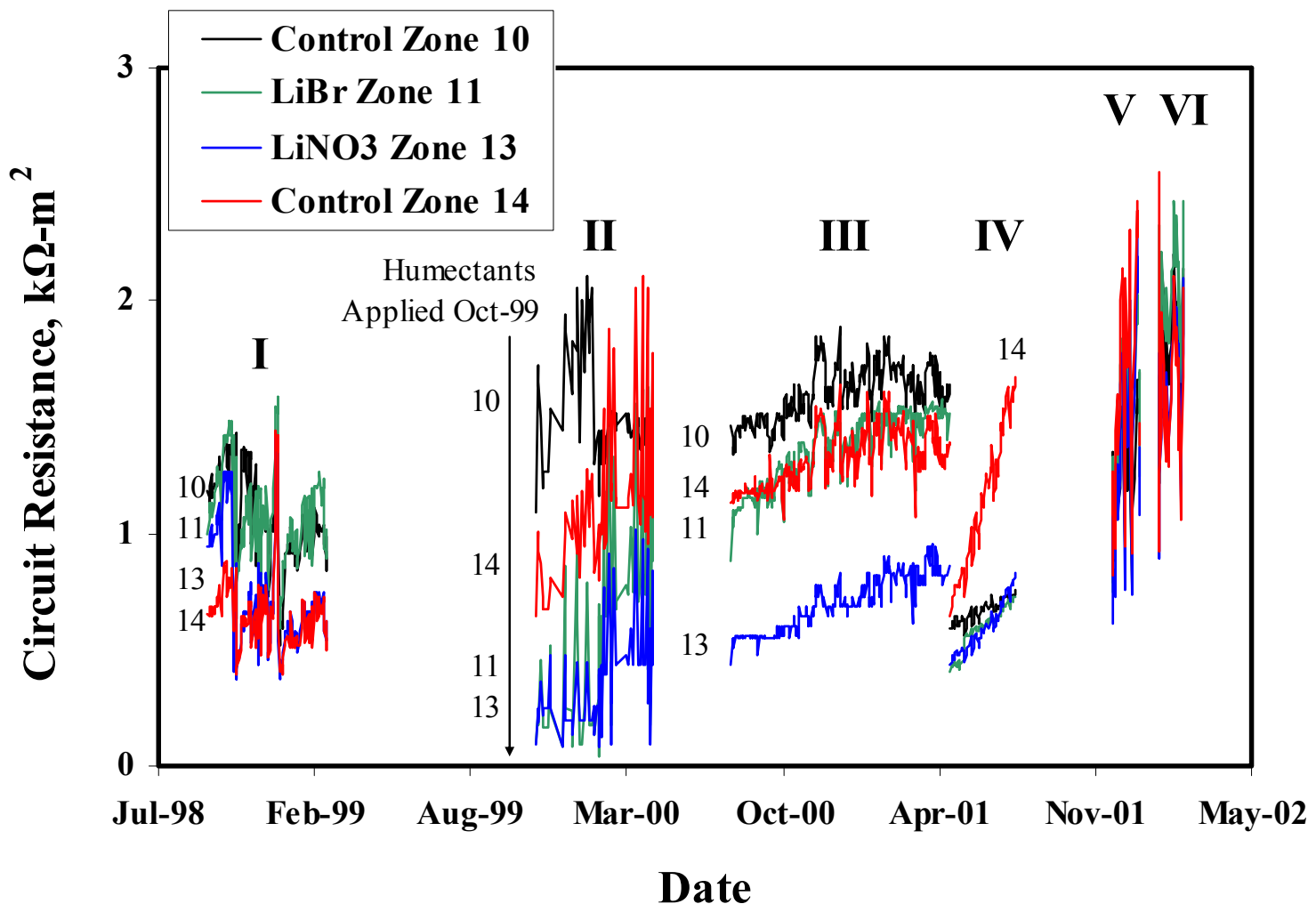

Figure 5.54: Circuit resistance data from the Yaquina Bay Bridge field trial

Period I was prior to humectant application. Periods II and III were after humectant application and were at a nominal current density of $2.2 \mathrm{~mA} / \mathrm{m}^{2}$. The difference in the noise between II and III results from the number of decimal places with which the voltage and current data were stored (the "ON" and "SRP" data as described in Section 4.4.5). Period II data was stored with only 1 voltage and 2 current decimal places; period III data was stored with 4 decimal places for both voltage and current. Due to this variation, the Period II data shows much more noise in circuit resistance. During Periods IV and V the nominal current density jumped up to $13 \mathrm{~mA} / \mathrm{m}^{2}$. The increase was a result of failures in the potentiometers in the rectifiers, which caused the voltages and currents to drift upward. The ICCP zones were at this accelerated level for approximately 8 months, which resulted in premature electrochemical aging of the anodes by about four years. In period VI the current levels dropped back to normal levels. The data for each of the six time periods are given in Table 5.5. 
Table 5.5: Summary of Yaquina Bay Bridge field trial

\begin{tabular}{l|c|c|c|c|c|c|c}
\multicolumn{1}{c|}{ Time Period } & I & II & III & IV & V & VI \\
\hline Start Date & $09 / 25 / 98$ & $11 / 20 / 99$ & $07 / 26 / 00$ & $05 / 03 / 01$ & $11 / 26 / 01$ & $01 / 24 / 02$ \\
\hline End Date & $02 / 25 / 99$ & $04 / 18 / 00$ & $05 / 02 / 01$ & $07 / 25 / 01$ & $12 / 29 / 01$ & $02 / 26 / 02$ \\
\hline \multicolumn{7}{c|}{ Mean Current Density, $\mathbf{m A} / \mathbf{m}^{2}$} \\
\hline $10-\mathrm{Control}$ & 3.0 & 2.0 & 2.4 & 13.9 & 13.5 & 2.2 \\
\hline $11-\mathrm{LiBr}$ & 2.3 & 2.4 & 2.6 & 17.0 & 16.6 & 2.5 \\
\hline $13-\mathrm{LiNO}$ & 2.5 & 2.2 & 2.3 & 16.2 & 15.9 & 2.5 \\
\hline $14-$ Control & 2.7 & 2.2 & 3.0 & 13.3 & 13.6 & 2.5 \\
\hline
\end{tabular}

Mean Voltage, $V$

\begin{tabular}{l|c|c|c|c|c|c|c}
\hline $10-$ Control & 3.2 & 3.0 & 3.8 & 9.3 & 16.8 & 4.1 \\
\hline $11-\mathrm{LiBr}$ & 2.5 & 1.4 & 3.6 & 10.0 & 24.5 & 5.1 \\
\hline $13-\mathrm{LiNO}_{3}$ & 1.9 & 0.8 & 1.6 & 9.6 & 22.2 & 4.0 \\
\hline $14-$ Control & 1.8 & 2.5 & 4.0 & 15.0 & 22.6 & 4.0 \\
\hline
\end{tabular}

Mean Circuit Resistance, $\mathrm{k} \Omega-\mathrm{m}^{2}$

\begin{tabular}{l|l|l|l|l|l|l}
\hline $10-$ Control & 1.07 & 1.51 & 1.60 & 0.67 & 1.25 & 1.83 \\
\hline $11-\mathrm{LiBr}$ & 1.08 & 0.58 & 1.37 & 0.59 & 1.48 & 2.02 \\
\hline $13-\mathrm{LiNO} 3$ & 0.74 & 0.38 & 0.70 & 0.59 & 1.40 & 1.63 \\
\hline $14-$ Control & 0.65 & 1.11 & 1.33 & 1.13 & 1.67 & 1.62 \\
\hline
\end{tabular}

The effects of humectants can be seen in Figure 5.55, where the mean circuit resistance values in Table 5.5 are shown for the time periods where the current densities were nominally $2.2 \mathrm{~mA} / \mathrm{m}^{2}$. The control zones show gradually increasing circuit resistances, with Zone 10 (farther from the bay) having higher values than Zone 14 (closer to the bay). Without humectant treatments one would expect the circuit resistances in Zones 11 and 13 to follow the same trends and be bounded by the Zone 10 and Zone 14 data. The dip in circuit resistances in Period II for LiBr and $\mathrm{LiNO}_{3}$ zones show the benefits of the humectant treatment. However, by time Period III the benefits of $\mathrm{LiBr}$ have disappeared. After the accelerated aging in time Periods IV and $\mathrm{V}$ the benefits of using $\mathrm{LiNO}_{3}$ have also disappeared. Figure 5.55 shows that the benefits of $\mathrm{LiNO}_{3}$ were present for 2-3 years. 


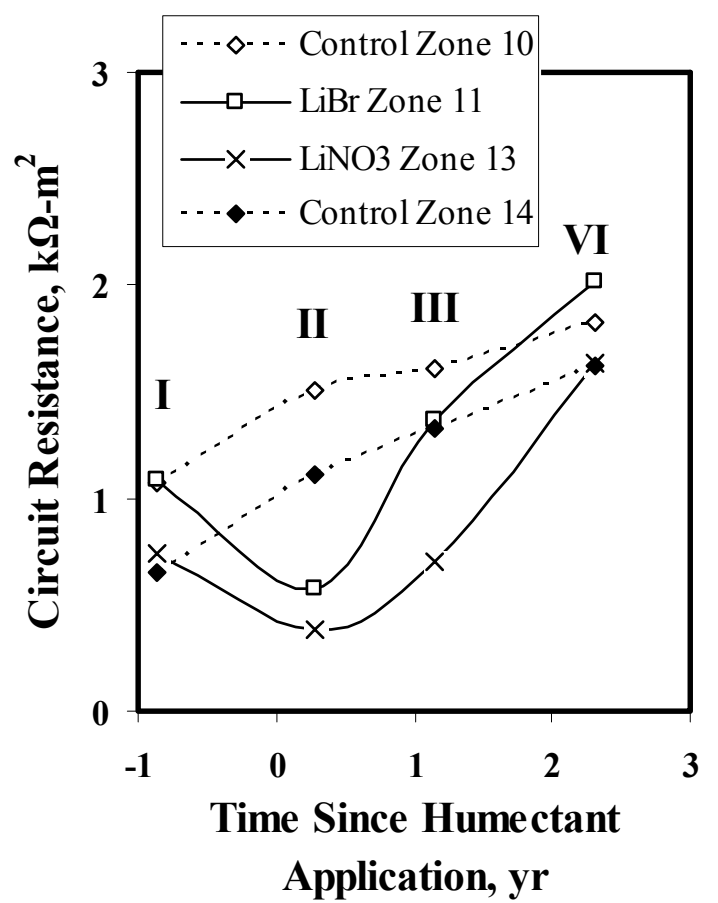

Figure 5.55: Mean circuit resistance data from periods with nominal current of $2.2 \mathrm{~mA} / \mathrm{m}^{2}$. Period I was prior to humectant application. 


\subsection{DISCUSSION}

The main goals of this project (humectant effectiveness, increased service life, and life cycle considerations) are discussed along with the appropriateness of accelerated laboratory tests and the importance of collecting and examining operating data.

\subsection{HUMECTANT EFFECTIVENESS}

A summary of all of the different experiments is shown in Table 6.1, along with a ranking of the relative effectiveness of the humectants and the control. The ranking reflects circuit resistance and depolarization results for ICCP and long-term galvanic current for GCP. According to Figure 3.1, $\mathrm{LiBr}$ should lower the activity of water more than $\mathrm{LiNO}_{3}$, especially in environments with a RH below 50\%. All things being equal, one would expect better results with LiBr. For GCP, $\mathrm{LiBr}$ is generally more effective than $\mathrm{LiNO}_{3}$, and both are generally more effective than the control. However, for ICCP, $\mathrm{LiNO}_{3}$ is generally more effective than $\mathrm{LiBr}$, and both are generally more effective than the control. The same basic electrochemical processes occur in both GCP and ICCP, so the question arises as to what is causing the humectant rankings to change between GCP and ICCP. 
Table 6.1: Summary of humectant rankings for each CP experiment

\begin{tabular}{|c|c|c|c|c|c|}
\hline $\begin{array}{c}\text { СP } \\
\text { Type }\end{array}$ & $\begin{array}{c}\text { APPLIED } \\
\text { CURRENT } \\
\mathbf{m A} / \mathbf{m}^{2}\end{array}$ & DURATION $^{\mathbf{A}}$ & ENVIRONMENT & NOTE & RANK \\
\hline ICCP & 0.22 & Short & Variable RH & Equilibrated at RH & $\mathrm{LiBr}=\mathrm{LiNO}_{3}>$ Control \\
\hline ICCP & 27 & Long & High RH & New Slabs & $\mathrm{LiNO}_{3}>\mathrm{LiBr}=$ Control \\
\hline ICCP & 27 & Long & High RH & Aged Slabs & $\mathrm{LiNO}_{3}>\mathrm{LiBr}>>$ Control $^{\mathrm{B}}$ \\
\hline ICCP & 27 & Long & Low RH & New Slabs & $\mathrm{LiNO}_{3}>\mathrm{LiBr}>$ Control \\
\hline ICCP & 10 & Long & Low RH & Aged Slabs & $\mathrm{LiNO}_{3}>\mathrm{LiBr}$ \\
\hline ICCP & $27 / 2.2$ & Long & High RH & Cyclic Current & $\mathrm{LiNO}_{3}>\mathrm{LiBr}>$ Control \\
\hline ICCP & $27 / 2.2$ & Long & Low RH & Cyclic Current & $\mathrm{LiNO}_{3}=\mathrm{LiBr}>$ Control \\
\hline ICCP & 2.2 & Long & Yaquina Bay & Before High Currents & $\mathrm{LiNO}_{3}>\mathrm{LiBr}>$ Control \\
\hline ICCP & 13 & Long & Yaquina Bay & After High Currents & $\mathrm{LiNO}_{3}=\mathrm{LiBr}=$ Control \\
\hline GCP & -- & Long & High RH & New Slabs & $\mathrm{LiBr}>\mathrm{LiNO}_{3}=$ Control \\
\hline GCP & -- & Long & High RH & Aged Slabs & $\mathrm{LiBr}>\mathrm{LiNO}_{3}$ \\
\hline GCP & -- & Long & Low RH & New Slabs & $\mathrm{LiBr}>\mathrm{LiNO}_{3}>$ Control \\
\hline GCP & -- & Long & Low RH & Aged Slabs & $\mathrm{LiBr}>\mathrm{LiNO}_{3}$ \\
\hline GCP & -- & Long & $55 \% \mathrm{RH}$ & Never Wetted & $\mathrm{LiNO}_{3}>\mathrm{LiBr}>>$ Control \\
\hline GCP & -- & Long & $80 \%$ RH & Never Wetted & $\mathrm{LiBr}>\mathrm{LiNO}_{3}>>$ Control \\
\hline GCP & -- & Long & Cleveland $\mathrm{OH}$ & Covered & $\mathrm{LiBr}>\mathrm{LiNO}_{3}>$ Control \\
\hline GCP & -- & Medium & Cleveland $\mathrm{OH}$ & Exposed & $\mathrm{LiBr}>\mathrm{LiNO}_{3}>$ Control \\
\hline GCP & -- & Long & Cleveland $\mathrm{OH}$ & Exposed & $\mathrm{LiBr}>$ Control $>\mathrm{LiNO}_{3}$ \\
\hline GCP & -- & Medium & $55 \%$ & $\begin{array}{c}4.9,7.3 \& 9.8 \mathrm{~kg} / \mathrm{m}^{3} \\
\mathrm{NaCl}\end{array}$ & $\mathrm{LiBr}=\mathrm{LiNO}_{3}>>$ Control \\
\hline GCP & -- & Medium & $80 \%$ & $\begin{array}{c}4.9,7.3 \& 9.8 \mathrm{~kg} / \mathrm{m}^{3} \\
\mathrm{NaCl}\end{array}$ & $\mathrm{LiBr}=\mathrm{LiNO}_{3}>>$ Control \\
\hline GCP & -- & Medium & Cleveland $\mathrm{OH}$ & $\begin{array}{c}4.9,7.3 \& 9.8 \mathrm{~kg} / \mathrm{m}^{3} \\
\mathrm{NaCl}, \text { Exposed }\end{array}$ & $\mathrm{LiBr}=\mathrm{LiNO}_{3}>>$ Control \\
\hline
\end{tabular}

${ }^{\mathrm{A}}$ Duration: Short $<1$ month $<$ Medium $<1$ year $<$ Long

${ }^{\mathrm{B}}$ Control comparison from untreated data in Bullard. (1998).

One possibility is that the GCP results reflect a much smaller electrochemical age than the ICCP results. The electrochemical ages in the GCP tests, in the high humidity enclosure, averaged 92 $\mathrm{kC} / \mathrm{m}^{2}$ for the $\mathrm{LiNO}_{3}$-treated slabs, and $185 \mathrm{kC} / \mathrm{m}^{2}$ for the LiBr-treated slabs. In the low humidity enclosure, the GCP ages were quite small and averaged $19 \mathrm{kC} / \mathrm{m}^{2}$ for the $\mathrm{LiNO}_{3}$-treated slabs, and $31 \mathrm{kC} / \mathrm{m}^{2}$ for the $\mathrm{LiBr}$-treated slabs. These compare with average ICCP electrochemical ages of $741 \mathrm{kC} / \mathrm{m}^{2}$ in the high humidity enclosure and $379 \mathrm{kC} / \mathrm{m}^{2}$ in the low humidity enclosure. However, the separation between the $\mathrm{LiNO}_{3}$ - and $\mathrm{LiBr}$-treated slabs had already appeared in the 100 to $200 \mathrm{kC} / \mathrm{m}^{2}$ range in the ICCP experiments in the high $\mathrm{RH}$ exposure (Figure 5.1). Thus, the reversal of humectant rankings does not appear to be a function of electrochemical age.

Another possibility is that the higher voltages experienced in ICCP caused the rankings to change. Since the humectants appear to reside in the reaction zone (Br in Figures 5.20-5.23), and this is the region of the highest voltage drop (Orlova, et al. 1999), it is possible that the bromide ions are being oxidized (the nitrate ions are already fully oxidized). Bromide oxidation reactions were discussed in Section 3.2. It is possible that the high voltages in the accelerated ICCP tests eliminated bromide as a humectant and not the nitrate. Bromide oxidation would also explain the very low bromide levels found in the aged, low RH cross-section (Table 5.1). If bromide 
oxidation occurs by Equation 3-3, then $\mathrm{Br}_{2}(\mathrm{~g})$ evolution would produce very low bromide concentrations.

To summarize, both humectants are more effective than the control. $\mathrm{LiBr}$ is inherently more effective as a humectant since it lowers the activity of water more than $\mathrm{LiNO}_{3}$. $\mathrm{LiBr}$ was found to be more effective in GCP, while $\mathrm{LiNO}_{3}$ was more effective in ICCP. It is probable that $\mathrm{LiBr}$ is less effective in ICCP because of the loss of humectant from the oxidation of $\mathrm{Br}^{-}$and subsequent $\mathrm{Br}_{2}$ evolution or conversion to oxygen derivatives of $\mathrm{Br}$.

\subsection{INCREASED SERVICE LIFE}

The service life of TS Zn anodes can be limited in a variety of ways. Failures can occur from faulty application of the anode, incorrect operation of the CP system, or from limitations of the anode. Humectants are aimed at the third type — anode limitations.

\subsubsection{Reduced Anode Bond Strength and Delamination}

Insertion of a weak intermediate layer of anode reaction products between the anode and concrete has been shown to reduce bond strength with increasing electrochemical age. In addition, stresses develop within the reaction product layer as the layer grows. This can cause micro-cracking or delamination of the coating along the anode-concrete interface and also reduce anode bond strength. Zinc oxide reaction products accumulate along the highly uneven interface between the TS zinc anode and the concrete during ICCP. Zinc oxide occupies a greater volume than zinc, which creates stresses at sharp bends in the interface. This will eventually lead to micro- cracking or delamination of the anode from the concrete. This appears as minute cracks across the uneven topography of the interface, with cracks both in the zinc reaction product and in the cement paste.

Zinc ions have been shown to migrate into the cement paste and displace calcium ions, a process that is facilitated by the increased ion mobility associated with moister concrete. This results in secondary mineralization of the cement paste and of the original zinc reaction products to form new mineral species and chemical bonds. To some extent this reduces the damaging effects of zinc oxide formation. It improves the mixing of cement and zinc reaction product minerals at the interface and can result in a stronger bond than the original mechanical bond between anode and concrete. This also helps to dissipate the zinc reaction products, thereby delaying the development of the reaction product layer and the associated stresses that lead to micro-cracking and delamination along the interface. Accelerated ICCP tests have predicted service lives of 27 years in environments with periodic wetting (Covino, et al. 1996a; Covino, et al. 1996b; Covino, et al. 2002; Holcomb, et al. 1996) and just five years without wetting (Bullard, et al. 1997a; Bullard, et al. 1998; Covino, et al. 2002). Secondary mineralization improves with increased wetting and humidity and to a large extent accounts for the much greater predicted service life for the periodically wetted anodes.

This project used two measurements of how humectants might extend the service life based on adhesion strength and delamination. The first was the adhesion strength tests. The second was 
the use of microscopy to examine the zinc anode-concrete structure for evidence of increased secondary mineralization, which should lead to less micro-cracking and delamination.

The effects on service life from adhesion strength changes were inconclusive, in large part because of the inherent variation that accompanies such measurements. However, when a comparison is made with prior results without humectants, as was done in Figures 5.27-5.30, a few points can be made:

- With the exception of some $\mathrm{KC}_{2} \mathrm{H}_{3} \mathrm{O}_{2}$-treated slabs, the bond strengths after GCP were much higher than was found with ICCP in either prior experiments or this investigation. This large increase in bond strength with GCP is consistent with the observations from the Richmond-San Rafael Bridge (Bullard, et al. 1997b; Covino, et al. 2002), where the bond strength of the GCP anode was greater than the field test equipment could measure.

- In the case where the best comparison with prior experiments can be made (i.e., with the same conditions, ICCP current levels, and slabs), the aged slabs in Figure 5.28 show perhaps a 0 to 3 year advantage with $\mathrm{LiBr}$ and $\mathrm{LiNO}_{3}$. Note that $12-13$ years of the equivalent age for the aged samples in Figure 5.28 occurred while treated with the humectants.

- Casting doubt on the benefits shown above for the aged slabs in Figure 5.28, are the results for the new slabs in Figure 5.28. The bond strength of the new slabs plummeted to near zero. However, the control slab also had very low bond strength. This indicates that something besides humectants was probably the cause.

\subsubsection{Anode-Concrete Interface Chemistry}

The driest environments show little secondary mineralization of $\mathrm{Zn}$ dissolution products. In wetter environments, the interfacial chemistry becomes more complex, with evidence of a $\mathrm{ZnO}$ layer adjacent to the anode and of $\mathrm{Zn}$ ions diffused into the cement paste. For CP zones with similar operating histories, the reaction zone width increases substantially, moving from driest to the wettest environment. The trend in reaction zone width is similar to that for chloride profiles and concrete surface salt concentrations $\left(C_{o}\right.$ values $)$, i.e., the closer to the bay, the greater the impact that moisture and salt deposition have on zone properties that can affect the service life of the structure and the $\mathrm{CP}$ zone. $\mathrm{Cl}^{-}$accumulate at the anode-concrete interface, most likely as a zinc hydroxychloride. The lowest $\mathrm{Cl}^{-}$levels at the anode-concrete interface occur where there is less moisture to aid penetration of $\mathrm{Cl}^{-}$into and transported through the concrete.

\subsubsection{Loss of Rebar Protection}

Galvanic CP anodes can fail by not providing enough galvanic current to protect the rebar. As Table 6.1 shows, LiBr always provided better long-term galvanic current than without a humectant for all of the experiments, and in most cases performed better than $\mathrm{LiNO}_{3}$ as well.

The minimum required current is an empirically derived value and may well be different for different climates and chloride levels. For example, Oregon DOT has found that $0.2 \mathrm{~mA} / \mathrm{ft}^{2}(2.2$ $\mathrm{mA} / \mathrm{m}^{2}$ ) is sufficient for their coastal thermal-sprayed zinc ICCP systems (Bullard, et al. 1998; 
Covino, et al. 1997a; Covino, et al. 2002), while Fontana and Greene (1978, p. 207) give 0.1-0.5 $\mathrm{mA} / \mathrm{ft}^{2}\left(1.1-5.4 \mathrm{~mA} / \mathrm{m}^{2}\right)$ as sufficient for protecting reinforcing bars in concrete.

Table 6.2 shows the long-term currents for the GCP tests in this report. In many cases, $\mathrm{LiBr}$ supplied sufficient galvanic current $\left(\sim 2 \mathrm{~mA} / \mathrm{m}^{2}\right)$ to protect the rebar even after a year. In most cases $\mathrm{LiNO}_{3}$ did not supply enough galvanic current, while none of the controls did either.

Table 6.2: Summary of medium and long term galvanic current densities

\begin{tabular}{|c|c|c|c|c|c|}
\hline \multirow[t]{2}{*}{ DURATION $^{\mathbf{A}}$} & \multirow[t]{2}{*}{ ENVIRONMENT } & \multirow[t]{2}{*}{ NOTE } & \multicolumn{3}{|c|}{$\begin{array}{l}\text { LONG-TERM GALVANIC } \\
\text { CURRENT DENSITY }^{\mathrm{B}}, \mathrm{mA} / \mathrm{m}^{2}\end{array}$} \\
\hline & & & LiBr & $\mathrm{LiNO}_{3}$ & Control \\
\hline Long & Low RH & New Slabs & 0.3 & 0.2 & 0.04 \\
\hline Long & Low RH & Aged Slabs & 0.5 & 0.3 & \\
\hline Long & High RH & New Slabs & 0.8 & 0.2 & 0.3 \\
\hline Long & High RH & Aged Slabs & 2.9 & 1.2 & \\
\hline Long & $55 \% \mathrm{RH}$ & Never Wetted, $3.0 \mathrm{~kg} / \mathrm{m}^{3} \mathrm{NaCl}$ & 0.5 & 1.1 & $<0.1$ \\
\hline Medium & $55 \% \mathrm{RH}$ & Never Wetted, $4.9 \mathrm{~kg} / \mathrm{m}^{3} \mathrm{NaCl}$ & 1.0 & 1.0 & $<0.1$ \\
\hline Medium & $55 \% \mathrm{RH}$ & Never Wetted, $7.3 \mathrm{~kg} / \mathrm{m}^{3} \mathrm{NaCl}$ & 0.8 & 1.5 & $<0.1$ \\
\hline Medium & $55 \% \mathrm{RH}$ & Never Wetted, $9.8 \mathrm{~kg} / \mathrm{m}^{3} \mathrm{NaCl}$ & 2.0 & 1.5 & $<0.1$ \\
\hline Long & $80 \% \mathrm{RH}$ & Never Wetted, $3.0 \mathrm{~kg} / \mathrm{m}^{3} \mathrm{NaCl}$ & 2.8 & 1.9 & 0.5 \\
\hline Medium & $80 \% \mathrm{RH}$ & Never Wetted, $4.9 \mathrm{~kg} / \mathrm{m}^{3} \mathrm{NaCl}$ & 1.8 & 1.1 & $<0.1$ \\
\hline Medium & $80 \% \mathrm{RH}$ & Never Wetted, $7.3 \mathrm{~kg} / \mathrm{m}^{3} \mathrm{NaCl}$ & 1.9 & 2.2 & 0.3 \\
\hline Medium & $80 \% \mathrm{RH}$ & Never Wetted, $9.8 \mathrm{~kg} / \mathrm{m}^{3} \mathrm{NaCl}$ & 3.1 & 1.9 & 0.8 \\
\hline Long & Cleveland $\mathrm{OH}$ & Covered & 1.2 & 0.9 & 0.4 \\
\hline Medium & Cleveland $\mathrm{OH}$ & Exposed & 3.1 & 0.9 & 0.6 \\
\hline Long & Cleveland $\mathrm{OH}$ & Exposed & 2.0 & 0.3 & 1.3 \\
\hline
\end{tabular}

${ }^{\mathrm{A}}$ Duration: 1 month $<$ Medium $<1$ year $<$ Long.

${ }^{\mathrm{B}}$ Mean current density after 1 year for long duration tests and after 150 days for medium duration tests.

It appears that treatment with $\mathrm{LiBr}$ should increase the protective power and service life of the GCP anode. With the exception of the Cape Perpetua Viaduct, Oregon has only installed ICCP systems on coastal bridges. Occasionally zones have been converted to GCP because of shorts between the rebar and the anode, or because of power supply failures. In these cases, application of $\mathrm{LiBr}$ to the anode should help in providing sufficient protection current.

Another measure of the effectiveness of a CP system is depolarization. A common standard is that depolarization, after the IR drop has occurred, should be at least $100 \mathrm{mV}$. Figure 5.16 for ICCP tests shows that in most cases the $100 \mathrm{mV}$ depolarization was achieved in both the high and low RH environments and without much dependence upon electrochemical age. Figure 5.17 for GCP tests shows that in many cases $100 \mathrm{mV}$ was not achieved, especially as the equivalent electrochemical age increased. The large spread of the depolarization data, combined with very few measurements on control samples, results in no conclusions as to the effectiveness of humectants to achieve $100 \mathrm{mV}$ of depolarization. 


\subsubsection{Excessive Required Voltage or Circuit Resistance}

One way that ICCP anodes can fail is by excessive circuit resistance. This translates to voltage requirements above the ability of the providing power supplies. For example, this was the primary reason that the ICCP test on the Richmond-San Rafael Bridge was ended (Bullard, et al. 1997b; Covino, et al. 2002).

Circuit resistance, for a constant current, is proportional to voltage. So reductions in circuit resistance would alleviate the problem of elevated voltage requirements. The rankings, Table 6.1 , for ICCP tests are primarily based on long-term values in circuit resistance. In all cases, the use of $\mathrm{LiNO}_{3}$ reduced the circuit resistances as compared to controls. In nearly all of the cases, the use of $\mathrm{LiBr}$ also reduced the circuit resistances. Therefore, application of $\mathrm{LiNO}_{3}$ should help to extend the service life of ICCP systems with excessive voltage requirements. The use of $\mathrm{LiBr}$ is suspect in this case because the high voltage may lead to oxidation of $\mathrm{Br}^{-}$, which would limit the time period that this humectant would be effective. However, bridge systems have voltages on the order of $10 \mathrm{~V}$, instead of the $100-300 \mathrm{~V}$ sometimes found in the accelerated laboratory tests, so the proposed mechanism of $\mathrm{Br}^{-}$oxidation may or may not be applicable.

\subsection{LIFE CYCLE CONSIDERATIONS}

There are two types of benefits for using humectants described in Section 6.2. The first involves increased time, until adhesion strength loss, results in delamination. This is a long-term benefit and would require repeated applications of a humectant over the lifetime of the anode. The second type involves prolonging the usefulness of the anode when there is a specific problem, such as insufficient protection current in GCP or too high of a voltage in ICCP. These would require spot applications of humectants in problem areas, with reapplication dependant upon the measured success of the humectant to address the problem. It is the first type of humectant use, (the scheduled reapplication of humectant for long-term benefits), which is most amenable to life cycle calculations.

One such life cycle calculation involves translating future costs, $F$, into what those would represent in today's dollars, $P$, given a constant annual interest rate, $i$, for $n$ years in the future (Newnan 1980), Equation 6-1.

$$
P=F(1+i)^{-n}
$$

If one considers two recurring future costs, the cost of ICCP re-installation, $C$, and the cost of humectant application, $H$, then Equation 6-1 can be repeatedly used with various assumptions for $H, C, i$, and $n$. The values for $n$ would come from $y_{C}$ (the years until ICCP re-installation is required without the use of humectants), $y_{H}$ (the years between humectant applications), and $y_{L}$ (the years of added anode lifetime from the humectant). For example, the future cost of the fifth humectant application, with applications occurring every 2 years $\left(y_{H}=2\right)$ would be $H(1+i)^{-10}$. Each of these terms is discussed below.

The cost of ICCP re-installation, $C$, can be estimated from the initial application costs. It should in principle be lower, since part of the initial costs involved restoration of damaged concrete, 
assurance of rebar continuity, and elimination of surface metal (Holcomb and Cryer 1998), which should all be lower during reinstallation. Offsetting these cost reductions would be the removal and disposal of the existing zinc anode. In the calculations that follow, the benefits of humectant use will be given in terms of a percentage of, $C$. A positive benefit is a net gain in present value. A negative benefit is a net loss in present value.

The cost of humectant application, $H$, should in some respects correlate with the cost of ICCP reinstallation, $C$. This is because both $H$ and $C$ are functions of the size of the anode and the difficulty of access to the concrete surfaces. With little surface preparation and fast application rates, humectant application costs should be relatively lower in ICCP zones that are easily accessible than those that are not easily accessible. In the calculations that follow, $H$ will be given a value of some small percentage of $C$.

The annual interest rate, $i$, is assumed to be a constant even though it is very likely to change over time. Examining the consequences of changes in $i$ with time is beyond the scope of this simple life cycle analysis.

The years until ICCP re-installation, $y_{C}$, depends on the conditions (corrosion rate and $\mathrm{Cl}^{-}$ content) and microclimate (including humidity, temperature, and rainfall) of the bridge. For relatively wet conditions, 27 years is a reasonable estimate (Covino, et al. 1996a; Covino, et al. 1996b; Covino, et al. 2002; Holcomb, et al. 1996). For dry conditions this will be much lower, and could be as little as 5 years (Bullard, et al. 1997a; Bullard, et al. 1998; Covino, et al. 2002). The benefit of using humectants, in additional years before ICCP re-installation, $y_{L}$, can be estimated from changes in adhesion strength and secondary mineralization with humectant use. This investigation was inconclusive as far as bond strength results. However, the possible adhesion strength increases shown for the aged slabs in Figure 5.28, combined with increased $\mathrm{Zn}$ infusion into the concrete paste, Figure 5.24, indicate that some increase is probable.

The determination of the time between humectant applications, $y_{H}$, was not an emphasis of this study. However, humectants were reapplied in the GCP tests shown in Figures 5.39-5.40. In Figures 5.39 and 5.40b there was a small, but measurable, long-term benefit from the retreatment that was done after 200 days of the initial GCP. This indicates that the original humectants were still effective. However, in Figures 5.40a, there was a major benefit from reapplication. The results from these particular tests at $55 \% \mathrm{RH}$ were a bit odd in that these were the only ones that resulted in $\mathrm{LiNO}_{3}$ being superior to $\mathrm{LiBr}$ during GCP. Overall, one could surmise that reapplication periods of 1 to 3 years would be appropriate. Data from the field trial, Figure 5.55, indicate a similar period of effectiveness of 2-3 years for $\mathrm{LiNO}_{3}$. One would expect increasing exposure of the treated anode to the washing effects of precipitation would decrease $y_{H}$. The more exposed the anode, the higher the expected humectant losses from runoff effects (and thus smaller values for $y_{H}$ ). The field trial zones were a mix of sheltered and boldly exposed areas within each ICCP zone, Figure 4.4. Overall one could surmise that reapplication periods of 1 to 5 years would be appropriate. The microclimate of both the bridge location and location on the bridge can affect the amount of exposure and precipitation runoff. Humectants may be washed from the surface in a similar manner as chlorides are washed from the surface, as illustrated by Figures 5.46 and 5.47. The amount of washing that a surface experiences is a function of rainfall, wave splash, dew formation, wind, and fog. 
The results of some sample calculations using Equation 6-1 are shown in Figures 6.1-6.3. In these calculations a time frame of 40 years was considered. In Figure 6.1, with $y_{C}=27$ years and an interest rate of $4 \%$, the case when the humectants increased the lifetime of the anode by 9 years (a) and 6 years (b) were considered. The importance of the cost to apply the humectants $\left(H, \mathrm{x}\right.$-axis) and the time between reapplications $\left(y_{H}\right)$ are apparent in that the benefit of applying humectants are positive with small $H$ and large $y_{H}$ values, and negative with large $H$ and small $y_{H}$ values. In dryer conditions, when the time until ICCP installation is reduced $\left(y_{C}\right)$, the benefits of humectants are increased, Figure 6.2. In Figure 6.2: $y_{C}=15$ years, $i=4 \%$, and humectants increase the lifetime of the anode by 5 years (a) and 3 years (b). 


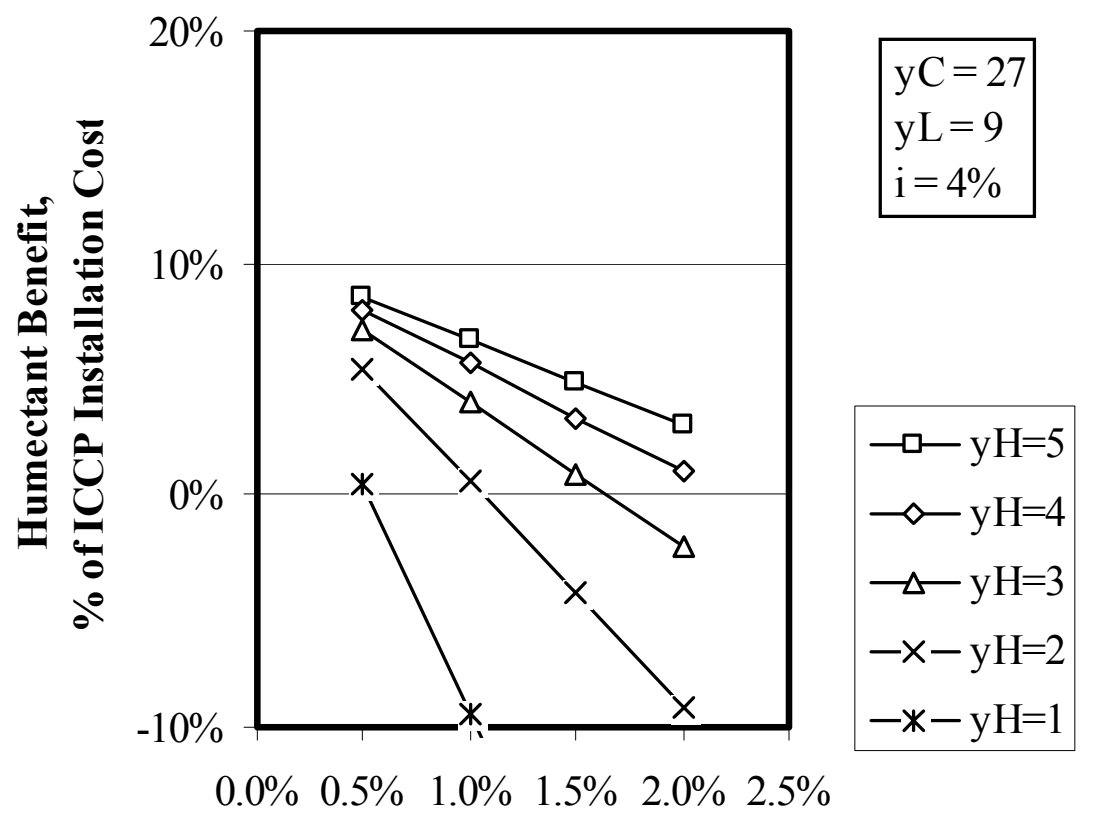

Humectant Cost, \% of ICCP Ins tallation Cost

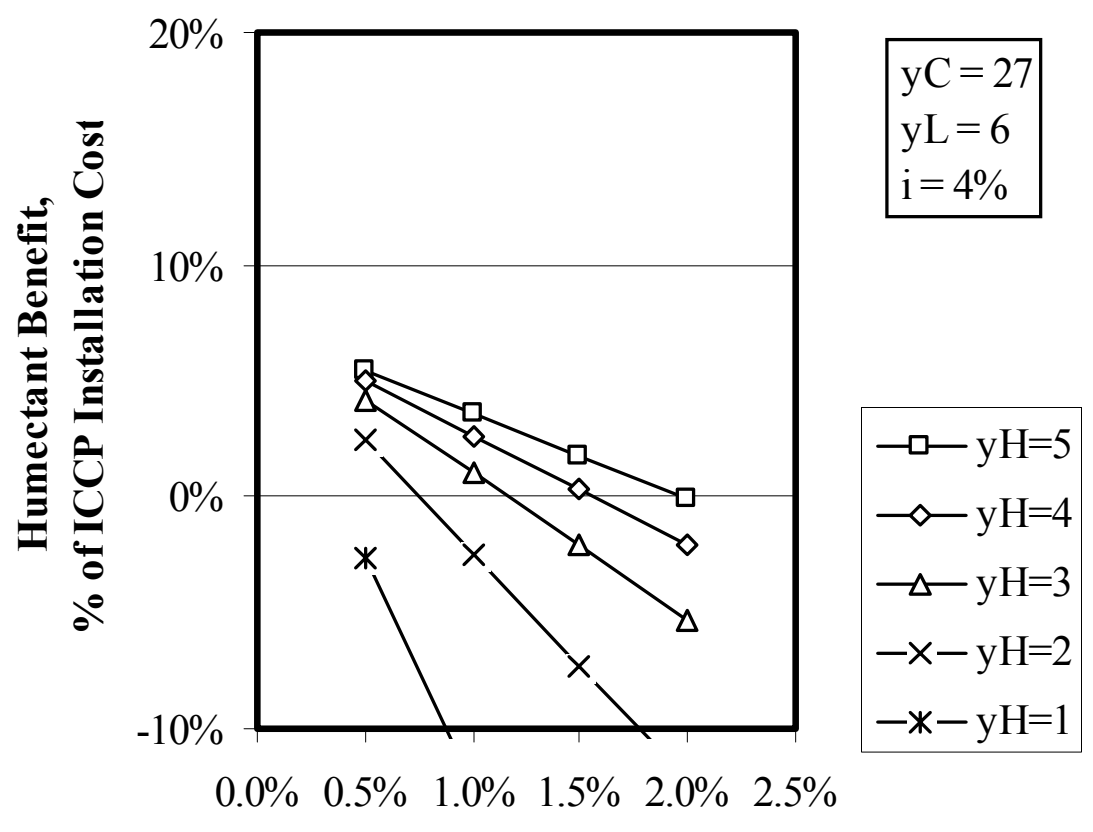

Humectant Cost, $\%$ of ICCP Ins tallation Cost

Figure 6.1: Benefits of using humectants, as a \% of ICCP installation costs as functions of humectant application costs and cycle times $\left(\mathrm{y}_{\mathrm{H}}\right)$ for 27 years of anode life (without humectants), an interest Rate of $4 \%$, and an anode life extension of a) 9 years (top) and b) 6 years (bottom). Calculations cover 40 years. 


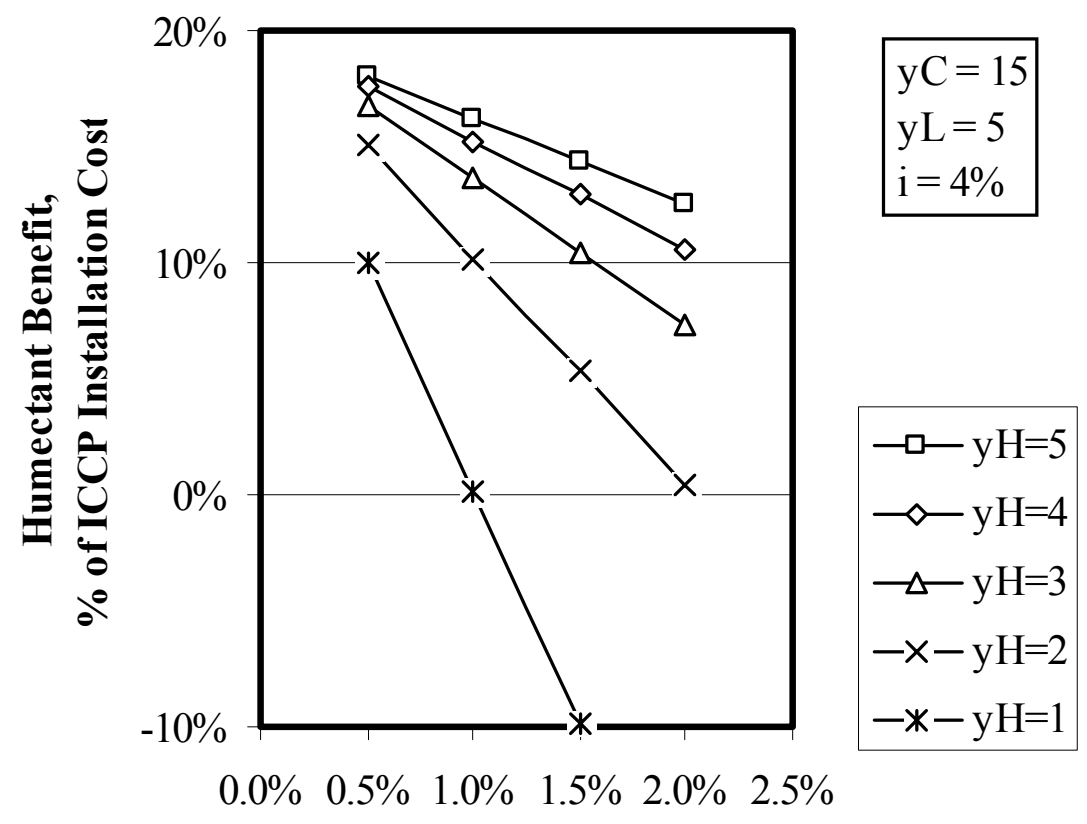

Humectant Cost, $\%$ of ICCP Installation Cost

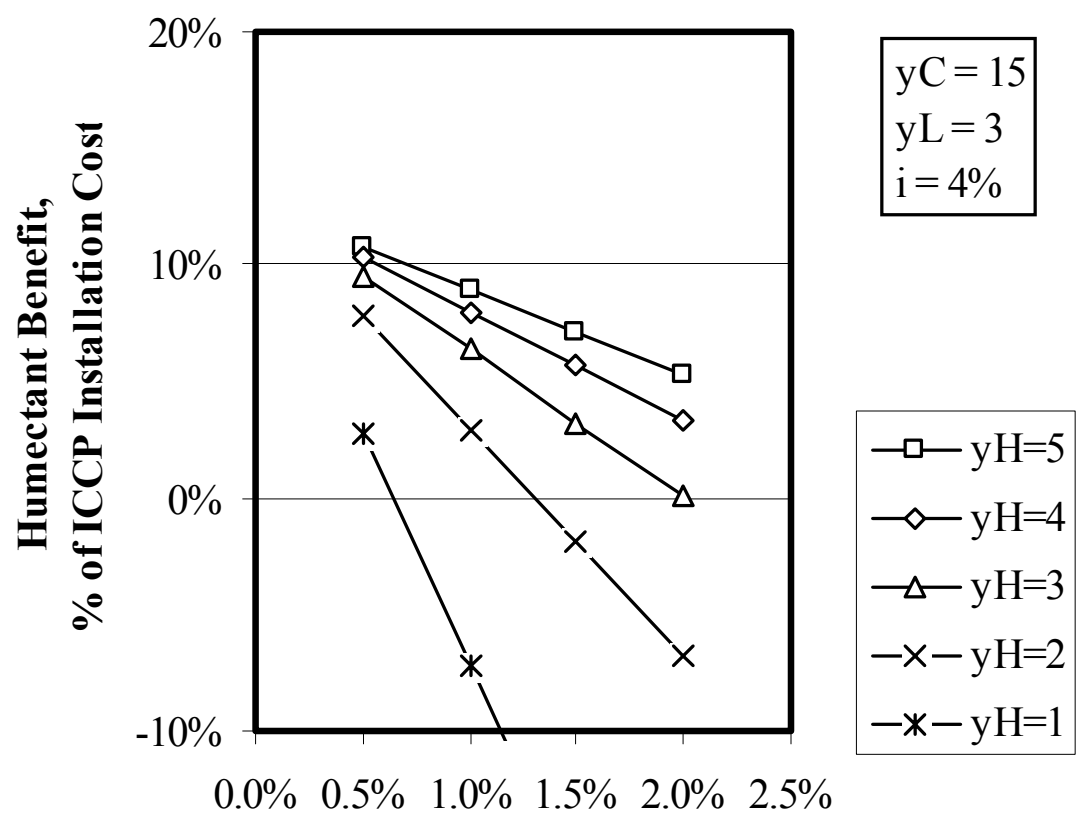

Humectant Cost, $\%$ of ICCP Ins tallation Cost

Figure 6.2: Benefits of using humectants, as a \% of ICCP installation costs as functions of humectant application costs and cycle times $\left(\mathrm{y}_{\mathrm{H}}\right)$ for 15 years of anode life (without humectants), an interest Rate of $4 \%$, and an anode life extension of a) 5 years (top) and b) 3 years (bottom). Calculations cover 40 years. 
The influence of interest rates are shown in Figure 6.3 for the case of $y_{C}=27$ years, $y_{L}=9$ years, $y_{H}=3$ years and $H / C=1 \%$. At very low interest rates the additional costs of applying the humectants $(H)$ overrides any benefits. In the limit of $0 \%$ interest the "benefit" is $-13 \%$ (13 applications of humectant each costing $1 \%$ of $\mathrm{C}$ ). At high interest rates the earlier costs of applying humectants every 3 years becomes more important. In Figure 6.3 the benefit would become negative at an interest rate of $11.5 \%$.

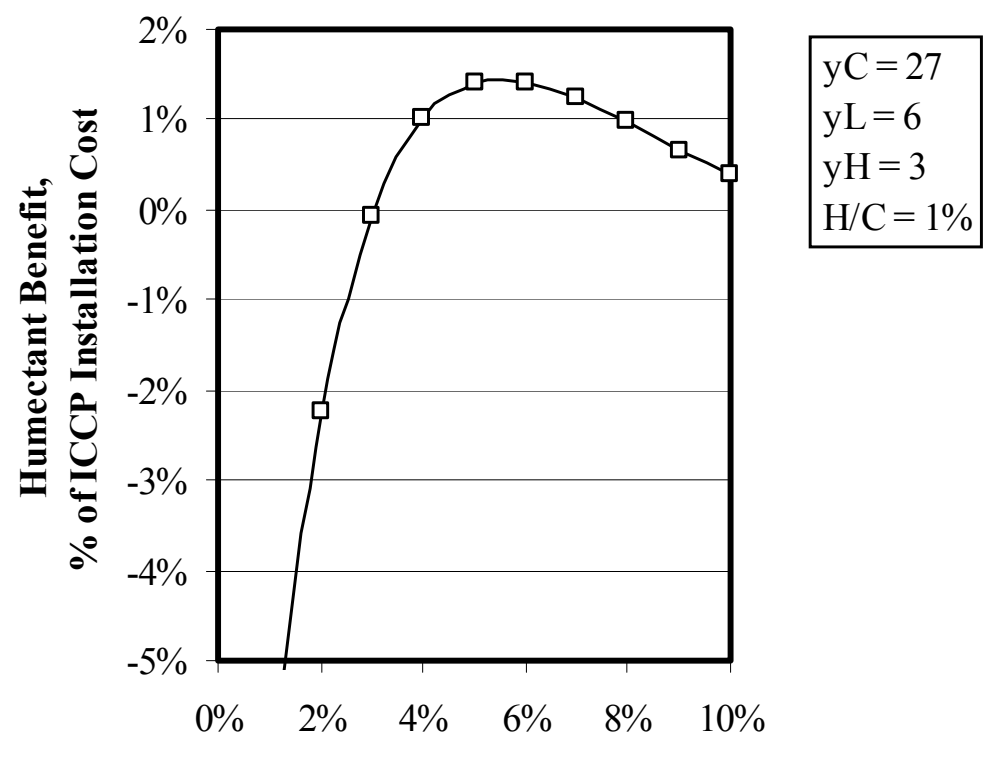

Annual Interest Rate

Figure 6.3: Benefits of using humectants, as a \% of ICCP installation costs as a function of interest rate for 27 years of anode life (without humectants), a lifetime extension of 6 years, 3 years between humectant applications, and the cost of applying humectants equal to $1 \%$ of the ICCP installation costs. Calculations cover 40 years.

To summarize, the five parameters used to obtain Figures 6.1-6.3 were:

- $\quad H / C$ - the ratio of the cost of humectant application to the cost of ICCP reinstallation. Values from 0.005 to 0.02 were used.

- $y_{C}$ - the expected lifetime of the anode without humectant treatment. Values of 27 years (normal wet conditions) and 15 years (dryer conditions) were used.

- $y_{L}-$ the expected lifetime gain from humectant use. Values of 9 and 6 years were used for $y_{C}=27$; values of 5 and 3 years were used for $y_{C}=15$.

- $y_{\boldsymbol{H}}-$ the time between humectant applications. Values between 1 and 5 years were used.

- $\boldsymbol{i}$ - the interest rate. Most calculations used a value of $4 \%$. 


\subsection{ACCELERATED LABORATORY TESTS}

The usefulness of accelerated ICCP tests for ICCP applications was demonstrated by producing similar rankings in humectant effectiveness and in producing similar microscopic reaction zones in the zinc/concrete interface.

The use of circuit resistance allows ICCP applications with different current levels to be compared. The cyclic tests between accelerated and non-accelerated ICCP, at low RH, showed similar results in terms of circuit resistance with that found after the period of high impressed currents on the Yaquina Bay Bridge. In both cases (Figures 5.7 and 5.54) the higher current levels produced lower circuit resistances than the low current levels. This was the case even though circuit resistance normally tracks the same, regardless of current levels (as in Figure 5.6).

The different results between those found with $\mathrm{LiBr}$ and $\mathrm{LiNO}_{3}$ in GCP and ICCP tests showed how one must be careful when using accelerated tests. Most of the electrochemical processes between GCP and ICCP are the same. So both humectants could be expected to respond with the same rankings in GCP as in ICCP. However, the higher voltages in ICCP may have led to the oxidation of $\mathrm{Br}^{-}$ions in the $\mathrm{LiBr}$ treated samples, which did not occur in $\mathrm{GCP}$.

\subsection{COLLECTING AND EXAMINING OPERATING DATA}

The CP systems on the Oregon coast are well instrumented in terms of recording current levels and voltages, and in delivering that data to off-site locations. However, there has not been a systematic approach that allows for the data to be readily examined or interpreted. As Figure 5.54 shows, gaps in data can result from inoperative equipment or loss of collected data. Differences in the noise levels in Figure 5.54 showed the importance of gathering the data to a sufficient number of decimal places (more than the 1 and 2 decimal places for voltage and current used to calculate the circuit resistance during time Period II).

Besides collecting operating data, the data also need to be regularly examined for defective equipment or for errors in operating the equipment. Examples of this would be current levels being set too low (for insufficient corrosion protection) or too high (for unnecessary aging of the anode, Periods IV-V in Figure 5.54).

Beyond examining current density and voltage, circuit resistance offers a measurement that relates to the electrochemical age of the anode and to more readily compare structures with different current levels. It should be noted that increases in current density are also apparent in circuit resistance data, as seen in the transition between Periods II and III in Figure 5.54. 


\subsection{CONCLUSIONS}

\section{$\underline{\text { Humectant Mechanisms }}$}

- Humectants bring moisture into the $\mathrm{Zn}$ anode and concrete by their affinity for water (i.e., lowering the activity of water).

- From a thermodynamic argument, $\mathrm{LiBr}$ should be a more effective humectant than $\mathrm{LiNO}_{3}$, since it lowers the activity of water more than $\mathrm{LiNO}_{3}$, especially in environments with an $\mathrm{RH}$ below $50 \%$.

\section{$\underline{\text { Humectant Effectiveness }}$}

- $\mathrm{LiNO}_{3}$ and $\mathrm{LiBr}$ were both effective in lowering the long-term circuit resistance in ICCP, raising the long-term galvanic current density in GCP, and in keeping the depolarization voltage above $100 \mathrm{mV}$ in laboratory ICCP tests.

- $\mathrm{LiBr}$ was more effective than $\mathrm{LiNO}_{3}$ in GCP. This was consistent with the lower water activity expected with $\mathrm{LiBr}$ as compared with $\mathrm{LiNO}_{3}$.

- $\mathrm{LiNO}_{3}$ was more effective than $\mathrm{LiBr}$ in ICCP.

- Based on literature sources, the low Br levels found in aged ICCP anodes was consistent with higher voltages leading to $\mathrm{Br}^{-}$oxidation and the subsequent evolution of $\mathrm{Br}_{2}$ or conversion to oxygen derivatives of $\mathrm{Br} . \mathrm{LiNO}_{3}$ is already fully oxidized and is not susceptible to further oxidation.

- $\mathrm{KC}_{2} \mathrm{H}_{3} \mathrm{O}_{2}$ was not effective as a humectant and was especially detrimental in terms of loss of adhesion strength. It was dropped from consideration after poor early results.

- Application of $\mathrm{LiBr}$ and $\mathrm{LiNO}_{3}$ to aged anodes was just as effective as applications to new anodes.

- The field trial suggests that the chemistry of the anode-concrete interface was modified somewhat by the presence of the humectant, leading to improved ion mobility as evidenced by greater chloride accumulation at the interface and broadening of the zinc oxide reaction product layer.

- Significant leaching of $\mathrm{LiNO}_{3}$ from the treated zone on the Yaquina Bay Bridge occurred over a two-year test period. 


\section{Increased Service Life}

- Humectant treatment increased the protection current in GCP. Spot application of humectants would prolong the useful life of GCP zones that were not achieving sufficient galvanic current.

- Long-term increases in circuit resistances occur during ICCP. Spot applications of humectants lower the circuit resistance, retarding the effects of electrochemical aging on the anode and extending its service life.

- Increased service life, based on bond strength results, was inconclusive. However, a case can be made for small increases of $0-3$ years based on treatments to anodes with prior ICCP aging.

- Increased service life was apparent from circuit resistance results from the Yaquina Bay Bridge field trial. Service life extensions of 2-3 years are possible by treatment with $\mathrm{LiNO}_{3}$. Longer service life extension may have been indicated by these results if the anode had not been aged at a greatly accelerated rate during the field trial.

\section{$\underline{\text { Life Cycle Considerations }}$}

- A life cycle cost model was developed for humectant application and its effects on delaying anode replacement.

- The usefulness of the model is limited by uncertainties in the expected lifetime gains due to humectants $\left(y_{L}\right)$ and by the years between humectant reapplication $\left(y_{H}\right)$.

- Humectant treatments are expected to be most beneficial, in terms of life cycle costs, when the ratio of the cost of humectant application to the cost of ICCP reinstallation $(H / C)$ is small (likely in ICCP zones with easy access), or when the time between humectant applications $\left(y_{H}\right)$ is large (likely in sheltered ICCP zones with less humectant loss due to washing).

\section{Accelerated Laboratory Tests}

- Accelerated tests proved useful in producing similar humectant rankings as found in the Yaquina Bay Bridge field trial.

- The increased voltages used in accelerated ICCP tests, as compared with GCP, may have caused the differences in humectant rankings between ICCP and GCP. This illustrated one of the hazards in using accelerated tests. 


\section{Other Conclusions About CP Systems}

- Bond strengths of GCP anodes were much greater than those of ICCP anodes for equivalent electrochemical ages.

- Circuit resistance arises from a variety of bulk and interfacial resistances, and from polarization at the anode and cathode. The 60-cycle AC resistance accounts for an average of $25 \%$ of the total circuit resistance.

- Operating data from field installations of CP need to be regularly examined for equipment malfunctions and changes in operating parameters that adversely impact the service life of ICCP anodes. 


\subsection{RECOMMENDATIONS}

- Spot applications of LiBr should allow GCP zones that are not achieving enough galvanic current to remain useful and to prolong their useful life.

- Spot applications of $\mathrm{LiNO}_{3}$ should allow ICCP zones that are becoming voltage limited to remain useful and to prolong their useful life.

- The decision to use $\mathrm{LiNO}_{3}$ in ICCP zones for increased service life needs to be examined further, on a case-by-case basis, in terms of $H / C$ (the ratio of the cost of humectant application to the cost of ICCP reinstallation), $y_{C}$ (the expected lifetime of the anode without humectant treatment), $y_{L}$ (the expected lifetime gain from humectant use), and $y_{H}$ (the time between humectant applications).

- In cases where $H / C$ is expected to be small (i.e., ICCP zones with easy access) and $y_{H}$ is expected to be large (sheltered ICCP zones with less humectant loss due to washing) the use of $\mathrm{LiNO}_{3}$ is expected to be cost effective.

- Operating data from CP field installations need to be regularly examined for malfunctions of operating equipment and changes in system operating conditions that may have detrimental consequences for the service life of coastal bridge ICCP systems. Out of specification operating conditions must be corrected in a timely manner to preserve Oregon's investment in these systems. 


\subsection{REFERENCES}

AASHTO. 1995. Sampling and Testing for Chloride Ion in Concrete and Concrete Raw Materials. Standard Specifications for Transportation Materials and Methods of Sampling and Testing, 17th ed., part II. no. T 260-94. Washington, DC.

Bennett, J. 1998. Chemical Enhancement of Metallized Zinc Anode Performance. CORROSION/98, paper 98640. Houston: NACE International.

Bennett, J.E., Schue, T.J., Clear, K.C., Lankard, D.L., Hartt, W.H., and Swiat, W.J. 1993. Electrochemical Chloride Removal and Protection of Concrete Bridge Components: Laboratory Studies. Report SHRP-S-657, Washington D.C.: Strategic Highway Research Program, National Research Council.

Bennett, J.E., Bushman, J.B., Costa, J., and Noyce, P. 2000. Field Application of Performance Enhancing Chemicals to Metallized Zinc Anodes. Corrosion/2000, paper 00790. Houston: NACE International.

Bullard, S. J., Covino, B. S., Jr., Holcomb, G. R., Cramer, S. D., and McGill, G. E. 1997a. Bond Strength of Thermal-Sprayed Zinc on Concrete During Early Stages of Electrochemical Aging. CORROSION/97, paper 97232. Houston: NACE International.

Bullard, S. J., Cramer, S. D., Covino, B. S., Jr., Holcomb, G. R., McGill, G. E., Cryer, C. B., Reis, R. 1997b. Thermal Sprayed Zinc Anodes: Laboratory and Field Studies. In Expanding Coatings Knowledge Worldwide, Proceedings of the SSPC 1997 Seminars, pp. 309-319. Pittsburgh: Steel Structures Paint Council.

Bullard, S. J., Cramer, S. D., Covino, B. S., Jr., Holcomb, G. R., McGill, G. E., and Reis, R. 1998. Thermal-Sprayed Anodes for Cathodic Protection of Reinforced Concrete Bridges. In Concrete Under Sever Conditions: Environment and Loading, Proceedings of the Second International Conference on Concrete Under Severe Conditions, eds. O. E. Gjørv, K. Sakai, and N. Banthia, pp. 959-969. London: E\&FN Spon.

Bullard, S. J., Covino, B. S., Jr., Cramer, S. D., Holcomb, G. R., Russell, J. H., Bennett, J. E., Cryer, C. B. 2000. Performance Of Thermal-sprayed Zinc Anodes Without and with Humectants in Impressed Current Cathodic Protection Systems. In Corrosion Control as a Base for a Suitable Development, Proceedings of LATINCORR: 2000, 7th Ibero-American Congress of Corrosion and Protection and 4th NACE Latin-American Region Corrosion Congress. Cartagena de Indias, Columbia. 
Bullard, S. J, Covino, B. S., Jr., Cramer, S. D., Holcomb, G. R., Russell, J. H., Bennett, J. E., Milius, J. K., Cryer, C. B., Soltesz, S. M. 2001. Performance of Thermal-Sprayed Zinc Anodes Treated with Humectants in Cathodic Protection Systems. In Concrete Under Severe Conditions: Environment and Loading, Proceedings of the Third International Conference on Concrete Under Severe Conditions, Vol. 2, eds. N. Banthia, K. Sakai, and O. E. Gjørv, pp. 1801-1808. Vancouver BC, Canada: The University of British Columbia, 2001.

Covino, B. S., Jr., Bullard, S. J., Holcomb, G. R., Cramer, S. D., McGill, G. E., and Cryer, C. B. 1995. Factors affecting the bonding of arc-sprayed zinc to concrete. In Balancing economics and compliance for maintaining protective coatings, p. 115. Pittsburgh, PA: Steel Structures Painting Council.

Covino, B. S., Jr., Cramer, S. D., Bullard, S. J., Holcomb, G. R., McGill, G. E., and Cryer, C. B. 1996a. Factors Affecting Thermal-Sprayed Zinc Anodes on Concrete. In Proceedings of 13th International Corrosion Congress, Vol. II, paper 173. Clayton, Australia: Australasian Corrosion Association.

Covino, B. S., Jr., Cramer, S. D., Holcomb, G. R., Bullard, S. J., McGill, G. E., and Cryer, C. B. 1996b. Thermal-Sprayed Zinc Anodes for Cathodic Protection of Reinforced Concrete Structures. In Materials for the New Millennium, Proceedings of the 4th Materials Conference, Vol. 2, ed. K. P. Chong, pp. 1512-1521. New York: American Society of Civil Engineers.

Covino, B. S., Jr., Bullard, S. J., Cramer, S. D., Holcomb, G. R., McGill, G. E., Cryer, C. B., Stoneman, A., and Carter, R. R. 1997a. Interfacial Chemistry of Zinc Anodes for Reinforced Concrete Chemistry. CORROSION/97, paper 97233. Houston: NACE International.

Covino, B. S., Jr., Bullard, S. J., Holcomb, G. R., Cramer, S. D., McGill, G. E., and Cryer, C. B. 1997b. Bond strength of electrochemically-aged arc-spray coatings on concrete. Corrosion 53(5): $399-411$.

Covino, B. S., Jr., Bullard, S. J., Holcomb, G. R., Russell, J. H., Cramer, S. D., Bennett, J. E., and Laylor, H. M. 1999a. Chemical Modification of Thermal-Sprayed Zinc Anodes for Improved Cathodic Protection of Reinforced Concrete. In Proceedings of the 14th International Corrosion Congress, paper 33.0. Kelvin, South Africa: Corrosion Institute of Southern Africa.

Covino, B. S., Jr., Bullard, S. J., Holcomb, G. R., Russell, J. H., Cramer, S. D., Bennett, J. E., and Laylor, H. M. 1999b. Chemically-Modified Thermal-Spray Zinc Anodes for Galvanic Cathodic Protection. Materials Performance. 38(12): 28-32.

Covino, B. S., Jr., Holcomb, G. R., Bullard, S. J., Russell, J. H., Cramer, S. D., Bennett, J. E., and Laylor, H. M. 1999c. Electrochemical Aging of Humectant-Treated Thermal-Sprayed Zinc Anodes for Cathodic Protection. CORROSION/99, paper 99548. Houston: NACE International.

Covino, B. S., Jr., Russell, J. H., Bullard, S. J., Holcomb, G. R., and Cramer, S. D. 2000. Nondestructive Evaluation of Thermal Spray Cathodic Protection Anodes. CORROSION/2000, paper 00811, Houston: NACE International. 
Covino, B. S., Jr., Cramer, S. D., Bullard, S. J., Holcomb, G. R., Russell, J. H., Collins, W. K., Laylor, H. M., and Cryer, C. B. 2002. Performance of Zinc Anodes for Cathodic Protection of Reinforced Concrete Bridges. Final Report, SPR 364 (FHWA-OR-RD-02-10), Washington, DC: Federal Highway Administration.

Cramer, S. D., Bullard, S. J., Covino, B. S., Jr., Holcomb, G. R., Russell, J. H., Cryer, C. B., and Laylor, H. M. 2002a. Carbon Paint Anode for Reinforced Concrete Bridges in Coastal Environments. CORROSION/2002, paper 02265, Houston: NACE International.

Cramer, S. D., Covino, B. S., Jr., Bullard, S. J., Holcomb, G. R., Russell, J. H., Nelson, F. J., Laylor, H. M., and Soltesz, S. M. 2002b. Corrosion Prevention and Remediation Strategies for Reinforced Concrete Coastal Bridges. Cement \& Concrete Composites 24:101-117.

Fontana, M. G., and Greene, N. D. 1978. Corrosion Engineering. 2nd ed. New York: McGrawHill.

Holcomb, G. R., Bullard, S. J., Covino, B. S., Jr., Cramer, S. D., Cryer, C. B., and McGill, G. E. 1996. Electrochemical Aging of Thermal-Sprayed Zinc Anodes on Concrete. In Thermal Spray: Practical Solutions for Engineering Problems, Proceedings of the 9th National Thermal Spray Conference, ed. C. C. Berndt, pp. 185-192. Metals Park, OH: ASM International.

Holcomb, G. R., and Cryer, C. B. 1998. Cost of Impressed Current Cathodic Protection for Coastal Oregon Bridges. Materials Performance 37(7): 22-26.

Holcomb, G. R., Covino, B. S., Jr., Russell, J. H., Bullard, S. J., Cramer, S. D., Collins, W. K., Bennett, J. E., and Laylor, H. M. 2000a. Humectant Use in Cathodic Protection of Reinforced Concrete. CORROSION/2000, paper 00812. Houston: NACE International.

Holcomb, G. R., Covino, B. S., Jr., Russell, J. H., Bullard, S. J., Cramer, S. D., Collins, W. K., Bennett, J. E., and Laylor, H. M. 2000b. Humectant Use in Cathodic Protection of Reinforced Concrete. Corrosion. 56: 1140-1157.

Koch, G. H., Brongers, M. P. H., Thompson, N. G., Virmani, Y. P., and Payer, J. H. 2002. Corrosion Cost and Preventive Strategies in the United States, FHWA-RD-01-156, Washington, DC: Federal Highway Administration, U.S. Department of Transportation.

Mehta, P. K. 1991. Concrete in the Marine Environment. NewYork, NY: Elsevier Applied Science, pp. 73-100.

Newnan, D. G, 1980. Engineering Economic Analysis. San Jose, CA: Engineering Press. pp. 45, 286.

Orlova, N. V., Westall, J. C., Rehani, M., and Koretsky, M. D. 1999. The Study of Chloride Ion Migration in Reinforced Concrete under Cathodic Protection, Salem, OR: Oregon Department of Transportation. FHWA-OR-RD-00-03.

Pourbaix, M. 1974. Atlas of Electrochemical Equilibria. Houston: NACE International. pp. 99, 604-610. 
Powers, R., Sagues, A., and Murase, T. 1992. Sprayed-Zinc Galvanic Anodes for the Cathodic Protection of Reinforcing Steel in Concrete. In Materials: Performance and Prevention of Deficiencies and Failures, ed. T.D. White, pp. 732-747. New York: American Society of Civil Engineers.

Robinson, R. A., and Stokes, R. H. 1959. Electrolyte Solutions. 2nd ed. London: Butterworths Publications. p. 510.

Sagues, A., Powers, R., Murase, T., and Lasa, I.. 1994. Low-Cost Sprayed Zinc Galvanic Anode for Control of Corrosion of Reinforcing Steel in Marine Bridge Substructures. Final Report, Contract No. SHRP-88-ID024, Washington D.C.: Strategic Highway Research Program, National Research Council.

Scannell, W. T., Sohanghpurwala, A. A., and Powers, R. G. 1995. Sacrificial Cathodic Protection of Prestressed Concrete Bridge Pilings in a Marine Environment. 1995 Conference on Corrosion and Infrastructure: Practical Applications and Case Histories. Conference Abstracts. pp. 91-94. Houston, TX: NACE International.

Sugino, K. 1964. Bromates, Electrolytic Production. The Encyclopedia of Electrochemistry, ed. C.A. Hampel, pp. 127-130. New York: Reinhold Publishing Corp.

Stokes, R. H., and Robinson, R. A. 1949. Standard Solutions for Humidity Control at $25^{\circ}$ C. Industrial \& Engineering Chemistry 41:2013.

Wagner, J. 1992. Cathodic Protection-Design I Course. Houston: NACE International. p. 3:15. Weast, R. C., ed. 1979. Handbook of Chemistry and Physics. 59th ed. Boca Raton, FL: CRC Press. pp. B131-B132.

Zaytsev, I. D., and Aseyev, G. G. 1992. Properties of Aqueous Solutions of Electrolytes. Boca Raton, FL: CRC Press. pp. 1691, 1721 


\section{APPENDIX}

\section{POSTASSIUM ACETATE RESULTS}





\section{APPENDIX \\ RESULTS FOR POTASSIUM ACETATE $\left(\mathrm{KC}_{2} \mathrm{H}_{3} \mathrm{O}_{2}\right)$}

During the course of the project it was decided by the researchers and the technical advisory committee to drop potassium acetate, $\mathrm{KC}_{2} \mathrm{H}_{3} \mathrm{O}_{2}$, from further study. The initial laboratory results (both indoor and outdoor) showed that $\mathrm{KC}_{2} \mathrm{H}_{3} \mathrm{O}_{2}$ was detrimental to the $\mathrm{Zn}$ anode in terms of ICCP circuit resistance and GCP protection current. This appendix presents the data that was collected on the $\mathrm{KC}_{2} \mathrm{H}_{3} \mathrm{O}_{2}$-treated samples prior to eliminating it from the study (and that was not presented in the main body of the report). The figure caption numbers are used for referring back to equivalent figures in the main body of the report for comparison with $\mathrm{LiBr}$ - and $\mathrm{LiNO}_{3}-$ treated samples.

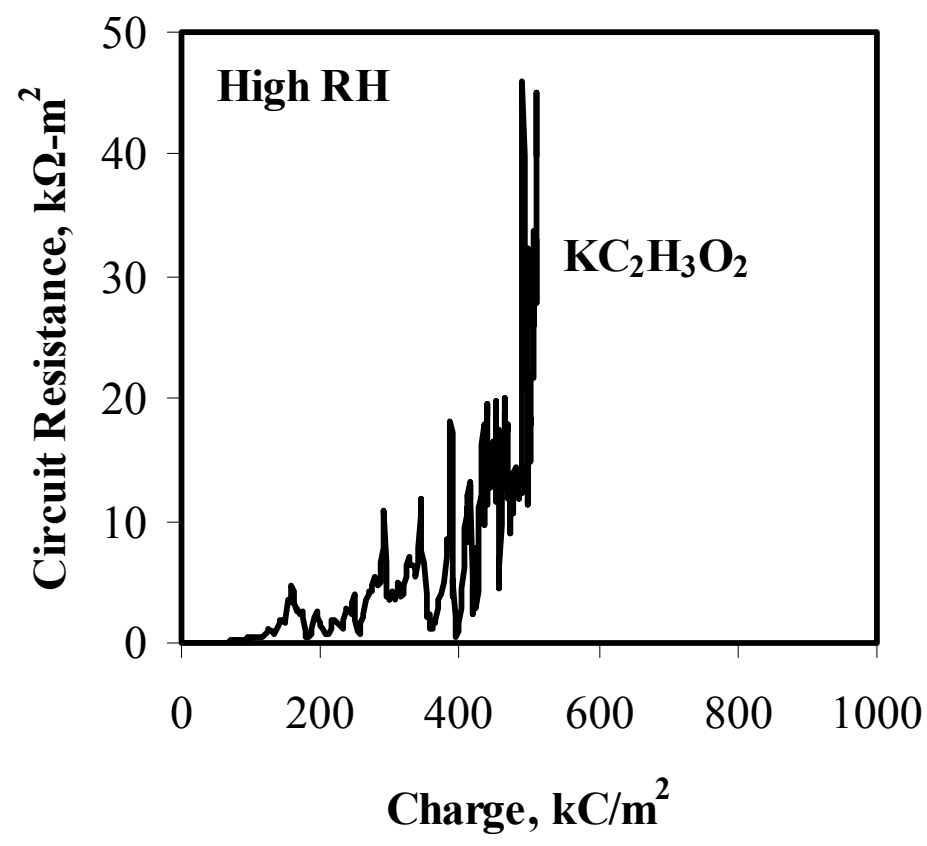

Figure A5.1: Circuit resistances of new ICCP slabs in high RH conditions 


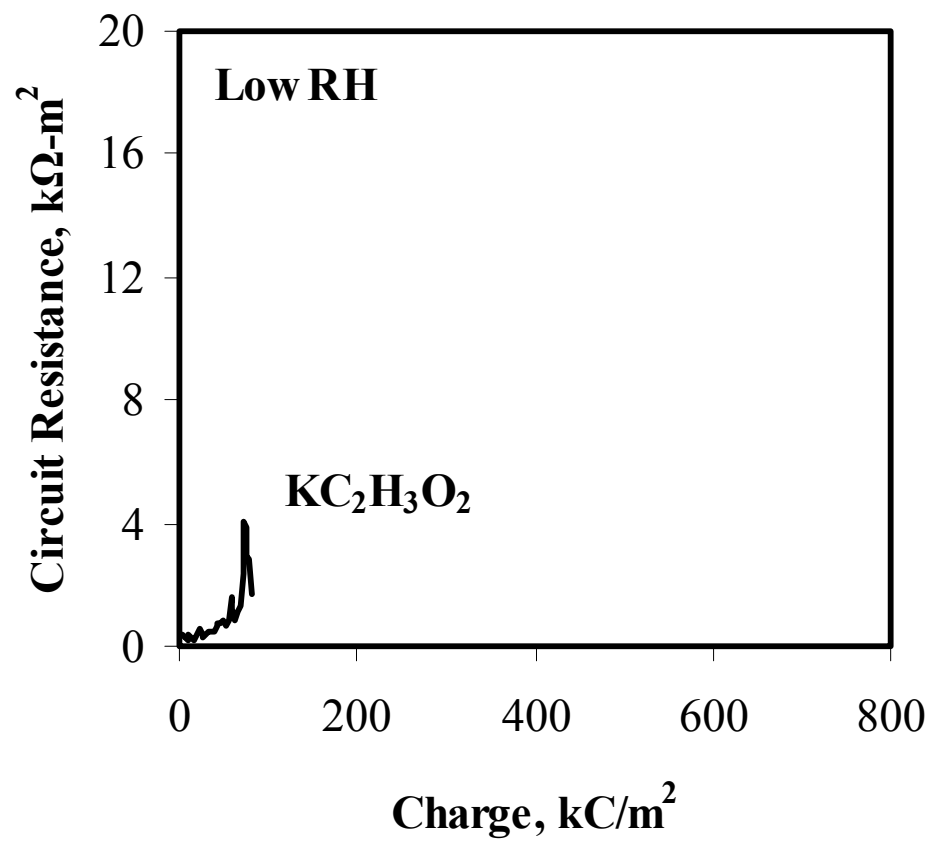

Figure A5.2: Circuit resistances of new ICCP slabs in low RH conditions

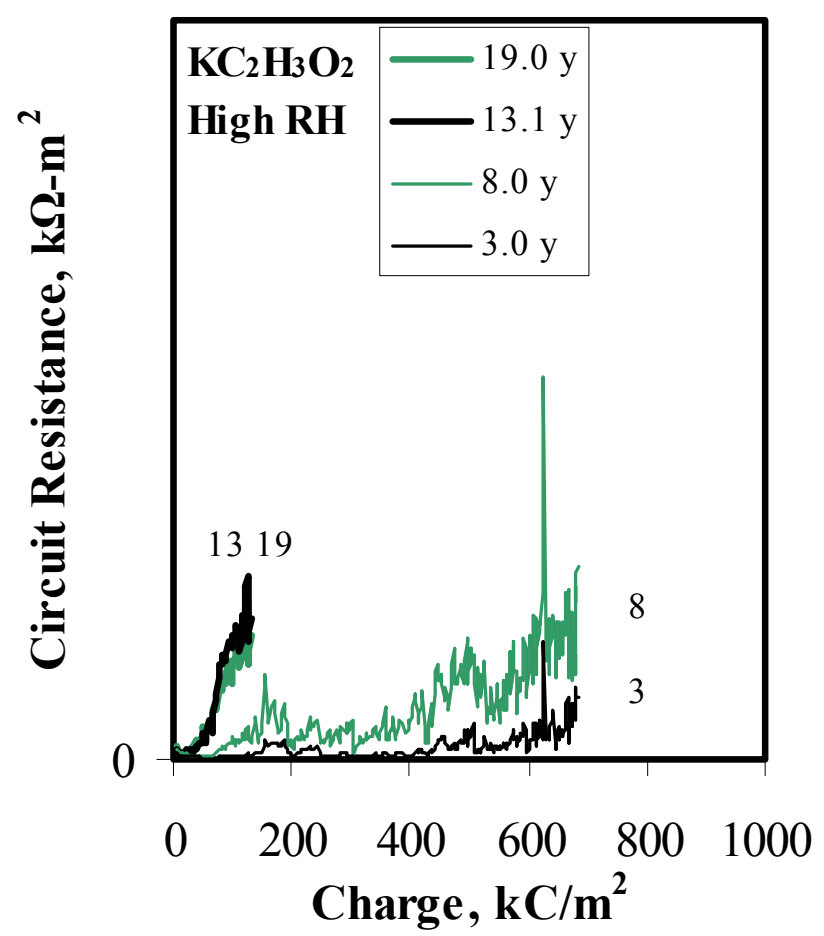

Figure A5.3: Circuit resistances of aged ICCP slabs in high RH conditions 


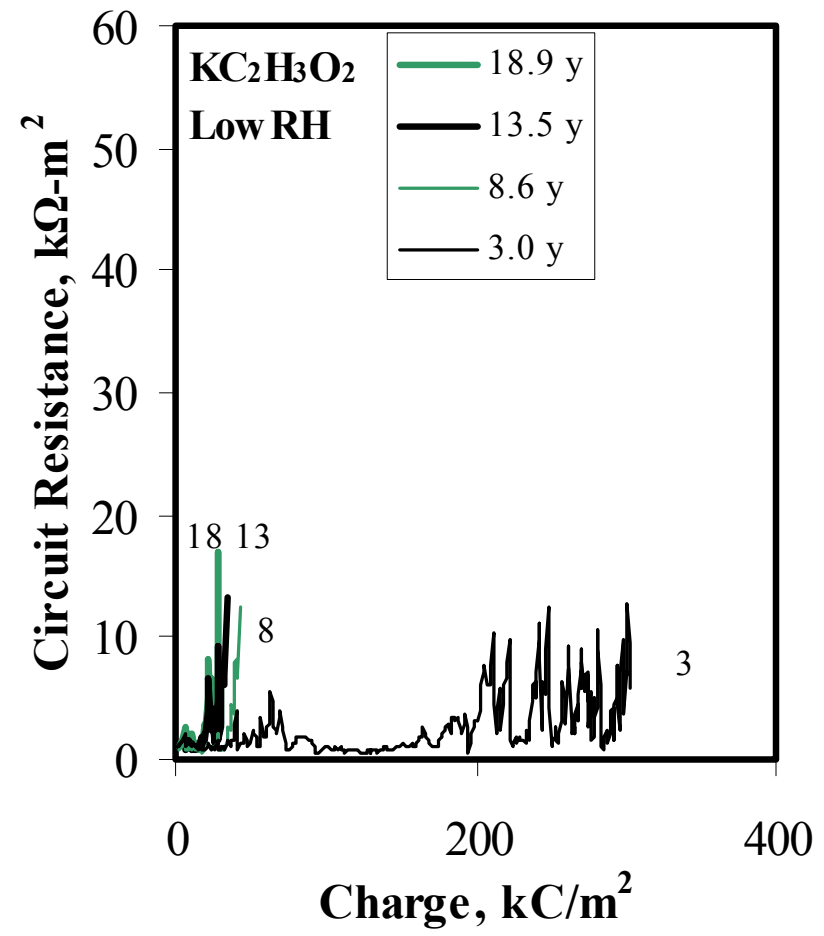

Figure A5.4: Circuit resistances of aged ICCP slabs in low RH conditions
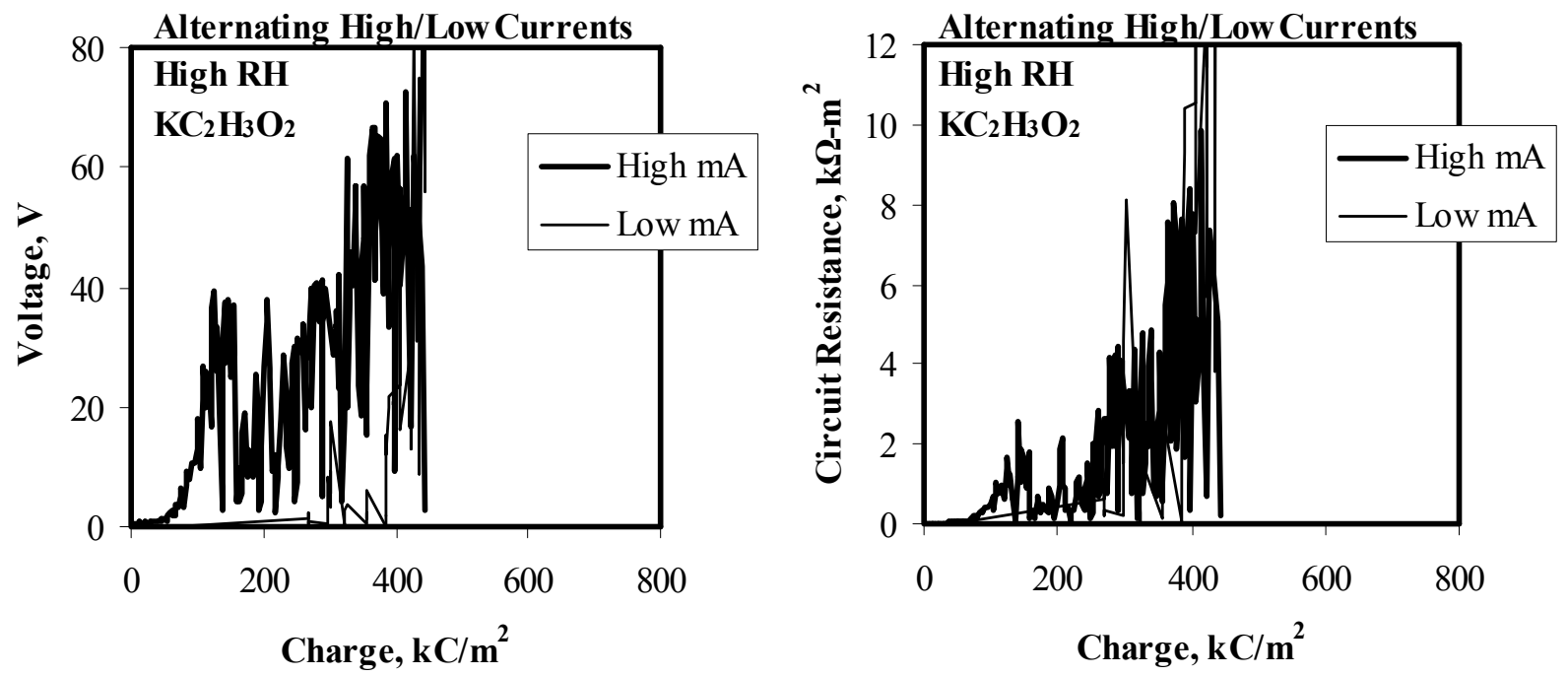

Figure A5.6: Cyclic ICCP voltages (left) and circuit resistances (right) in high RH conditions 

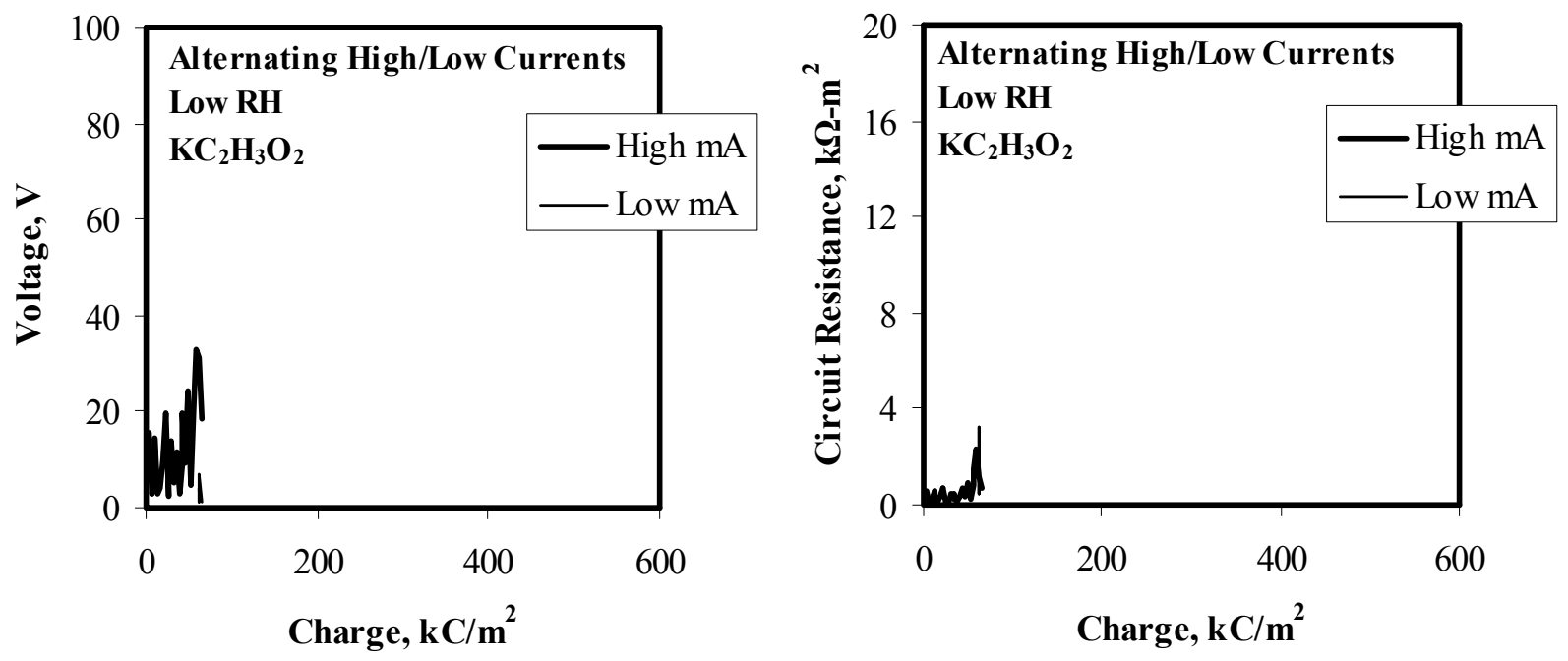

Figure A5.7: Cyclic ICCP voltages (left) and circuit resistances (right) in low RH conditions 


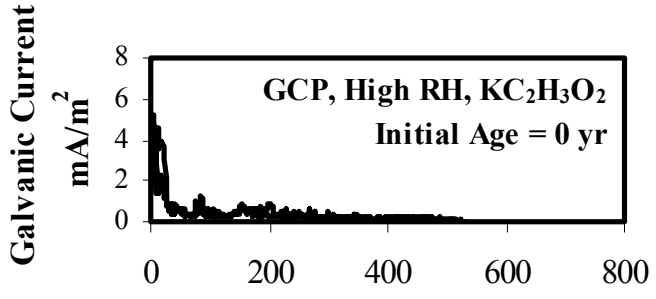

Elaps ed Time, days

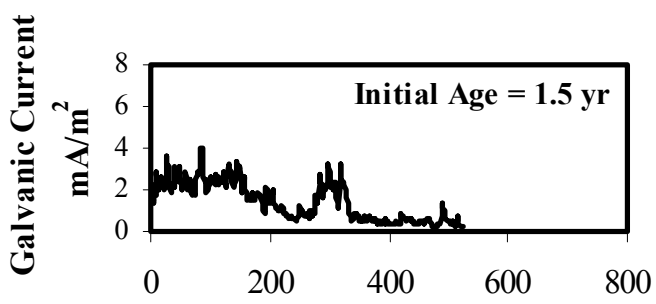

Elaps ed Time, days

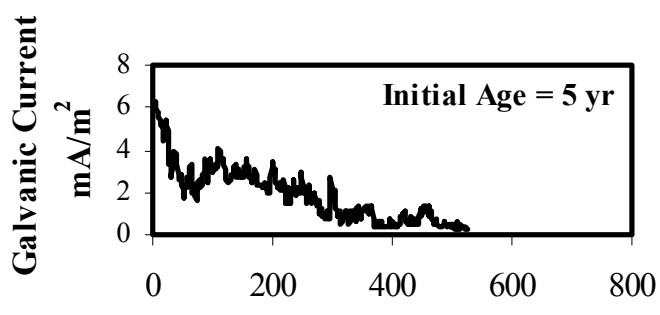

Elapsed Time, days

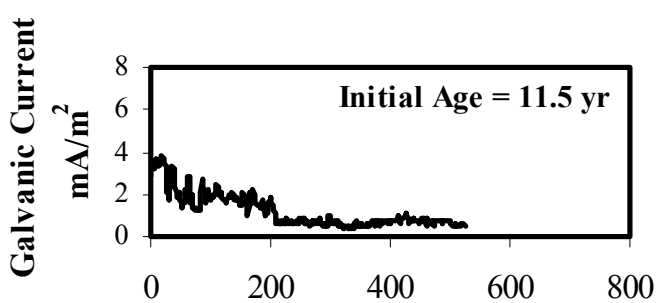

Elapsed Time, days

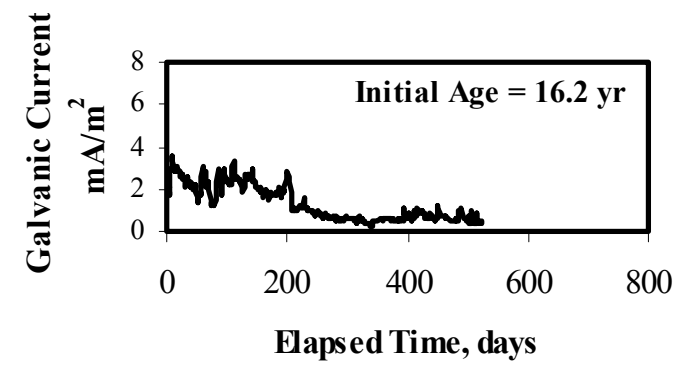

Figure A5.8: Galvanic currents for new and aged slabs with $\mathrm{KC}_{2} \mathrm{H}_{3} \mathrm{O}_{2}$ in high $\mathrm{RH}$ conditions

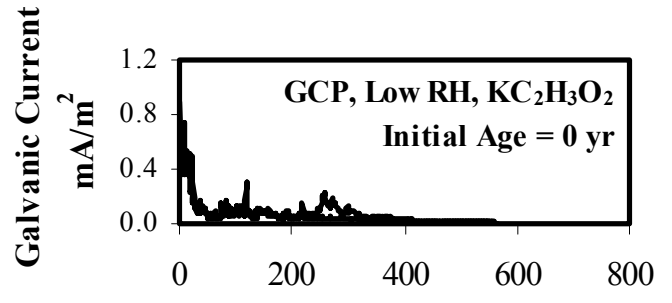

Elaps ed Time, days

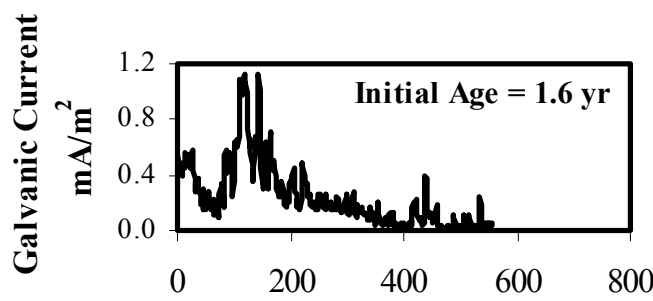

Elaps ed Time, days
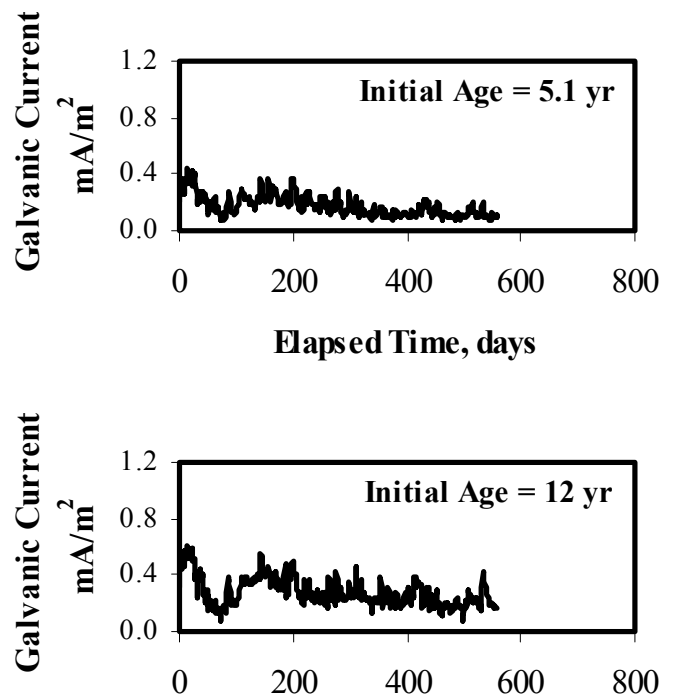

Elaps ed Time, days

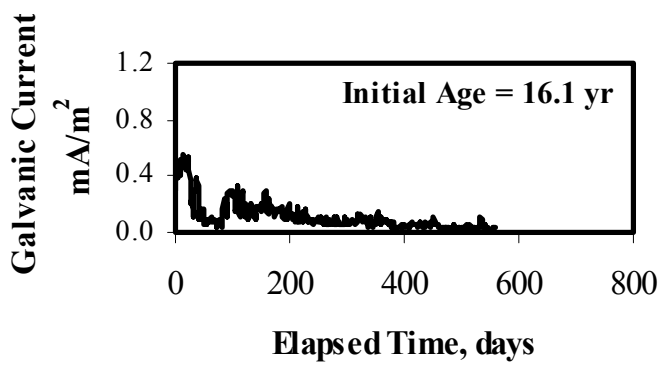

Figure A5.10: Galvanic currents for new and aged slabs with $\mathrm{KC}_{2} \mathrm{H}_{3} \mathrm{O}_{2}$ in low $\mathrm{RH}$ conditions 

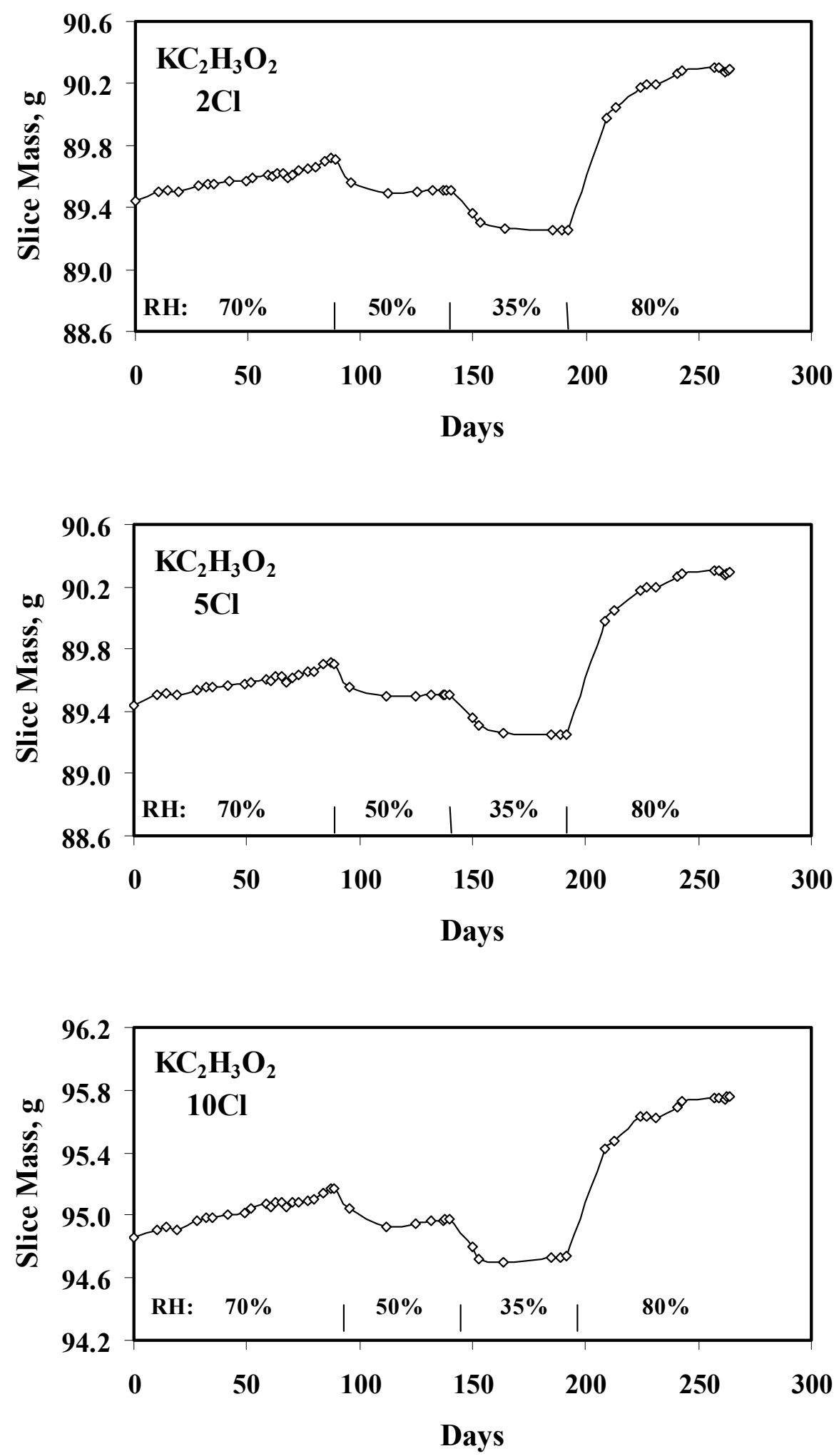

Figure A5.34: Mass change with exposure time of $\mathrm{KC}_{2} \mathrm{H}_{3} \mathrm{O}_{2}$-treated slices at $90^{\circ} \mathrm{F}\left(32.2^{\circ} \mathrm{C}\right)$. The $\mathrm{NaCl}$ concentrations were $2.0,5.0$, and $10.0 \mathrm{lb} / \mathrm{yd}^{3}\left(1.2,3.0\right.$, and $\left.5.9 \mathrm{~kg} / \mathrm{m}^{3}\right)$. 

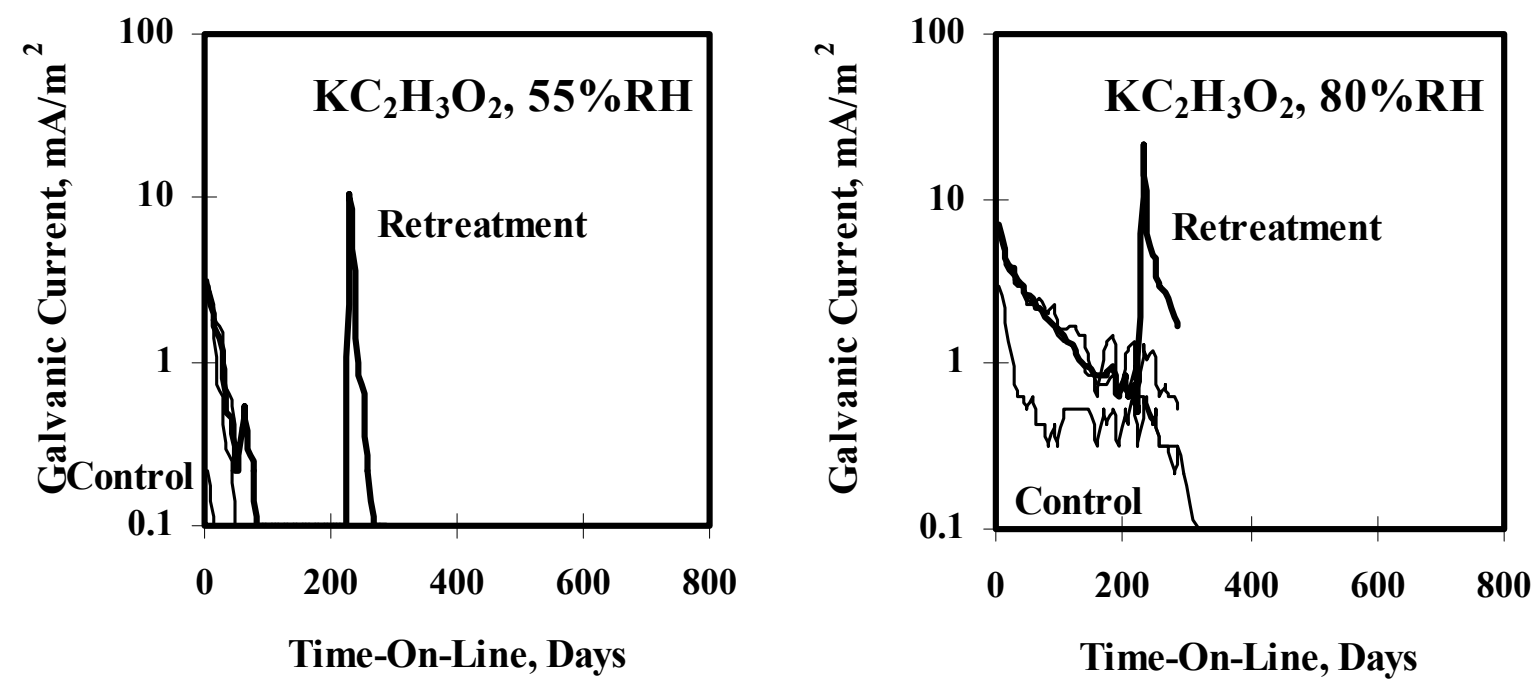

Figure A5.39: Galvanic current for $\mathrm{KC}_{2} \mathrm{H}_{3} \mathrm{O}_{2}$-treated blocks (with $3.0 \mathrm{~kg} / \mathrm{m}^{3} \mathrm{NaCl}$ ). Retreatment of one block after about 200 Days (shown in bold). The environments were a) 55\% RH (left) and b) $80 \%$ RH (right). 